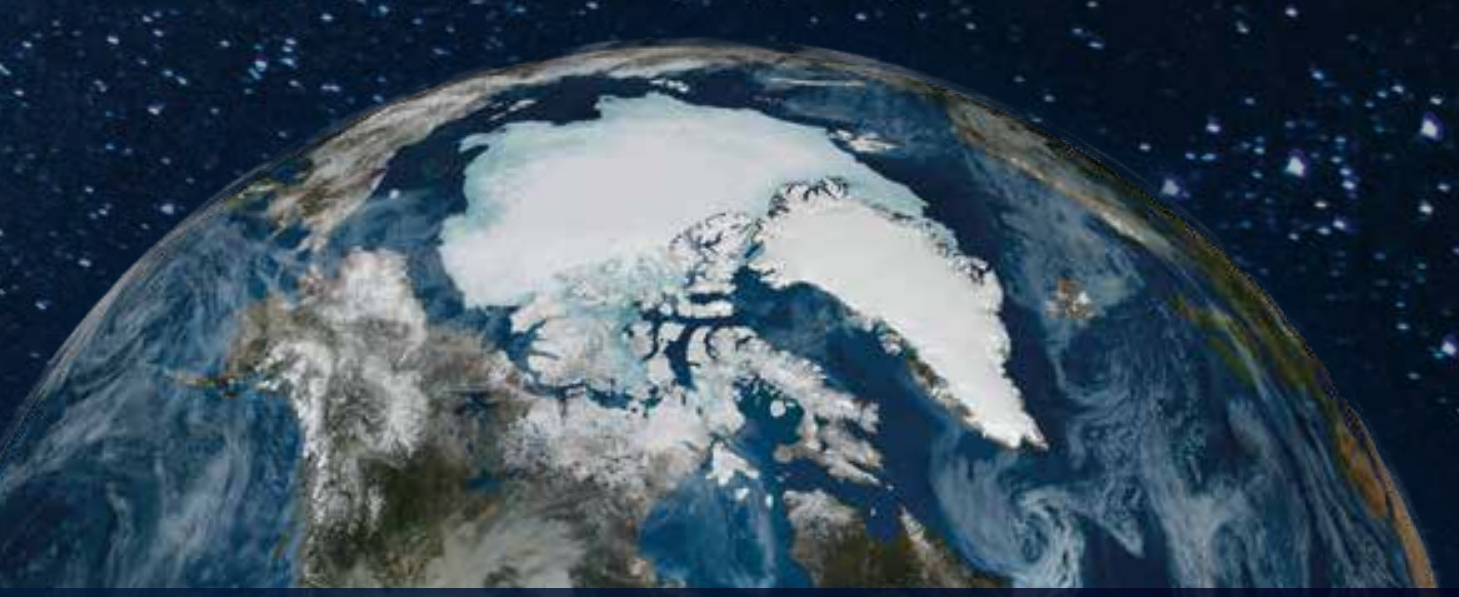

Simulating the Greenland Ice Sheet Surface Mass Balance

using an Earth System Model

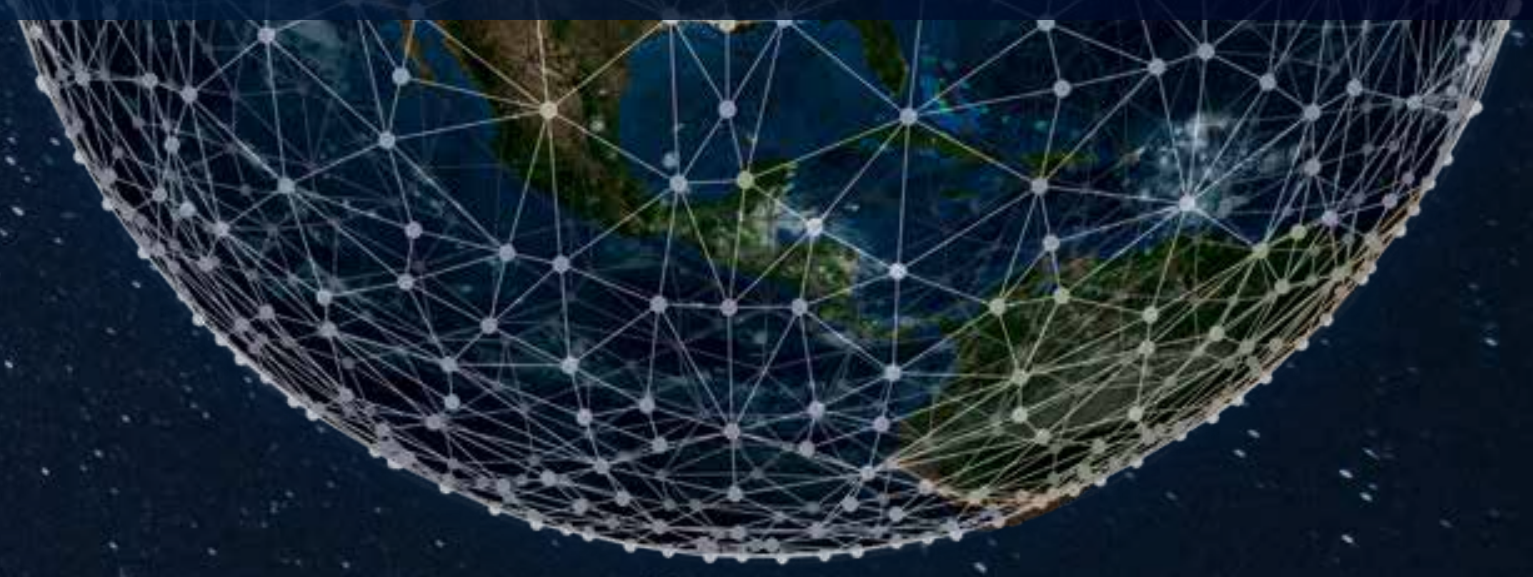




\section{Simulating the Greenland Ice Sheet Surface Mass Balance using an Earth System Model}

Leo van Kampenhout 
Copyright (C) 2020, L. van Kampenhout, Utrecht, The Netherlands

Author: Leo van Kampenhout

ISBN: $\quad$ 978-94-6416-085-7

Print: Ridderprint, Alblasserdam

Institute for Marine and Atmospheric Research Utrecht (IMAU)

Department of Physics

Faculty of Science

Utrecht University

Financial support was provided by the Netherlands Earth System Science Center (www.nessc.nl), funded by the Netherlands Organisation for Scientific Research (NWO).

Cover design by YASCHI Vormgeving (www . yaschi.nl). Earth imagery courtesy of NASA/Goddard Space Flight Center Scientific Visualization Studio. The Blue Marble data is courtesy of Reto Stockli (NASA/GSFC). 


\section{Simulating the Greenland Ice Sheet Surface Mass Balance using an Earth System Model}

Modelleren van de oppervlaktemassabalans van de Groenlandse ijskap met behulp van een aardsysteemmodel

(met een samenvatting in het Nederlands)

\section{PROEFSCHRIFT}

ter verkrijging van de graad van doctor aan de Universiteit Utrecht op gezag van de rector magnificus, prof. dr. H. R. B. M. Kummeling, ingevolge het besluit van het college voor promoties in het openbaar te verdedigen op maandag 7 september 2020 des middags te 12.45 uur

door

Leonardus van Kampenhout

geboren op 21 maart 1986 te Beilen 
Promotor:

Prof. dr. M. R. van den Broeke

Copromotor:

Dr. J. T. M. Lenaerts 


\section{Contents}

List of abbreviations

Summary $\quad$ v

Samenvatting (Summary in Dutch) vii

1 Introduction 1

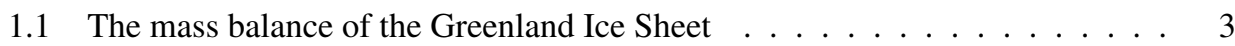

1.2 The surface mass balance and non-linear feedbacks . . . . . . . . . . . 4

1.3 Earth system models, and a case for a two-way coupled modelling approach . 7

1.4 Challenges for modelling surface mass balance within Earth system models . 8

1.5 The Community Earth System Model . . . . . . . . . . . . . . . . . 10

1.6 Outline of this thesis . . . . . . . . . . . . . . . 11

2 Improving the Representation of Polar Snow and Firn in CESM 13

2.1 Introduction . . . . . . . . . . . . . . . . . . . . 14

2.2 Model description . . . . . . . . . . . . . . . . . . . 15

2.3 Snow model development . . . . . . . . . . . . . . . . . . . . . 17

2.4 Evaluation of code changes in absence of melt . . . . . . . . . . . 22

2.5 Evaluation in CESM . . . . . . . . . . . . . . . . 28

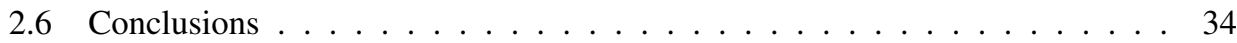

3 Regional grid refinement: impacts on the simulated Greenland surface mass $\begin{array}{ll}\text { balance } & 37\end{array}$

3.1 Introduction . . . . . . . . . . . . . . . . . 38

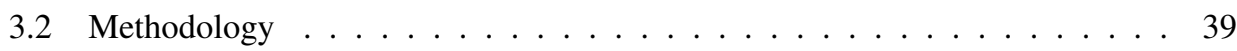

3.3 Results and Discussion . . . . . . . . . . . . . . . . 45

3.4 Summary and Conclusions . . . . . . . . . . . . . . 57 
4 Present-day Greenland ice sheet climate and surface mass balance in CESM2 59

4.1 Introduction . . . . . . . . . . . . . . . . . . . 60

4.2 Methods . . . . . . . . . . . . . . . . . . . . 61

4.3 Results . . . . . . . . . . . . . . . . . . . 67

4.4 Discussion . . . . . . . . . . . . . . . . . . . . 84

4.5 Conclusions . . . . . . . . . . . . . . . . . 85

$5 \quad$ A 21 st century warming threshold for Greenland ice sheet mass loss $\quad 87$

5.1 Introduction . . . . . . . . . . . . . . . . . 87

5.2 Summary of methodology . . . . . . . . . . . . . . 88

5.3 Results . . . . . . . . . . . . . . . . . . . . . 91

5.4 Discussion . . . . . . . . . . . . . . . . . . . 92

5.5 Methods .............................. 97

6 Conclusions \& Outlook 99

6.1 General conclusions from this thesis . . . . . . . . . . . . . . . 99

6.2 Modelling challenges: discussion \& recommendations . . . . . . . . . . 100

6.3 Science outlook . . . . . . . . . . . . . . . . . . . 102

6.4 The need for transformative change .................. 103

$\begin{array}{ll}\text { Bibliography } & 107\end{array}$

$\begin{array}{ll}\text { Acknowledgements (Dankwoord) } & 123\end{array}$

$\begin{array}{lr}\text { List of publications } & 127\end{array}$

$\begin{array}{ll}\text { Curriculum vitae } & 131\end{array}$ 


\section{List of abbreviations}

AIS

CAM

CESM

CISM

CLM

CMIP

CWP

D

DJF

EC

ERAI

ESM

GCM

GHF

GICs

GrIS

Gt

IPCC

ISM

JJA

LHF

LW

MB

MHF

MODIS

RACMO

$\mathrm{RCM}$

RCP

RMSE

SEB

SHF

SW

SMB

VR

VR-CESM

w.e.
Antarctic Ice Sheet

Community Atmosphere Model

Community Earth System Model

Community Ice Sheet Model

Community Land Model

Coupled Model Intercomparison Project

cloud water path

discharge (of solid ice)

December-January-February

elevation class

ERA Interim reanalysis

Earth system model

general circulation model

ground heat flux

glaciers and ice caps, on the periphery of Greenland

Greenland Ice Sheet

gigatonne $\left(10^{12} \mathrm{~kg}\right)$

Intergovernmental Panel on Climate Change

ice-sheet model

June-July-August

latent heat flux

longwave radiation

mass balance

melt heat flux

Moderate Resolution Imaging Spectroradiometer

Regional Atmospheric Climate MOdel

regional climate model

representative concentration pathway

root-mean-square error

surface energy balance

sensible heat flux

shortwave radiation

surface mass balance

variable resolution

variable-resolution CESM

water equivalent 



\section{Summary}

On decadal to centennial time scales, global mean sea level is determined by two factors, which are (1) the amount of heat in the ocean, and (2) the amount of water stored on land, primarily in the form of land ice, i.e. glaciers, ice caps and ice sheets. In the northern hemisphere, the largest body of ice is the Greenland Ice Sheet (GrIS) which would, if it were to melt completely, raise global mean sea level by $\sim 7.4$ metres. Observational evidence shows that the GrIS is currently losing mass, and that this mass loss is accelerating.

A first order approach to estimating the future GrIS contribution to sea level rise is simply extrapolating these trends in time. Although this may give reasonable predictive skill on the short term $(\sim 10$ years), such an approach is bound to fail on longer time scales as it accounts for neither geometric nor physical considerations. Such considerations, like the non-linear temperature-elevation feedback and the snowmelt-albedo feedback, are expected to strongly impact future ice sheet melt behaviour in a warming climate.

A more sophisticated approach is that of numerical computer modelling, in which one can account for many processes and feedbacks in the system under study. In this dissertation, we look at the representation of GrIS climate in the Community Earth System Model (CESM), a coupled climate model, in which ice sheet interactions with other parts of the climate system (oceans, the atmosphere, the land) can be explicitly and consistently resolved. Confidence in ice sheet projections-and following from those, sea level rise projections-with CESM depends in part on the degree of realism of simulating key mass balance processes, as well as the ability to simulate the GrIS present-day climate and state. An important metric to consider is the surface mass balance (SMB), defined as the difference between accumulation by snowfall on one hand, and surface ablation-primarily by meltwater runoff and sublimation —on the other. A realistic representation of SMB is a key prerequisite for simulating ice sheet mass loss using coupled models. The various chapters of this thesis constitute different studies concerned with improved GrIS SMB modelling within CESM.

The first study investigates the representation of polar snow and firn in CESM. The thermodynamic and hydrologic evolution of the GrIS is to a large extent controlled by snow, for instance through its high reflectance and its capacity to store and refreeze liquid water from melt and rain. Previous work identified snow model limitations in CESM, including an insufficient refreezing capacity for liquid water, as well as spurious subsurface melt rates due to an underestimation in snow thermal conductivity. To address the latter, our work introduces new parametrizations for fresh snow density and snow compaction, leading to an overall denser snowpack with a higher conductivity. The former is addressed by increasing the maximum snow depth in the model, as well as the maximum number of snow layers. Standalone snow model simulations are evaluated using near-surface snow and deep firn density measurements from both Antarctica and Greenland, and show improved performance with the new parameters.

Spatial resolution is another important consideration when modelling GrIS SMB. Previous work on regional climate models has indicated that a horizontal resolution of $\sim 20 \mathrm{~km}$ or less is needed to resolve 
steep SMB gradients near the GrIS margins, caused by e.g. orographic precipitation and microclimate effects. By contrast, Earth system models such as CESM have a nominal resolution of $1^{\circ}$ in the atmosphere, or $\sim 110 \mathrm{~km}$, due to computational constraints. CESM employs a subgrid parameterization called elevation classes (ECs) that partly compensates for this lack of horizontal resolution. Another method is the use of regional grid refinement, where the simulation runs at a higher spatial resolution over the GrIS than the rest of the globe. The second study in this thesis implements, for the first time, regional grid refinement to the Greenland region using variable resolution (VR) CESM. On refined grids of $55 \mathrm{~km}$ and $28 \mathrm{~km}$ around Greenland, we demonstrate that precipitation is greatly improved with enhanced resolution, with VR-CESM performing on-par to regional climate models. However, a positive SMB bias is created in the ablation zone of the ice sheet, which is linked to changes in cloud cover and a reduced effectiveness of ECs. Further work is needed to address this bias, but we show that there is certainly potential for VR-CESM in the realm of high-resolution modelling of GrIS SMB.

The performance of CESM version 2 (CESM2) at the default resolution of $1^{\circ}$ is assessed in a third study, with a focus on the present-day GrIS climate, surface energy balance, and SMB. CESM2 features improved parametrizations for snow, surface albedo, and clouds, and semi-statistically downscales climate variables such as near-surface temperature and longwave radiation using ECs. CESM2 is evaluated using a range of external data, including reanalysis, remote sensing products for clouds and albedo, and regional climate model data from RACMO2. We find that CESM2 overestimates the net radiative input at the surface in summer, primarily driven by a low biased albedo, which is compensating for a lack in sensible turbulent heat flux. GrIS ablation zones do not always overlap with that in RACMO2, but the difference in total ablation area is small (-11\%). Mean GrIS integrated SMB during 1961-1990 is $508 \pm 73 \mathrm{Gt}$ per year. Integrated amounts of SMB components melt, refreezing and runoff are all bracketed by RACMO2 equivalents at the resolutions $11 \mathrm{~km}$ (native) and $1 \mathrm{~km}$ (statistically downscaled), indicating a good performance. An analysis of time series reveals a breakpoint in SMB at the year $1993 \pm 8$, driven by an increase in melt and runoff.

The fourth and last study constitutes a practical application of the improved model, and explores the future timing of GrIS SMB turning from positive to negative. If such a situation, net mass loss at the surface, would be sustained, the ice sheet is bound to disappear since there is no other mass gaining mechanism. To pinpoint the regional warming threshold at which SMB $=0$ occurs, we combine CESM2 21 st century projections with simulations by the state-of-the-art regional climate model RACMO2. We find a regional Greenland warming threshold of $4.5 \pm 0.3{ }^{\circ} \mathrm{C}$, relative to preindustrial conditions. Then, climate model output from the Coupled Model Intercomparison Project Phase 5 (CMIP5) and Phase 6 (CMIP6) are used to translate this regional threshold into a global warming threshold for irreversible GrIS mass loss of $2.7 \pm 0.2^{\circ} \mathrm{C}$.

With these studies we demonstrate the potential of Earth system models (ESMs) for simulating future ice sheet climates and SMB. Realistic SMB is an important prerequisite in robust, interactive coupling of ice sheets within ESMs. Interactive ice-sheet-ESM simulations can be used to comprehensively project ice sheet mass balance and sea level change on long time scales. 


\section{Samenvatting}

De wereldgemiddelde zeespiegel wordt op tijdschalen van 10-100 jaar bepaald door twee factoren, te weten (1) de hoeveelheid warmte in de oceanen en (2) de hoeveelheid water die op het land ligt opgeslagen, voornamelijk in de vorm van landijs: gletsjers en ijskappen. Het grootste reservoir aan ijs op het noordelijke halfrond is de Groenlandse ijskap (Engels: Greenland Ice Sheet, GrIS) welke de wereldgemiddelde zeespiegel met $\sim 7,4 \mathrm{~m}$ zou laten stijgen, mocht zij volledig wegsmelten. Momenteel verliest de GrIS ieder jaar massa en dit massaverlies versnelt, zo blijkt uit waarnemingen.

Een eerste orde benadering om de toekomstige bijdrage van de GrIS aan zeespiegelstijging te bepalen zou zijn om de huidige trends eenvoudigweg te extrapoleren. Hoewel dit misschien redelijke voorspellingskracht heeft op de korte termijn ( $~ 10$ jaar) is zo'n benadering gedoemd om te falen op de langere termijn doordat het geen rekening houdt met de fysica van de ijskap, noch met haar geometrie.

Een meer geïnformeerde methode is die van numerieke computermodellering, waarbij men de aanwezige processen en feedbacks binnen het fysische systeem in acht kan nemen. In deze dissertatie kijken we naar de representatie van de GrIS in een numeriek aardsysteemmodel, het Community Earth System Model (CESM), waarmee interacties tussen de ijskap en andere onderdelen van het klimaatsysteem (oceanen, atmosfeer, landoppervlak) expliciet en consistent gemodelleerd kunnen worden. Het vertrouwen dat we mogen stellen in de voortvloeiende zeespiegelprojecties hangt o.a. samen met de vraag of de processen van massabalans van de ijskap voldoende realistisch gesimuleerd worden, en of het hedendaagse klimaat van de ijskap klopt. Een belangrijke graadmeter daarin is de oppervlaktemassabalans (Engels: surface mass balance, $\mathrm{SMB}$ ) welke gedefinieerd wordt als het verschil tussen accumulatie door sneeuwval enerzijds, en oppervlakteablatie door bijvoorbeeld smeltwaterafvloeiing en sublimatie anderzijds. Een voldoende realistische representatie van SMB is een cruciale voorwaarde voor het simuleren van ijskapmassaverlies in gekoppelde aardsysteemmodellen. De verschillende hoofdstukken van dit proefschrift hebben elk betrekking op GrIS SMB-modellering in CESM.

De eerste studie onderzoekt de numerieke weergave van polaire sneeuw en firn in CESM. Sneeuw heeft grote invloed op de thermodynamische en hydrologische evolutie van de GrIS door o.a. haar hoge reflectiecoëfficient en haar capaciteit om smeltwater te herbevriezen. Eerder werk identificeerde tekortkomingen in het sneeuwmodel van CESM, waaronder een te beperkte herbevriezingscapaciteit en een onderschatting in de thermische geleidbaarheid welke leidde tot onrealistisch hoge smeltwaarden onder het oppervlakte. Om deze twee zaken aan te pakken introduceert onze studie een aantal nieuwe parametrisaties. Het potentieel voor herbevriezing wordt verhoogt door een verdieping van het sneeuwpakket en verhoging van het (maximum) aantal sneeuwlagen, terwijl nieuwe parameters voor sneeuwcompactie en verse sneeuwdichtheid zorgen voor een hogere geleidbaarheid van het sneeuwpakket. Ongekoppelde sneeuwmodel-simulaties tonen aan dat deze parameters verbeteringen zijn, waarbij we referentiemetingen van sneeuwdichtheid gebruiken van zowel Groenland als Antarctica.

De resolutie van het rekenrooster is een ander belangrijk aspect bij het modelleren van GrIS SMB. Eerder werk heeft laten zien dat een horizontale resolutie van $\sim 20 \mathrm{~km}$ of minder vereist is om de sterkte 
SMB-gradiënten aan de randen van Groenland op te lossen die worden veroorzaakt door b.v. orografische neerslag en de aanwezigheid van een microklimaat. Aardsysteemmodellen zoals CESM hebben daarentegen een lagere resolutie van doorgaans $1^{\circ}(\mathrm{ca} .110 \mathrm{~km})$ in de atmosfeer wegens computationele beperkingen. CESM past een subgrid parametrisatie toe genaamd "hoogteklasses" (Engels: elevation classes, ECs) die deels compenseren voor het gebrek aan horizontale resolutie. Een alternatieve methode is regionale gridverfijning, waarbij de simulatie boven de GrIS op een hogere resolutie draait dan elders op de wereld. De tweede studie in dit proefschrift past deze techniek voor het eerst toe op de Groenlandse regio met variabele resolutie (VR) CESM. We laten zien dat neerslagpatronen sterk verbeteren op onze verfijnde roosters van $55 \mathrm{~km}$ en $28 \mathrm{~km}$ rond Groenland, waarmee VR-CESM op gelijk niveau presteert als regionale klimaatmodellen. Echter, tegelijkertijd constateren we een positieve SMB afwijking in de ablatiezone van de ijskap, welke wordt gelinkt aan veranderingen in wolkenbedekking en een gereduceerde effectiviteit van de ECs. Hoewel er meer werk is vereist om deze ontstane afwijking te verhelpen is er beslist potentieel voor VR-CESM in het simuleren van GrIS SMB op hoge spatiale resolutie.

Een derde studie onderzoekt de prestaties van CESM versie 2 (CESM2) op het gebruikelijke rekenrooster van $1^{\circ}$ waarbij de nadruk ligt op zowel het hedendaagse klimaat, de oppervlakte-energiebalans, alsmede de SMB van de GrIS. CESM2 heeft vernieuwde parametrisaties voor sneeuw, oppervlaktealbedo en wolken, en past een semi-statistische downscaling toe op klimaatvariabelen als $2 \mathrm{~m}$ oppervlaktetemperatuur en langgolvige straling middels ECs. De evaluatie maakt gebruik van een reeks externe data waaronder reanalyse, remote sensing producten voor wolken en albedo, en regionale klimaatdata van RACMO2. We vinden dat CESM2 de netto stralingsinput aan het oppervlak overschat in de zomer, voornamelijk vanwege een te laag albedo welke een tekort in de voelbare warmteflux meer dan compenseert. De GrIS ablatiegebieden overlappen niet overal met RACMO2 maar het verschil in totale oppervlakte is klein (-11\%). De GrIS-geïntegreerde SMB over de periode 1961-1990 is gemiddeld $508 \pm 73$ Gt per jaar. Geïntegreerde waarden voor de SMB-componenten smelt, herbevriezing en afvloeiing bevinden zich tussen de equivalenten RACMO2 op resoluties $11 \mathrm{~km}$ (standaard rekenrooster) en $1 \mathrm{~km}$ (statistisch neergeschaald), een bevinding welke een goede prestatie suggereert. Analyse van de tijdsseries toont een breekpunt in SMB in het jaar $1993 \pm 8$ gedreven door een toename in smelt en afvloeiing.

De vierde en laatste studie van dit proefschrift vormt een praktische toepassing van het verbeterde CESM model en verkent het moment in de toekomst wanneer SMB van positief naar negatief zou kunnen omslaan. Als deze situatie (met netto massaverlies aan het oppervlak) aanhoudt, is de ijskap gedoemd om te verdwijnen. Om de opwarmingsdrempel waarvoor SMB $=0$ te bepalen combineren we 21e eeuw projecties met simulaties van het state-of-the-art regionale klimaatmodel RACMO2. We vinden een regionale opwarmingsdrempel van $4,5 \pm 0,3{ }^{\circ} \mathrm{C}$ ten opzichte van pre-industrieel. Klimaatmodeluitvoer uit de Coupled Model Intercomparison Project Phase 5 (CMIP5) en Phase 6 (CMIP6) worden gebruikt om deze regionele drempelwaarde te vertalen naar een mondiale drempelwaarde voor GrIS-deglaciatie van $2,7 \pm 0,2{ }^{\circ} \mathrm{C}$.

Met deze studies demonstreren we het potentieel van aardsysteemmodellen (Engels: Earth System Models, ESMs) voor het simuleren van toekomstige ijskap-klimaten en bijbehorend SMB. Een realistische weergave van SMB is een belangrijke voorwaarde voor het robuust en interactief koppelen van ijskappen binnen ESMs. Interactieve ijskap-ESM simulaties kunnen worden gebruikt voor het integraal simuleren van een ijskapbalans en bijbehorende zeespiegelveranderingen op lange tijdsschalen. 


\section{1 \\ Introduction}

"The furnaces of the world are now burning about 2,000,000,000 tons of coal a year. When this is burned, uniting with oxygen, it adds about 7,000,000,000 tons of carbon dioxide to the atmosphere yearly. This tends to make the air a more effective blanket for the earth and to raise its temperature. The effect may be considerable in a few centuries."

— Francis Molena, science writer for Popular Mechanics magazine, 1912.

"The average global temperature has risen by about $1.1{ }^{\circ} \mathrm{C}$ since the pre-industrial era and ocean heat content is at a record level. On the current path of carbon dioxide emissions, we are heading towards a temperature increase of 3 to 5 degrees Celsius by the end of century. We expect to see much extreme weather throughout 2020 and the coming decades, fuelled by record levels of heat-trapping greenhouse gases in the atmosphere."

— Petteri Taalas, secretary-general of the World Meteorological Organization, 2020.

Human-caused climate change can rightly be called the most defining issue of our time, as it increasingly threatens global stability and the foundations of our way of life. All of human civilization has developed during the Holocene, a climatically stable period lasting about 11,000 years. Primarily due to the burning of fossil fuels, we have now left this climatically stable period and are moving further into uncharted territory, at least as far as human civilization is concerned (Figure 1.1). Besides the increase in global average temperatures, there is a myriad of other climate change impacts, ranging from heatwaves, stronger storms, heavier rainfall events, prolonged periods of drought, an increased intensity of wildfires, to rapidly shifting ecological zones that drive species extinction and may enable plague insects. Given that all of these impacts may directly damage agricultural production, combined with the fact that agriculture forms the foundation of our sedentary way of life, one must conclude that there are grave, if not existential, risks ahead for civilization [Lenton et al., 2019].

For society in the Netherlands, long-term sea-level rise is another major threat to reckon with. Geological evidence shows that global mean sea level was 6-9 m higher during the Eemian, the previous interglacial that lasted from approximately 129,000 to 116,000 years ago, a period during which global average surface temperature exceeded the Holocene average by $0.5-1.0{ }^{\circ} \mathrm{C}$ [Oppenheimer et al., 2019]. In other words, relatively small changes in temperature can be associated with large changes in sea level. 


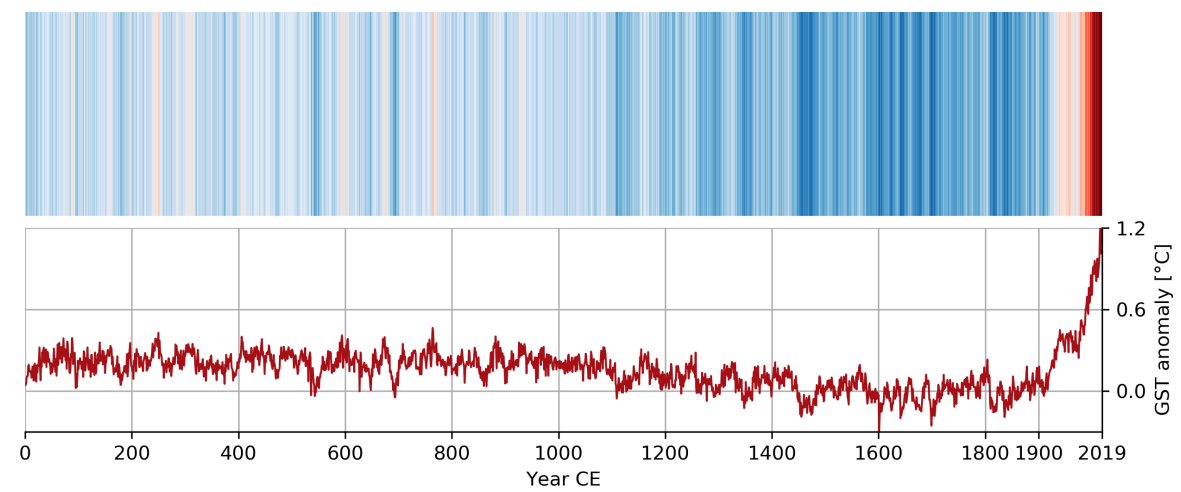

Figure 1.1: Global average surface temperature during the Common Era. In 2019, temperature was $\sim 1.1{ }^{\circ} \mathrm{C}$ higher than during pre-industrial times [WMO, 2020]. The 'warming stripes' and the line graph both represent the same data, but use different baseline periods for calculating the anomalies (the warming stripes are relative to the 20th century mean, whereas the line graph is relative to the 19 th century mean). Data originates from the PAGES2k database, a multiproxy reconstruction based from trees, ice, sediment, corals and other sources [PAGES2k Consortium, 2019]. Only for the period 2000-2019, when PAGES2k has no data, HadCRUT4.6 [Morice et al., 2012] is used instead.

In 2019, global average surface temperature, computed as sea surface temperature over the ocean, and near-surface air temperature over land, is estimated to have exceeded pre-industrial conditions by $1.1{ }^{\circ} \mathrm{C}$ [WMO, 2020], constituting a similar departure from the Holocene average as the Eemian. On this evidence alone, one can conclude that at least 6 metres of global sea level rise has been committed to, which is far beyond what the Netherlands could prepare for in protecting its low-lying regions. All of this is assuming that the warming is stabilized at $1.1{ }^{\circ} \mathrm{C}$, which obviously is not the case, and that there are not geographical variations in sea level rise, which there are. Taking these considerations into account is likely to make matters worse.

When assessing the risk of sea level rise, however, it is essential to consider the time scale on which that takes place. The largest contribution is expected from melting land ice, and in particular the major ice sheets of Greenland and West Antarctica [Oppenheimer et al., 2019]. Even though these massive reservoirs of water are losing mass at an increasing rate, their contribution to sea level rise is still counted in millimetres per year, not in centimeters or meters. Indeed, a near-total deglaciation of the Greenland and West Antarctic ice sheets would take hundreds to thousands of years to materialize [DeConto and Pollard, 2016; Aschwanden et al., 2019]. But the uncertainties on the exact rates are large. In order to better constrain the contribution of these ice sheets to sea level rise under sustained warming, numerical climate models known as Earth system models (ESMs) can be used. The work contained in the current thesis revolves around modelling the mass balance of one particular ice sheetthe Greenland Ice Sheet-within an ESM. In particular, we will focus on surface processes. These various topics - the mass balance of the Greenland ice sheet, the surface mass balance, and Earth system modelling — are now introduced in more detail. 
a.
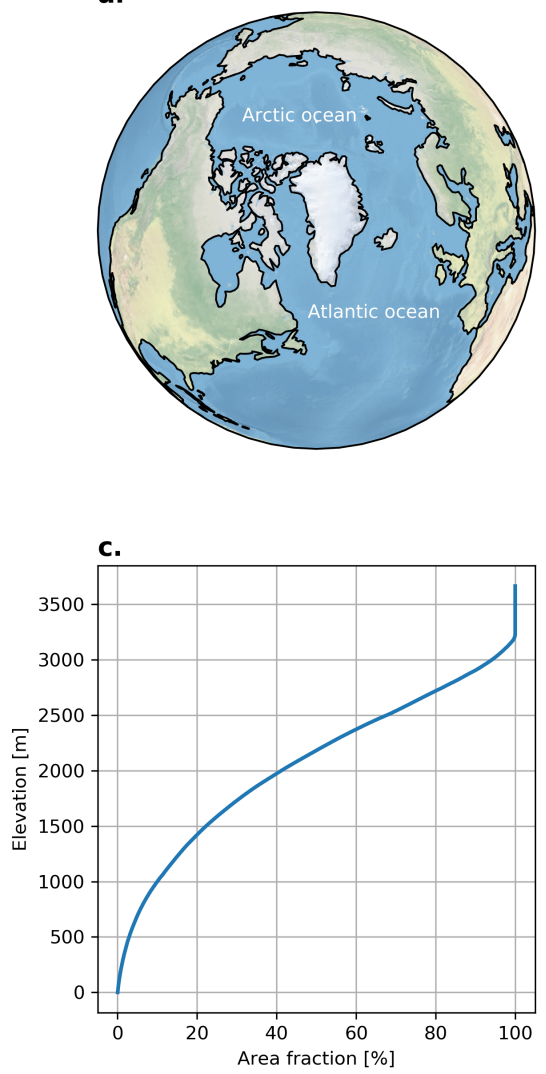

b.

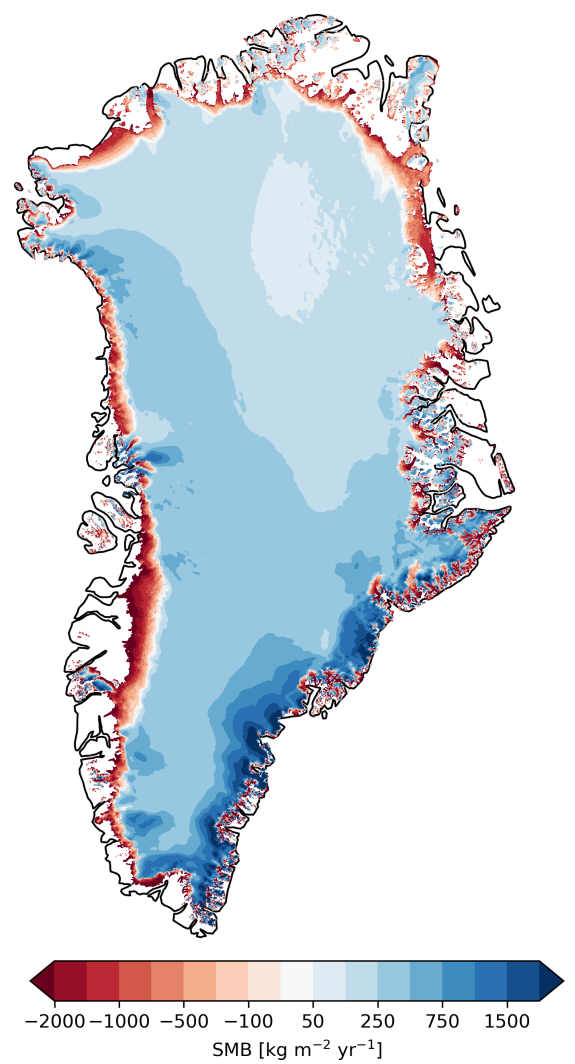

Figure 1.2: Geographic location, surface mass balance, and hypsometry of the Greenland ice sheet. Blue shading in the SMB plot (panel b) indicates net mass gain (accumulation), whereas red shading indicates net mass loss (ablation). SMB data was sourced from the RACMO2.3p2 at $1 \mathrm{~km}$ [Noël et al., 2019a] and averaged over the period 1958-2017, and hypsometry data was sourced from the BedMachine3 project at $150 \mathrm{~m}$ resolution [Morlighem et al., 2017].

\subsection{The mass balance of the Greenland Ice Sheet}

Ice sheets are continental-scale glaciers that form through prolonged snow that accumulates in winter and does not melt away in summer. Snow grains are pressed together under the increasing weight of overlying snow to eventually become glacial ice at a density of $830-923 \mathrm{~kg} \mathrm{~m}^{-3}$ [Cuffey and Paterson, 2010]. Glacial ice flow would occur on sloped terrain or simply when an ice sheet grows large enough, through the process of viscous deformation under the force of gravitational pull. Ice flow is typically directed from the cold interior out towards the warmer margins of the ice sheet, where the ice either melts or breaks off into the ocean as icebergs. An ice sheet is considered to be in equilibrium with the surrounding climate when its geometry does not change, that is, it neither shrinks nor expands and mass 
gains are balanced by mass losses. However, often an ice sheet in apparent equilibrium is still slowly adjusting to changes in climate that have happened many millennia ago [Cuffey and Paterson, 2010].

The Greenland Ice Sheet (GrIS) is the only remaining ice sheet on the northern hemisphere, located east of the Canadian Archipelago and west of Iceland (Figure 1.2a), spanning the latitudes of $\sim 60^{\circ} \mathrm{N}$ to $\sim 83^{\circ} \mathrm{N}$. The GrIS has an area equivalent to three times the size of France and its thickness reaches over $3 \mathrm{~km}$ in the interior. The volume of ice stored is estimated at $\sim 3$ million $\mathrm{km}^{3}$, which would raise global mean sea level by $\sim 7.4 \mathrm{~m}$ was it all to melt away [Morlighem et al., 2017]. Over the period 2007-2016, the GrIS was losing mass at a rate of $0.8 \pm 0.04 \mathrm{~mm}$ sea level equivalent [Bamber et al., 2018b], a rate which is expected to increase non-linearly in a warming world [Pattyn et al., 2018].

Currently, there are three distinct methods in use for calculating the mass balance of an ice sheet [The IMBIE team, 2020]. The first method, altimetry, takes surface height measurements from satellites such as ERS, ENVISAT, CryoSat-2 or ICESat2, and converts them into ice volume and mass changes. The second method, gravimetry, uses the GRACE satellites which measure small changes in the Earth's gravitational field caused by the displacement of water from the ice sheet into the ocean. The third method is the input-output method, a physically-based approach combining estimates of snowfall (and other surface mass fluxes) from regional climate models (RCMs; the input) with observations of ice discharge at the outlet glaciers near the coast (the output). Net ice-sheet mass balance (MB) is then calculated as the difference between the input and the output. Each of these methods comes with certain pros and cons. For instance, MB derived by the input-output method has a wider time span than the other two methods, but suffers from relatively large uncertainties as it results from differing two large numbers.

RCMs providing the input for the input-output method need to be forced at the boundaries of their spatial domain. For the present-day, this forcing can be taken from reanalyses, such as ERA5, which provide gridded meteorological data that has been data-assimilated towards vast archives of meteorological observations. When projecting into the future, observations are obviously lacking and meteorological data must come from elsewhere. The common approach is to use free-running climate models such as ESMs, forced with different scenarios of increased concentrations of greenhouse gases [Rae et al., 2012; Fettweis et al., 2013a; van Angelen et al., 2013; Mottram et al., 2017; Noël et al., 2019b; Goelzer et al., 2020]. Observations of ice discharge (the output) are replaced by projections of dynamical ice-sheet models, i.e. numerical models that compute the flow of ice.

\subsection{The surface mass balance and non-linear feed- backs}

A more descriptive name for the input is the specific (or climatic) surface mass balance (SMB, units in $\mathrm{kg} \mathrm{m}^{-2} \mathrm{yr}^{-1}$ ). In the cold interior of the GrIS, SMB $>0$ and is dominated by snowfall, with only minor (negative) contributions from sublimation and erosion (Figure 1.2b). This is the so-called accumulation zone (Figure 1.3). In the highest parts of the accumulation zone, above $3 \mathrm{~km}$ elevation, snow barely melts in summer and when it does, all meltwater will refreeze in the perennial snowpack, which is referred to as firn (Figure 1.3). Towards the margins of the ice sheet, however, snow melt starts to become significant and meltwater runoff occurs, either at the surface (in meltwater rivers) or at depth. 


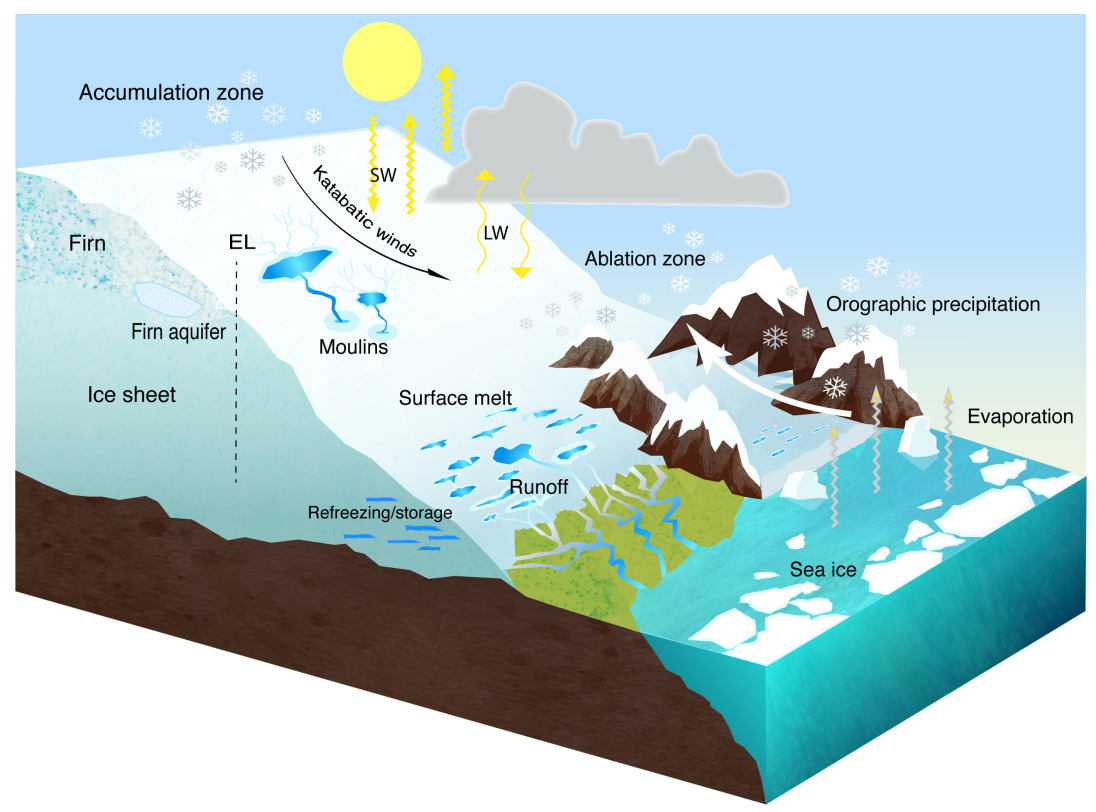

Figure 1.3: Relevant surface features and processes for the Greenland Ice Sheet. The abbreviations $S W, L W$, and EL stand for shortwave radiation, longwave radiation, and equilibrium line, respectively. Figure reprinted from Lenaerts et al. [2019] with permission.

$\mathrm{SMB}=0$ when annual runoff matches annual accumulation, which is the case at the equilibrium line of the ice sheet. In the ablation zone, SMB $<0$ and the mass balance is dominated by runoff (Figure $1.2 \mathrm{~b}$ and 1.3). For the most part, the ablation zone overlaps with the bare ice zone, locations on the GrIS where the snowpack is seasonal and bare ice is exposed at the surface during summer.

Due to its geographical location, GrIS SMB is particularly susceptible to anthropogenic warming [Hanna et al., 2020]. In contrast to the Antarctic Ice Sheet, the GrIS is situated further off-pole in a milder climate and had already substantial ablation zones before 1990, when the ice sheet was in approximate equilibrium [van den Broeke et al., 2016]. Any additional warming on the GrIS will therefore directly lead to an upward shift in the equilibrium line altitude and an expansion of ablation area, and therefore smaller SMB. Moreover, due to the hypsometry of the GrIS (Figure 1.2c), the expansion of ablation area will proceed in a nonlinear fashion, with increasingly large areas experiencing ablation when the equilibrium line moves upwards.

In addition, there are two major climate-SMB feedback mechanisms that further contribute to the nonlinear behaviour. First, melting snow is darker than dry snow, and will therefore absorb more sunlight. This can be compared to wearing black clothes in summer, which run more hot than white ones. In glaciology, this phenomenon is dubbed the snowmelt-albedo ${ }^{1}$ feedback, and represents a powerful melt-

\footnotetext{
${ }^{1}$ Albedo $(\alpha)$ is another word for 'reflectivity'. $\alpha=1$ indicates that all shortwave radiation is reflected, whereas $\alpha=0$ indicates full absorption. The albedo of fresh snow is about 0.85 .
} 


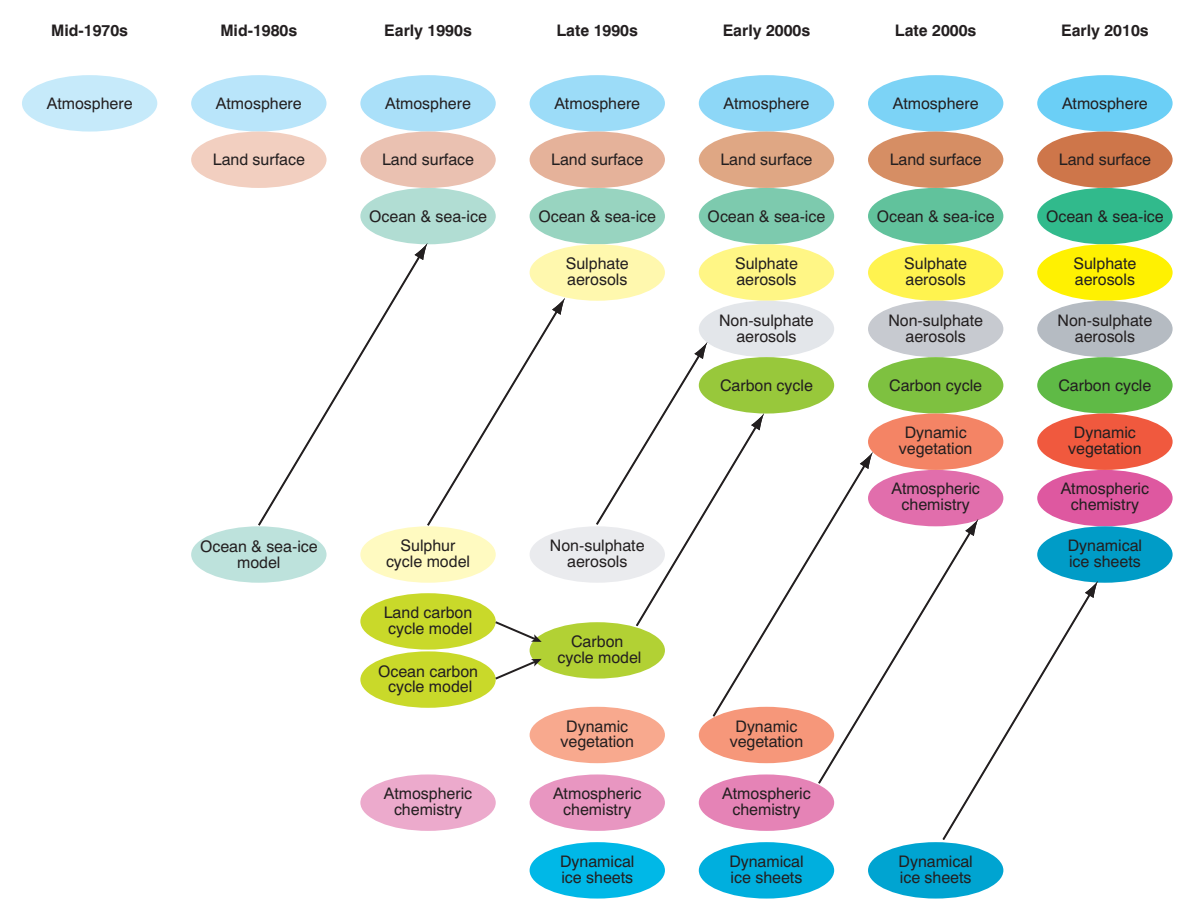

Figure 1.4: History of coupled climate models. Darker shading indicates that model components grow in sophistication over time. Black arrows indicate that previously independently used model components are added to the coupled model framework. Coupled models with an active carbon cycle are generally referred to as Earth system models (ESMs). Figure reprinted from Stocker [2011] with permission.

amplifying process that operates on short time scales (sub-daily to seasonally). This feedback may even play out inter-annually, for instance when darker snow layers with refrozen meltwater are exposed at the surface. The second mechanism, the temperature-elevation feedback, operates on much longer time scales. When an ice sheet loses mass, it will slowly shrink and decrease in height, meaning that the icesheet surface will now reside in a lower and warmer layer of the troposphere. The change in ambient temperature will generally lead to enhanced melt.

To summarize, GrIS SMB represents the combined signal of surface mass gains, mainly snowfall, and mass losses, mainly runoff and sublimation. SMB $>0$ in the interior, and SMB $<0$ in the ablations zones at the margins. There are two feedback mechanisms that may amplify any increase in snowmelt and runoff, namely the snowmelt-albedo and temperature-elevation feedbacks. In the next section, we briefly introduce the concept of Earth system modelling and motivate why ESMs might be useful when interested in projections of future ice-sheet mass balance. 


\subsection{Earth system models, and a case for a two-way coupled modelling approach}

When the equations of motion are discretized on a grid, one obtains a numerical flow model. When such a model is combined with both a description of radiative transfer as well as parametrizations for convection, turbulence and cloud formation, a numerical atmosphere model is obtained. Historically, the first climate models were just that-standalone atmosphere models or general circulation models (GCMs). Over time, these models grew in sophistication and were coupled to numerical models for other 'spheres' of the Earth, including the ocean, sea ice, the land surface, and atmospheric chemistry (Figure 1.4). When also the most important biogeochemical cycles are included-i.e. the transfer of chemicals between living things and their environment - then these coupled models are referred to as Earth system models (ESMs). Examples of such biogeochemical cycles are the carbon cycle and the nitrogen cycle, which require inclusion of relevant processes (sources and sinks) in at least the ocean, atmosphere and land components.

Ice sheets form integral parts of the Earth system. For instance, they exchange energy with the atmosphere through radiation, turbulent energy, and sublimation, and constitute energy sinks on the planetary scale [van den Broeke, 2004]. Mass is exchanged with the atmosphere in the form of precipitation, and with the ocean in the form of meltwater runoff and ice bergs. The rate of freshwater discharge into neighbouring oceans has been linked to marine bioproductivity [Bhatia et al., 2013] and increased stratification which can inhibit deep convection and dampen the strength of the 'conveyor belt' in the climate system, the Atlantic overturning meridional overturning circulation [Fichefet et al., 2003]. A recent review paper by Fyke et al. [2018] exhaustively lists the many interactions and feedbacks between ice sheets and the rest of the Earth system, schematically summarized in Figure 1.5).

Many of these interactions and feedbacks are currently not well represented in ESMs. For instance, most mainstream ESM simulations hold ice-sheet topography static in time when projecting into the future [Nowicki et al., 2016]. Especially on longer time scales (>100 years), this will impact model outcomes on regional [Ridley et al., 2005] and global scales [Manabe and Broccoli, 1985]. Fyke et al. [2018] argues that it is "impossible to fully understand ice sheet behavior-including robust projections of future sea level rise-if ice sheets are treated as isolated units that simply respond to external forcings". Instead, they argue, ice sheets should be considered as integral components of the coupled Earth system model, in particular in simulations with long ( $>100$ year) time scales.

An integral approach with interactive ice sheets is accomplished by coupling dynamical ice-sheet models into the climate modelling framework (Figure 1.4). Ice sheet models discretize and solve the physical equations that control the flow (dynamics) and temperature (thermodynamics) of ice. Furthermore, they parameterize processes that are known to affect the evolution of the ice sheet but that are hard to model explicitly, such as basal melting. Coupling ice-sheet models to ESMs has been referred to as 'tight coupling' as well as 'two-way coupling'. Here, we prefer the latter term which makes explicit the bi-directionality of the interaction: not only does the climate system give input the ice sheet (for the GrIS, mainly through SMB and melting of marine-terminating outlet glaciers) but the now dynamical ice sheet feeds back into the other components of the Earth system, notably the circulation in the ocean and the atmosphere (see Figure 1.5). 


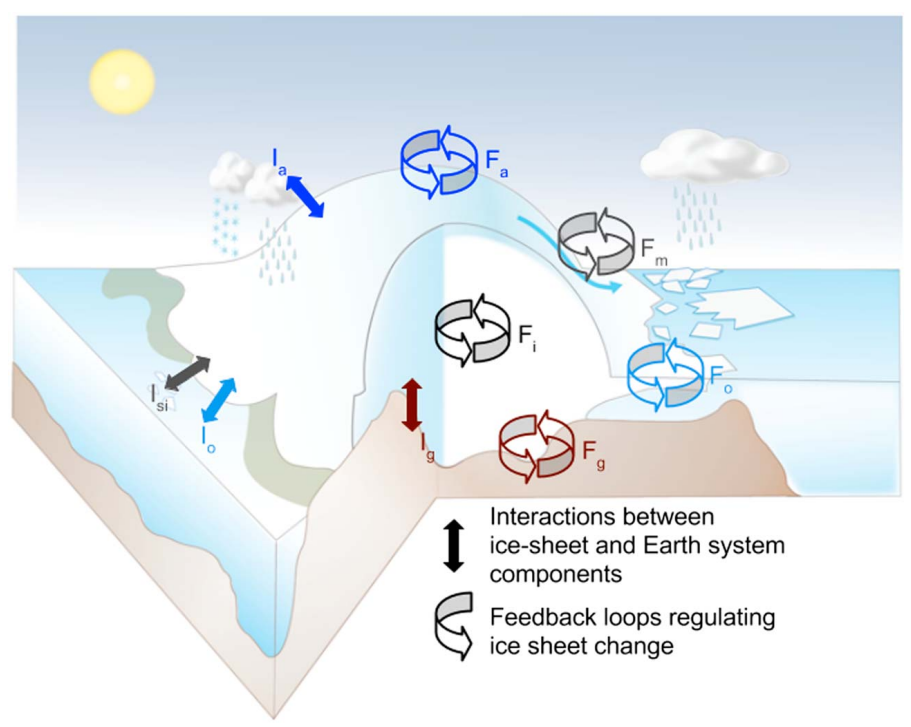

Figure 1.5: Interactions between ice sheets and the climate system. Interactions and feedbacks exist with the atmosphere (a), the ocean (o), sea ice (si), and the solid Earth ( $g$ ). In addition, feedbacks likely exist that involve multiple Earth system components $(m)$ or those that are purely internal to the ice sheet (i). Reprinted from Fyke et al. [2018] with permission.

An important prerequisite towards two-way coupling in ESMs (and a long-standing problem, [Goelzer et al., 2017]) is a realistically simulated SMB field. Failure in this regard would imply unrealistic ice sheet geometries, which undermine the value of future predictions in both sea level rise, and the response of the surrounding climate system. The next section looks at some specific challenges that relate to SMB modelling from within ESMs.

\subsection{Challenges for modelling surface mass balance within Earth system models}

Two-way coupling of ice sheets in ESMs poses a wide range of challenges to the modeller, from the gaps in spatial and temporal resolution to the need of resolving surface processes that are unique to land ice, such as meltwater refreezing. A complete overview of issues that may arise in the context of two-way coupling has been provided by [Vizcaíno et al., 2014]. Here, we highlight three challenges which are deemed most important for modelling SMB, with a particular focus on the GrIS.

\section{i) Model resolution}

Presently, the typical horizontal resolution of ESMs is $1^{\circ}(\sim 110 \mathrm{~km})$ in the ocean and atmosphere. Resolution does increase slowly over time, but is heavily constrained by the availability of both computational power and storage space at the supercomputing centres where simulations are performed. 
Higher resolution setups exist but are computationally expensive, which prohibits the execution of multiple ensemble members and limits their usage [Haarsma et al., 2016]. By contrast, polar RCMs that produce today's state-of-the-art SMB products have a native horizontal resolution of 5-20 km. Their substantially higher resolution has clear benefits for the quality of the simulations. For instance, the distribution of precipitation in these models is unparalleled by any ESM [Fettweis et al., 2020]. Resolutions below $\sim 5 \mathrm{~km}$ may be desirable for resolving steep SMB gradients in the GrIS ablation zones, but are ruled out by the hydrostatic assumption in use by many polar RCMs [van de Berg et al., 2019]. Instead, statistical downscaling approaches are used to downscale RCM data to the $\sim 1 \mathrm{~km}$ scale [Noël et al., 2016], with clear benefits on ablation zone SMB and conforming to the spatial resolution of dynamic ice-sheet models [Goelzer et al., 2020].

Two techniques exist that partially overcome or circumvent the current deficiency in ESM model resolution. The first, referred to as elevation classes or elevation tiles, builds upon the notion that near the GrIS margins, SMB is strongly elevation dependent. This elevation-dependence is exploited when multiple elevation tiles exist within a single grid cell, that can be used to interpolate SMB towards a high-resolution ice-sheet grid. The second method is to employ regionally refined or variable resolution grids, in which a selected region is resolved at a higher resolution than the rest of the globe. Both of these techniques will be used and examined later in this dissertation.

\section{ii) Atmospheric forcing}

Surface melt is, to a large extent, determined by the amount of available radiation-both shortwave (solar) and longwave (thermal) - and turbulent heat. In turn, these energy fluxes are controlled by the atmospheric forcing, by which we mean atmospheric macroproperties such as clouds, wind speed and humidity. Especially clouds are known to be highly relevant for melt and therefore SMB over ice sheets. On one hand, clouds reflect incoming solar radiation back into space, and therefore have a cooling effect. On the other hand, they are made up of water molecules, either liquid or solid, which add to the greenhouse effect and thus have a warming effect. The net radiative effect of clouds depends on their composition and optical thickness, but also on the underlying surface. In the GrIS interior, where surface albedo is high, clouds typically have a warming effect. Over bare ice and the darker ablation zones, clouds typically have a net cooling effect. Because of their large control over the surface radiative budget, it seems paramount to accurately model clouds [Lenaerts et al., 2019].

Unlike polar RCMs, ESMs have a hard time tuning their cloud microphysics towards one particular region, since they are global models. Getting one region perfectly right would go at the expense of the rest of the globe, which is unacceptable. As a result, ESMs have long suffered from strong cloud biases over the Arctic and GrIS regions [e.g., McIlhattan et al., 2017]. In particular the representation of supercooled liquid clouds is believed to be crucial to model the onset of melt correctly [Bennartz et al., 2013]. In this thesis, we consider liquid clouds water content as an important metric to consider when evaluating the representation of GrIS climate.

\section{iii) Snow and radiation physics}

Surface melt is initiated when the temperature of the snowpack reaches $0{ }^{\circ} \mathrm{C}$ and when there is a surplus of energy, often from the absorption of shortwave radiation. Surface runoff is generated when surface 
meltwater can not be contained in the underlying snowpack, and water runs off laterally, either at the surface or at depth. In an attempt to simulate both of these processes realistically, a snow model must be used that accounts for at least the following processes: explicit snow albedo with multiple spectral bands for radiation, heat transfer, snow densification, meltwater percolation in firn, and refreezing [Rae et al., 2012]. Historically, ESMs do not consider these processes—or only partially—which means there is a need for model development and implementation of improved physics representing the icesheet snow/ice cover.

The SMB modelling challenges just described set the stage for the work presented in our thesis. They will be revisited later in Chapter 6, where we review our work in their context. Now, as the final part of the introduction, we introduce the particular ESM that will be used for our modelling studies.

\subsection{The Community Earth System Model}

The Community Earth System Model (CESM) and its predecessors have been used in hundreds of studies to better understand climate variability and climate change [Hurrell et al., 2013]. In addition, its simulations inform international assessments on climate, such as the Intergovernmental Panel on Climate Change (IPCC). The CESM is developed at the National Center for Atmospheric Research in the US, in collaboration with scientists from universities and laboratories both within and outside of the US. The most recent version of the model, CESM version 2 (CESM2) was released to the community in June 2018 and an overview of this model version in Danabasoglu et al. [2020], along with an evaluation of pre-industrial controls simulations. CESM2 takes part in the Coupled Model Intercomparison Project phase 6 [Eyring et al., 2016] that informs the next comprehensive IPCC report, the 6th Assessment Report, due in 2021.

The CESM version 1 was one of the first ESMs to incorporate a dynamical ice sheet model. The coupling between the climate model and ice-sheet model at that time was strictly one-directional, however, meaning that there was no feedback from the ice sheet back to the rest of the climate system [Lipscomb et al., 2013]. The same model version also exhibited a fairly realistic overall GrIS climate [Vizcaíno et al., 2013], a prerequisite for two-way coupling as discussed in the previous section. However, some issues concerning SMB modelling remained. For one, the results of Vizcaíno et al. [2013] were obtained with an already ageing atmospheric model, version 4 of the Community Atmosphere Model (CAM4). CAM5, its successor, was also implemented into CESM1 and although that represented a "significant advancement from CAM4" [Hurrell et al., 2013], it did not reproduce the same promising results over Greenland. In part, this may be blamed on CAM5 itself, introducing new (cloud) biases over the polar regions. However, it also revealed the possibility of compensating errors in the CAM4 results. As one example, total GrIS precipitation in CAM4 was overestimated by 20\% compared to RCM results, which was balanced by a positive bias in runoff of similar magnitude resulting in an overall acceptable SMB [Vizcaíno et al., 2013]. The bias in runoff, although never fully diagnosed, can be traced back to at least three different factors: (1) rainfall was overestimated by a factor of $\sim$ four, making the surface darker and therefore leading to more melt; (2) CESM1 had a limited snow pack depth of $1 \mathrm{~m}$ water equivalent (w.e.), which is unrealistically shallow for the accumulation zone of ice sheets and puts a too strong restriction on the refreezing capacity; and (3) too few clouds in CAM4 combined with excessive liquid water content will have biased the surface energy budget, as demonstrated by a later study by Lenaerts et al. [2020b] which focused specifically on Greenland clouds in CAM. 
CESM2 improves on CESM1 in several aspects, regarding land ice. First, it features an improved dynamical ice-sheet model [Lipscomb et al., 2019] that can more simulate ice flow with greater fidelity. Secondly, CESM2 incorporates new software infrastructure which enables two-way coupling between ice sheet and atmosphere [Danabasoglu et al., 2020]. We note that two-way ice-sheet-ocean coupling is a different problem with distinct challenges, and although CESM development on that is ongoing, it is not at the same level as the atmosphere coupling. Third, the atmospheric component in CESM2, CAM6, contains many improvements over previous CAM versions, such as better cloud microphysics with greater performance over Greenland [Lenaerts et al., 2020b]. Finally, CESM2 features important updates to the snow model and other aspects of SMB modelling, which will be detailed later in this dissertation (specifically, Chapters 2 and 5).

\subsection{Outline of this thesis}

All studies contained in this thesis relate to the simulation of GrIS SMB using the Community Earth System Model (CESM). Chapter 2 specifically looks at the representation of polar snow and firn in the CESM, and describes model updates to improve this representation. Chapter 3 focuses on the importance of horizontal resolution in the atmosphere component, in a novel approach that uses variable resolution grids over Greenland. Chapter 4 contains a detailed evaluation of GrIS climate and SMB in a set of $1^{\circ}$ CESM2 simulations that have been performed in the context of the Coupled Model Intercomparison Project phase 6 (CMIP6). Finally, Chapter 5 presents a study on a possible warming threshold for the GrIS which, if crossed, would lead to an eventual deglaciation of the entire ice sheet. This study was carried out using a combination of data sets, including CESM, a regional climate model, and CMIP5 and CMIP6 climate model output. 


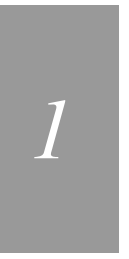




\section{Improving the Representation of Polar Snow and Firn in CESM}

\section{Summary}

In Earth system models, terrestrial snow is usually modelled by the land surface component. In most cases, these snow models have been developed with an emphasis on seasonal snow. Questions about future sea level rise, however, prompt the need for a realistic representation of perennial snow, as snow processes play a key role in the mass balance of glaciers and ice sheets. Here we enhance realism of modelled polar snow in the Community Land Model (CLM), the land component of the Community Earth System Model (CESM), by implementing 1) new parametrizations for fresh snow density, destructive metamorphism and compaction by overburden pressure, 2) by allowing for deeper snow packs, and 3) by introducing drifting snow compaction, with a focus on the ice sheet interior. Comparison with Greenlandic and Antarctic snow density observations show that the new physics improve model skill in predicting firn and near-surface density in the absence of melt. Moreover, compensating biases are removed and spurious subsurface melt rates at ice sheets are eliminated. The deeper snow pack enhances refreezing and allows for deeper percolation, raising ice temperatures up to $15^{\circ} \mathrm{C}$ above the skin temperature.

This chapter is based on: van Kampenhout, L., Lenaerts, J. T. M., Lipscomb, W. H., Sacks, W. J., Lawrence, D. M., Slater, A. G., and van den Broeke, M. R. Improving the Representation of Polar Snow and Firn in the Community Earth System Model. J. Adv. Model. Earth Syst., 9(7):2583-2600, Nov. 2017. ISSN 1942-2466. doi: 10.1002/2017MS000988 


\subsection{Introduction}

The Greenland ice sheet (GrIS) and parts of the Antarctic ice sheet (AIS) are located in the world's fastest warming regions [Masson-Delmotte et al., 2006], and their mass loss is expected to contribute significantly to future sea level rise. The Intergovernmental Panel on Climate Change (IPCC) estimates a global mean sea level rise of $0.28-0.98 \mathrm{~m}$ by 2100 , of which up to $40 \%$ is attributed to ice sheet mass loss (IPCC AR5, Church et al. [2013]). Beyond 2100, ice sheet-climate feedbacks start playing a role, especially in high-emission scenarios. For instance, Ridley et al. [2005] showed that changes in ice sheet topography will affect large-scale atmospheric circulation. Also, increasing freshwater fluxes from melting ice and snow could cause shifts in ocean circulation, affecting regional climate [Hu et al., 2009; Zhu et al., 2014; Lenaerts et al., 2015].

To capture these feedbacks, ice sheet models are now being incorporated into Earth system models (ESMs) [e.g. Mikolajewicz et al., 2007; Vizcaíno et al., 2010; Lipscomb et al., 2013], and the Ice Sheet Model Intercomparison Project for CMIP6 (ISMIP6) recently defined ice sheet-climate feedbacks as a modeling goal [Nowicki et al., 2016]. There are two major challenges involved. The first challenge concerns the difference in scales, both spatially and temporally. A typical ice sheet model has a length scale of $10 \mathrm{~km}$ and a long response time - decades to millennia. In contrast, global atmosphere models typically run at a coarser resolution $(100 \mathrm{~km})$, yet have comparatively short response times - weeks to months. This difference in scales is addressed by employing asynchronous coupling between ice sheet and climate models [Ridley et al., 2005; Helsen et al., 2013], and by applying upscaling and downscaling techniques to coupling fields. The second challenge concerns realistic coupling fields, usually temperature and surface mass balance (SMB). SMB is commonly defined as the mass flux through the atmosphere/snow interface (precipitation minus sublimation), less runoff from snow and bare ice. Failure to accurately represent SMB results in unrealistic ice sheet geometries [Nowicki et al., 2013; Goelzer et al., 2013; Cullather et al., 2014]. Of course, SMB modeling cannot be studied entirely independently from resolution, because of local spatial heterogeneity on scales smaller than the current resolution of atmosphere models. Downscaling techniques exist that attempt to partially remedy this, using subgrid tiling [e.g. Lipscomb et al., 2013].

Another challenge to realistic modeling of ice sheet SMB is the representation of snow and ice melt. Energy balance and vertically resolved snow pack models are known to yield more realistic ablation rates than so-called temperature-index schemes, which are tuned to present-day climates [Bougamont et al., 2007; Pritchard et al., 2008]. Additionally, in a warming climate, firn (a term used for snow that has survived at least one season) acts as a buffer delaying the occurrence of meltwater runoff until storage capacity is reached [van Angelen et al., 2013; Machguth et al., 2016a; Pelt et al., 2016; Noël et al., 2017]. Obtaining realistic results from an energy balance and snow pack model is challenging because of the many meteorological parameters to which it is sensitive, affecting e.g. albedo [Rae et al., 2012]. Nevertheless, most climate models have implemented detailed snow pack models and found improvements to their SMB simulations [Punge et al., 2012; Vizcaíno et al., 2013; Cullather et al., 2014].

Here we evaluate and improve the representation of snow and firn in the Community Land Model version 4 (CLM4), the terrestrial component of the Community Earth System Model (CESM; Hurrell et al. [2013]). Previous work with this model has highlighted problems associated with (1) the limited refreezing capacity in the shallow snow pack (maximum snow depth $H_{\max }=1 \mathrm{~m}$ snow water equivalent 
(SWE), Vizcaíno et al. [2013]), and (2) unrealistic melt rates due to an underestimation of vertical heat transport [Lenaerts et al., 2016]. In this study, the representation of polar snow and firn in CESM is improved by changing the fresh snow density and density evolution, and by increasing the maximum depth. We evaluate the changes using a standalone firn densification model with a high vertical resolution, and a set of global CLM simulations forced by atmospheric reanalysis data. For this study, firn density observations are taken from the ice sheet interior, where melt is mostly absent. Follow-up work is planned to evaluated the surface energy and mass balance in the coupled model, including the percolation and ablation zones of the ice sheet. The paper is organized as follows. Section 2.2 introduces CESM and describes the main characteristics of its terrestrial snow pack model. Changes in model physics are described in Sect. 2.3 and subsequently evaluated using a firn densification model (Sect. 2.4). CLM simulation setup and results are discussed in Sect. 2.5, followed by concluding remarks (Sect. 4.5).

\subsection{Model description}

CESM is a fully coupled climate model with as principal components the Community Atmosphere Model (CAM; Neale et al. [2012]), the Parallel Ocean Program (POP2; Smith et al. [2010]), the Community Land Model (CLM; Lawrence et al. [2011]), Community Ice CodE (CICE; [Hunke et al., 2010] and the Community Ice Sheet Model (CISM; [Lipscomb et al., 2013]). Energy balance calculations over ice sheets are performed in CLM4, which typically runs at a latitudinal resolution of $1^{\circ}(\sim 111$ $\mathrm{km}$ ), i.e. too coarse to accurately capture the steep slopes and other topographic variations found at ice sheet edges. In contrast, CISM runs at a much higher resolution (typically $4 \mathrm{~km}$ ) but has no energy balance scheme to interact with the atmosphere. To overcome this discrepancy in resolution, the surface energy balance is calculated by CLM at multiple elevations simultaneously, with lapse-rate corrections for temperature and longwave radiation per elevation class. Each elevation class also maintains an independent snow pack state, and as such yields an elevation-dependent SMB. The vertical SMB-profile is subsequently downscaled towards the high resolution ice sheet grid, which is a considerable improvement over just using a single value per CLM grid cell [Vizcaíno et al., 2013]. Moreover, the multiple elevation classes approach is computationally cheap, uses the existing CLM4 snow pack model and, importantly, enables the atmosphere to react instantaneously to changes in ice sheet surface, including albedo changes [Lipscomb et al., 2013].

The multi-layer snow module in CLM4 originates from the SNTHERM snow model [Jordan, 1991] and has previously been described by Oleson et al. [2010]; Lawrence et al. [2011]; Oleson [2013]. Here, only details relevant to this study are outlined. Variables modelled are snow density, water content, temperature, grain size, and aerosol concentration. Vertical discretization is performed in an Eulerian fashion, where each layer has a prescribed maximum thickness $\Delta z_{\max }$. Thinner layers are used near the surface where gradients of temperature and grain size are larger; see Table 2.1. Layers also have a prescribed minimum thickness $\Delta z_{\min }$. Whenever layer thickness drops below this minimum, e.g. by sublimation or compaction, the layer is merged with a neighbouring layer. In the special case that there are no neighbouring layers, the snow pack becomes virtual, i.e. a single layer is assumed which is no longer modelled explicitly. When a layer grows beyond its prescribed maximum, a downward mass transfer occurs such that $\Delta z_{\max }$ is satisfied. A new layer is created when there are no layers below. To ensure mass conservation, snow density is corrected during these mass transfers. CLM4 uses a 5-layer 
Table 2.1: Minimum and maximum layer thicknesses (actual, not SWE) in the CLM4 snow model with 5 layers. From: Oleson [2013]. The maximum layer thickness $\Delta z_{\max }$ depends on whether the current layer $(k)$ is the bottom layer $(N)$, or not. Indicated in the table is $N=5$, but $N$ may be smaller depending on the conditions.

\begin{tabular}{llll}
\hline Layer $(k)$ & $\Delta z_{\min }$ & \multicolumn{2}{c}{$\Delta z_{\max }$} \\
\cline { 3 - 4 } & & $N=k$ & $N>k$ \\
\hline 1 (top) & $0.010 \mathrm{~m}$ & $0.03 \mathrm{~m}$ & $0.02 \mathrm{~m}$ \\
2 & $0.015 \mathrm{~m}$ & $0.07 \mathrm{~m}$ & $0.05 \mathrm{~m}$ \\
3 & $0.025 \mathrm{~m}$ & $0.18 \mathrm{~m}$ & $0.11 \mathrm{~m}$ \\
4 & $0.055 \mathrm{~m}$ & $0.41 \mathrm{~m}$ & $0.23 \mathrm{~m}$ \\
5 (bottom) & $0.115 \mathrm{~m}$ & - & - \\
\hline
\end{tabular}

snow model, with a maximum total depth (or cap) of $1 \mathrm{~m} \mathrm{SWE}$ [Oleson, 2013]. This translates to about 2.5 meters of snow, assuming a bulk snow density of about $400 \mathrm{~kg} \mathrm{~m}^{-3}$. In contrast, the depth of the Greenland and Antarctic firn layer extends up to hundreds of meters in the coldest locations [van den Broeke, 2008]. Glacial ice in CLM4 is modelled as fully saturated, frozen soil [Oleson, 2013]. Fifteen ice layers are used that have a combined depth of $42.1 \mathrm{~m}$.

Radiation calculations over snow-covered areas are handled by the Snow, Ice, and Aerosol Radiative (SNICAR) module [Flanner and Zender, 2006]. SNICAR implements two-stream radiation transfer theory to calculate shortwave radiation penetration to deeper layers. Albedo is independently calculated for five different wavelengths and is then averaged into two radiation bands for use in CLM: near-infrared and visible light. Aerosol concentrations (soot) as well as grain size are tracked across layers as they affect scattering and absorption. Following the radiation routine, the heat equation is numerically solved for all snow and soil layers, using an implicit method. In turn, hydrological processes are accounted for, including melt, vertical water transport using a tipping bucket method, capillary retention, and refreezing.

The refreezing capacity is determined by three factors: snow depth, thermal capacity ('cold content'), and porosity. No geothermal heat flux is assumed at the bottom of the soil or ice column, thus the thermal state is solely dependent on the skin temperature, divergence of penetrated shortwave radiation, and latent heat released through refreezing. Snow thermal conductivity is calculated following Jordan [1991]:

$$
\lambda=\lambda_{\text {air }}+\left(7.75 \cdot 10^{-5} \rho+1.105 \cdot 10^{-6} \rho^{2}\right)\left(\lambda_{\text {ice }}-\lambda_{\text {air }}\right)
$$

where $\rho$ is the bulk density of snow, $\lambda_{\text {air }}=0.023 \mathrm{~W} \mathrm{~m}^{-1} \mathrm{~K}^{-1}$ and $\lambda_{\text {ice }}=2.29 \mathrm{~W} \mathrm{~m}^{-1} \mathrm{~K}^{-1}$ the thermal conductivity of air and ice, respectively. The irreducible water content is set to $3.3 \%$ of the effective porosity, and any liquid water that cannot be stored in the snow is converted to runoff.

Fractional snow cover is a subgrid parametrization that is used to capture the nonlinear feedback of snow cover on albedo [Oleson, 2013] and surface fluxes [Swenson and Lawrence, 2012]. 
Table 2.2: New minimum and maximum layer thicknesses (actual, not SWE) in the extended, 12-layer snow model.

\begin{tabular}{llll}
\hline Layer $(k)$ & $\Delta z_{\min }$ & \multicolumn{2}{c}{$\Delta z_{\max }$} \\
\cline { 3 - 4 } & & $N=k$ & $N>k$ \\
\hline 1 (top) & $0.010 \mathrm{~m}$ & $0.03 \mathrm{~m}$ & $0.02 \mathrm{~m}$ \\
2 & $0.015 \mathrm{~m}$ & $0.07 \mathrm{~m}$ & $0.05 \mathrm{~m}$ \\
3 & $0.025 \mathrm{~m}$ & $0.18 \mathrm{~m}$ & $0.11 \mathrm{~m}$ \\
4 & $0.055 \mathrm{~m}$ & $0.41 \mathrm{~m}$ & $0.23 \mathrm{~m}$ \\
5 & $0.115 \mathrm{~m}$ & $0.88 \mathrm{~m}$ & $0.47 \mathrm{~m}$ \\
6 & $0.235 \mathrm{~m}$ & $1.83 \mathrm{~m}$ & $0.95 \mathrm{~m}$ \\
7 & $0.475 \mathrm{~m}$ & $3.74 \mathrm{~m}$ & $1.91 \mathrm{~m}$ \\
8 & $0.955 \mathrm{~m}$ & $7.57 \mathrm{~m}$ & $3.83 \mathrm{~m}$ \\
9 & $1.915 \mathrm{~m}$ & $15.24 \mathrm{~m}$ & $7.67 \mathrm{~m}$ \\
10 & $3.835 \mathrm{~m}$ & $30.59 \mathrm{~m}$ & $15.35 \mathrm{~m}$ \\
11 & $7.675 \mathrm{~m}$ & $61.30 \mathrm{~m}$ & $30.71 \mathrm{~m}$ \\
12 (bottom) & $15.355 \mathrm{~m}$ & - & - \\
\hline
\end{tabular}

\subsection{Snow model development}

In the previous section we described general characteristics the CLM snow model. Here, aspects of the model are presented that were changed or newly introduced, in order to gain a better representation of polar snow and firn. Model changes can be broadly divided into three categories: (1) bug fixes, (2) parameter updates, and (3) introduction of new physics. As we will see, some changes have an opposing effect.

\subsubsection{Snow pack depth}

We increased the maximum allowed snow depth $H_{\max }$ from $1 \mathrm{~m}$ to $10 \mathrm{~m}$ SWE, which seeks a balance between observations of pore close-off depth and practical limitations. In reality, firn depth can exceed 100 meters [van den Broeke, 2008], which translates to $>60 \mathrm{~m}$ SWE assuming a bulk density of about $600 \mathrm{~kg} \mathrm{~m}^{-3}$. However, allowing for such a deep snow pack to develop in CLM would induce significantly longer spin-up times. For example, a grid point that receives an annual snowfall of $100 \mathrm{~mm} \mathrm{yr}^{-1}$ requires 100 years of spin-up with $H_{\max }=10 \mathrm{~m} \mathrm{SWE}$, versus 500 years if $H_{\max }=50 \mathrm{~m}$ SWE. Moreover, imperfect meteorological forcing during spin-up may result in permanent snow cover in places that have seasonal snow in reality. Such a spin-up bias is harder to remove when snow depth is greater, because of hysteresis. We acknowledge a modeling error is made when the snow depth is limited to $10 \mathrm{~m}$ SWE, but deem this error small compared to other uncertainties. Also, atmosphere-snow pack interaction mainly affects the snow state in the top few meters. Below 10 meters depth, the seasonal cycle in temperature is usually small, $<1 \mathrm{~K}$ [Cullather et al., 2014]. The number of snow model layers is increased from 5 to 12, which is a trade-off between vertical resolution (Table 2.2) and computational cost. A recursive formula was used to calculate the new layer thicknesses (Supporting Information in van Kampenhout et al. [2017]). The effect of the deeper snow pack will be evaluated in Sect. 2.5. 


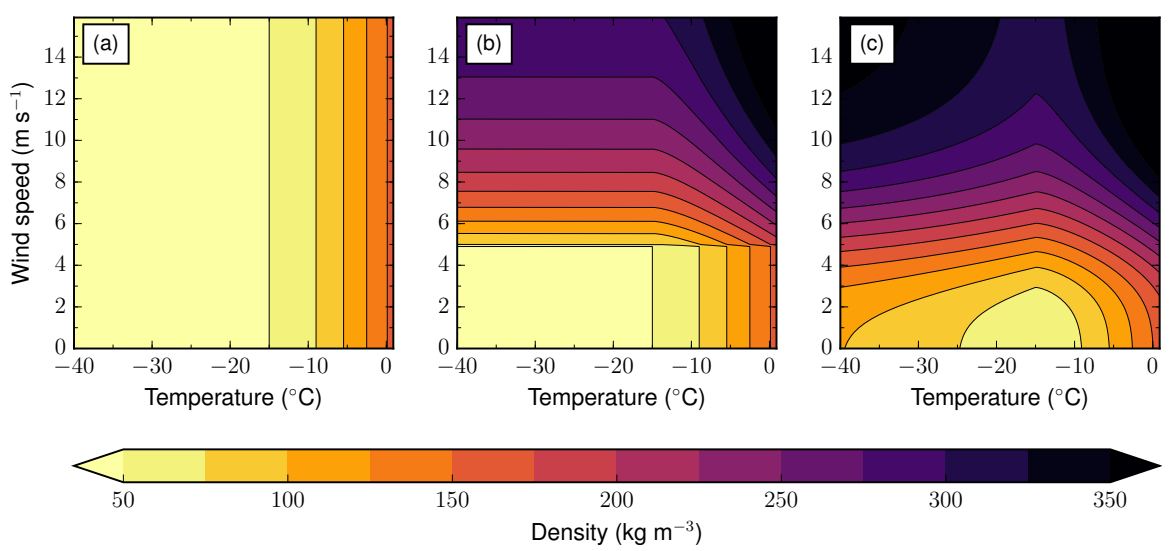

Figure 2.1: Fresh snow density as a function of temperature and wind speed, (a) the CLM4, temperature-only expression [Anderson, 1976]; (b) the same expression, but with an additional winddependent term [Liston et al., 2007], (c) the proposed expression in this paper.

\subsubsection{Snow capping}

CLM prescribes a maximum snow depth (or snow cap), $H_{\max }$, in order to prevent runaway snow depths. Any mass in excess of the snow cap (either rain or snow) is routed to the river component and ultimately to the ocean. However, the original code had a design flaw in the way in which this cap was maintained: any precipitation that would force $H>H_{\max }$ was routed directly to runoff, and snow pack characteristics were not updated (except for grain size). As a result, the top snow layer aged unrealistically and had high density throughout the year, even during snowfall events. The snow capping code has been rewritten to allow the snow pack to refresh from the top. In the new code, any excess mass is removed from the lowest snow layer instead. The phase of the runoff (liquid or solid) is determined based on the phase ratio present in the bottom snow layer (solid runoff is a crude parametrization of ice berg discharge).

\subsubsection{Fresh snow density}

In the original CLM code, fresh snow or deposition density is parametrized following Anderson [1976]. This parametrization is based on density measurements at a high-elevation site in the Rocky Mountains (Alta, Utah, USA). We argue that the surface climate at this site is not representative for ice sheets, as ice sheets are generally much colder and more windy than lower-latitude mountainous regions. The inadequacy of the fresh snow density parametrization is one of the main reasons for the excessive subsurface melt that was predicted in Antarctica [Lenaerts et al., 2016]. With surface densities being predicted as low as $50 \mathrm{~kg} \mathrm{~m}^{-3}$ in cold conditions (Fig. 2.1(a)), thermal conductivity was also greatly underpredicted (cf. Eqn. 2.1). The surface layer then insulates deeper layers from the atmosphere, inhibiting outward heat transport and promoting warming and eventually, subsurface melt. In reality, heat produced in the subsurface is conducted away, both towards and away from the surface. Therefore, improving the fresh snow density parametrization is key to alleviating issues with excessive subsurface melt. 
Here, fresh snow density is parameterized by introducing a linear wind-dependent density term $\rho_{w}$ that is added to the temperature term $\rho_{T}$, similar to Liston et al. [2007]:

$$
\rho_{\mathrm{fs}}=\rho_{T}+\rho_{w} .
$$

This choice is motivated by the fact that strong winds during snowfall cause crystal breaking, thus reducing the snow effective grain size [Sato et al., 2008], which leads to more efficient packing and increased density. Furthermore, snow crystal size depends on temperature, with the smallest particles being found at very low temperatures due to limited moisture availability during crystal formation. Based on unpublished work by A.G. Slater, and assuming $\rho$ in $\mathrm{kg} \mathrm{m}^{-3}$, we change the temperaturedependent term to:

$$
\rho_{T}= \begin{cases}50+1.7(17)^{3 / 2} & \text { if } T>T_{\mathrm{frz}}+2, \\ 50+1.7\left(T-T_{\mathrm{frz}}+15\right)^{3 / 2} & \text { if } T_{\mathrm{frz}}-15<T \leq T_{\mathrm{frz}}+2, \\ -3.8328\left(T-T_{\mathrm{frz}}\right)-0.0333\left(T-T_{\mathrm{frz}}\right)^{2} & \text { if } T \leq T_{\mathrm{frz}}-15,\end{cases}
$$

where $T$ denotes the atmospheric near-surface temperature (in ${ }^{\circ} \mathrm{K}$ ), and $T_{\text {frz }}$ the freezing temperature of water $\left(273.15^{\circ} \mathrm{K}\right)$. Equation 2.3 predicts a density inversion at very low temperatures, which agrees with observational data (not shown). The wind-dependent term is calculated as follows:

$$
\rho_{w}=266.861 *\left(\frac{1}{2}(1+\tanh (U / 5))\right)^{8.8}
$$

where $U$ denotes $10-\mathrm{m}$ wind speed in $\mathrm{m} \mathrm{s}^{-1}$. The wind dependent term is based on experimental data and the wind enhancement expression of Liston et al. [2007]. The proposed parametrization of fresh snow density (Fig. 2.1(c)) describes a smooth transition at $5 \mathrm{~m} \mathrm{~s}^{-1}$ wind speed, in contrast to Liston et al. [2007] (Fig. 2.1(b)).

\subsubsection{Snow densification}

Once fallen on the ground, CLM allows snow to densify through three distinct processes: (1) destructive metamorphism, which describes water molecules moving along the snow crystals by sublimation and condensation in order to reduce the surface free energy; (2) compaction by overburden pressure; and (3) melt metamorphism, which captures changes in crystal shape due to the presence and refreezing of liquid water. A fourth process known as constructive metamorphism [Yen, 1981], which relates to temperature gradients and the formation of depth hoar, is not included in CLM. Another limitation of CLM is the absence of microstructural snow properties such as bond size, grain dendricity, and grain sphericity, which are present in more detailed snow pack models like CROCUS [Vionnet et al., 2012] and SNOWPACK [Lehning et al., 2002]. Adding these microstructural properties to CLM would require accurate observational constraints, in particular from seasonal snow, and is left to future work. 


\section{Destructive metamorphism}

Destructive metamorphism is assumed to be depth-independent, and has a fixed upper limit. As in the original CLM model, the rate of compaction depends only on temperature [Anderson, 1976]:

$$
\frac{\partial \rho_{i}}{\partial t}=c_{3} c_{2} c_{1} \exp \left[-c_{4}\left(T_{\mathrm{frz}}-T_{i}\right)\right]
$$

where $\rho_{i}$ is the bulk density of snow in layer $i$ (excluding liquid water), $T_{i}$ the layer temperature $(\mathrm{K})$, $T_{\text {frz }}$ the freezing temperature of water $(273.15 \mathrm{~K}), c_{3}=2.777 \cdot 10^{-6} \mathrm{~s}^{-1}, c_{4}=0.04 \mathrm{~K}^{-1}, c_{2}$ is either 1 or 2 depending on the presence of liquid water, and $c_{1}$ is a tapering constant that equals 1 in the range $\rho \in\left[0, \rho_{\max }^{\mathrm{DM}}\right]$ and decreases exponentially beyond that. The value of $\rho_{\max }^{\mathrm{DM}}=175 \mathrm{~kg} \mathrm{~m}^{-3}$ was chosen heuristically and differs from CLM4, where a value of $100 \mathrm{~kg} \mathrm{~m}^{-3}$ was used [Oleson, 2013]. Yen [1981] found that destructive metamorphism is slow when $\rho$ exceeds $250 \mathrm{~kg} \mathrm{~m}^{-3}$, which supports the current value.

\section{Compaction by overburden pressure}

Overburden pressure stress causes sintering and mechanical creep and is the dominant force in firn densification. Before, it was modelled following the equations of Anderson [1976]:

$$
\frac{\partial \rho_{i}}{\partial t}=\frac{P_{i}}{\eta_{i}}
$$

where $P_{i}$ is the vertical stress or snow load on layer $i\left(\right.$ in $\mathrm{kg} \mathrm{m}^{-2}$ ) which includes half the weight of the present layer, and $\eta_{i}$ is a viscosity coefficient $\left(\mathrm{kg} \mathrm{s}^{-1} \mathrm{~m}^{-2}\right)$ that varies with density and temperature as:

$$
\eta=\eta_{0} \exp \left[c_{5}\left(T_{f}-T_{i}\right)+c_{6} \rho_{i}\right]
$$

where $\eta_{0}=9 \cdot 10^{5} \mathrm{~kg} \mathrm{~s}^{-1} \mathrm{~m}^{-2}, c_{5}=0.08 \mathrm{~K}^{-1}$ and $c_{6}=0.023 \mathrm{~m}^{3} \mathrm{~kg}^{-1}$. Although this parametrization may work well for seasonal snow, it has low skill in predicting polar firn density. In particular, it predicts too strong densification leading to an overestimation of firn density (Sect. 2.4).

Densification models used for correcting satellite altimetry data over ice sheets typically use empirical compaction schemes, rather than overburden compaction schemes [Ligtenberg et al., 2011; Kuipers Munneke et al., 2015]. In principle, an empirical firn densification expression could also be adopted in CLM, but this poses several problems. First, the steady-state assumption in empirical models is problematic for most places on Earth where year-to-year climate variability is large, as well as for changing climates. Second, these models require the annual balance rate to be positive, which limits the applicability of the empirical model to glacier accumulation zones. We conclude that a process-based densification model is preferred over an empirical model for global applications, even though it may not perform as well in ice sheet dry snow zones.

The detailed snow model CROCUS also employs overburden pressure compaction (Eqn. 2.6), yet defines viscosity differently [Vionnet et al., 2012]:

$$
\eta=f_{1} f_{2} \eta_{0} \frac{\rho_{i}}{c_{\eta}} \exp \left[a_{\eta}\left(T_{f}-T_{i}\right)+b_{\eta} \rho_{i}\right]
$$


where $\eta_{0}=7.62237 \cdot 10^{6} \mathrm{~kg} \mathrm{~s}^{-1} \mathrm{~m}^{-2}, a_{\eta}=0.1 \mathrm{~K}^{-1}, b_{\eta}=0.023 \mathrm{~m}^{3} \mathrm{~kg}^{-1}$ and $c_{\eta}=250 \mathrm{~kg} \mathrm{~m}^{-3}$. $f_{1}$ and $f_{2}$ are correction factors to snow viscosity that account for the presence of liquid water $\left(f_{1}\right)$ and angular grains $\left(f_{2}\right)$. Here, we adopt this expression with two changes: (1) we fix $f_{2}=4.0$, which removes the dependency on grain size, assuming relatively large grains (340 microns or more), and (2) we set $c_{\eta}=358 \mathrm{~kg} \mathrm{~m}^{-3}$ to give a better agreement with firn core data (Sect. 2.4).

\subsubsection{Compaction by drifting snow}

Drifting snow is associated with redistribution of surface snow, enhanced sublimation, and crystal breakage. Unfortunately, explicit modeling of redistribution is impractical, due to the large typical length scales in CLM [Lenaerts and van den Broeke, 2012]. Here, we only introduce the effect of drifting snow on snow compaction at the surface, where crystal breakage is known to lead to more efficient packing, and therefore higher surface densities [Brun et al., 1997].

The compaction effect of drifting snow is included in a simple, parameterized way, following Vionnet et al. [2012] who build on experimental work by Guyomarc'h and Mérindol [1998]. We define a mobility index $M_{\mathrm{O}}$ that describes the potential for snow erosion for a given snow layer, assuming non-dendritic snow:

$$
M_{\mathrm{O}}=0.34\left(-0.583 g_{s}-0.833 s+0.833\right)+0.66 F(\rho) .
$$

We assume a constant grain size $\left(g_{s}=0.35 \mathrm{~mm}\right)$ and spherical grains $(s=1)$, which leads to the following simplification:

$$
M_{\mathrm{O}}=-0.069+0.66 F(\rho)
$$

$F(\rho)$ denotes a density-dependent term and is computed as $F(\rho)=\left[1.25-0.0042\left(\max \left(\rho_{\min }, \rho\right)-\rho_{\min }\right)\right]$ with $\rho_{\min }=50 \mathrm{~kg} \mathrm{~m}^{-3}$. The value of $F$ ranges between 0.2 for consolidated snow $\left(\rho=300 \mathrm{~kg} \mathrm{~m}^{-3}\right)$ to over 1.0 for low-density snow ( $\rho=100 \mathrm{~kg} \mathrm{~m}^{-3}$ or less). We conclude that the mobility index is dominated by the density dependent term, even if we would allow for varying dendricity and sphericity (low sphericities are typical of fresh snow, having a low density), which implies that the error introduced by assuming non-dendritic, spherical snow is acceptable.

The mobility index is combined with wind speed to compute the driftability index:

$$
S_{\mathrm{I}}=-2.868 \exp (-0.085 U)+1+M_{\mathrm{O}}
$$

where positive values of $S_{\mathrm{I}}$ indicate that drifting snow occurs [Vionnet et al., 2012]. As we assume constant snow grain properties, only snow density is affected by drifting snow events:

$$
\frac{\partial \rho_{i}}{\partial t}=\frac{\rho_{\max }-\rho}{\tau_{i}}
$$

with upper limit $\rho_{\max }=350 \mathrm{~kg} \mathrm{~m}^{-3}$ and $\tau_{i}$ the characteristic timescale dependent on the driftability index:

$$
\tau_{i}=\frac{\tau}{\Gamma_{\mathrm{drift}}^{i}} \quad, \Gamma_{\mathrm{drift}}^{i}=\max \left[0, S_{\mathrm{I}}^{i} \exp \left(-z_{i} / 0.1\right)\right] .
$$

The upper limit $\rho_{\max }$ to which drifting snow compaction is active is based on observations on both ice sheets (Fig. 2.2 and Groot Zwaaftink et al. [2013]). The characteristic time scale for drifting snow 
compaction $\tau$ is empirically set to $48 \mathrm{~h}$, and the pseudo-depth $z_{i}$ takes into account previous hardening of snow layers above the current layer: $z_{i}=\sum_{j} D_{j} \cdot\left(3.25-S_{\mathrm{I}}^{j}\right)$, with $D_{j}$ being the layer thickness [Vionnet et al., 2012].

\subsection{Evaluation of code changes in absence of melt}

In the absence of melt, snow compaction is solely driven by the mechanisms that were just described. So, in order to justify the physical changes made, we ran a number of simulations using an offline dry firn densification model and compared these to observational data.

\subsubsection{Model description, data and methods}

The processes presented in Sect. 2.3 have been implemented in a single-column numerical model that couples the heat equation to snow compaction and snow metamorphism laws. This simple model allows for quick development and efficient simulations with greater vertical detail than is possible in CLM. At the surface, the model is forced with high-frequency meteorological data: skin temperature (applied as a Dirichlet boundary condition), SMB, and 10-m wind speed. No heat transport is allowed through the bottom of the column (Neumann boundary condition), which is a valid assumption when the deep snow pack is isothermal at the mean annual surface temperature [Li and Zwally, 2004]. No trend in surface temperature is assumed. The heat equation is solved using Crank-Nicholson implicit time discretization and a tridiagonal solver (LAPACK DGTSV). Thermal conductivity is parameterized according to Eqn. 2.1. The model does not simulate hydrological processes, which limits its applicability to locations where melt is absent or marginal, i.e. interior Antarctica and Greenland. 6-hourly meteorological forcing is used from the regional climate model RACMO version 2.3 for the reference periods 19572000 [GrIS, Noël et al., 2015] and 1979-2013 [AIS, Van Wessem et al., 2014]. During the spin-up, meteorological forcing is looped until an approximate equilibrium is reached, measured in terms of temperature and density.

Model experiments at 89 sites have been performed, and results are compared to in-situ measurements (snow pits and firn cores). Observational sites are divided into 53 Antarctic sites [Wagenbach et al., 1994; Oerter et al., 2000; Graf and Oerter, 2006; van den Broeke, 2008; Fernandoy et al., 2010] and 36 Greenland sites [Benson, 1962; Mosley-Thompson et al., 2001; Morris and Wingham, 2011; Kuipers Munneke et al., 2015]. On Greenland, we only selected firn cores that see little to no melt, i.e. where the ratio of melt to accumulation is less than or equal to 0.02 ).

Two metrics are used to evaluate each experiment. The first is the depth of the $\rho=550 \mathrm{~kg} \mathrm{~m}^{-3}$ density level ( $z 550$ hereafter) as a proxy for the transition from settling to sintering as the dominant process in the upper-firn compaction. $z 550$ is commonly used to evaluate firn compaction models [e.g., Ligtenberg et al., 2011]. The second metric is near-surface density, a quantity that is notoriously difficult to constrain from observations, for several reasons. First, large heterogeneities may exist horizontally due to redistribution and differences in atmospheric forcing. Second, low-density layers on top of consolidated snow have been observed, which make surface density an ambiguous concept [Brun et al., 2011]. Finally, snow density measurements are sparse and performed at different depths, from several centimeters up to half a meter or more. In this study, we will distinguish between skin density $\rho_{\text {skin }}$, 
the density of the upper model layer, and near-surface density $\overline{\rho_{1 m}}$, which represents the average snow pack density in the upper meter. Both these quantities are averaged over a climatological period (set to 30 years) to filter out seasonal differences. This means they incorporate ageing and compaction effects and therefore, both these quantities will differ significantly from the deposition density.

Modelled values of $\overline{\rho_{1 m}}$ are compared to snow pit and firn core observations at varying depth and time. As such, there is a mismatch both in time (climatological mean vs. single measurement) and space (grid cell average vs. point measurement), which adds uncertainty. For data records that have more than one sample in the upper first meter, we selected the node depth closest to $0.5 \mathrm{~m}$. Not all measurement sites had recordings of both metrics of interest. The mean observed $z 550$ over the 56 available measurements is $11.7 \mathrm{~m}$. The mean observed $\overline{\rho_{1 m}}$ over the 64 available measurements is $374 \mathrm{~kg} \mathrm{~m}^{-3}$. Table 2.3 lists the different experiments and their performance on the two metrics. The goal of these experiments is to allow for understanding the processes that control near surface density and firn density, and describe the steps that were taken in order to at least qualitatively match observations. Uncertainties arise from the RACMO2 forcing data used, measuring errors in the firn core data, sparsity of in-situ data, and a possible summer bias in the measurements. The good fit of observed firn density profiles with semi-empirical steady-state firn densification models suggests that the steady-state assumption (constant accumulation and temperature) is reasonable for the selected forcing (RACMO).

\subsubsection{Results and discussion}

The first experiment in Table 2.3, S1, is best regarded as a benchmark experiment for $z 550$. Instead of a prognostic equation for overburden compaction, it employs the empirical, steady-state firn model of Herron and Langway [1980], which involves the local mass balance rate. Recent work improved upon the steady-state parametrization by Herron and Langway [1980] resulting in better fits over the GrIS [Li and Zwally, 2004], AIS [Helsen et al., 2008; Ligtenberg et al., 2011] and coastal Antarctica [Arthern et al., 2010] using new observational data and introducing temperature dependent activation energies. Since our interest here lies in using S1 as a benchmark experiment, and Herron and Langway [1980] is not tuned towards one ice sheet in particular, this expression is deemed fit-for-purpose. Fresh snow density is set according to the empirical relation by Helsen et al. [2008], which, in fact, was developed as a parametrization for $\overline{\rho_{1 m}}$. Therefore, we must realize that a modeling error is introduced by using Helsen et al. [2008] as a predictor for deposition density. This is reflected by the overprediction of $\overline{\rho_{1 m}}$ by $51.8 \mathrm{~kg} \mathrm{~m}^{-3}$. Also, this error may have contributed to the small underprediction of $z 550$ by 0.22 $\mathrm{m}$. What is more, the expression by Helsen et al. [2008] contains a slope correction for the AIS. On account of that, we expect model skill in predicting GrIS $z 550$ to be worse than AIS $z 550$. Indeed, the fit is considerably better at Antarctic sites $\left(r^{2}=0.78\right)$ than at Greenland sites $\left(r^{2}=0.22\right)$. Combined, the predictive skill is fair $\left(r^{2}=0.66\right)$.

S2 uses the original CLM4 pressure compaction and fresh snow density formulations [Anderson, 1976]. By intercomparing S2 and S1 we get a sense of how much skill CLM has in resolving firn density. Unfortunately, we find that it is rather inadequate in resolving the basic ice sheet snow properties that were selected (Table 2.3). Near surface density $\overline{\rho_{1 m}}$ is substantially underestimated (Fig. 2.2), which is attributed to the absence of key model physics, of which wind-dependent fresh snow density is deemed the most important. The depth of $\rho=550 \mathrm{~kg} \mathrm{~m}^{-3}$ is much closer to the surface than in the observations (Fig. 2.3). Indeed, no $550 \mathrm{~kg} \mathrm{~m}^{-3}$ value is found deeper than $7 \mathrm{~m}$. Somewhat surprisingly, the biases 


\begin{tabular}{|c|c|}
\hline 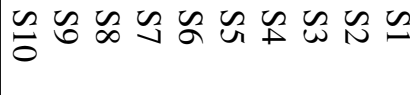 & 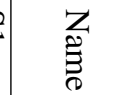 \\
\hline 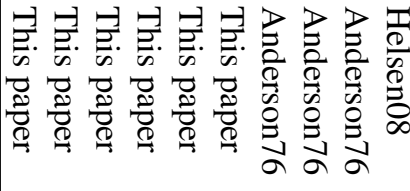 & $\stackrel{\pi}{\Omega}$ \\
\hline 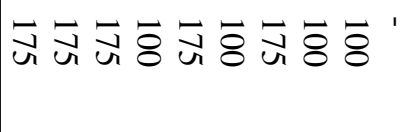 & 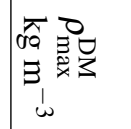 \\
\hline 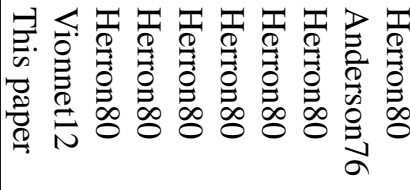 & 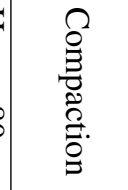 \\
\hline 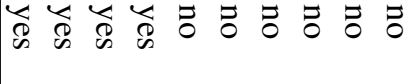 & $\underset{ٍ}{\rightleftarrows}$ \\
\hline 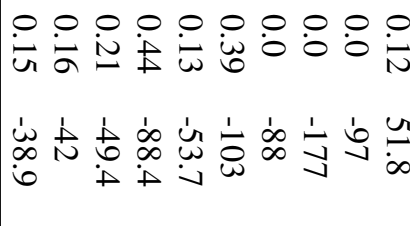 & 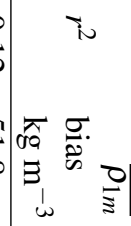 \\
\hline 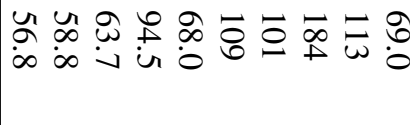 & 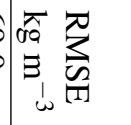 \\
\hline 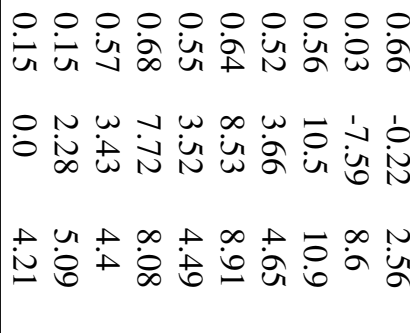 & 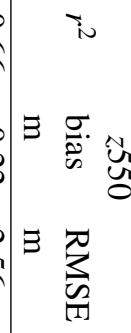 \\
\hline
\end{tabular}

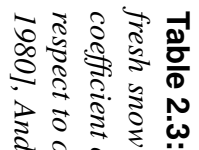

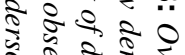

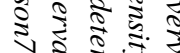

ת)

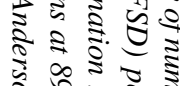

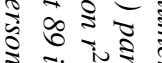

จ

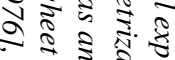

万人.

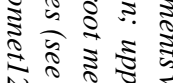

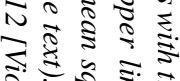

$\rightarrow$ 要

क्र

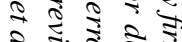

ㄷำ

ㄷํㄹ

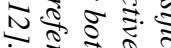

은 2

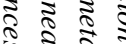

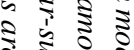

족

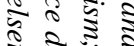

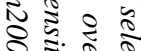

इईई

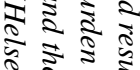

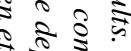

2

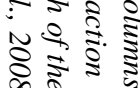

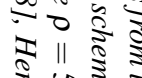

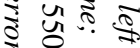

क저용

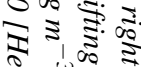

帘

ह है है

ร)

ह $\frac{1}{5}$

ज

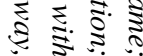




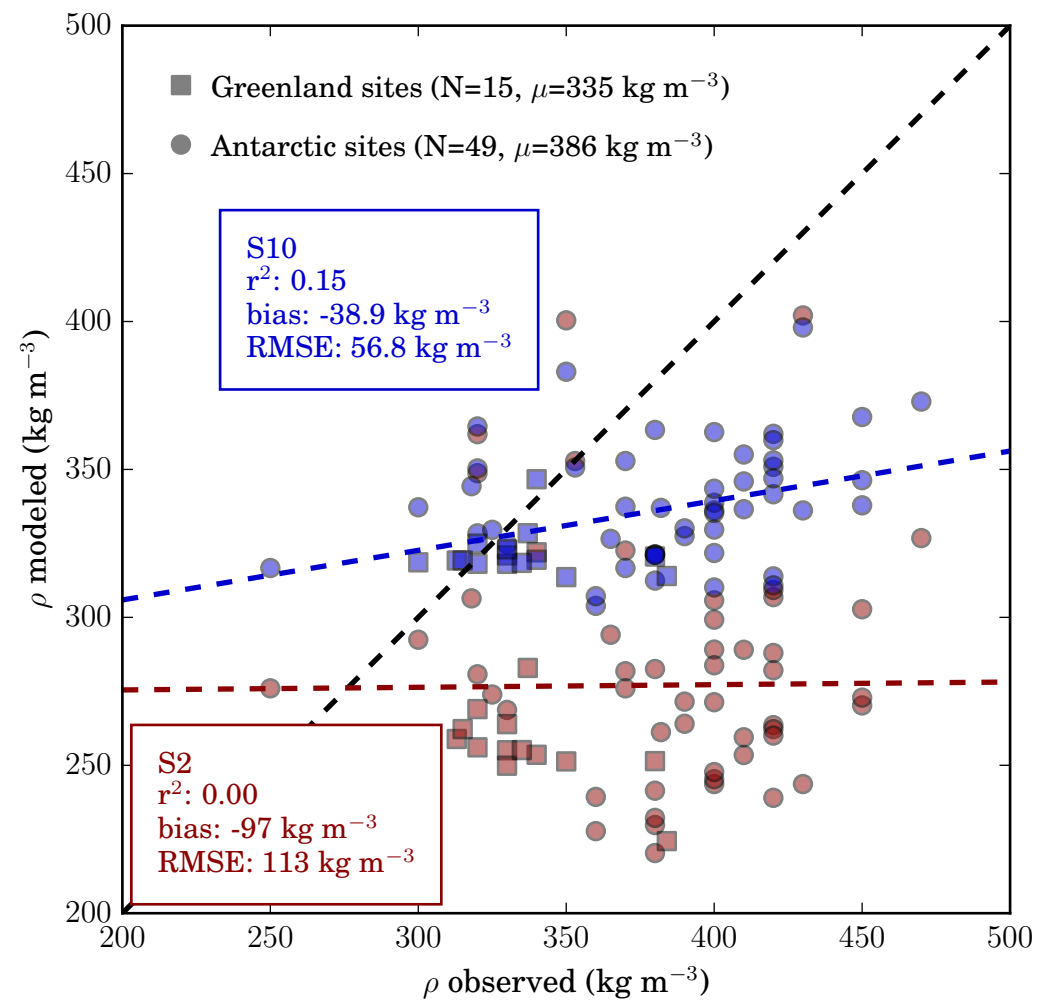

Figure 2.2: Average near-surface density in observations and model experiments. S2 has the original CLM4 expressions for fresh snow density and densification, whereas 110 contains the improvements described in the text (Table 2.3).

in $\overline{\rho_{1 m}}$ and $z 550$ are of opposing sign: one would expect a negative bias in $\overline{\rho_{1 m}}$ coinciding with deeper $z 550$, which is not the case here. We attribute this to the overburden compaction scheme, which predicts exceptionally high compaction rates, thus compensating the underestimation of $\overline{\rho_{1 m}}$. This effect is clearly observed when plotting the density profile for a particular site (Fig. 2.4).

To separate the effect of fresh snow density and overburden compaction, we conducted a series of sensitivity experiments assuming the steady-state Herron and Langway [1980] compaction model as the best-estimate expression for firn compaction with depth. This setup allowed us to evaluate the effect of fresh snow density, destructive metamorphism, and drifting snow compaction. First, the unaltered CLM expressions for metamorphism and fresh snow density are combined with the steady-state model (experiment S3). Our hypothesis is that because S3 sees lower, more realistic compaction rates than S2, it should predict deeper $z 550$ and probably also a decrease in $\overline{\rho_{1 m}}$ (because $\overline{\rho_{1 m}}$ is a depth-integrated quantity). Indeed, both effects are apparent (Table 2.3): z550 changes from being underestimated to being overestimated (bias: $10.5 \mathrm{~m}$ ), and the negative bias in $\overline{\rho_{1 m}}$ increases to $-177 \mathrm{~kg} \mathrm{~m}^{-3}$. In other words, when a compensating bias is removed, a strong underestimation in $\overline{\rho_{1 m}}$ is revealed. 


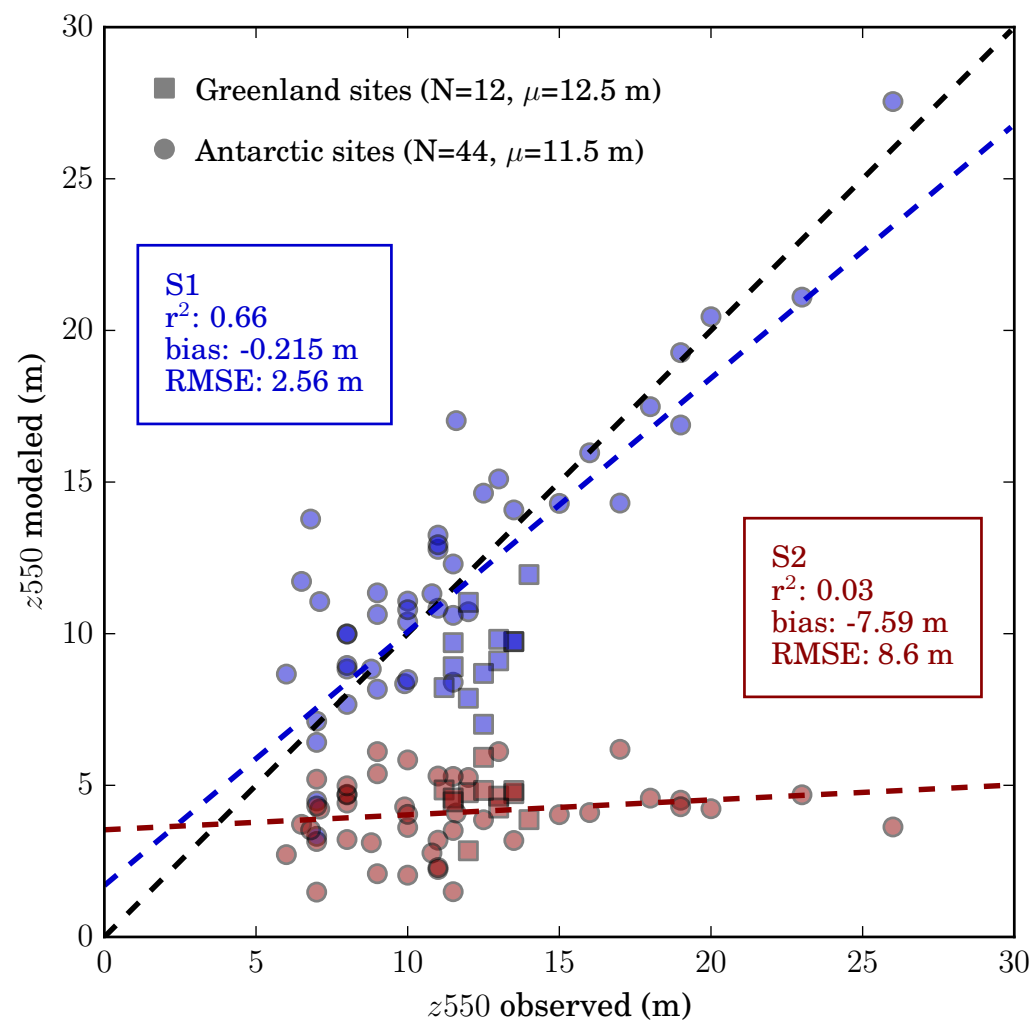

Figure 2.3: Depth of the $\rho=550 \mathrm{~kg} \mathrm{~m}^{-3}$ density level in observations and model experiments. S1 uses empirical expressions for fresh snow density and overburden densification, whereas $S 2$ uses prognostic expressions for those processes, as originally present in CLM4 (Table 2.3).

Second, experiment S4 shows that a higher upper limit for destructive metamorphism is beneficial to the simulation of $\overline{\rho_{1 m}}$; compared to the S3 experiment, the bias is halved. However, both S3 and S4 show no predictive skill in $\overline{\rho_{1 m}}$, as wind speed is not taken into account. We conclude that new physics are needed to get a better simulation of near surface density.

This is attempted in experiment S5, where the newly developed fresh snow density parametrization is used (Eqn. $2.3 \& 2.4$ ), with wind speed dependence. Finally, near-surface density is predicted with some skill $\left(r^{2}=0.39\right)$, yet having a large bias $\left(-103 \mathrm{~kg} \mathrm{~m}^{-3}\right)$. Like before, this bias is reduced by increasing $\rho_{\max }^{\mathrm{DM}}$, in experiment S6. Compared to simulation S4, there is just a slight improvement in $z 550$ modeling skill in S6. We conclude that the newly developed fresh snow density expression greatly improves the model performance, especially in near surface density.

More new physics are introduced in experiment S7 and S8, that have active drifting snow compaction (Sect. 2.3.5). Compared to runs with the same $\rho_{\max }^{\mathrm{DM}}$, S5 and S6, we observe small increases in predictive skill and reduced biases for both metrics. This favours inclusion of drifting snow compaction into the model. Its effect is probably not crucial, yet it may be important in special cases, e.g. when deposition density is low. Another argument to include drifting snow is that it is an actual, observed phenomenon. 


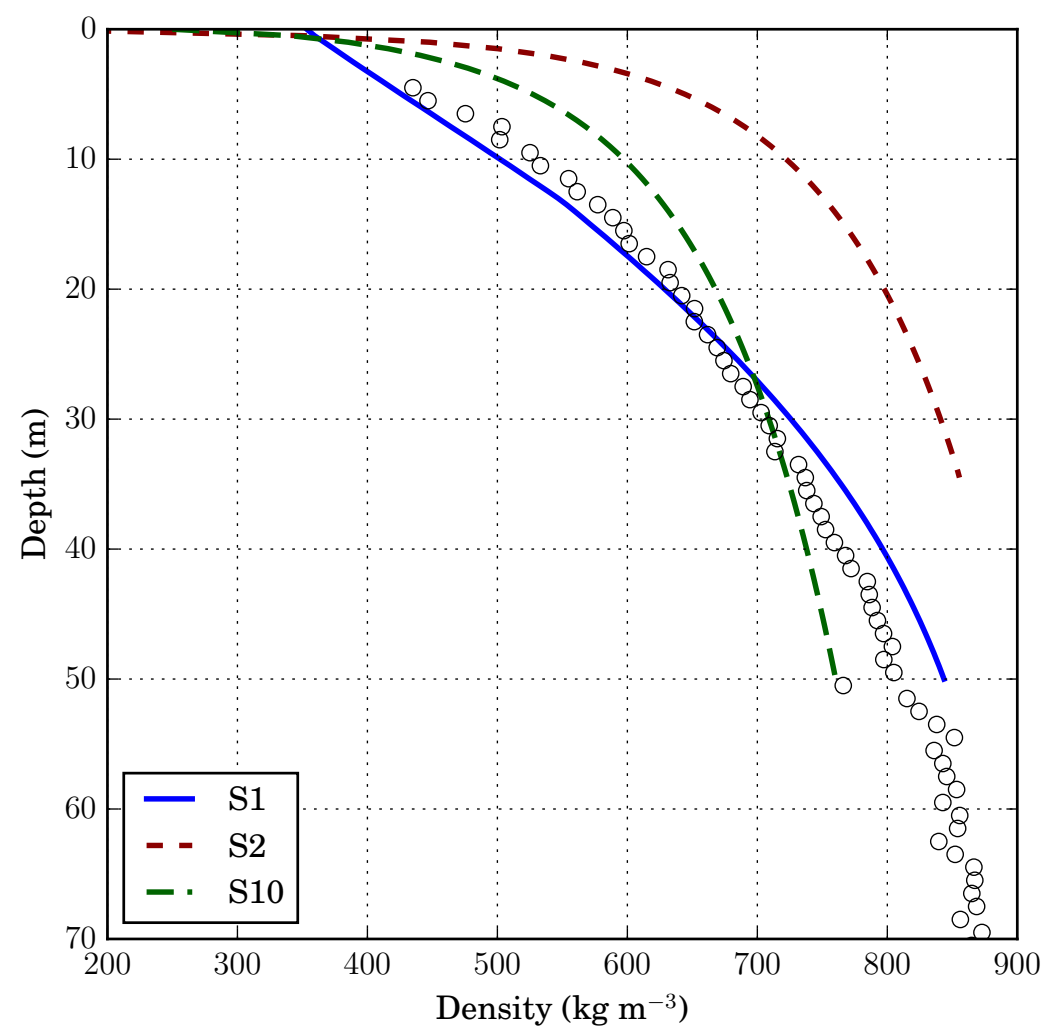

Figure 2.4: Mean density profiles for the period 1979-2011 as calculated by a single-column densification model, compared to firn core data [Lamorey, 2003] at Siple Dome, Antarctica. Solid lines correspond to the Herron and Langway [1980] empirical model (experiment S1 in Table 2.3), the original CLM4 overburden pressure compaction scheme (S2), and the modified Vionnet et al. [2012] overburden pressure compaction scheme (S10). Mean forcing accumulation and temperature at this site equal 57.9 $m m y r^{-1}$ and $243^{\circ} \mathrm{K}$, respectively.

Similar to what we found previously, the increase of $\rho_{\max }^{\mathrm{DM}}$ from $100 \mathrm{~kg} \mathrm{~m}^{-3}$ to $175 \mathrm{~kg} \mathrm{~m}^{-3}$ reduces predictive skill in favour of improved RMSE and bias.

Experiment S9 replaces the Herron and Langway [1980] steady-state firn model by a prognostic pressure compaction expression (Vionnet et al. [2012]). The motivation to why [Herron and Langway, 1980] is unfit for use in a ESM is given in Sect. 2.3.4. Although S9 captures the mean $z 550$ reasonably well (bias: $-2.28 \mathrm{~m}$ ), there is still a sizable spread $\left(r^{2}=0.15\right)$. In experiment $\mathrm{S} 10$, one of the viscosity parameters has been modified (Sect. 2.3.4) in order to remove the remaining z550 bias. Unfortunately, this does not improve the spread, yet RMSE decreases by almost $1 \mathrm{~m}$. We conclude that the subtle interplay of temperature, wind and SMB remains a great challenge to the overburden pressure scheme.

On balance, the settings in experiment S10 yield an improved simulation of polar snow with respect the the old physics in experiment S2. A compensating bias in $\overline{\rho_{1 m}}$ has been identified and resolved, and model skill has improved in this metric. The depth of $\rho=550 \mathrm{~kg} \mathrm{~m}^{-3}$ is now better predicted, although 


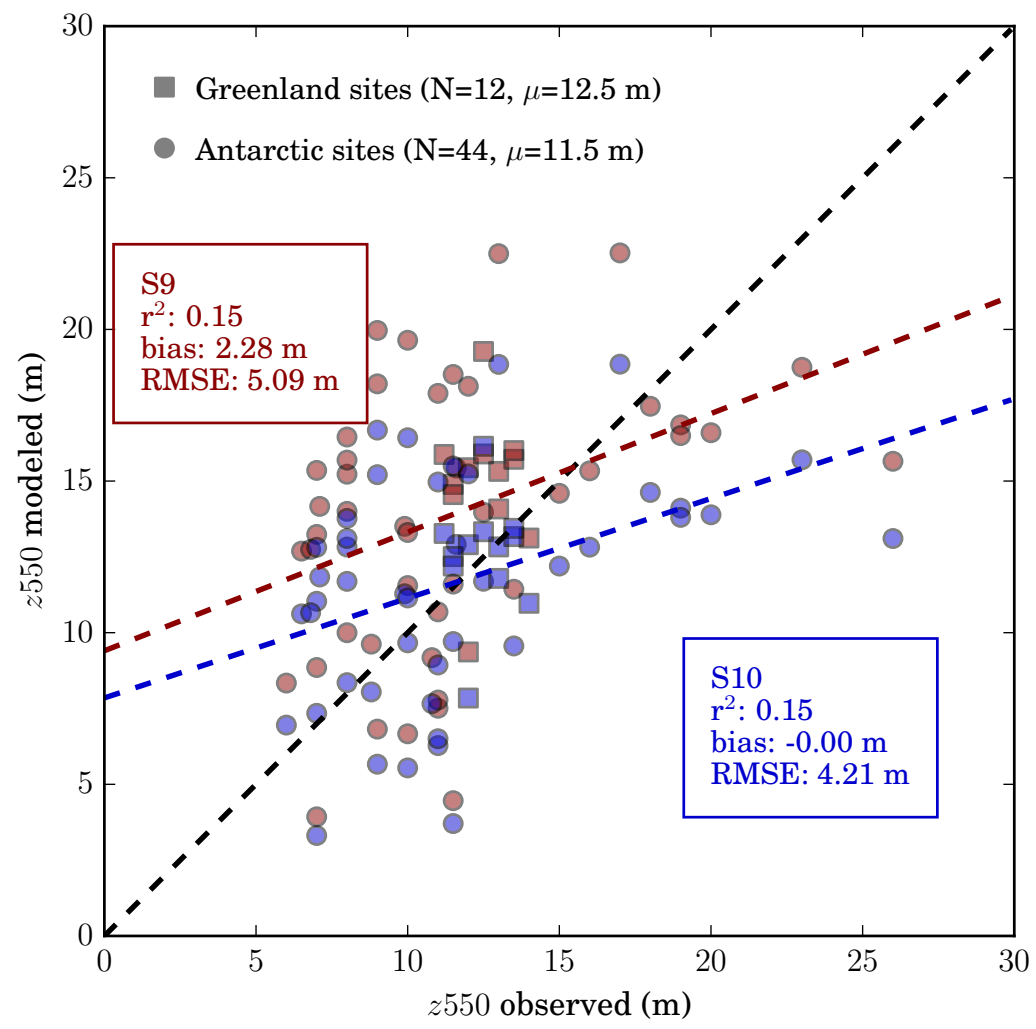

Figure 2.5: Depth of the $\rho=550 \mathrm{~kg} \mathrm{~m}^{-3}$ density level in observations and model experiments. Both $S 9$ and $S 10$ use the new fresh snow density expression and $\rho_{\max }^{D M}$, however differ in their calculation of viscosity (Table 2.3).

a fairly large spread remains (Fig. 2.5). The settings in S10 have been implemented in CLM and will be standard in the next release of the model.

\subsection{Evaluation in CESM}

\subsubsection{Data and methods}

Next, three global, land-only (CLM) simulations are performed that show the impact of the deeper snow pack $\left(H_{\max }=10 \mathrm{~m}\right)$ and new snow physics on melt and refreezing. Fixed meteorological forcing was chosen in favour of coupled atmosphere-land because of simplicity and computational cost. Meteorological forcing is taken from ERA-Interim reanalysis data [Dee et al., 2011] spanning the years 1979 to 1998 , a period with good satellite coverage and relatively little climate change, at a resolution of approximately $80 \mathrm{~km}$ (T255 spectral), upscaled to the $\sim 1^{\circ}$ longitude-latitude CLM grid. The forcing frequency is 6-hourly. Precipitation is assumed solid when $T<T_{\mathrm{frz}}$, with $T$ the temperature in the 
Table 2.4: Model parameters used in three transient land-only simulations. Columns from left to right: experiment name; $N_{s}$ number of snow layers; $H_{\max }$ maximum snow depth ; fresh snow density parametrization; upper limit for destructive metamorphism; overburden compaction scheme; drifting snow compaction.

\begin{tabular}{lllllll}
\hline Name & $N_{s}$ & $\begin{array}{l}H_{\max } \\
\mathrm{m}\end{array}$ & Fresh snow density & $\begin{array}{l}\rho_{\max }^{\mathrm{DM}} \\
\mathrm{kg} \mathrm{m}^{-3}\end{array}$ & Compaction & Drift \\
\hline ERAI-OLD-1m & 5 & 1 & Anderson76 & 100 & Anderson76 & no \\
ERAI-NEW-1m & 5 & 1 & This paper & 175 & This paper & yes \\
ERAI-NEW-10m & 12 & 10 & This paper & 175 & This paper & yes \\
\hline
\end{tabular}

lowest available output layer, and $T_{\text {frz }}$ the water freezing point $\left(0^{\circ} \mathrm{C}\right)$. Precipitation is assumed liquid above $2^{\circ} \mathrm{C}$, and a ramped fraction method is used between 0 and $2^{\circ} \mathrm{C}$. On the East Antarctic Plateau, the simulated sublimation flux turned out to outweigh ERA-Interim snowfall, resulting in a negative SMB and bare ice exposure. Underestimation of snowfall in interior East Antarctica was previously reported by Bromwich et al. [2011]. This anomaly has been corrected by the application of a scaling factor to the precipitation field, which imposes a lower bound on annual accumulation of $20 \mathrm{~mm} \mathrm{yr}^{-1}$, a number supported by observations [Arthern et al., 2006].

Three spin-up simulations have been performed, one for each transient simulation. At the beginning of the spin-ups, ice temperatures over the glaciers and ice sheets were set to the annual average ERAInterim surface temperature. Meteorological forcing over the period 1979-1998 was looped until deep temperature reaches a quasi-equilibrium, when the maximum absolute difference of deep ice temperature over two consecutive decades did not exceed $1^{\circ} \mathrm{K}$. Following this procedure, ERAI-NEW-10m required 120 years of spin-up, whereas the other runs needed 80 years to equilibrate. We assumed that the snow pack is in steady state after this spin-up period. This assumption is not valid for very dry locations, where the firn has not been fully developed, but the departure from steady state is deemed insignificant.

The three spin-up simulations were used to initialize three transient experiments (Table 2.4). The reference simulation ERAI-OLD-1m uses the basic snow physics of CLM4 [Oleson, 2013], but other code is not identical to CLM4, e.g. the new snow capping scheme is used (Sect. 2.3.2). The second experiment ERAI-NEW-1m incorporates all the model changes described in Sect. 2.3, except that it still uses the shallow snow pack $H_{\max }=1 \mathrm{~m}$. Finally, 'firn' simulation ERAI-NEW-10m has $H_{\max }=10 \mathrm{~m}$.

\subsubsection{Results and discussion}

Figure 2.6 shows the mean annual surface density, for both ice sheets. Average density over the top 2 $\mathrm{cm}\left(\rho_{\text {skin }}\right)$ is shown, a depth at which overburden pressure compaction is virtually inactive. We find that in the GrIS interior, where previously $\rho_{\text {skin }}$ did not exceed $100 \mathrm{~kg} \mathrm{~m}^{-3}$, surface density now ranges from 250 to $300 \mathrm{~kg} \mathrm{~m}^{-3}$. This is interpreted as the effect of the newly introduced fresh snow density parametrization, as well as the increased active range of destructive metamorphism $\left(\rho_{\max }^{\mathrm{DM}}=175 \mathrm{~kg}\right.$ $\mathrm{m}^{-3}$ ), and drifting snow compaction. Given enough exposure time, drifting snow compaction drives any snow density up to a maximum of $350 \mathrm{~kg} \mathrm{~m}^{-3}$ (Sect. 2.3.5) in windy conditions. At lower elevations, however, drifting snow compaction is counterbalanced by fresh snowfall, resulting in lower densities at the GrIS margin. Strong katabatic winds in the escarpment zone of the East Antarctica ice sheet 

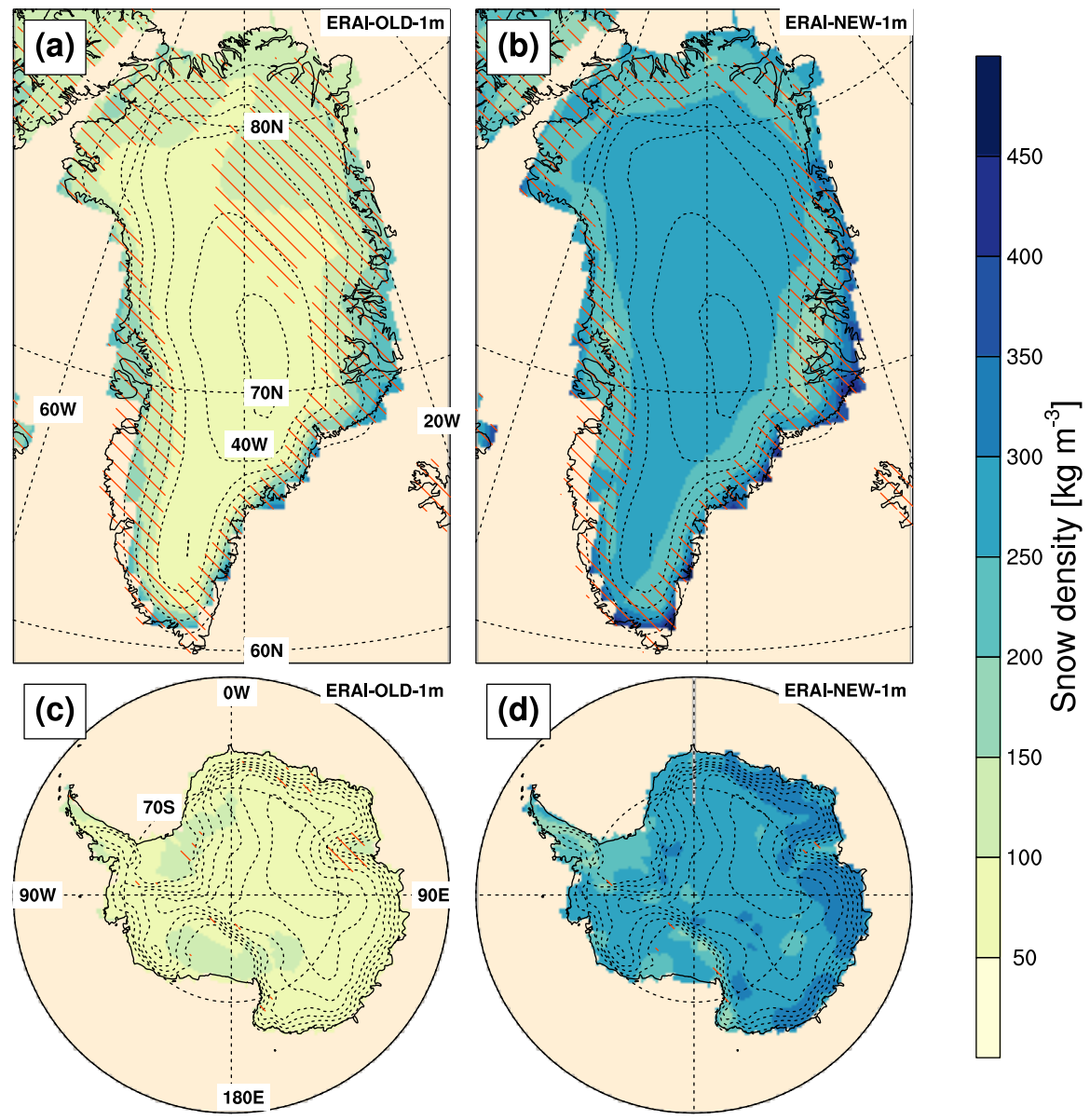

Figure 2.6: Annual mean density in the uppermost snow model layer (1979-1998) for (a), (c): old model physics, and $(b),(d)$ : new model physics. Dotted lines represent $500 \mathrm{~m}$ elevation contours. Dashed areas become snow-free at least once during the averaging period, which could bias the displayed annual density value away from the summer value. Note that the uppermost snow model layer has variable depth, with a minimum and maximum thickness of 1 and $3 \mathrm{~cm}$, respectively (Table 2.2). In case of a permanent deep snow cover, the layer thickness is approximately $2 \mathrm{~cm}$.

generate high $\rho_{\text {skin }}$ values. Lower surface densities on the Ross and Filchner-Ronne ice shelves are explained by the weaker winds in these regions.

The low surface densities simulated in the ERAI-OLD-1m experiment have a dramatic impact on melt rates. We find that due to excessive melt, large parts of the northern GrIS fail to sustain a permanent snow cover, i.e. SMB $<0$ (Fig. 2.6, dashed areas). On Antarctica, bare ice is found across the entire Amery ice shelf. This unrealistic behaviour is largely resolved in experiment ERAI-NEW-1m. With the new model physics, annual GrIS melt volume is reduced by $72 \%$ and AIS melt volume by as much as $88 \%$ (Table 2.5). 
Table 2.5: Comparison of integrated melt, refreezing and runoff fluxes between ERA-Interim forced $C L M$ and polar regional model RACMO version 2.3. Melt values represent the sum of ice and snow melt. For ERAI-CLM, the forcing period 1979-1998 was used and spatial integration was performed on the native CESM ice mask (GrIS area: 1,721,945 km², AIS area: 14,002,500 km²). RACMO2 time averages span the period 1961-1990 [GrIS, van den Broeke et al., 2016] and 1979-1998 [AIS, Van Wessem et al., 2014], and native RACMO2 ice masks were used for the spatial integration (GrIS area: $1,718,736 \mathrm{~km}^{2}$, AIS area: $13,926,689 \mathrm{~km}^{2}$ ).

\begin{tabular}{lllll}
\hline GrIS $\mu(\sigma)$ in $\mathrm{Gt} \mathrm{yr}^{-1}$ & ERAI-OLD-1m & ERAI-NEW-1m & ERAI-NEW-10m & RACMO2 \\
Melt & $572(141)$ & $160(49)$ & $156(48)$ & $433(68)$ \\
Refreezing & $418(98)$ & $128(35)$ & $143(36)$ & $200(27)$ \\
Runoff & $173(52)$ & $53(19)$ & $36(14)$ & $265(51)$ \\
\hline AIS $\mu(\sigma)$ in $\mathrm{Gt} \mathrm{yr}^{-1}$ & & & & \\
Melt & $913(784)$ & $105(69)$ & $100(64)$ & $94(22)$ \\
Refreezing & $770(605)$ & $88(51)$ & $92(52)$ & $91(27)$ \\
Runoff & $124(90)$ & $18(10)$ & $8(3)$ & $4(2)$ \\
\hline
\end{tabular}

To study this in more detail, we analyzed the vertical distribution of melt in the snow pack. As mentioned earlier, the SNICAR radiation scheme includes radiation penetration allowing for subsurface melt. With low snow densities, subsurface heat conduction is inhibited. There is neither much conduction towards the surface, where heat may be emitted through black body radiation, nor down towards the cold glacial ice. Heat is thus trapped by the insulating properties of the snow, increasing the chances of bringing temperature to the melting point. Subsurface radiation, accounting for only a small fraction of total absorbed solar radiation (Fig. 2.7), is therefore responsible for the majority of melt in the column (Fig. 2.8). The relationship between density and thermal conductivity is quadratic, meaning that this effect becomes increasingly weaker at higher densities (cf. Eqn. 2.1). Still, subsurface melt is the dominant form of melt in simulations ERA-NEW-1m and ERAI-NEW-10m (Fig. 2.8), but the relative importance decreases from $96 \%$ to $61 \%$ on the AIS, and from $89 \%$ to $59 \%$ on the GrIS (ERAINEW-1m). Note that there is a slight drop in subsurface radiation absorption with increasing density (Fig. 2.7). This is explained by the indirect effect that melt and refreezing have on grain size. Average grain size in simulation ERAI-NEW-1m is $1.5 x$ to $2 x$ smaller than in ERAI-OLD-1m (not shown), due to a combination of 1) reduced presence of liquid water, and 2) a drop in refreezing volume (Table 2.5). Both these processes reduce grain growth [Oleson et al., 2008] and therefore lead to a decrease in absorption. Clearly, these effects outweigh the density-dependence of grain size ageing, an opposing effect where denser snow is associated with larger grains and more absorption [Lawrence et al., 2011]. Idealized experiments would be needed to quantify the relative importance of each of these effects, which is left to future work. Overall, integrated melt over Greenland is now underestimated with respect to regional climate model results (Table 2.5). We attribute this to 1) substantial underprediction of solar radiation in the ERA-Interim product (not shown), and 2) remaining model biases that relate to snow melt, e.g. initial grain size, irreducible water content, and soot deposition [van Angelen et al., 2012]. On the AIS, melt and refreezing now compare well to RACMO, but we cannot exclude the possibility of compensating errors.

The increase in snow depth in simulation ERAI-NEW-10m leads to significantly higher snow and ice temperatures. Figure 2.9 shows vertical profiles at a grid cell located in the West Greenland percolation zone, during four consecutive years. Thermal conductivity, shown in the top panels, is somewhat time- 

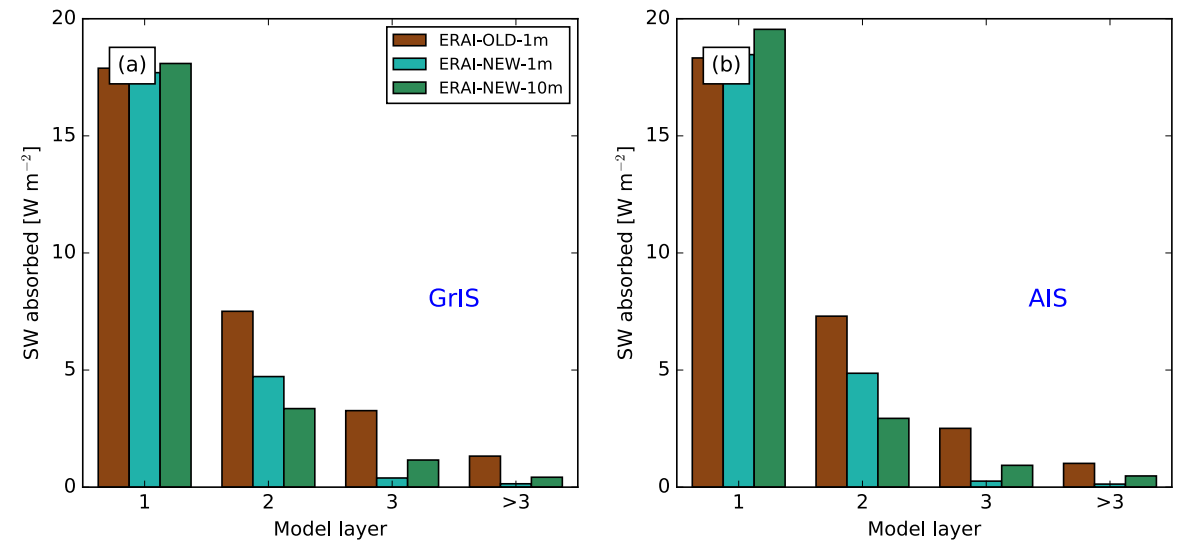

Figure 2.7: Mean annual absorbed shortwave radiation per model layer. Values represent areaaverages over the time period 1979-1998. (a) GrIS, (b) AIS. Numbering of layers starts at the snowatmosphere interface, increasing downwards. Note that absorption rates are raw model output and have not been normalized for layer thickness.
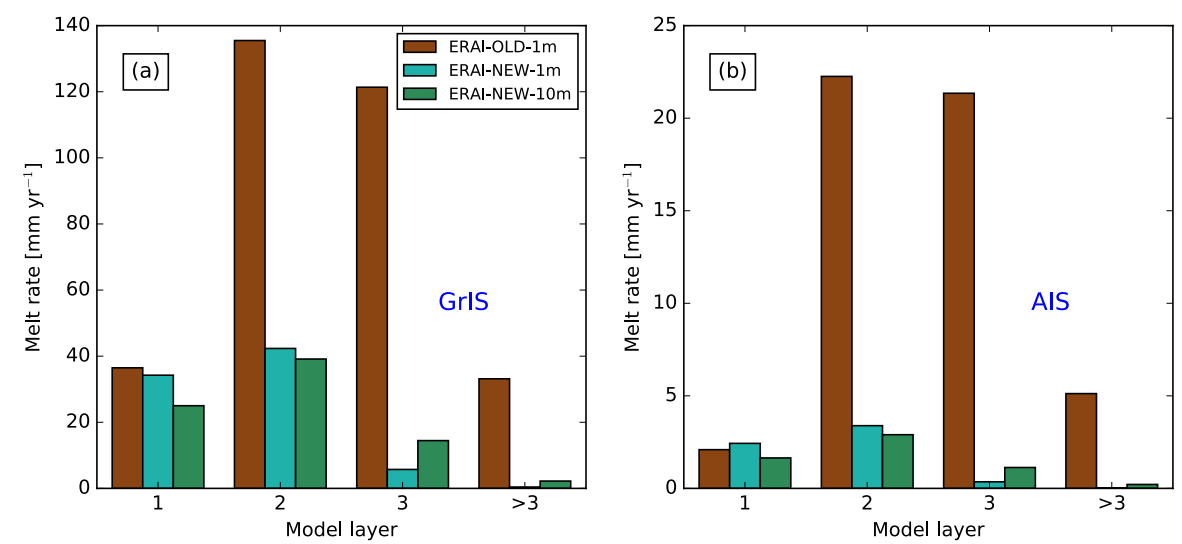

Figure 2.8: Melt rate distribution over individual model layers. Values represent area-averages over the time period 1979-1998. (a) GrIS, (b) AIS. Numbering of layers starts at the snow-atmosphere interface, increasing downwards. Note that melt rates are raw model output and have not been normalized for layer thickness.

dependent, yet does not vary greatly with depth, as density does not vary greatly with depth. Even with $H_{\max }=10 \mathrm{~m}$, the density profile is rather uniform because overburden pressure compaction is a relatively weak force. On the other hand, the sharp transition to ice density at zero height is clearly visible. Thermal heat flux exhibits a strong seasonal cycle in the shallow snow pack experiment (panel c). Heat is conducted upwards in winter, cooling the ice underneath the snow, with the reverse taking place in summer. With a deeper snow pack, this seasonal cycle changes in several aspects (panel d). First, the enhanced insulating properties of the deeper snow pack now shield the glacial ice from the strong heat fluxes near the surface, seen as lighter colors below $0 \mathrm{~m}$. Second, the pattern of heat transfer 
changes, with an overall stronger upward flux in winter and a weaker downward flux in summer. This is explained by the higher snow temperatures (panels e and f), which strengthen vertical temperature gradients in winter and weaken them in summer. Finally, the deep snow pack allows refreezing to take place at much greater depths, thereby damping the downward heat flux in summer. Refreezing continues well into autumn, with the highest snow temperatures seen in September and October, in contrast to the shallow snow pack where temperature peaks already in July. The deeper meltwater percolation, storage and refreezing is what causes the marked increase in (ice) temperature seen in the deeper snow pack configuration (Fig. 2.9f). In the shallow pack configuration (Fig. 2.9e), water percolating below $H_{\max }$ is sent to runoff, thereby removing latent heat from the pack. Additionally, heat released by refreezing in deeper model layers has a longer-lasting effect on the temperature profile compared to heat released close to the surface, since the overlying snow/firn acts as an insulator. At this particular site, we find that warming due to deeper percolation raises deep ice temperature by about $10^{\circ} \mathrm{C}$.

To quantify how important the effect of deep percolation is on the ice temperature, we carried out a set of idealized experiments with the dry snow densification model described in Sect. 2.4.1. The code was adapted in order to support 1) capping to a given $\left.H_{\max }, 2\right)$ glacial ice layers ( $25 \mathrm{~m}$ in total) that permanently sit underneath the simulated snow pack, and 3) an external heat flux Q $\left[\mathrm{J} \mathrm{s}^{-1}\right]$, that represents latent heat released through refreezing. Skin temperature is idealized as a sinoid, with a mean of $250{ }^{\circ} \mathrm{K}$ and an amplitude of $10{ }^{\circ} \mathrm{K}$. A constant accumulation rate is assumed, with a total annual accumulation of $1000 \mathrm{~mm}$. Surface density is set to a constant value of $350 \mathrm{~kg} \mathrm{~m}^{-3}$ and the Herron and Langway [1980] dry densification rate is used. The (virtual) refreezing volume is varied between 50, 100 and $200 \mathrm{~mm} \mathrm{yr}^{-1}$, from which the external heat flux Q is calculated. Q is only applied for 90 days during summer and the simulation is run to equilibrium. First, we applied $Q$ to just the top $1 \mathrm{~m} \mathrm{SWE}$, which represents the case that only shallow percolation and refreezing is allowed. We find that the difference in ice temperature at $25 \mathrm{~m}$ between the shallow $\left(H_{\max }=1 \mathrm{~m}\right)$ and the deep $\left(H_{\max }=\right.$ $10 \mathrm{~m}$ ) snow pack is negligible for all three refreezing rates $\left(<0.1^{\circ} \mathrm{C}\right)$. This suggests that the turnover rate of the snowpack, which is lower for greater $H_{\max }$, by itself does not affect the equilibrium ice temperature. Next, we performed a set of experiments that allow for deep percolation and refreezing, i.e. Q is applied to the full snow pack depth $H_{\max }$. Similar to the land-only CLM simulation, a net warming in the deep snow pack is observed. The virtual heat release of refreezing $50 \mathrm{~mm} \mathrm{yr}^{-1} \mathrm{SWE}$ raises deep ice temperature by $3.7^{\circ} \mathrm{C}$ relative to the shallow snow pack. This discrepancy increases dramatically in the medium $\left(100 \mathrm{~mm} \mathrm{yr}^{-1}\right)$ and high $\left(200 \mathrm{~mm} \mathrm{yr}^{-1}\right)$ refreezing scenarios, to $7.3^{\circ} \mathrm{C}$ and $14.4{ }^{\circ} \mathrm{C}$, respectively. Yet stronger external forcings brought equilibrium ice temperatures above the melting point, which rendered these solutions non-physical. We can conclude from these experiments that, in the presence of refreezing, percolation depth is a key determinant to the equilibrium deep ice temperature. Therefore, limiting snow depth by capping introduces a modelling error in many locations. In particular, ice temperature, used to force dynamical ice sheet models [Lipscomb et al., 2013], is underestimated.

Spatially, the deep ice warming due to additional latent heat release is present across the entire GrIS, yet most pronounced along the margins, where liquid water availability is greatest (Fig. 2.10). The average GrIS difference between ice temperature and skin temperature, $T_{\text {ice }}-T_{\text {skin }}$, is $2.3^{\circ} \mathrm{C}$ for ERAI-NEW$1 \mathrm{~m}$, with a maximum of $6.7^{\circ} \mathrm{C}$. Experiment ERAI-NEW-10m has an average $T_{\text {ice }}-T_{\text {skin }}$ value of $5.6^{\circ} \mathrm{C}$ and a maximum of $15.0^{\circ} \mathrm{C}$, which matches the range that was indicated by the idealized experiments. The higher ice temperatures in the GrIS refreezing zones also agree with Meierbachtol et al. [2015], who found that $10 \mathrm{~m}$ snow temperatures may exceed surface temperature by up to $15^{\circ} \mathrm{C}$ in West Greenland. 

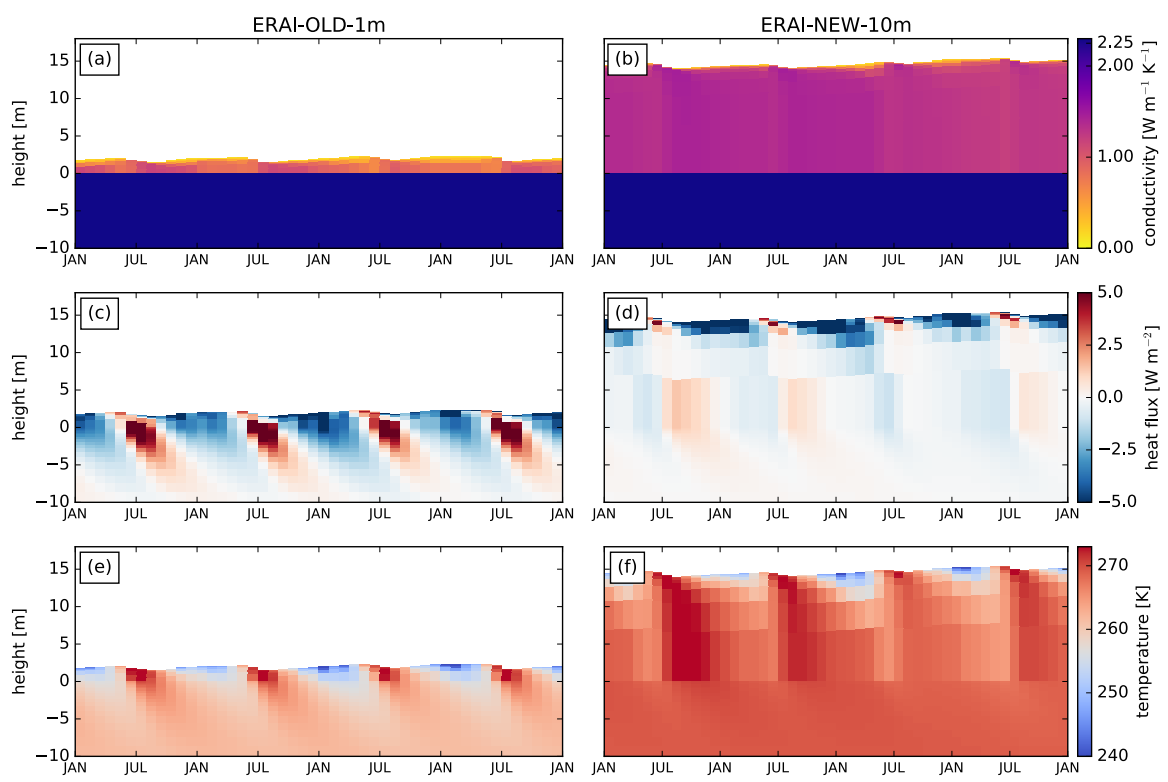

Figure 2.9: Vertical profiles at model grid point $67^{\circ} 23^{\prime} \mathrm{N}, 48^{\circ} 45^{\prime} \mathrm{W}$, approximately along the Greenland $K$-transect, for the period 1983-1987. Panels (a) and (b): thermal conductivity, panels $(c)$ and $(d)$ : heat flux, with positive values downwards, panels $(e)$ and $(f)$ : temperature. Zero height corresponds to the snow-ice interface. Only the upper $10 \mathrm{~m}$ of ice are shown.

To summarize, modelled $\rho_{\text {skin }}$ increases virtually everywhere over the ice sheets, due to the introduction of wind-dependent fresh snow density (Sect. 2.3.3), a wider destructive metamorphism range (Sect. 2.3.4), and drifting snow compaction (Sect. 2.3.5). The resulting snow densities are in line with other studies; for instance, Groot Zwaaftink et al. [2013] report deposited snow densities ranging from 250 to $450 \mathrm{~kg} \mathrm{~m}^{-3}$ at a site on the Antarctic Plateau. Surface density plays an important role in the production of subsurface melt through its direct link to thermal conductivity. The proposed model changes alleviate the excessive melt rates over the Antarctic [Lenaerts et al., 2016], provided that the atmospheric forcing is realistic. In our offline simulations, Greenland melt rates are underestimated, which is attributed to biases in the forcing data and outstanding model biases that relate to melt. These biases will be investigated in follow-up work. The deeper snow pack led to a net increase in refreezing volume, and increased percolation depth was shown to cause a substantial warming of (deep) ice. The increase of $H_{\max }$ to $10 \mathrm{~m} \mathrm{SWE}$ is a step in the right direction, but does not fully resolve firn processes, given that firn may grow up to tens of meters SWE in reality.

\subsection{Conclusions}

We presented a number of model improvements that enable a more realistic representation of polar firn and snow in CLM, while still providing realistic results for seasonal snow. The improvements have been tested using a series of offline dry firn densification experiments and were favourably compared 

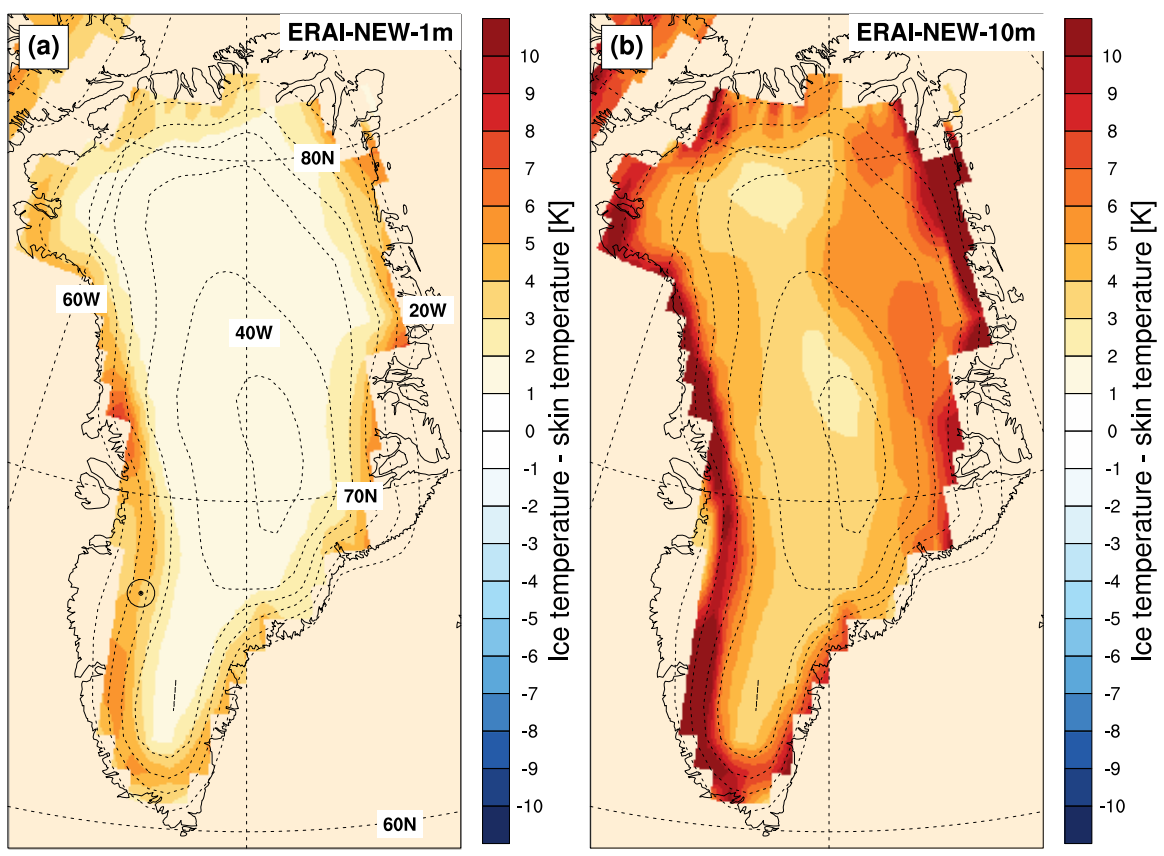

Figure 2.10: Mean annual difference of ice temperature minus skin temperature over the period 19791998, for simulations (a) ERAI-NEW-1m, and (b) ERAI-NEW-10m. Ice temperature is taken equal to the uppermost soil layer. The marker in panel (a) indicates the location of grid cell discussed in the text.

to in-situ data. The presented changes have recently been incorporated in the CLM codebase and will thus be standard in the next official release of CESM.

- We resolved a conceptual design issue in the snow capping code that led to surface density occasionally becoming unrealistically high when $H_{\max }$ was reached.

- We remedied the underestimation of surface snow density over ice sheets by the introduction of (1) a wind-dependent fresh snow density parametrization, (2) a higher maximum to the destructive metamorphism process, and (3) the introduction of compaction by drifting snow. With respect to a control run, we showed that these updates yield an improved simulation of nearsurface density, a reduction in melt volume and a vertical redistribution of melt.

- We replaced the overburden compaction scheme by an expression from Vionnet et al. [2012], showing greater skill in predicting firn density at depth. This update is relevant to the vertically integrated air content of the firn, or pore space, which partly determines refreezing capacity.

- We increased the maximum modelled snow depth to $H_{\max }=10 \mathrm{~m}$ SWE, which better approximates actual firn depth on ice sheets. The selected new maximum depth is a trade-off between a more realistic representation of total pore space, which acts as insulation for heat transfer and buffer for meltwater, and efficient spin-up of the snow pack in coupled model runs. Deeper percolation depths was found to raise snow and ice temperatures by several degrees. These find- 
ings are relevant to coupled ice-sheet climate models, since SMB and ice temperature are key boundary conditions for ice sheet models.

We intend to carry out a more complete analysis of CESM 2.0 ice sheet climate as soon as this new model version has been released. This explains why we have not analyzed the snow-atmosphere energy balance in the present paper. Further development of the CLM snow model could focus on one or more of the following topics: (1) the effect of vertical resolution on the thermal and hydrological state, (2) the adoption of a Lagrangian layering scheme in order to capture annual ice layers, (3) the introduction of grain shape parameters for modeling metamorphism, or (4) improving the pore close-off depth simulation. The latter would need particular attention were density to be used for predicting glacial inception. In future runs where the ice sheet is interactively coupled to the atmosphere, the lower Neumann boundary condition may be replaced by time-varying ice sheet temperature, to allow more realistic long-term transient runs. 


\section{Regional grid refinement: impacts on the simulated Greenland surface mass balance}

\section{Summary}

In this study, the resolution dependence of the simulated Greenland ice sheet (GrIS) surface mass balance (SMB) in the variable-resolution Community Earth System Model (VR-CESM) is investigated. Coupled atmosphere-land simulations are performed on two regionally refined grids over Greenland at $0.5^{\circ}(\sim 55 \mathrm{~km})$ and $0.25^{\circ}(\sim 28 \mathrm{~km})$, maintaining a quasi-uniform resolution of $1^{\circ}(\sim 111 \mathrm{~km})$ over the rest of the globe. On the refined grids, the SMB in the accumulation zone is significantly improved compared to airborne radar and in-situ observations, with a general wetting (more snowfall) at the margins and a drying (less snowfall) in the interior GrIS. Total GrIS precipitation decreases with resolution, which is in line with best-available regional climate model results. In the ablation zone, CESM starts developing a positive SMB bias with increased resolution in some basins, notably in the east and the north. The mismatch in ablation is linked to changes in cloud cover in VR-CESM, and a reduced effectiveness of the elevation classes subgrid parametrization in CESM. Overall, our pilot study demonstrates that variable resolution is a viable new tool in the cryospheric sciences, and could e.g. be used to dynamically downscale SMB in scenarios simulations, or to force dynamical ice sheet models through the CESM coupling framework.

This chapter is based on: van Kampenhout, L., Rhoades, A. M., Herrington, A. R., Zarzycki, C. M., Lenaerts, J. T. M., Sacks, W. J., and van den Broeke, M. R. Regional grid refinement in an Earth system model: Impacts on the simulated Greenland surface mass balance. The Cryosphere, 13(6):1547-1564, June 2019. ISSN 1994-0416. doi: $10.5194 /$ tc-13-1547-2019 


\subsection{Introduction}

The contribution of the Greenland ice sheet (GrIS) to global sea level rise is increasingly determined through its surface mass balance (SMB) [van den Broeke et al., 2016]. Accurate estimates of future GrIS SMB are therefore key in providing projections for sea level rise. Arguably the most realistic SMB projections to date are derived from general circulation model (GCM) scenario output downscaled using regional climate models (RCMs - e.g., Rae et al. [2012]; van Angelen et al. [2013]; Fettweis et al. [2013a]; Mottram et al. [2017]; Noël et al. [2018]). Compared to GCMs, the regional models offer more sophisticated snow models that have improved representation of albedo, melt, firn densification and refreezing, features that are lacking in most current GCMs [Ziemen et al., 2014; Helsen et al., 2017]. In addition, RCMs typically run at a horizontal grid resolution of $\mathscr{O}(10 \mathrm{~km})$ whereas atmospheric GCMs are typically run using $1^{\circ}$ or $\mathscr{O}(100 \mathrm{~km})$ grids. RCMs therefore tend to better resolve topographic gradients, which leads to more accurate spatio-temporal distributions in precipitation, wind, cloud cover, and temperature, enabling a detailed comparison to in-situ meteorological data. A fine spatial resolution seems indispensable for resolving narrow ablation zones found around the GrIS margins [Lefebre et al., 2005; Pollard, 2010].

Recently, significant efforts have been invested into making GCMs more suitable for snow and SMB modelling [e.g., Punge et al., 2012; Cullather et al., 2014; Fischer et al., 2014; Helsen et al., 2017; van Kampenhout et al., 2017; Shannon et al., 2019; Alexander et al., 2019]. In particular, improvements made to the Community Earth System Model (CESM) include a multi-layer snow model with a two-way radiative transfer model for albedo [Flanner and Zender, 2005], enhanced snow density parameterizations [van Kampenhout et al., 2017], and the introduction of multiple elevation classes for downscaling SMB with height [Lipscomb et al., 2013]. Still, significant biases remain with respect to RCMs, as the spatial resolution is limited [Vizcaíno et al., 2013; Helsen et al., 2017]. Although high-resolution GCM simulations exist (50 km, Delworth et al. [2011]; $25 \mathrm{~km}$, Wehner et al. [2014]; Small et al. [2014]; Bacmeister et al. [2014]; $80 \mathrm{~km}$, Müller et al. [2018]) a majority of ongoing modelling experiments, notably the forthcoming CMIP6 experiments [Eyring et al., 2016], maintain a $\sim 1^{\circ}$ atmosphere grid due to limitations in computational resources.

A middle road may be found in new techniques that apply regional grid refinement within a global climate model. In this approach, a static global mesh is constructed which has increased resolution over a specified region of interest. Over the past five years, progress has been made in developing regional grid refinement in CESM - variable resolution or VR-CESM. To date, studies looked at the effect of grid refinement on the global circulation and climatology [Zarzycki et al., 2015; Gettelman et al., 2018], the effect on tropical cyclones [Zarzycki and Jablonowski, 2014], regional climate in the presence of mountains [Rhoades et al., 2015; Huang et al., 2016; Rhoades et al., 2017], and the scale dependence of the underlying physics [Gettelman et al., 2018; Herrington and Reed, 2018]. Compared to RCM downscaling, Huang et al. [2016] notes several advantages of the variable resolution (VR) approach. First, using a unified modelling framework avoids the inconsistencies between RCM and GCM, in particular the different dynamical core and physics that are used. Second, VR allows for twoway interactions (i.e., downstream / upstream effects) between the refinement region and the global domain, which an RCM downscaling approach does not. Finally, some more practical advantages are the attractiveness of operating a single modelling framework, and the relatively low computational cost associated with VR-CESM. 
In this paper, we apply regional grid refinement over the Greenland area using VR-CESM, and explore the impacts that the refinement has on GrIS SMB. Two VR meshes are constructed with refined patches centered around the GrIS with $55 \mathrm{~km}$ and $28 \mathrm{~km}$ resolution, respectively. A 20-year atmosphere-only simulation spanning the historical period (1980-1999) is carried out over each of those grids and is then compared to a reference simulation without refinement, reanalyses data, airborne snow accumulation radar, in-situ SMB measurements, as well as gridded climate data from an RCM. The version of CESM used resembles the recently released CESM version 2 (CESM2), of which a more in-depth evaluation will be published in the near future. Our modelling setup and benchmark data are described in further detail in Section 3.2. The main findings of this study are presented and discussed in Section 3.3, and the main conclusions are found in Section 3.4. Our study is part of an ongoing effort to improve the representation of ice sheets in CESM [Lipscomb et al., 2013; Vizcaíno et al., 2013; Lenaerts et al., 2016; van Kampenhout et al., 2017].

\subsection{Methodology}

\subsubsection{Modelling setup}

The Community Earth System Model (CESM) is a global climate modelling framework comprised of several components, i.e. atmosphere, ocean, land surface, sea ice, and land ice, that may operate partially or fully coupled. When partially coupled, the missing components can be substituted by external data or even inactive (stub) components. Here, we follow the protocol of the Atmospheric Model Intercomparison Project (AMIP, Gates et al. [1999]) and dynamically couple the atmosphere-land components and prescribe ocean and sea ice data at monthly intervals [Hurrell et al., 2008]. Our three AMIP-style CESM simulations are carried out over the years 1980-1999, a period prior to the onset of persistent circulation change and a strong decline in GrIS SMB in the 2000s [Fettweis et al., 2013b; van den Broeke et al., 2016]. Aerosol and trace gas emissions are taken as observed.

The atmosphere component used is the Community Atmosphere Model version 5.4 [CAM5.4, Neale et al., 2012] with the spectral element dynamical core [CAM-SE, Dennis et al., 2012; Lauritzen et al., 2018], the only dynamical core currently in CESM supporting VR capabilities [Zarzycki et al., 2014]. VR capabilities in CAM6, the new atmosphere model in CESM version 2 (CESM2, www . cesm . ucar . edu/models/cesm2.0) were still under beta testing at the start of our study, which explains the slightly older model version of CAM. Our model configuration broadly follows that of Zarzycki and Jablonowski [2014], with a few modifications. These include updated rain and snowfall microphysics (MG2, Gettelman and Morrison [2014]), a new dry-mass, floating Lagrangian, vertical coordinate with 32 levels in the vertical, and slightly reduced horizontal diffusion in the SE dynamical core [Lauritzen et al., 2018]. Further, we adopt the Beljaars et al. [2004] orographic drag parameterization which replaces the turbulent mountain stress (TMS) scheme of CESM1 [Neale et al., 2012] in order to achieve more realistic (higher) wind speeds over the ice sheets. Physics tuning coefficients were set to default values specified in the supported CAM5 release. 

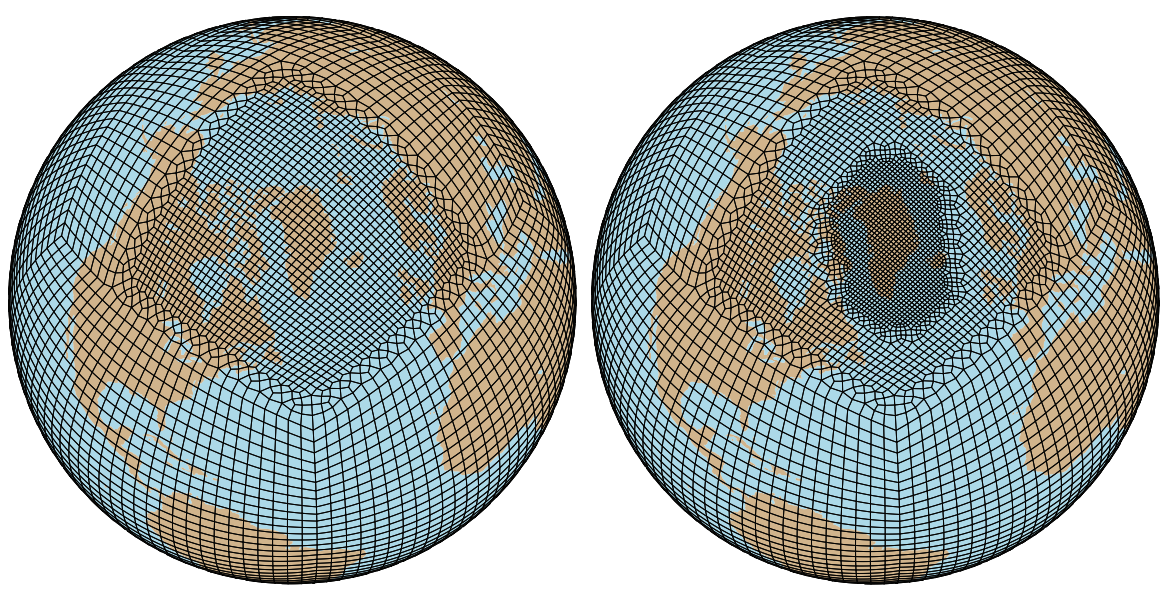

Figure 3.1: Computational domains of experiments VR-CESM55 (left) and VR-CESM28 (right). Each spectral element visible here contains an additional 3-by-3 grid of points, the exact position of which are determined by the spectral element method [Zarzycki and Jablonowski, 2014].

\subsubsection{Grids}

Our reference simulation, referred to as Uniform CESM, uses a standard cubed sphere grid which is quasi-uniform at $1^{\circ}(\sim 111 \mathrm{~km})$ resolution globally [Evans et al., 2012]. The first non-uniform VR mesh has a refined patch of $0.5^{\circ}(\sim 55 \mathrm{~km})$ over the greater Greenland region and is referred to as VRCESM55. The patch was constructed such that the boundary of the patch always extends at least six spectral elements away from the Greenland coast (Figure 3.1). This buffer region is intended to allow incoming "low-resolution" storms to develop finer-scale structures after entering the VR zone and prior to making landfall [Matte et al., 2017]. The second VR mesh is constructed off the VR-CESM55 grid, yet features a second level of refinement at $0.25^{\circ}(\sim 28 \mathrm{~km})$ inside the first level. This second patch was chosen such that, again, the boundary extends at least six spectral elements away from the Greenland coast. The simulation on this grid is referred to as VR-CESM28 and both VR grids were constructed using SQuadGen [Ullrich, 2014].

Topographic height over Greenland was interpolated from the $4 \mathrm{~km}$ CISM ice sheet domain, which in turn has been derived from the $90 \mathrm{~m}$ Greenland Ice Mapping Project product (GIMP, Howat et al. [2014]). Topography is static in time - ice sheet dynamics are not active in this configuration - a reasonable assumption for the decadal length simulations presented in this paper. The new ice topography was spliced into the global topography, similar to what is done in two-way coupled setups where ice sheet dynamics are turned on. Due to the hybrid sigma vertical coordinate system implemented in CAM-SE, a differential smoothing procedure was applied to ensure numerical stability and realistic flow, as described by Zarzycki et al. [2015]. Subgrid height variances, used by the orographic drag parameterization, are consistently recomputed as a residual of the smoothed topography. At increased resolutions, less smoothing is applied in total leading to a more detailed and accurate representation of topography, see Figure 3.2. Mean topographic height over the GrIS - as seen by CAM - is $1884 \mathrm{~m}$

For details, see the CESM Land Ice Documentation and User Guide, https://escomp.github.io/ cism-docs/cism-in-cesm/versions/release-cesm2.0/html/clm-cism-coupling.html 


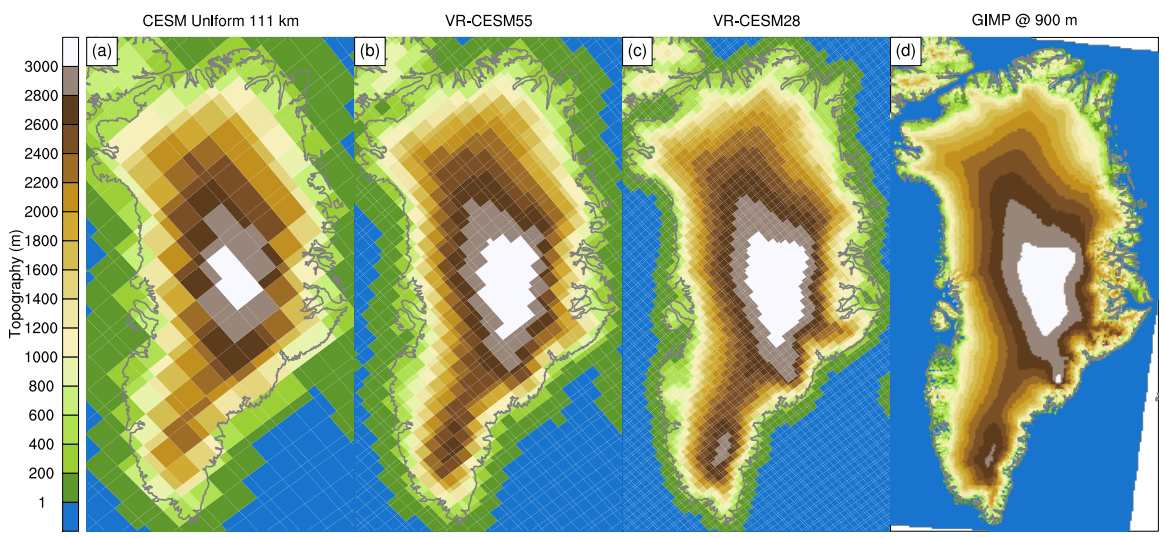

Figure 3.2: Topographic height in the three CESM simulations. For plotting purposes, spectral element node heights are displayed on control volumes equal to the area that they represent. The control volumes are identical to those used by the CESM coupler to conserve mass and energy. For reference, topographic height according to the Greenland Ice Mapping Project (GIMP, Howat et al. [2014]) is shown, which has been upscaled to $900 \mathrm{~m}$.

(Uniform CESM), 2009 m (VR-CESM55) and $2058 \mathrm{~m}$ (VR-CESM28), respectively. The feature most prominently improving is the southern ice dome, that "rises up" from $\sim 2300 \mathrm{~m}$ at $111 \mathrm{~km}$ to $\sim 2900 \mathrm{~m}$ at $28 \mathrm{~km}$ (Figure 3.2). Furthermore, the $28 \mathrm{~km}$ resolution seems sufficiently detailed to start resolving some of the fjord structures, especially in the east. The non-zero topographic heights over open ocean in Figure 3.2 are explained by the differential smoothing procedure.

The CAM physics (dynamics) time steps for Uniform CESM was 1800 (150) seconds. For the VRCESM runs, the physics time step was set to $450 \mathrm{~s}$ and the CAM dynamics time steps were scaled with horizontal resolution with VR-CESM55 at $150 \mathrm{~s}$ and VR-CESM28 at $75 \mathrm{~s}$. Hyperviscosity coefficients are scaled by the grid-resolution (element dimensions) for numerical stability and filter undesirable numerical artifacts [Guba et al., 2014]. Here the scaling is such that the hyperviscosity coefficients are reduced by an order of magnitude for each doubling of the resolution [Zarzycki and Jablonowski, 2014]. Some minor grid imprinting was noted in the grid transition zone over distorted SE elements. It is deemed unlikely, however, that these small, local anomalies materially impact the large-scale synoptic flow in the interior of the domain.

\subsubsection{Land surface model}

CAM is coupled to the Community Land Model (CLM) version 5.0, which incorporates several important bug fixes and snow parameters updates for CESM2. CLM simulates the interaction of the atmosphere with the land surface, notably the surface energy balance and hydrological processes such as interception by canopy, throughfall, infiltration, and runoff [Oleson, 2013]. For radiation calculations over snow, the two-way radiative transfer model SNICAR is used [Flanner and Zender, 2005]. The snow pack hydrological and thermal evolution is modelled as a one-dimensional column, which can reach depths of up to 10 metres of w.e. (water-equivalent), with up to 12 layers. Several snow model modifications have been implemented specifically for ice sheets, such as wind-dependent fresh 
snow density and wind driven snow compaction [van Kampenhout et al., 2017] and temperature dependent fresh snow grain size. Bare ice albedo is assumed constant, and is set to $0.50(0.30)$ for the visible (near-infrared) spectrum, reflecting the distinction made between these two shortwave bands in CLM [Oleson, 2013]. Due to a CAM model bias leading to excessive rainfall over the GrIS, the phase of precipitation is recomputed in CLM using a simple temperature threshold. Over non-glacier (glacier) landunits, a threshold temperature of $0{ }^{\circ} \mathrm{C}\left(-2{ }^{\circ} \mathrm{C}\right)$ is used for solid precipitation and $+2{ }^{\circ} \mathrm{C}\left(0{ }^{\circ} \mathrm{C}\right)$ for liquid precipitation, with a linear ramp in between, which has proven effective at removing most of the bias.

Over glaciated grid cells, CLM maintains 10 different elevation classes (ECs) in order to more accurately capture SMB gradients in the ablation zones [Lipscomb et al., 2013]. ECs are implemented as independent CLM columns, i.e. each one maintains its unique snow pack, temperature, hydrology, and snow grain size. The weight assigned to each EC is proportional to the subgrid topography present in the CLM grid cell and classes with zero weights are considered "virtual" and do not contribute to the grid cell average, i.e. the value that the atmosphere receives back. ECs are associated with elevation bins, but their specific elevation is determined by the distribution of topography within that bin (see [Lipscomb et al., 2013] for more details). Atmospheric surface temperature and downwelling longwave radiation are downscaled from the mean CLM grid cell elevation to the EC elevation, using global lapse rates. The lapse rate for temperature is $6 \mathrm{~K} \mathrm{~km}^{-1}$ (Lipscomb et al. [2013]) and that for longwave radiation $32 \mathrm{~W} \mathrm{~m}^{-2} \mathrm{~km}^{-1}$ (Figure 6 in Van Tricht et al. [2016a]), with a grid cell normalization to keep the mean value conserved. Further, specific humidity is downscaled following the assumption that relative humidity remains constant with height. Low lying ECs in the ablation zone typically experience larger melt rates because of enhanced sensible heat and downwelling longwave fluxes, and are therefore instrumental to resolving the narrow ablation zones of Greenland (Figure 3.3).

The Community Ice Sheet Model (CISM, Lipscomb et al. [2019]) is active as a diagnostic component in our simulations in order to benefit from the EC infrastructure. CISM operates on a $4 \mathrm{~km}$ Cartesian grid, and receives its surface forcing (temperature, SMB) from CLM through a bi-linear downscaling procedure in order to prevent artificial jumps between grid cells [Leguy et al., 2018]. In this study, we deviate from the standard CLM definition of SMB, which does not take into account changes in snow pack height, in favour of the definition that is common to glaciology, in absence of redistribution/erosion by drifting snow

$$
\mathrm{SMB}=\text { Precipitation }- \text { Sublimation }- \text { Runoff. }
$$

For the remainder of the paper, modelled accumulation (ablation) is defined as modelled SMB for locations where $\mathrm{SMB}>0(\mathrm{SMB}<0)$.

Following Rhoades et al. [2018], the distribution of plant functional types in CLM is assumed constant at year 2000 values for all simulations. As the main focus of this work is on precipitation and snow cover in non-vegetated regions, we argue this assumption has a negligible impact on our results.

\subsubsection{Initialisation}

In glaciated regions, the subsurface conductive heat flux at the ice sheet surface is potentially large due to the high thermal conductivity of ice. To avoid unrealistic energy losses or gains from the subsurface, one should start with ice that is in thermal equilibrium with the ambient climate. In our modelling 

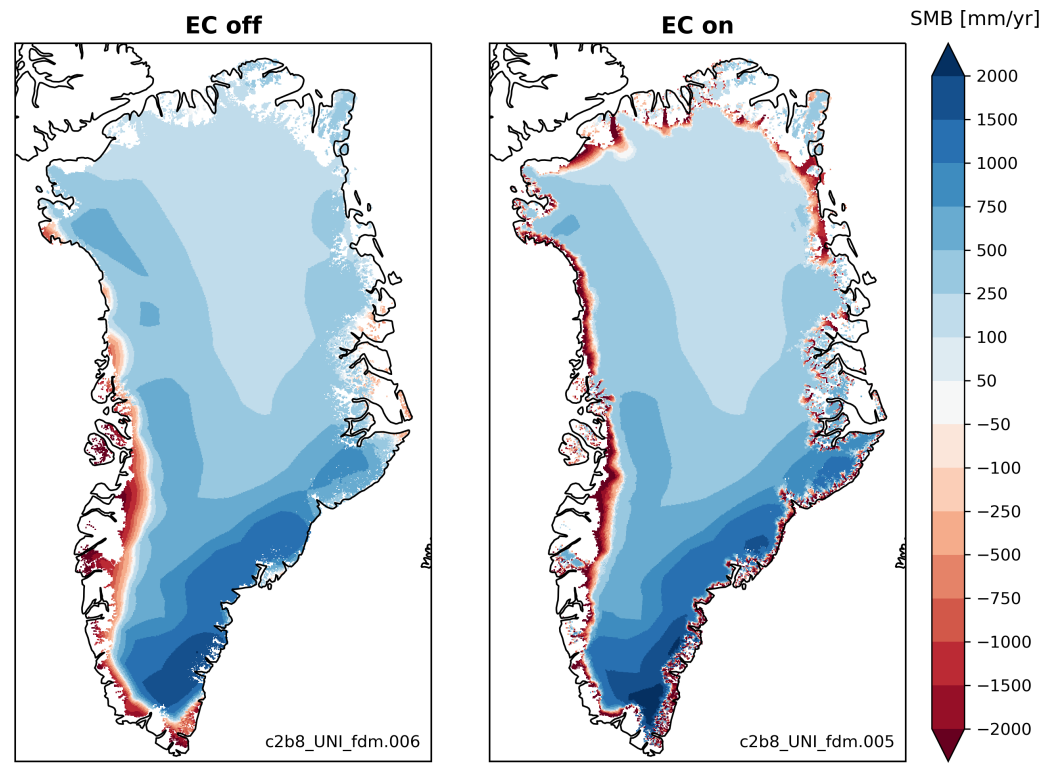

Figure 3.3: Annual mean SMB at $4 \mathrm{~km}$ over the period 1980-1999 in two $1^{\circ}$ CESM simulations. Left panel: a simulation identical in setup to Uniform CESM, except that both EC lapse rates (for temperature and longwave radiation) are set to zero. Right panel: simulation Uniform CESM.

setup, however, a sufficiently long spinup period to achieve such equilibrium was not feasible due to computational constraints. Instead, it was decided to initialise deep ice temperature from values close to observed, in this case $10 \mathrm{~m}$ firn temperatures from a firn densification model, forced by RCMdownscaled reanalysis data [Ligtenberg et al., 2018]. A nearest neighbour procedure was followed to interpolate ice temperature from the $11 \mathrm{~km}$ firn model to the different resolutions used in this study.

Below $1774 \mathrm{~m}$ in elevation (which corresponds to the highest GrIS elevation where $\mathrm{SMB}=0$ in the RACMO2 climatology), the initial snow amount was set to a maximum value of $100 \mathrm{~mm}$ w.e. to avoid snow cover hysteresis resulting from errors in the interpolated initial conditions. A spinup simulation was then carried out to rebuild snow packs in CLM columns below this reset altitude, at least where CESM climate allows it. The relevance of this spinup is two-fold: (1) the dependence of fractional snow cover on snow height [Swenson and Lawrence, 2012], (2) the refreezing capacity of the snow pack. For both of these, a period of 5 years was deemed sufficiently long to capture the first-order effect. Nonetheless, it is recognised that the resulting snow depth distribution over the GrIS contains an artificial jump at $1774 \mathrm{~m}$.

\subsubsection{Performance}

All simulations have been performed on NCAR's supercomputing facility "Cheyenne" in Wyoming, USA, which is equipped with Intel Broadwell processors. No real load-balancing was needed since the active components (i.e., CAM, CLM, CISM, and coupler) perform well when sharing all the available cores. On 1800 cores (or 50 compute nodes) the cost of Uniform CESM at $1^{\circ}$ (48,602 CAM-SE grid 
points) amounts to $\sim 1070$ core hours per simulated year. Keeping the number of cores the same, this cost was tripled to 3250 core hours for the VR-CESM55 simulation with the refined patch of $0.5^{\circ}$ (59,402 CAM-SE grid points), and quadrupled to $\sim 4300$ core hours for the VR-CESM28 simulation with the additional $0.25^{\circ}$ patch $(69,887 \mathrm{CAM}$-SE grid points). By comparison, the computational cost of limited area model RACMO2 at $11 \mathrm{~km}$ is $\sim 6800$ core hours per simulated year (Brice Noël, pers. comm.). The throughput was $\sim 25, \sim 13$ and $\sim 10$ simulated years per day for Uniform CESM, VRCESM55 and VR-CESM28, respectively.

\subsubsection{Reference data}

Output from the three CESM simulations is interpreted using reference data from a variety of sources. The evaluation of the climate at synoptic scales is supported by atmospheric reanalyses, i.e. hindcast climate models that employ data assimilation to match the observed state of atmosphere as close as possible. In particular, temperature and geopotential height from the European Centre for MediumRange Weather Forecasts Reanalysis (ERA-Interim, Dee et al. [2011]) and the Modern-Era Retrospective Analysis for Research and Applications-2 (MERRA2, Molod et al. [2015]) products are used.

For evaluation of GrIS near-surface climate and surface mass balance, data from the Royal Netherlands Meteorological Institute (KNMI) regional atmospheric climate model (RACMO) version 2.3p2 (RACMO2 hereafter) are used. RACMO2 is a state-of-the-art polar climate model that has been extensively evaluated over the GrIS [Noël et al., 2018, 2015] and compares favourably to observations. At its lateral boundaries, RACMO2 was forced using ERA-Interim data and the native spatial resolution of the data is $11 \mathrm{~km}$. When appropriate, however, the statistically downscaled product at $1 \mathrm{~km}$ is used, which better resolves narrow ablation zones and low-lying regions [Noël et al., 2016, 2018]. We argue that it is fair to compare VR-CESM directly to the downscaled $1 \mathrm{~km} \mathrm{RACMO} 2$ product as (i) CESM also performs on-line downscaling using the semi-statistical elevation classes (Section 3.2.3), and (ii) bestestimate data is preferred in order to identify either model improvements or regressions, in line with the purpose of this paper. Still, these best-estimate benchmark data are subject to some uncertainty. Noël et al. [2018] characterise the native spatial resolution of $11 \mathrm{~km}$ as a source of model uncertainty, as well as the representation of surface roughness and surface albedo. Two prime uncertainties in the RACMO2 downscaling procedure arise from the bare ice albedo used to correct runoff, and the ice sheet extent [Noël et al., 2016].

Field data analysis has been carried out through the Land Ice Verification \& Validation Toolkit (LIVVkit), an open source software package designed for evaluating ice sheet models and their forcing [Kennedy et al., 2017; Evans et al., 2018]. Three observational SMB datasets available for the GrIS are used: (i) airborne radar, (ii) field accumulation ( $\mathrm{SMB}>0$ ) measurements, and (iii) field ablation $(\mathrm{SMB}<0)$ measurements [Evans et al., 2018]. The airborne radar data stems from NASA's Operation IceBridge and covers most of the GrIS interior. The raw data, as described by Lewis et al. [2016], provides seasonal accumulation estimates for a given pixel, uniquely determined by its latitude and longitude. Following Evans et al. [2018], a simple time average is applied over all available periods for each record to yield a single accumulation value (in $\mathrm{mm}$ w.e. $\mathrm{yr}^{-1}$ ) per location. The resulting number of IceBridge data points is a sizeable 18,968 , which means that the spatial density is quite high over the radar transects. During the evaluation, a nearest neighbour method is used to determine the model cell closest to each observation. 
The in-situ field accumulation dataset is a compilation of different field campaigns carried out in the GrIS accumulation zone [Cogley, 2004; Bales et al., 2009; Evans et al., 2018]. Only records that have been retrieved using firn cores, snow pits or stake measurements are included in the evaluation. Moreover, if there are multiple measurements at one location then the data is averaged in time to yield a climatological SMB estimate for that location. In total, the number of accumulation zone measurements is 421. The in-situ field ablation dataset is a subset of the compilation of GrIS ablation zone SMB measurements by Machguth et al. [2016b]. Again, each record location is averaged in time to yield an annual SMB estimate. Only records that are on the CISM ice mask and have a record length equal or close (i.e., within a 5\% difference) to a full year are kept, which brings the total number of records down from 627 to 163 , spread over 22 rather than 46 glaciers. It is important to mention at this point that the spatial coverage of the ablation zone measurements is quite sparse. Indeed, Figure 1 in Evans et al. [2018] illustrates that all in-situ ablation data stem from merely 8 transects in total.

\subsection{Results and Discussion}

\subsubsection{Large-scale circulation}

We start with a comparison of modelled mid-troposphere climate to reanalyses data, which serves two purposes. First, it is useful to identify any significant climatic biases that CESM possesses, which could aid in interpreting e.g. snow melt rates later on. Second, the VR approach allows for feedbacks between the domain of interest and the global climate system, in contrast to dynamical downscaling using RCMs. One such feedback could be changes to the strength and location of planetary waves both in and outside the VR domain, due to the higher and steeper topography (Figures 3.1 and 3.2). If such upstream / downstream dynamical effects are present in our modelling setup they would make an imprint on mid-tropospheric climate on a hemispheric scale.

CESM geopotential height (Z500) at $500 \mathrm{hPa}$ is compared against ERA-Interim over the period 19801999. Note that the choice of ERA-Interim versus MERRA-2 does not impact our results much, so only ERA-Interim is shown. In boreal summer, the season most relevant to GrIS SMB, anomaly maps of Z500 display consistent patterns across all three CESM simulations (Figure 3.4a-c). A positive height anomaly is found over the Arctic ocean, which is most pronounced in the Uniform CESM $111 \mathrm{~km}$ simulation. It is surrounded by a band of negative height anomalies in all three simulations, with one of the minima approximately centred over Iceland / South Greenland, indicating more cyclonic flow over the GrIS in CESM. At mid-latitudes, positive height anomalies are found instead, indicating more anticyclonic flow there. Over the region 55-90N, the Z500 root mean squared error (RMSE) is decreased from 3.6 dam (Uniform CESM) to 3.5 dam (-2\%, VR-CESM55) and 3.3 dam (-8\%, VR-CESM28), which could signal minor benefits of the grid refinement on resolving the large-scale circulation. However, no VR-CESM grid point within the domain of interest can be significantly differentiated from Uniform CESM (t-test, $\mathrm{p}<0.05$ ). Furthermore, similar decreases in RMSE are not consistently found in the other seasons (not shown) so these changes are attributed to internal variability.

Similarly, anomalies of $500 \mathrm{hPa}$ air temperature (T500) with respect to ERA-Interim are computed (Figure 3.4d-f). Major features in T500 are again shared by the three simulations, such as a cold bias exceeding $0.75^{\circ} \mathrm{C}$ over Russia, which is most pronounced in VR-CESM55 and VR-CESM28. A 

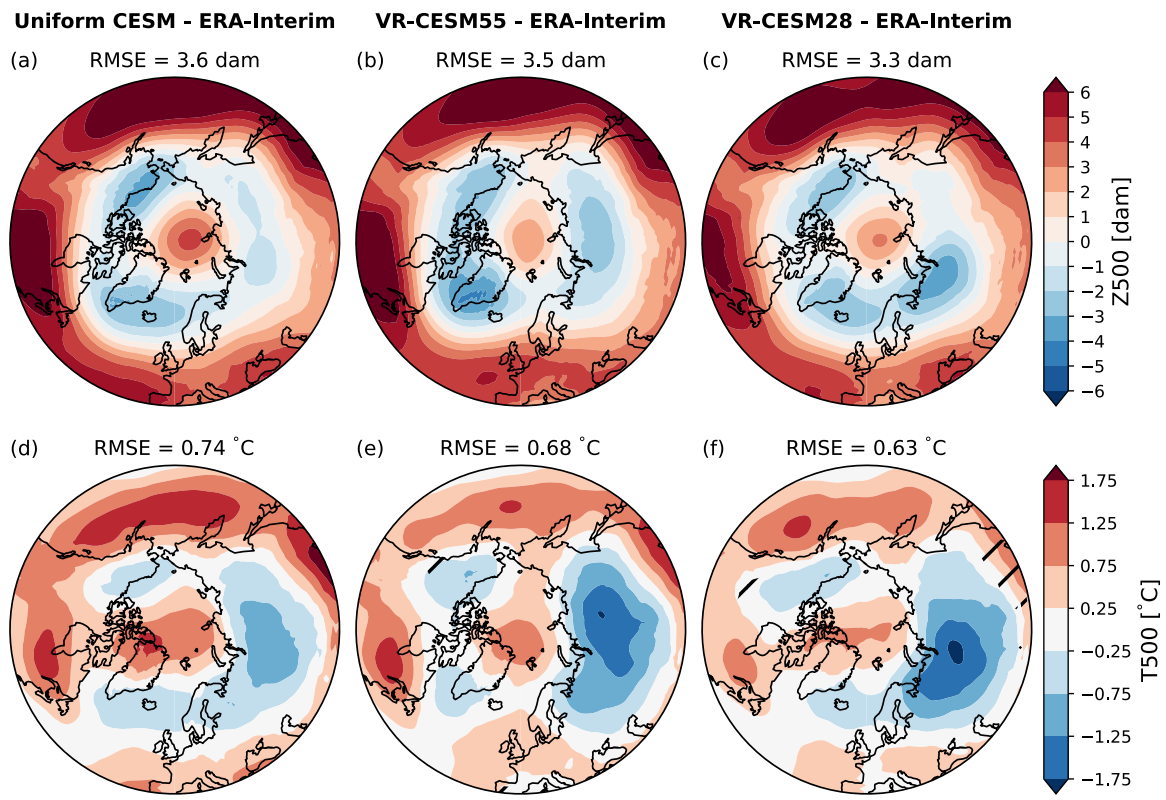

Figure 3.4: Mean summer (JJA) anomalies of 500 hPa geopotential height (Z500, panels a-c) and air temperature (T500, panels d-f) with respect to ERA-Interim over the period 1980-1999. Shown is 55-90N, the same region over which the area-weighted RMSE was calculated that is listed above each panel. Hatching in panel $f$ indicates that the VR-CESM simulation is significantly different $(p<0.05)$ from Uniform CESM. No significance was found in panels $b, c$, and e. Prior to subtraction, all data have been regridded to a common regular mesh of $1^{\circ}$ using bi-linear interpolation.

slight June-July-August (JJA) warm bias of around $0.5-1{ }^{\circ} \mathrm{C}$ is indicated over the Arctic Ocean and Northern Greenland in all three simulations. Over the region 55-90N, RMSE is decreased from 0.74 ${ }^{\circ} \mathrm{C}$ (Uniform CESM) to $0.68{ }^{\circ} \mathrm{C}\left(-8 \%\right.$, VR-CESM55) and $0.63{ }^{\circ} \mathrm{C}(-14 \%$, VR-CESM28). Similar improvements are found in March-April-May but not in the other two seasons (not shown). Some point-by-point significance is found between VR-CESM and Uniform, albeit not over the Greenland area (Figure 3.4d-f).

To conclude, heights at $500 \mathrm{hPa}$ seem not substantially affected by the enhanced resolution and topography in VR-CESM. In all three CESM simulations, more cyclonic flow is indicated over Greenland with respect to ERA-Interim. Temperature at $500 \mathrm{hPa}$ demonstrates a weakly positive bias in CESM, and shows no significant change with refinement over the GrIS. A weak signal cannot be excluded, however, as it may remain undetected by the Student's t-test due to the relatively short sample period of 20 years.

\subsubsection{Precipitation}

Both the steep edges of ice sheets as well as topographic promontories are effective drivers of orographic precipitation, as is e.g. apparent from the RACMO2 precipitation field (Figure 3.5d). The largest source of moisture is the North Atlantic basin, which is connected to Greenland by large-scale storm systems 


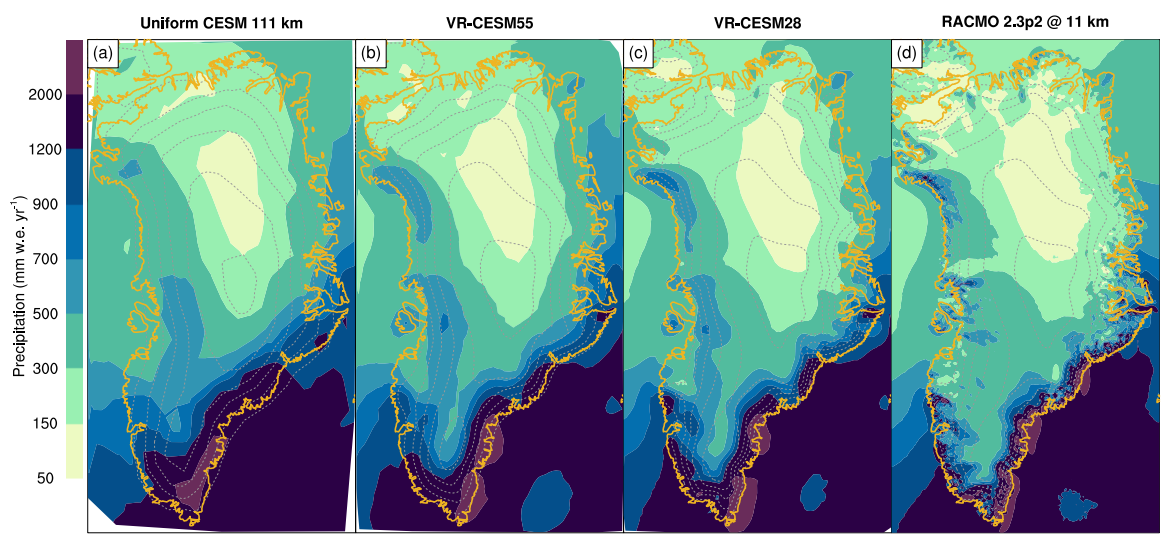

Figure 3.5: Spatial distribution of mean annual precipitation over Greenland. CESM data are displayed at the native CAM resolution for the period 1980-1999. RACMO2 data are shown at native 11 $\mathrm{km}$ resolution for the same period. Coastlines and $500 \mathrm{~m}$ elevation contours are overlain in orange and grey, respectively. Note the non-linear colour scale.

[Sodemann et al., 2008]. Cyclonic activity associated with the persistent Icelandic Low drives warm and moist air onto land from the south-east, resulting in strong orographic uplift which causes rapid cooling, condensation, and precipitation. By comparison, northern Greenland is much drier with accumulation rates locally below $150 \mathrm{~mm} \mathrm{yr}^{-1}$ [Cogley, 2004].

Since orographic precipitation is dominant over southern Greenland, it is not surprising that we find significant improvements with increasing resolution (Figure 3.5), compared with RACMO2. At uniform $111 \mathrm{~km}$ resolution, CESM correctly predicts a band of high $\left(>1000 \mathrm{~mm}\right.$ w.e. $\mathrm{yr}^{-1}$ ) precipitation rates in the south-east, however it extends too far into the interior (Figure 3.5a). This is attributed to the fact that the poorly resolved topography is $\sim 600 \mathrm{~m}$ lower in the model than in reality (Figure 3.2a) and that topographic gradients are smoothed out, which weakens the effect of orographic uplift. The VR-CESM55 result (Figure 3.5b) shows that this is mostly a resolution issue as the band of high precipitation rates is more confined to the low-lying areas and slopes, similar to RACMO2. Other effects that can be seen in this VR-CESM55 result are the emergence of orographic precipitation in other locations around the margins, albeit weak, and a general drying of the northern interior. In VRCESM28, similar resolution dependent patterns continue to emerge, with even stronger orographic precipitation and more pronounced drying in the north (Figure 3.5c). Integrated over the entire GrIS, including peripheral glaciers and ice caps, precipitation is reduced from $946 \pm 107 \mathrm{Gt} \mathrm{yr}^{-1}$ (Uniform CESM) to $870 \pm 72$ (VR-CESM55) and $821 \pm 62 \mathrm{Gt} \mathrm{yr}^{-1}$ (VR-CESM28). By comparison, RACMO2 simulates a mean annual precipitation flux of $743 \pm 64 \mathrm{Gt} \mathrm{yr}^{-1}$ over these glaciated areas. Both the improved patterns (Figure 3.5) and the more reasonable integrated amount of precipitation over the GrIS are positive results for the application of VR-CESM to this region.

\subsubsection{IceBridge}

Operation IceBridge accumulation data is used to further quantify the effect of the improved precipitation patterns on SMB. As described in Section 3.2.3, CESM SMB is downscaled to $4 \mathrm{~km}$ using the 

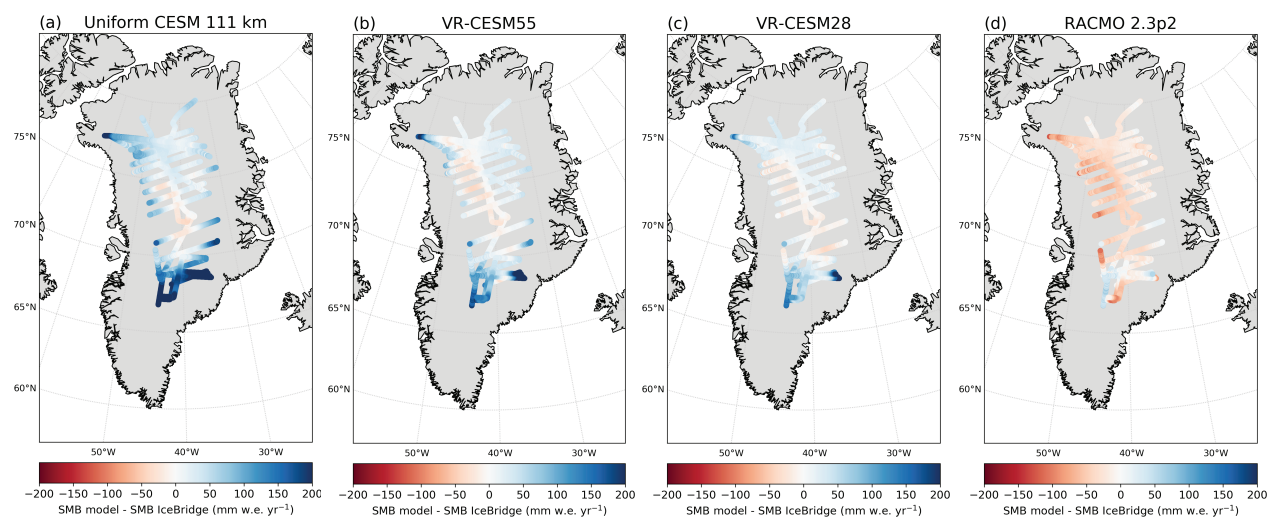

Figure 3.6: SMB differences between IceBridge radar (mean over available period) and model climatology (1980-1999). Blue (red) colours indicate that the model is wetter (dryer) than observations.

EC method and averaged over the period 1980-1999, prior to comparison to the processed IceBridge SMB samples (Section 3.2.6). Figure 3.6 displays the resulting SMB anomalies in $\mathrm{mm}$ w.e. $\mathrm{yr}^{-1}$. As can be seen, the comparison with IceBridge radar data supports the pattern of interior drying with increasing resolution. In Uniform CESM at $111 \mathrm{~km}$ resolution, we find a mean wet bias of $81 \mathrm{~mm}$ w.e. $\mathrm{yr}^{-1}$ which is most pronounced in regions near the edges of the IceBridge domain (Figure 3.6a). The strongest bias is found in the south, where absolute precipitation rates are highest (Figure 3.5) and any relative error will consequently lead to a larger absolute error. With increasing resolution, the mean bias drops from 81 to $37 \mathrm{~mm}$ w.e. $\mathrm{yr}^{-1}$ (VR-CESM55) and $24 \mathrm{~mm}$ w.e. $\mathrm{yr}^{-1}$ (VR-CESM28), which suggests that the largest improvement is made going from $111 \mathrm{~km}$ to $55 \mathrm{~km}$ (Figure 3.1). The largest SMB differences remain to be found near the margins of the IceBridge domain (Figure 3.6b-c). The spread in SMB anomaly also decreases with resolution, which can be visually seen as a narrowing of the SMB anomaly distribution in Figure 3.7a. As a measure for this spread, the difference between the 95 th percentile and the 5th percentile falls from $308 \mathrm{~mm}$ w.e. $\mathrm{yr}^{-1}$ (Uniform CESM) to $178 \mathrm{~mm}$ w.e. $\mathrm{yr}^{-1}$ (VR-CESM55) and $115 \mathrm{~mm}$ w.e. $\mathrm{yr}^{-1}$ (VR-CESM28), respectively. As another measure, the RMSE decreases from $126 \mathrm{~mm}$ w.e. $\mathrm{yr}^{-1}$ (Uniform CESM) to $68 \mathrm{~mm}$ w.e. $\mathrm{yr}^{-1}$ (-46\%, VR-CESM55) and $46 \mathrm{~mm}$ w.e. $\mathrm{yr}^{-1}(-64 \%$, VR-CESM28). At the same time, the spatial correlation is substantially enhanced $\left(r^{2}\right.$, Table 3.1). The bias and RMSE of RACMO2 are $-25 \mathrm{~mm}$ w.e. $\mathrm{yr}^{-1}$ and $38 \mathrm{~mm}$ w.e. $\mathrm{yr}^{-1}$, respectively, which suggests a dry bias in RACMO2 (Figure 3.6d). We conclude that based these statistics, VR-CESM28 performs on-par with RACMO2 (Table 3.1).

\subsubsection{Accumulation sites}

A similar analysis is carried out for the in-situ accumulation zone observations. Compared to the airborne radar data, these measurements cover a greater portion of the GrIS, including the southern dome [cf. Figure 1 in Evans et al., 2018], which should make it more representative of the GrIS as a whole. As before, the greatest absolute improvement is found in the doubling of resolution from $111 \mathrm{~km}$ to 55 $\mathrm{km}$, with smaller benefits going further to $28 \mathrm{~km}$ (Figure 3.7b and Table 3.1). The mean bias substantially reduces from $187 \mathrm{~mm}$ w.e. $\mathrm{yr}^{-1}$ (Uniform CESM) to $105 \mathrm{~mm}$ w.e. $\mathrm{yr}^{-1}$ (-44\%, VR-CESM55) 

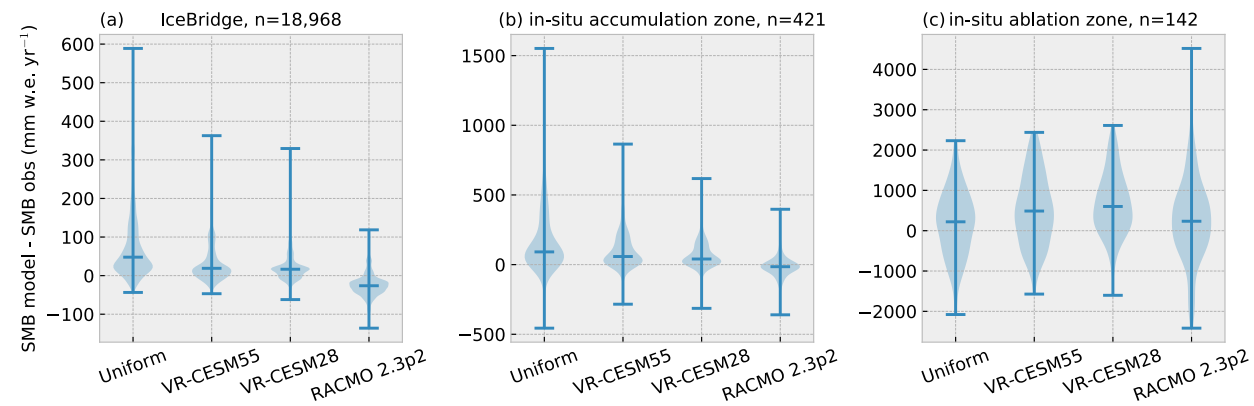

Figure 3.7: Point-by-point SMB differences between model and reference observations. Shading indicates the distribution, and horizontal line segments indicate maximum, median, and minimum value. Model climatologies have been computed over the period 1980-1999.

Table 3.1: Selected statistics of CESM climatological SMB (downscaled to $4 \mathrm{~km}$ ) and RACMO2 climatological SMB (downscaled to $1 \mathrm{~km}$ ) with respect to IceBridge radar data, accumulation zone sites, and ablation zone sites. Shown are mean bias, coefficient of determination, and root mean square error. Model climatologies have been computed over the period 1980-1999, which not necessarily overlaps with the date of each measurement.

\begin{tabular}{|c|c|c|c|c|c|c|c|c|c|}
\hline \multirow[b]{4}{*}{ Uniform CESM } & \multicolumn{3}{|c|}{ Icebridge } & \multicolumn{3}{|c|}{ Acc. sites } & \multicolumn{3}{|c|}{ Abl. sites } \\
\hline & \multirow[t]{2}{*}{$r^{2}$} & Bias & RMSE & \multirow[t]{2}{*}{$r^{2}$} & Bias & RMSE & \multirow[t]{2}{*}{$r^{2}$} & \multicolumn{2}{|c|}{ Bias RMSE } \\
\hline & & \multicolumn{2}{|c|}{$\left(\mathrm{mm}\right.$ w.e. $\left.\mathrm{yr}^{-1}\right)$} & & \multicolumn{2}{|c|}{$\left(\mathrm{mm}\right.$ w.e. $\left.\mathrm{yr}^{-1}\right)$} & & \multicolumn{2}{|c|}{$\left(\mathrm{mm}\right.$ w.e. $\left.\mathrm{yr}^{-1}\right)$} \\
\hline & 0.78 & 81 & 126 & 0.61 & 187 & 319 & 0.71 & 170 & 793 \\
\hline VR-CESM55 & 0.88 & 37 & 68 & 0.74 & 105 & 172 & 0.69 & 462 & 941 \\
\hline VR-CESM28 & 0.92 & 24 & 46 & 0.79 & 71 & 124 & 0.72 & 600 & 951 \\
\hline RACMO & 0.94 & -25 & 38 & 0.71 & -13 & 91 & 0.54 & 160 & 922 \\
\hline
\end{tabular}

and $71 \mathrm{~mm}$ w.e. $\mathrm{yr}^{-1}$ (-62\%, VR-CESM28) and the RMSE reduces from $319 \mathrm{~mm}$ w.e. $\mathrm{yr}^{-1}$ (Uniform CESM) to $172 \mathrm{~mm}$ w.e. $\mathrm{yr}^{-1}$ (-46\%, VR-CESM55) and 124 (-61\%, VR-CESM28). A small positive accumulation bias remains even in the highest resolution run (VR-CESM28), a bias that is not apparent in the RACMO2 data (Table 3.1). For RACMO2, the bias and RMSE values are similar to those mentioned by Noël et al. [2018], who report in their Figure 11a an accumulation zone mean bias of $-22 \mathrm{~mm}$ w.e. $\mathrm{yr}^{-1}$ (here: $-13 \mathrm{~mm}$ w.e. $\mathrm{yr}^{-1}$ ) and an RMSE of $72 \mathrm{~mm}$ w.e. $\mathrm{yr}^{-1}$ (here: $91 \mathrm{~mm}$ w.e. $\mathrm{yr}^{-1}$ ). Our $r^{2}$ is slightly lower, however, 0.71 against 0.85 . These differences can be explained by the different methodology used. Namely, Noël et al. [2018] correlate SMB values based off daily data, thus reflecting the meteorological conditions during which the measurement was made, whereas here we compare climatological averages of the model to each measurement, which introduces additional noise in the comparison.

\subsubsection{Ablation sites}

High up on the ice sheet, and thus deep into the accumulation zone, SMB is dominated by snowfall. In the ablation zone, by contrast, there is a delicate balance between different factors - snowfall, sublimation, snowmelt, refreezing, and runoff — that complicates SMB modelling. Furthermore, SMB 


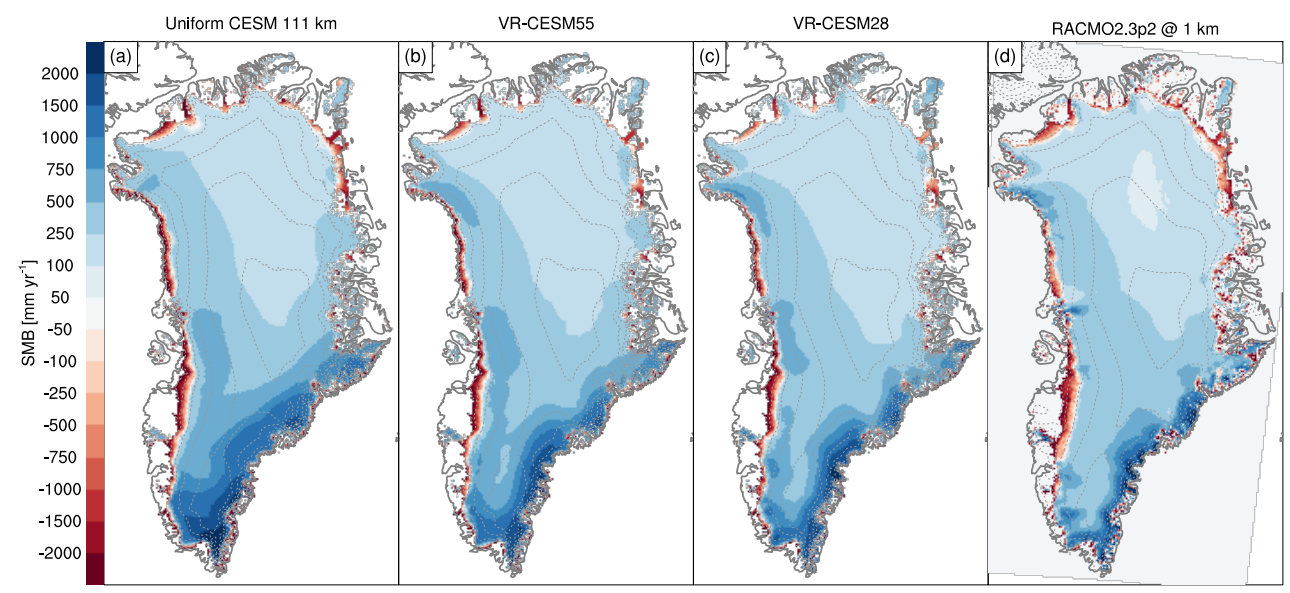

Figure 3.8: Mean annual SMB in $\mathrm{mm}$ w.e. $\mathrm{yr}^{-1}$. All CESM data are downscaled to $4 \mathrm{~km}$ CISM resolution for the period 1980-1999. RACMO2 data have been statistically downscaled from 11 to 1 $\mathrm{km}$. Note the non-linear colour scale.

gradients are typically much stronger in the ablation zone than they are in the accumulation zone, mainly due to steep topography and non-linearity of SMB with height (Figure 3.8). Therefore, as one expects, CESM model skill in the ablation zone is lower than in the accumulation zone, signalled by a larger spread and modelling biases exceeding $1000 \mathrm{~mm}$ w.e. $\mathrm{yr}^{-1}$ at many locations (Figure 3.7c). Nonetheless, ablation zones are mostly predicted in the right locations (Figure 3.8), owing to the EC downscaling (Section 3.2.3) that is active in all simulations.

In contrast to the accumulation zone and somewhat surprisingly, model skill in the ablation zone does not improve with resolution (Table 3.1). The mean bias grows from $170 \mathrm{~mm}$ w.e. $\mathrm{yr}^{-1}$ (Uniform CESM) to $462 \mathrm{~mm}$ w.e. $\mathrm{yr}^{-1}$ (VR-CESM55) and $600 \mathrm{~mm}$ w.e. $\mathrm{yr}^{-1}$ (VR-CESM28), which are substantial increases of $+172 \%$ and $+253 \%$, respectively. The model spread is only marginally detoriated, and RMSE ranges 793 - $951 \mathrm{~mm}$ w.e. $\mathrm{yr}^{-1}$ for all simulations (Table 3.1). The ablation statistics of the overall best simulation (Uniform CESM) are comparable to those of RACMO2 which are, analogous to CESM, computed using a 1980-1999 climatology. The bias, $r^{2}$, and RMSE of RACMO2 are considerably worse than those reported by Noël et al. [2018], who find a bias of $120 \mathrm{~mm}$ w.e. $\mathrm{yr}^{-1}$ (here: 160 mm w.e. $\mathrm{yr}^{-1}$ ), an $r^{2}$ of 0.72 (here: 0.54 ), and RMSE of $870 \mathrm{~mm}$ w.e. $\mathrm{yr}^{-1}$ (here: $922 \mathrm{~mm}$ w.e. $\mathrm{yr}^{-1}$ ) in their ablation zone comparison with similar data (their Figure 11c). Again, this is explained by the different methodology used. In particular, we believe that some extreme ablation events that happened after the year 2000 are not well captured by the climatological mean of the two 20th century decades considered here. When the period of the RACMO2 climatology is changed to 1995-2017, we find a bias of $-9 \mathrm{~mm}$ w.e. $\mathrm{yr}^{-1}$, an $r^{2}$ of 0.69 , and RMSE of $722 \mathrm{~mm}$ w.e. $\mathrm{yr}^{-1}$, which confirms that the time frame used is a crucial factor. Overall, we conclude that both VR-CESM55 and VR-CESM28, despite their higher resolution over the GrIS, fail to recover in-situ ablation rates with a skill similar or better than the reference simulation. Instead, a strong positive SMB bias develops in some ablation zone sites, suggesting too little runoff and/or too much precipitation in these locations. 


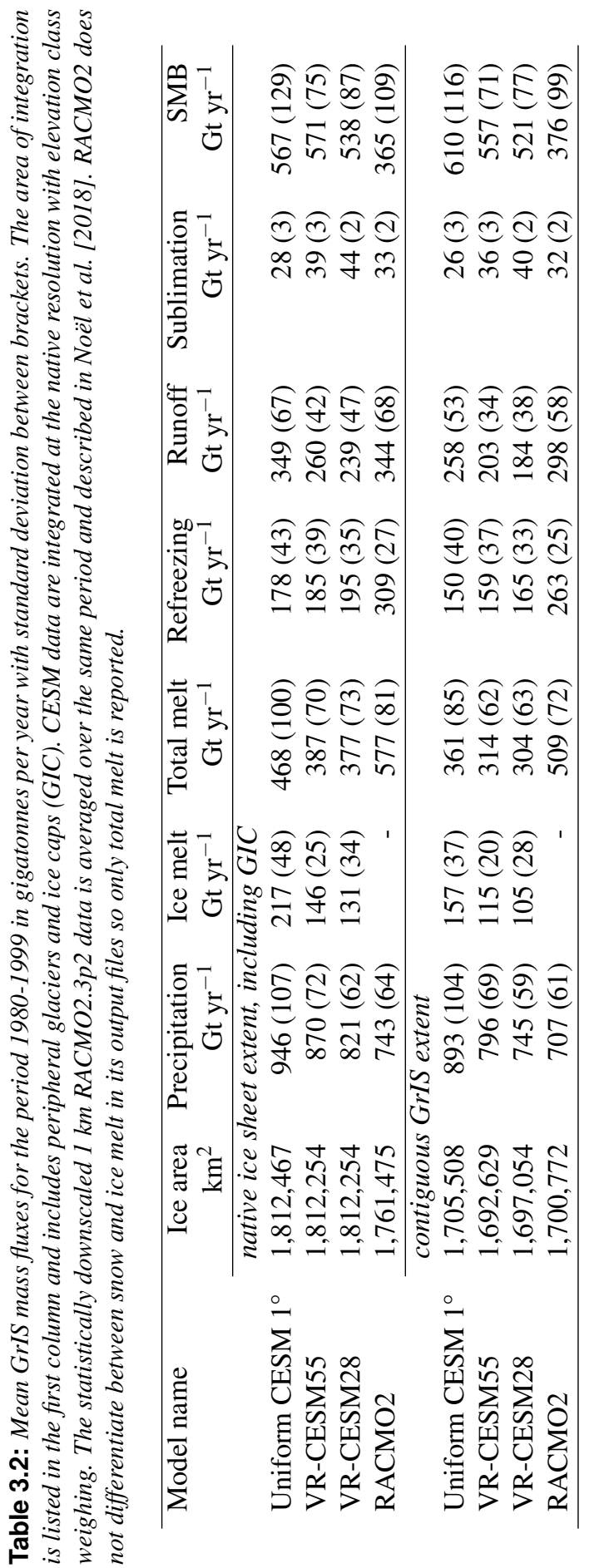




\subsubsection{Integrated SMB}

In this section, all major surface mass balance components are spatially integrated. We use both the ice masks native to each model as well as a common ice mask for this. Compared to RCMs, which are strongly forced by atmospheric reanalyses, our AMIP-style simulations experience relatively weak forcing at the ocean boundaries, which renders it unlikely that the actual historical Greenland weather conditions are reasonably resolved. Furthermore, a 20-year model simulation is arguably not long enough to attain a robust mean climate. Hence, the numbers presented in Table 3.2 should be interpreted with some caution, as RACMO2 and CESM are not necessarily experiencing the same climate. The common ice mask is constructed based on the contiguous GrIS definition, as laid out by the PROMICE mapping project [Citterio and Ahlstrøm, 2013], which is bilinearly upscaled from the $1 \mathrm{~km}$ RACMO domain to the respective CESM grids. In the remainder of this section, we will focus on the results that were obtained on the common ice mask.

GrIS-integrated precipitation is overestimated in all CESM simulations with respect to the RACMO2 regional model (Table 3.2). The bias in precipitation is largest for Uniform CESM $\left(+186 \mathrm{Gt} \mathrm{yr}^{-1}\right.$, or $+26 \%)$ and reduces with increasing resolution to $+89 \mathrm{Gt}(+13 \%$, VR-CESM55) and $+38 \mathrm{Gt}(+5 \%$, VR-CESM28). This is in line with our earlier findings of progressive drying with increased resolution discussed in Sections 3.3.2, 3.3.3, and 3.3.4. Melt, on the other hand, seems consistently underestimated in all CESM simulations (Table 3.2). The bias in total melt volume is smallest for coarse-resolution Uniform CESM (-148 Gt, or -29\%) and largest for fine-resolution run VR-CESM28 (-205 Gt, or -40\%). Melt is reduced by $47 \mathrm{Gt}$ in VR-CESM55 and by $57 \mathrm{Gt}$ in VR-CESM28, with respect to Uniform CESM. The majority of that is due to ice melt, which sees similar reductions of $42 \mathrm{Gt}$ and $52 \mathrm{Gt}$, respectively (Table 3.2), with snow melt accounting for the remainder of $5 \mathrm{Gt}$ in both cases. Refreezing volume is comparable across the three different CESM simulations (Table 3.2), with only slightly higher numbers at higher resolution. These could be explained, for instance, by lower snow temperatures (greater "cold content") in these runs, which is consistent with the lower melt rates found. Surface runoff in CESM is the sum of bare ice melt and drainage from the bottom of the snow pack, i.e. liquid water originating from rain or melt that does not refreeze. Due to the reductions in total melt volume, runoff is also significantly reduced at higher resolutions (Table 3.2), leading to significant negative biases when compared against the downscaled $1 \mathrm{~km}$ RACMO2 data. With respect to RACMO2, Uniform CESM underestimates runoff by $40 \mathrm{Gt}$ (-13\%), VR-CESM55 by $95 \mathrm{Gt}(-32 \%)$, and VR-CESM28 by $114 \mathrm{Gt}$ $(-38 \%)$, which agrees with the reduction in ablation found in Section 3.3.5. Sublimation is enhanced in both VR runs compared to Uniform CESM (Table 3.2) which we attribute to higher $10 \mathrm{~m}$ wind speeds occurring in VR-CESM (not shown). GrIS sublimation in VR-CESM28 is $54 \%$ higher than in Uniform CESM, and exceeds the RACMO2 figure by $8 \mathrm{Gt}$.

Overall, GrIS integrated SMB exceeds $500 \mathrm{Gt}$ in all CESM simulations (Table 3.2), which is markedly more than the $376 \pm 99$ that RACMO2 estimates over the common mask. There appear to be two balancing factors. On one hand, precipitation is overestimated in all CESM runs, and more so in the runs at low resolution (Uniform CESM and VR-CESM55). On the other hand, runoff is underestimated in all CESM runs, and more so in the runs at high resolution (VR-CESM55 and VR-CESM28). However, the decrease in precipitation is larger than decrease in runoff, which means that the lowest integrated $\mathrm{SMB}$ value is found in VR-CESM28 $\left(521 \pm 77 \mathrm{Gt} \mathrm{yr}^{-1}\right)$. 


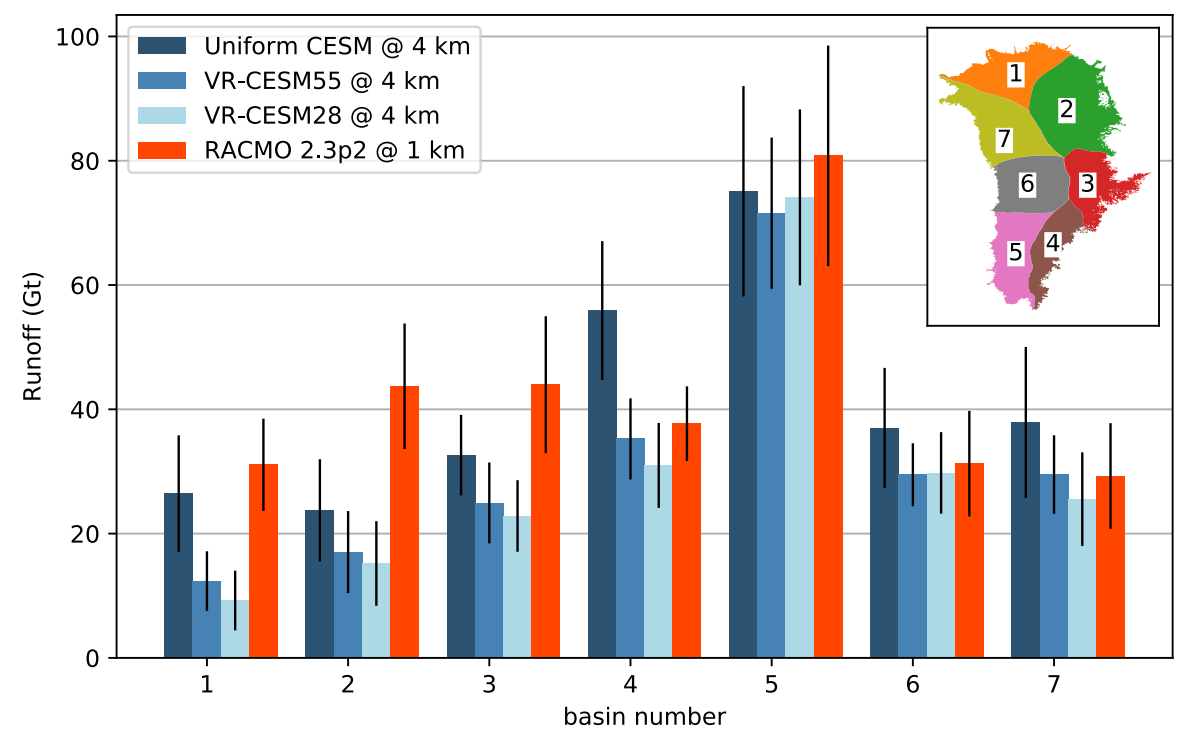

Figure 3.9: Mean basin-integrated runoff over the period 1980-1999. Error bars represent one standard deviation. CESM data have been manually downscaled down from their native resolution to $4 \mathrm{~km}$ using vertical SMB profiles generated by the elevation classes. For reference, RACMO2 downscaled runoff at $1 \mathrm{~km}$ resolution is shown. The extent of all basins combined equals the common ice mask in Table 3.2. Due to the manual interpolation, however, the total runoff for CESM does not match the value reported in Table 3.2 .

\subsubsection{Drivers of runoff changes}

In the previous sections, it was established that CESM reproduces the in-situ ablation zone measurements with less skill at higher spatial resolutions (Section 3.3.5) and that melt/runoff are increasingly underestimated (Section 3.3.6). Here, we further examine what is driving these regressions using both the grid cell mean output, as well as elevation class (EC) output that is manually downscaled to the CISM topography at $4 \mathrm{~km}$ using bilinear interpolation (for details on ECs, see Section 3.2.3). Note that this bilinear downscaling technique does not conserve mass and differs from the downscaling procedure inside the CESM coupler [Leguy et al., 2018].

First, we examine the spatial heterogeneity of runoff to uncover any regional differences. To this end, we aggregate the downscaled runoff over 7 major GrIS drainage basins, derived from an ice flow mosaic updated from Rignot and Mouginot [2012], and use downscaled RACMO2 at $1 \mathrm{~km}$ as a reference. The results in Figure 3.9 indicate that Uniform CESM underestimates mean runoff in basin 1 (north), basin 2 (north-east), and basin 3 (east). In both VR runs, runoff decreases further in these regions and now falls outside of the standard deviation of RACMO2. In basin 4 (south-east), runoff is substantially overestimated in Uniform CESM (Figure 3.9), which can be explained through the poorly resolved precipitation field in Uniform CESM. In reality, precipitation has steep gradients over this basin that are not resolved due to the coarse resolution (Figure 3.5). In both VR runs, precipitation shifts to lower elevations, which enhances meltwater buffering / refreezing and prevents bare ice exposure, two mechanisms through which runoff can be limited. Indeed, VR-CESM55 runoff is decreased and falls 
within one RACMO2 standard deviation in basin 4, whereas VR-CESM28 runoff seems slightly too low. The largest absolute runoff flux is found in basin 5 (south-west), which is equally well resolved by all CESM simulations, with integrated numbers that fall within one standard deviation of the RACMO2 estimate. Finally, runoff in basin 6 (west) and basin 7 (north-west) is slightly overestimated in Uniform CESM, a bias that appears to be removed in both VR runs. In summary, this basin analysis indicates that runoff is decreased across all GrIS basins, but with regional differences in magnitude. CESM underestimates runoff in the north (basin 1), north-east (basin 2) and east (basin 3) and this bias deepens with increasing resolution.

Next, we examine a number of atmospheric processes that could be driving the decreases in runoff. The results presented in Section 3.3.1 suggested that large-scale circulation changes are deemed to play a minor role. Still, temperature at the $700 \mathrm{hPa}$ pressure level (T700, linked to Greenland melt, e.g. Fettweis et al. [2013b]) is slightly lower in the VR-CESM simulations compared to Uniform CESM (Figure 3.10a). However, we note that the magnitude of this cooling does not match the much cooler surface temperatures (Figure 3.10b) and that the turbulent sensible heat flux is generally increased in VR-CESM, indicating that more heat is transferred to the surface in these simulations, not less (Figure S3 in Supplement of van Kampenhout et al. [2019]). We hypothesize that the lower T700 in VR-CESM could be caused by the colder surface, rather than the other way around.

Instead, we argue that the observed decrease in runoff is driven by a combination of two main factors, and several feedbacks that relate to them. The first driver relates to a general decrease in GrIS cloud cover in VR-CESM, the associated cooling in the longwave radiative spectrum, and the notion that the thermal effect of clouds is crucial in triggering the onset of melt [Bennartz et al., 2013; Van Tricht et al., 2016b; Cullather and Nowicki, 2018]. Figure 3.10c-e shows anomalies in VR-CESM surface elevation, cloud water path (CWP) and downwelling longwave radiation (LWd). The elevation anomalies appear similar in both VR-CESM55 and VR-CESM28, with lower surface topography over the ocean and near the margins of the island, and with higher surface elevations inland (Figure 3.10c). Due to the higher and steeper terrain near the margins, orographic uplift and condensation are enhanced leading to increased cloud water path (CWP, the vertically integrated mass of liquid water and solid ice contained in clouds) with a decreased CWP higher up (Figure 3.10d). There are some exceptions, e.g. in northeast Greenland where locally CWP is reduced over the margin and ocean as well. Either changes in meso-scale flow driven by local topography, or increased katabatic surface winds (Figure S2) are possible explanations for this. Due to the thermal effect of clouds, we find a strong correlation of LWd to CWP (Figure 3.10d-e). Both VR-CESM simulations show wide-spread decreases in LWd, including but not limited to the northern ablation zones, and we hypothesize that the onset of melt could be delayed in these sites. To some extent, LWd also correlates to skin temperature (Figure 3.10b), thereby providing a possible mechanism by which surface temperature are decreased in VR-CESM. We remark that the improved representation of topography, by itself, does not lead to surface cooling, since ECs in CLM already account for differences between atmospheric topography and the actual ice sheet elevation (Section 3.2.3). Both a lower skin temperature - affecting snow ageing - and a delayed onset of melt are relevant controls on surface albedo and the associated albedo feedback. Figure 3.10f reveals positive JJA albedo anomalies up to 0.2 or more in VR-CESM, suggesting that this feedback is indeed active on Greenland, with the caveat that this plot may be severely impaired in places where ocean and land are mixed at 1 degree resolution (i.e. Uniform CESM), leading to an artificial dipole pattern around the margins with negative anomalies over open ocean, and positive over land. The albedo feedback appears 


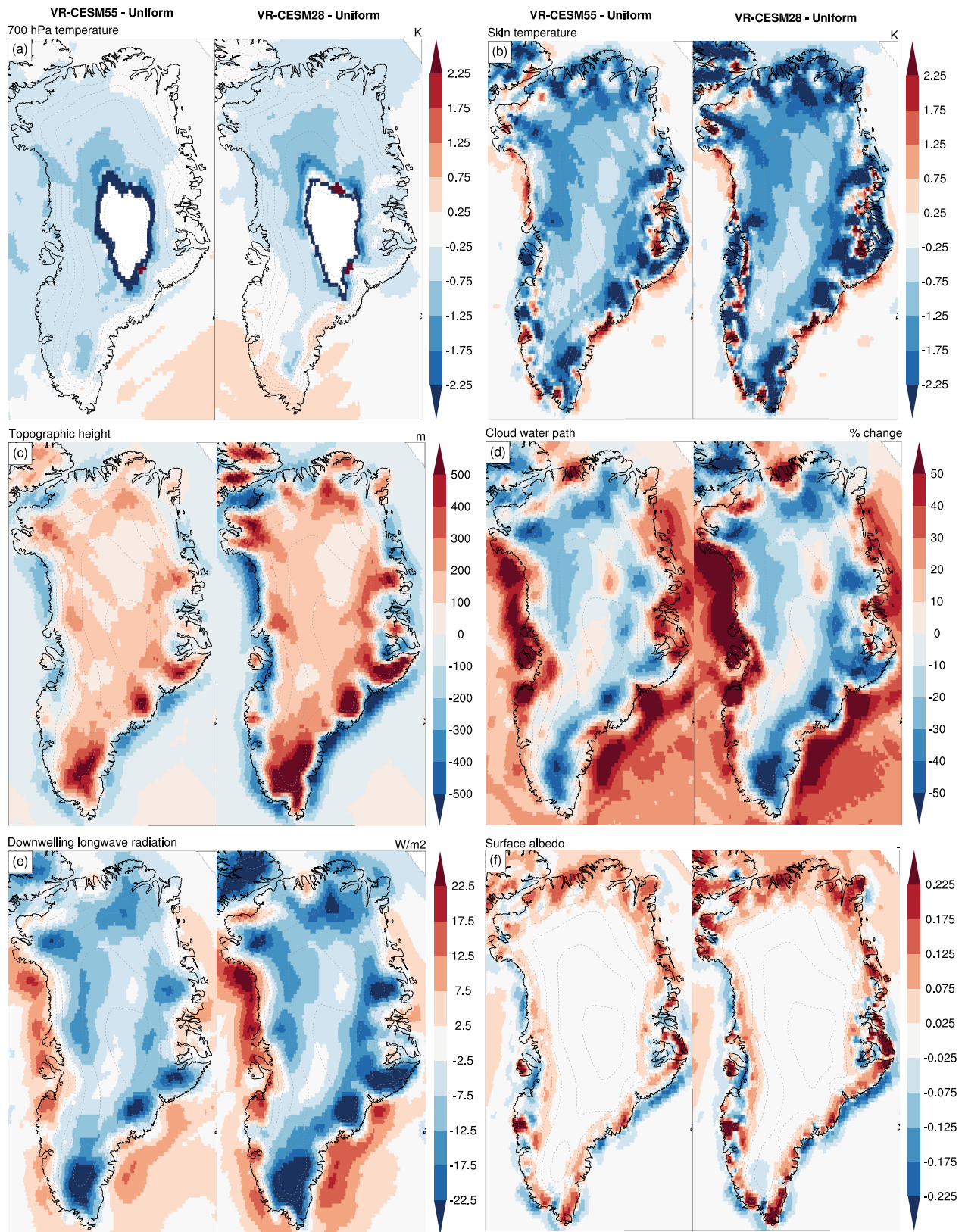

Figure 3.10: Summer (JJA) anomalies of atmospheric (CAM) variables over the period 1980-1999, relative to the coarse resolution reference simulation (Uniform CESM). Panel (a) 700 hPa air temperature $[K],(b)$ radiative skin temperature $[K],(c)$ CAM topographic height $[m],(d)$ cloud water path [\% change], (e) surface downwelling longwave radiation $\left[\mathrm{W} \mathrm{m}^{-2}\right],(f)$ surface albedo [-]. Prior to subtraction, all data have been regridded to a common regular mesh of $0.25^{\circ}$ using bi-linear interpolation. Therefore, these anomalies should be interpreted with some caution since they contain interpolations errors. The "sinking oceans" in panel (c) are explained by the smoothing operator applied to CAM topography, the imprint of which is much wider at low resolution than it is at high resolution (cf. Figure 3.2 and Section 3.2.2). 

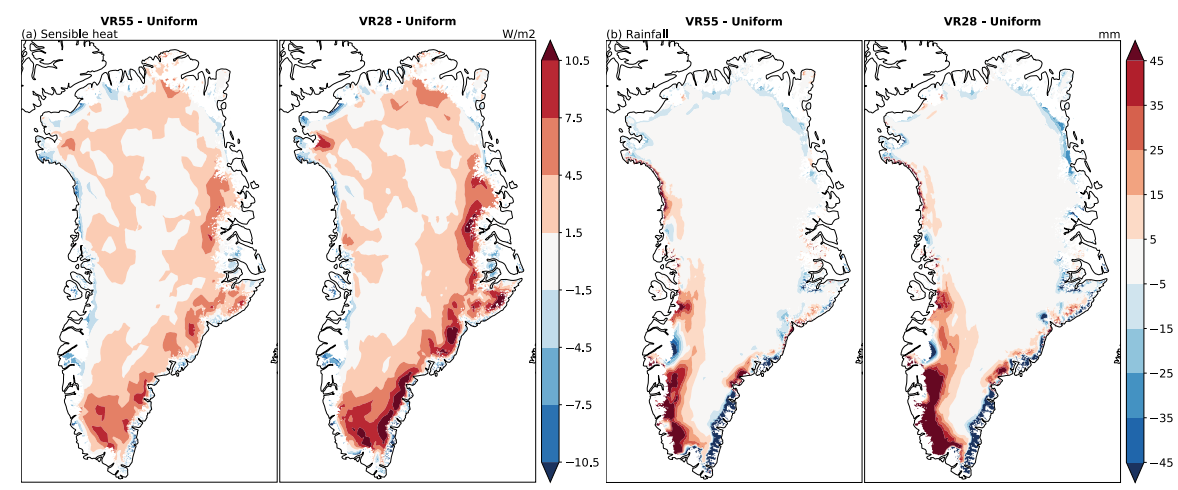

Figure 3.11: Summer (JJA) anomalies of (a) CLM sensible heat and (b) CLM rainfall over glaciated landunits, after downscaling, relative to the coarse resolution reference simulation (Uniform CESM) over the period 1980-1999. Data have been downscaled to 4 km using EC output.

to be active over the adjacent sea ice as well (Figure 3.10f), since the fraction of sea ice is prescribed in these simulations, but we did not further investigate this.

The second driver relates to the EC subgrid downscaling (Section 3.2.3), which is argued to be less effective at compensating atmospheric biases at high spatial resolutions. We recall that the EC method in CESM has two mechanisms targeted to increase melt in low-lying ablation zones, (1) a temperature lapse rate, which increases sensible heat transfer at low elevations, and (2) a downwelling longwave lapse rate, which does the same for LWd . Without these lapse rates, many GrIS ablation zones would not be resolved at all (Figure 3.3). The relevance of the EC downscaling depends, however, on the elevation variability actually present in a grid cell. Large variability (found at coarse grid spacing) means a sizeable difference between ablation zone and the grid cell mean elevation, leading to large corrections in sensible heat and LWd in low-lying ablation zones. Vice versa, a small variability in elevation (found at fine grid spacing) would lead to only minor corrections. Figure 3.11a depicts anomalies in downscaled sensible heat flux, and indeed we see a decrease in sensible heat over many low-lying ablation zones in VR-CESM, despite the higher grid cell means (Figure S3 in Supplement of van Kampenhout et al. [2019]). Detecting a similar EC fingerprint is harder for LWd, due to the large cloud-induced signals in the anomaly maps (Figure S4 in Supplement of van Kampenhout et al. [2019]). But besides these energy fluxes, another variable that is expected to be elevation dependent is rainfall, since the partitioning of snow and rain is recalculated in CLM based on temperature (Section 3.2.3) and temperature is EC-downscaled. Rainfall events add liquid water to the snow pack, thereby releasing latent heat, speeding up grain growth, and thus lower snow albedo [Oleson, 2013]. We find that rainfall is reduced in VR-CESM across many ablation zones (Figure 3.11b), notably in the north and east, and is therefore likely to play a role in the reduction of melt and runoff in these locations.

\subsubsection{Directions for further study}

Our results underscore the notion that modelling GrIS ablation zones is a challenging task for a GCM, and that increasing the spatial resolution alone does not necessarily improve model skill. This ties in with Bacmeister et al. [2014], who remarked that increasing horizontal resolution by itself does not lead 
to dramatically improved climate simulations, and must be accompanied by new cloud and convection parametrizations. Existing parameterizations in CAM were developed with specific spatial and temporal scales in mind, and contain assumptions that may break down at higher resolutions [Bacmeister et al., 2014]. Here, we shortly reflect on our findings from the previous sections and propose directions for future studies, with the aim of simulating a realistic Greenland surface climate at high spatial resolution.

Permanent snow cover over the northern tundras is a known model bias in this version of CESM and our results suggest that this bias worsens, rather than improves, on the VR refined grids (see e.g. 3.10f). This is an important model bias, with implications for surface temperature, albedo, and shortwave radiation over these areas (Figure S6-S8 in Supplement of van Kampenhout et al. [2019]), possibly underpinning or reinforcing a general cold bias in northern Greenland. This bias may carry over to the GrIS, where cold tundra air might contribute to the weak sensible heat flux in north Greenland when compared to RACMO2 (Figure S9 in Supplement of van Kampenhout et al. [2019] ), although different surface wind speeds (Figure S10 in Supplement of van Kampenhout et al. [2019]) play a role here as well. Further, it appears that the EC downscaling method is no longer effective in compensating for regional climate biases (Section 3.3.7) at higher resolutions, so future studies will need to address such climate biases directly.

On one hand, a further assessment of important atmospheric processes should be made, for instance the representation of super-cooled liquid clouds in CAM, and new parametrizations may be needed. Relevant metrics are cloud phase, frequency, and optical thickness. A recent study indicated that CAM5 simulates insufficient summer clouds when compared to observational data, in particular non-opaque liquid-containing clouds that have a strongly positive cloud radiative effect [Lacour et al., 2018]. Next to their radiative properties, clouds have large control over the amount and phase of precipitation. We note that the three CAM-SE experiments presented in this study seem to underestimate the magnitude of rainfall over north Greenland, when compared to RACMO2 (Figure S11 in Supplement of van Kampenhout et al. [2019]).

On the other hand, the representation of surface processes may need to be reviewed. There is reason to believe that the precipitation phase repartitioning currently implemented in CLM (Section 3.2.3) has a detrimental effect on the north Greenland simulation, where supercooled rain may be needed to darken snow and set off the melt-albedo feedback. Further, we note that CESM currently lacks drifting snow sublimation and erosion, which are important SMB factors in the relatively dry north of Greenland. To illustrate this, blowing snow was overestimated in a previous version of RACMO2 (RACMO 2.3p1) and caused too-wide ablation zones in the north [Noël et al., 2018]. The three CESM experiments presented here all simulate north Greenland ablation zones which appears too narrow (Figure 3.8), which could be due to such missing processes. CLM snow physics could be another point of future development, as RCM studies have highlighted the importance of water percolation and sensitivity of melt to irreducible water content [e.g., van Angelen et al., 2012].

\subsection{Summary and Conclusions}

For the first time, regionally refined GCM simulations using VR-CESM have been performed at 55 and $28 \mathrm{~km}$ over the greater Greenland region to study the impact of spatial resolution on GrIS SMB. 
Compared to a uniform resolution $\left(1^{\circ}\right.$ or $\sim 111 \mathrm{~km}$ ) control run, topography is resolved with greater fidelity, leading to improved patterns in orographic precipitation, most notably in southern Greenland and along the western and eastern margins. At the same time, a general drying in the GrIS interior occurs, which substantially improves correlations to IceBridge accumulation radar and in-situ measurements of accumulation. Arguably, VR-CESM performs on-par with RCMs in reproducing these observations, especially at $28 \mathrm{~km}$. GrIS integrated precipitation is reduced from 893 to $745 \mathrm{Gt}$ in VR-CESM28, which is within $6 \%$ of a best-estimate RCM figure ( $707 \mathrm{Gt}$ ). The improved distribution of accumulation may prove pivotal in transient simulations, as snowfall modulates the timing and strength of the snow-albedo feedback [Picard et al., 2012] and impacts ice advection.

In the ablation zone, the CESM simulations were evaluated using geographically sparse in-situ measurements. Despite its coarse resolution of $\sim 111 \mathrm{~km}$, we found that Uniform CESM reproduces these measurements to a reasonable degree, which represents a positive result for CESM at low resolution and suggests that the subgrid ECs are effective (Section 3.2.3, Figure 3.3). In both VR-CESM simulations, a positive SMB bias (i.e. too little ablation) developed in the ablation zone, which signals a regression. This was reflected in GrIS-integrated runoff, which was found to be substantially lower in VR-CESM55 and VR-CESM28 compared to Uniform CESM and RACMO2. A basins-by-basin analysis revealed that the largest reductions in runoff are found in the northern and eastern basins, with a fairly good agreement in the other basins. The decrease in runoff is argued to be driven by two independent factors: (1) substantial reductions in LWd are found over large parts of the GrIS due to cloud redistribution, which is likely to delay the onset of melt; (2) a higher spatial resolution implies lower topographic variability within a given grid cell, which renders the EC downscaling less effective in compensating for atmospheric biases in VR-CESM. Both these factors will induce the melt-albedo in a negative way, i.e. leading to higher albedo and further reduced melt, and are difficult to untangle from one another.

To conclude, our case study demonstrates that VR-CESM is a promising technique for dynamically downscaling GCM climate simulations over an Arctic region, while maintaining model consistency and allowing for feedbacks between the region of interest and the rest of the globe. A finer resolution leads to better resolved storms that are taking different pathways than their low-resolution counterparts, and therefore change precipitation and cloud cover patterns on a local scale. VR-CESM can serve as a tool for modellers that are interested in the dynamical response of the GrIS to future SMB changes, at a reasonable computational cost. At the time this manuscript was written, it was not possible to run VRCESM in coupled mode with an active ocean model. Still, high-resolution future projections of GrIS SMB could be generated using VR-CESM when high-frequency output from a fully-coupled scenario simulation is used as a boundary conditions at the sea surface. 


\section{4}

\section{Present-day Greenland ice sheet climate and surface mass balance in CESM2}

\section{Summary}

The response of the Greenland Ice Sheet (GrIS) to a warmer climate is uncertain on long time scales. Climate models, such as those participating in the Coupled Model Intercomparison Project phase 6 (CMIP6), are used to assess this uncertainty. The Community Earth System Model version 2.1 (CESM2) is a CMIP6 model capable of running climate simulations with either one-way coupling (fixed ice-sheet geometry) or two-way coupling (dynamic geometry) to the GrIS. The model features prognostic snow albedo, online downscaling using elevation classes, and a firn pack to refreeze percolating melt water. Here we evaluate the representation of the GrIS surface energy and mass balance (SEB and $\mathrm{SMB}$ ) in CESM2 at $1^{\circ}$ resolution with fixed GrIS geometry. CESM2 agrees closely with ERA-Interim reanalysis data for key controls on GrIS SMB: surface pressure, sea ice extent, $500 \mathrm{hPa}$ geopotential height, wind speed, and $700 \mathrm{hPa}$ air temperature. Cloudsat-CALIPSO data show that supercooled liquid-containing clouds are adequately represented, whereas comparisons to MODIS and CLARA-A2 data suggest that CESM2 underestimates surface albedo. The seasonal cycle and spatial patterns of SEB and SMB components in CESM2 agree well with regional climate model RACMO2.3p2, with GrIS-integrated melt, refreezing and runoff bracketed by RACMO2 counterparts at $11 \mathrm{~km}$ and $1 \mathrm{~km}$. Time series of melt, runoff, and SMB show a break point around 1990, similar to RACMO2. These results suggest that GrIS SMB is realistic in CESM2, which adds confidence to coupled ice sheet-climate experiments that aim to assess the GrIS contribution to future sea level rise.

This chapter is based on: van Kampenhout, L., Lenaerts, J. T. M., Lipscomb, W. H., Lhermitte, S., Noël, B., Vizcaíno, M., Sacks, W. J., and van den Broeke, M. R. Present-Day Greenland Ice Sheet Climate and Surface Mass Balance in CESM2. Journal of Geophysical Research: Earth Surface, 125(2):e2019JF005318, 2020. ISSN 2169-9011. doi: 10.1029/2019JF005318 


\subsection{Introduction}

The Greenland Ice Sheet (GrIS) is the Earth's second largest freshwater reservoir (after the Antarctic Ice Sheet), with the potential to raise global mean sea level by about $7.4 \mathrm{~m}$ were it to melt completely [Morlighem et al., 2017]. During 2012-2016, the GrIS lost $247 \pm 15 \mathrm{Gt} \mathrm{yr}^{-1}$, or $0.69 \pm 0.04 \mathrm{~mm}$ sea level equivalent (SLE) [Bamber et al., 2018b]. Mass loss is expected to increase in a warming climate [Church et al., 2013], with implications for global sea level rise, marine biology [e.g., Bamber et al., 2018a; Bhatia et al., 2013], and ocean circulation [Fichefet et al., 2003; Gerdes et al., 2006; Hu et al., 2012; Gillard et al., 2016; Böning et al., 2016]. A large uncertainty in future GrIS mass loss is the sensitivity of the surface mass balance (SMB) to atmospheric warming, with estimates ranging from 5 to $13 \mathrm{~cm}$ of SLE in 2100 under a high emissions scenario [Fettweis et al., 2013a]. Accurately representing ice sheet surface processes in global climate models, such as those participating in the Coupled Model Intercomparison Project phase 6 (CMIP6, Eyring et al. [2016]), could reduce this uncertainty and improve our understanding of feedbacks, for example with ocean circulation [Little et al., 2016; Fyke et al., 2018]. On centennial timescales, dynamic feedbacks become important, and ice sheet volume and extent must be modelled with a dynamical ice sheet model [Levermann and Winkelmann, 2016; Le clec'h et al., 2019]. This is recognised by the Ice Sheet Model Intercomparison Project for CMIP6 (ISMIP6), which provides protocols for coupled ice-sheet-climate model experiments [Nowicki et al., 2016]. The evolution of a dynamical ice sheet model is sensitive to the applied SMB [Khan et al., 2015], underscoring the need for a realistic representation of ice sheet surface climate and snow/firn properties in climate models.

The most realistic contemporary GrIS gridded SMB products originate from polar regional climate models (RCMs) forced by reanalysis data (e.g., MAR, Fettweis et al. [2017]; RACMO2, Noël et al. [2018]; and HIRHAM5, Langen et al. [2017]), an approach that is often referred to as "dynamical downscaling". These models usually operate at a high spatial resolution ( $\sim 10 \mathrm{~km}$ or less), have cloud physics tuned to polar conditions, and incorporate snow models that explicitly solve the evolution of grain size, albedo, density, liquid water percolation, and drifting snow [Lenaerts et al., 2012]. Fettweis et al. [2013a] forced the RCM MAR with climate model data from different global models and found a large spread in present-day and future SMB, with strong sensitivity to the applied external forcing. Their study highlights that external forcing biases - e.g., in $500 \mathrm{hPa}$ wind speed, wind direction, and 700 $\mathrm{hPa}$ temperature - can result in a GrIS SMB that is inconsistent with current best estimates. Regional consistency with reanalyses in these variables should therefore be an additional goal for global climate models, when used either to directly model GrIS SMB or for dynamic RCM downscaling.

Calculating SMB directly within the global model offers the advantage of performing long transient coupled ice-sheet-climate simulations within a single modelling framework, also in paleo configurations with large ice sheet domains [Ziemen et al., 2014]. Global models pose challenges in terms of unresolved physical processes, regional biases, and limited spatial resolution [Vizcaino, 2014; Fyke et al., 2018]. Nevertheless, some Earth system models (ESMs) now incorporate full energy-balance models and multi-layer snow models to calculate ice sheet surface melting in a physically realistic way [Punge et al., 2012; Cullather et al., 2014; Shannon et al., 2019; Alexander et al., 2019]. As noted by Rae et al. [2012], adequate energy-balance schemes are a critical prerequisite for modelling SMB realistically, with more detailed snow schemes agreeing better with observations than simpler models. Furthermore, some ESMs address the challenge of spatial resolution by using elevation tiles or elevation classes (ECs) that resolve SMB at multiple vertical levels within a single grid cell [Lipscomb et al., 
2013; Shannon et al., 2019]. The use of ECs is motivated by the observation that the SMB in ablation zones typically varies nonlinearly with height (due, for example, to the snow-albedo feedback). ECs can be essential for resolving narrow ablation zones in a coarse-resolution model [cf. Figure S1, van Kampenhout et al., 2019].

The Community Earth System Model version 1 (CESM1) was among the first ESMs to produce a realistic present-day GrIS SMB using (1) explicit calculation of snow albedo, (2) elevation classes, and (3) melt rates calculated through energy balance modelling [Vizcaíno et al., 2013; Sellevold et al., 2019]. CESM1 was not used, however, in coupled ice-sheet-climate experiments because the required infrastructure changes - specifically, dynamic landcover change with mass and energy conservation were not ready at the time. CESM1 had a number of physics limitations. For example, snow height was limited to a maximum of $1 \mathrm{~m}$ water equivalent (w.e.) which is insufficient to simulate firn and limits the refreezing capacity [Vizcaíno et al., 2014; Lenaerts et al., 2016]. Further, compensating errors were found in vertical gradients of snowfall, melt, and refreezing [Sellevold et al., 2019]. CESM version 2 (CESM2) aims to address these shortcomings. Most importantly, dynamic landcover is now operational [Lawrence et al., 2019] allowing two-way coupled ice-sheet-climate simulations, e.g. in the context of ISMIP6. Further, snowpack/firn physics have been improved, and the maximum firn depth has been increased to $10 \mathrm{~m}$ w.e. [van Kampenhout et al., 2017], which is relevant to GrIS SMB projections since firn can store and refreeze surface meltwater [van Angelen et al., 2013].

Here, we assess the skill of CESM2 in simulating GrIS SMB, with the goal of providing confidence in GrIS simulations and suggesting directions for future development. First, we use best-estimate reanalysis data to evaluate large-scale circulation patterns during the late 20th century (1979-1999). As explained above, consistency with present-day reanalysis data is a relevant goal for global models, since biases may lead to unrealistic SMB (or an SMB that is right for the wrong reasons), which will have implications for SMB projections under external forcing. Second, we use remotely sensed cloud water path observations to evaluate CESM2 clouds over Greenland, since clouds have a strong impact on the radiative budget at the surface [McIlhattan et al., 2017]. Of particular importance are liquid-bearing clouds, which are thought to be the leading cause of the extreme GrIS melt event in July 2012 [Bennartz et al., 2013; Van Tricht et al., 2016b], as well as other widespread melt events [Cullather and Nowicki, 2018]. Third, CESM2 surface albedo is evaluated using a combination of remotely-sensed data and RCM output. Finally, best-estimate RCM output is used to assess monthly-mean CESM2 energy and mass fluxes over the GrIS, with a focus on the seasonal cycle and spatial distribution. In order to account for the increased (vertical) detail that is obtained through ECs, we downscale CESM2 fluxes offline from each EC to the RCM grid.

The layout of the paper is as follows. Section 4.2 describes CESM2, with a focus on SMB computations and the EC method, and also details the experimental setup and the benchmark or reference data. Section 4.3 presents the main results, including a detailed model evaluation and a brief time series analysis. Section 4.4 reflects on the development process towards CESM2 and discusses directions for future development. Conclusions are found in Section 4.5.

\subsection{Methods}




\subsubsection{Model description}

CESM2 is a climate modelling framework that encompasses the Earth's major physical and biochemical components operating on decadal to centennial time scales, including the atmosphere, oceans, terrestrial systems, sea ice, and land ice. The public release of CESM2.1 in December 2018 included source code, forcing files for CMIP6 Diagnostic, Evaluation and Characterization of Klima (DECK) experiments, and scientifically validated configuration files. This is the version referred to here as "CESM2". Ocean dynamics and physics are modelled by the Parallel Ocean Program version 2 (POP2, updated from Smith et al. [2010]) and sea ice dynamics and physics by CICE, the Los Alamos Sea Ice Model [Hunke et al., 2015]. The atmospheric component is the Community Atmosphere Model version 6 (CAM6, Gettelman et al. [2019]) which features a new subgrid cloud parametrization [CLUBB, Bogenschutz et al., 2013], new cloud microphysics [Morrison-Gettelman (MG2), Gettelman and Morrison, 2014; Gettelman et al., 2014], and a new surface drag parametrization [Beljaars et al., 2004] that replaces the former Turbulent Mountain Stress scheme. The land surface component is the Community Land Model version 5 (CLM5), which contains many updated parametrizations and which introduces dynamic land units - a requirement for coupled ice-sheet-climate experiments [Lawrence et al., 2019].

Due to the global nature of CESM2, regional biases will likely remain. Relevant to our study is a bias in CAM6 that causes unrealistically high rainfall over the interior GrIS, similar to CAM4 [Vizcaíno et al., 2013], and may be due to incorrect cloud liquid-to-rain conversion rates for polar conditions. As rainfall is simulated even at very low $\left(<-20^{\circ} \mathrm{C}\right)$ near-surface temperatures, a bias correction was implemented into CLM to reduce the impact of rain on the mass and energy budget (e.g., on albedo). During a precipitation event, the phase of precipitation is recalculated by CLM, based on a near-surface temperature threshold that depends on the land cover type. Within each CLM grid cell, up to five different land cover types are simulated - natural vegetation, lake, urban, glacier, and crop - that each may be subdivided into multiple columns and patches. For all non-glacier land cover types, all precipitation is assumed to be snow below a near-surface temperature threshold of $0^{\circ} \mathrm{C}$, and rain above $2^{\circ} \mathrm{C}$. Between these threshold temperatures, a linear ramp is assumed. For the glacier land cover type, both the lower $\left(-2{ }^{\circ} \mathrm{C}\right)$ and higher threshold $\left(0{ }^{\circ} \mathrm{C}\right)$ are adjusted to allow for more glacier melt in summer. The physical justification for this difference is that atmospheric inversions are more common over glaciers than over other land cover types, such that atmospheric temperatures above the surface layer can above the melting point when temperatures are below freezing near the surface. Any heat released or taken up by the phase change of precipitation is accounted by adjusting the sensible heat flux to the atmosphere, to ensure energy conservation. Note that the phase change is not uni-directional, and there may be grid points or specific events where snow is converted into rain, for example in the lowest ECs where reference-height temperature is higher due to downscaling (see Section 4.2.4).

The last CESM2 component of interest to this study is the Community Ice Sheet Model 2.1 [CISM, Lipscomb et al., 2019], which solves the dynamics and thermodynamics of the ice sheet. CISM incorporates a hierarchy of (parallel) Stokes flow solvers: the shallow ice approximation; the shallow shelf approximation; a depth-integrated higher order solver; and a 3-D higher order solver. Parametrizations for basal sliding, iceberg calving and sub-ice-shelf melt are included as well. For the GrIS, CISM runs on a $4 \mathrm{~km}$ polar stereographic (Cartesian) grid on which it receives a downscaled temperature and SMB field from CLM when coupled within CESM2. CISM participated in the initMIP-Greenland study [Goelzer et al., 2018], the ISMIP6 standalone Greenland projections [Goelzer et al., 2020], and the 
two-way coupled ISMIP6 experiments [Nowicki et al., 2016]. In our study, however, CISM exclusively operates in one-way coupled mode, i.e. as a diagnostic component.

\subsubsection{Surface energy balance}

Surface energy balance (SEB) calculations over both ice sheets - and including Antarctic ice shelves are handled by CLM. The SEB equation may be written as follows [Greuell and Konzelmann, 1994]:

$$
\mathrm{F}_{\text {net }}=\mathrm{R}_{\mathrm{net}}+\mathrm{SHF}+\mathrm{LHF} \text {. }
$$

where $F_{\text {net }}$ is the net surface energy flux, $R_{\text {net }}$ is the net radiative flux, which is the sum of the net shortwave $\left(\mathrm{SW}_{\text {net }}\right)$ and net longwave $\left(\mathrm{LW}_{\text {net }}\right)$ fluxes, and SHF and LHF are the turbulent fluxes of sensible and latent heat, respectively, all defined positive towards the surface, i.e. downward. The net surface energy flux has two components, the conductive or ground heat flux (GHF) and the melt heat flux (MHF), which in CLM is computed separately for snow (variable FSM) and ice (variable QICE_MELT). The resulting SEB equation reads

$$
\mathrm{MHF}-\mathrm{GHF}=\mathrm{R}_{\mathrm{net}}+\mathrm{SHF}+\mathrm{LHF},
$$

where GHF is defined positive towards the surface, i.e. upward. Strictly speaking, Equations 4.1 and 4.2 represent the top few $\mathrm{cm}$ of snow or ice rather than an infinitesimally thin surface, since CLM allows for shortwave radiation penetration and subsurface melt.

The net shortwave flux $\mathrm{SW}_{\text {net }}$ depends on surface insolation $\left(\mathrm{SW}_{\mathrm{d}}\right)$ and effective surface albedo $(\alpha)$ :

$$
\mathrm{SW}_{\text {net }}=(1-\alpha) \mathrm{SW}_{\mathrm{d}}
$$

Ice albedo is assumed constant in space and time, and its value was modified in CESM2 to 0.5 in the visible and 0.3 in the near-infrared parts of the spectrum, based on a compilation of MODIS ice albedo values. (Values in CESM1 were 0.6 and 0.4, respectively.) Snow albedo is solved using the twostream, multi-layer SNow, ICe, and Aerosol Radiation (SNICAR) model, which accounts for radiation penetration, snow grain metamorphism, and snow impurities [Flanner and Zender, 2005; Flanner et al., 2007]. In CESM1, initial snow grain size was fixed to a constant value of $54.5 \mu \mathrm{m}$; this is a poorly constrained parameter that affects the strength of the albedo-melt feedback. In CESM2, initial grain size is a function of temperature, with larger grains at higher temperatures:

$$
d_{\text {initial }}=\left\{\begin{aligned}
54.5 \mu \mathrm{m} & \text { if } \mathrm{T}_{\text {ref }}<-30{ }^{\circ} \mathrm{C}, \\
\text { linear ramp } & \text { if }-30{ }^{\circ} \mathrm{C}<\mathrm{T}_{\text {ref }}<0{ }^{\circ} \mathrm{C} \\
204.5 \mu \mathrm{m} & \text { if } \mathrm{T}_{\text {ref }}>0{ }^{\circ} \mathrm{C}
\end{aligned}\right.
$$

with $\mathrm{T}_{\text {ref }}$ the temperature at the atmospheric reference height of $2 \mathrm{~m}$. This choice is informed by a remote sensing study using ICESat that indicates snow grain size ranges from 190 to $300 \mu \mathrm{m}$ over ice sheets [Yang et al., 2017], and is supported by an independent study suggesting that the original SNICAR formulation underpredicts grain size by about $160 \mu \mathrm{m}$ [Sandells et al., 2017]. 
The net longwave flux $\mathrm{LW}_{\text {net }}$ is calculated as:

$$
\mathrm{LW}_{\mathrm{net}}=\varepsilon \mathrm{LW}_{\mathrm{d}}-\varepsilon \sigma T_{\mathrm{rad}}^{4}
$$

with emissivity $\varepsilon$ (set to 0.97 over snow and ice), Stefan-Boltzmann constant $\sigma$, and radiative temperature $\mathrm{T}_{\mathrm{rad}}$. The assumption of grey body radiation with constant emissivity is not necessarily realistic - in particular in the polar regions [Kuo et al., 2018] - and therefore may need to be revised in the future. Finally, the turbulent fluxes SHF and LHF are calculated using Monin-Obukhov similarity theory, with a momentum roughness length of $10^{-2} \mathrm{~m}$ over ice and $2.4 \times 10^{-3} \mathrm{~m}$ over snow-covered surfaces, which is of the same order of magnitude as in the regional models MAR [Alexander et al., 2019] and RACMO2 $\left(1-5 \times 10^{-3} \mathrm{~m}\right)$. For further details on the SEB calculation, the reader is referred to the CLM Technical Documentation.

\subsubsection{Snow model and the computation of surface mass balance}

CLM5 incorporates a multi-layer snow model with up to 12 layers and a maximum snow/firn depth of $\mathrm{H}_{\max }=10 \mathrm{~m}$ water equivalent (w.e.). Snow layers can vary in height and prognostically evolve snow density, temperature, grain size, and impurities [Oleson, 2013]. During accumulation events, snow mass is advected downwards whenever a layer reaches its maximum height, and any excess snow in excess of $\mathrm{H}_{\max }$ is removed from the bottom. Liquid water is allowed to percolate and refreeze, and the irreducible water content for capillary retention is set to 3.3\% [Oleson, 2013]. Parametrizations for fresh snow density and snow compaction are updated in CESM2 and are described in van Kampenhout et al. [2017]. At typical ESM horizontal resolutions of $\sim 1^{\circ}$, sub-grid snow cover heterogeneity can be large due to subgrid topographic variability. Snow cover fraction is parameterized as a function of snow height and snow density following Swenson and Lawrence [2012], with uniform snow cover assumed when the snow pack exceeds $2 \mathrm{~m}$ w.e. in depth.

In most CESM2 configurations, as well as in this study, the dynamical ice sheet model CISM is active only as a diagnostic component, which implies that changes in ice volume are not considered by the coupled model. At its upper surface boundary, CISM is forced by temperature and SMB as calculated in CLM. A common definition of SMB in glaciology reads [e.g. van den Broeke et al., 2016; Lenaerts et al., 2019]:

$$
\mathrm{SMB}=\mathrm{PR}-\mathrm{RU}-\mathrm{SU}_{\mathrm{sfc}}-\mathrm{SU}_{\mathrm{ds}}-\mathrm{ER}_{\mathrm{ds}} .
$$

That is, SMB equals total precipitation ( $\mathrm{PR}$, snowfall plus rainfall) minus runoff (RU), sublimation at the surface $\left(\mathrm{SU}_{\mathrm{sfc}}\right)$, sublimation of drifting snow $\left(\mathrm{SU}_{\mathrm{ds}}\right)$, and drifting snow erosion $\left(\mathrm{ER}_{\mathrm{ds}}\right)$, all expressed in $\mathrm{mm}$ w.e. $\mathrm{yr}^{-1}$. If subsurface processes (such as refreezing) are considered, as is the case here, this definition is formally referred to as climatic mass balance [Cogley et al., 2011]. When used locally (i.e., not area-integrated), Equation 4.4 describes the specific SMB, and in that case accumulation is defined as $\mathrm{SMB}>0$, and ablation as $\mathrm{SMB}<0$. We note that drifting snow is not explicitly modelled in CESM2, so that $\mathrm{SU}_{\mathrm{ds}}=\mathrm{ER}_{\mathrm{ds}}=0$ throughout this paper. Further, the SMB calculated internally in CLM differs from Equation 4.4 altogether, and reads:

$$
\mathrm{SMB}=\mathrm{RU}_{\text {cap }}-\mathrm{RU}_{\text {ice }}-\mathrm{SU}_{\text {ice }}
$$

https://escomp.github.io/ctsm-docs/doc/build/html/tech_note/Fluxes/CLM50_Tech_ Note_Fluxes.html 
where $\mathrm{RU}_{\text {cap }}$ is the mass flux due to capping of excess snow, $\mathrm{RU}_{\text {ice }}$ is runoff due to bare ice melt, and $\mathrm{SU}_{\text {ice }}$ is sublimation from bare ice. When the snowpack reaches its maximum thickness $\left(H=H_{\max }\right)$ and precipitation falls, definition (4.5) is equivalent to definition (4.4), since the capping flux will equal the precipitation flux. When the snowpack is absent $(H=0)$ and ice melts, the two definitions are also equivalent, since the runoff flux RU equals the bare ice runoff flux $\mathrm{RU}_{\text {ice }}$. Differences occur when the snowpack gains or loses mass through accumulation or ablation. These changes are not taken into account by the CESM2 definition, which therefore yields SMB $=0$ in those cases. The reason for the distinct definition (4.5) in CLM is technical in nature, and relates to two-way coupled configurations with an active ice sheet model. One drawback of the CLM definition is that it prevents one from forcing an ice sheet model with a realistic SMB on sub-annual time scales, as pointed out by Lipscomb et al. [2013]. Future work is planned to adapt the computed SMB to include changes in snow mass, in agreement with the usual definition (4.4). We remark that, in the current study, the difference in SMB definition is largely irrelevant since most analysis is carried out for individual SMB components.

\subsubsection{Downscaling with elevation classes: online and offline}

Over glaciated surfaces, CLM employs a second method - elevation classes (ECs) - to account for subgrid topographic variability, in addition to the snow cover fraction parametrization described in the previous section. Within the glacier land cover type, the typical number of ECs is 10, each associated with a certain elevation bin and allowed to evolve independently of one another. The weight assigned to each EC is determined by the topography of an external high-resolution topographic map. Over Greenland, the elevation is provided by CISM at a resolution of $4 \mathrm{~km}$. In one-way coupled runs (i.e., the ice sheet is not evolving), CISM topography is assumed constant at observed values according to Morlighem et al. [2014], and is integrated into the CAM orography for consistency. Elevation classes with zero weight are marked "virtual" and do not contribute to the grid cell mean value of any state or flux. At $1^{\circ}$ resolution (finite volume), the mean EC topographic height over the GrIS and peripheral glaciers and ice caps (GICs) is $2085 \mathrm{~m}$. By contrast, mean CAM surface height is $1871 \mathrm{~m}$ over the same area, which shows that the use of ECs over Greenland increases the mean height by $214 \mathrm{~m}$ and thus cools the climate with respect to a simulation without ECs. This cooling might have implications for regional climate, such as increased sea ice cover in the North Atlantic [Sellevold et al., 2019].

Each EC, implemented as a CLM column, maintains independent elevation, soil/ice layers, snow layers, SEB, and SMB. Atmospheric temperature is downscaled to ECs using a constant lapse rate of $6{ }^{\circ} \mathrm{C}$ $\mathrm{km}^{-1}$, which falls into the range suggested by observational and model-based studies [Hanna et al., 2005; Fausto et al., 2009; Erokhina et al., 2017], but does not capture the seasonal cycle in lapse rate indicated by those same studies. Near-surface specific humidity is also downscaled, assuming that relative humidity is constant with elevation. New in CESM2 is an EC correction for $\mathrm{LW}_{\mathrm{d}}$ with a linear lapse rate of $32 \mathrm{~W} \mathrm{~m}^{-2} \mathrm{~km}^{-1}$, a value inferred from Van Tricht et al. [2016a] (their Figure 6). As no radiation should be added to (or removed from) the CLM grid cell mean, $\mathrm{LW}_{\mathrm{d}}$ is normalized after this downscaling. Also, to prevent extreme outcomes, the elevation correction is restricted to a maximum relative change of $50 \%$, i.e. $\mathrm{LW}_{\mathrm{d} \text {,downscaled }}$ is bounded by $[0.5,1.5] \cdot \mathrm{LW}_{\mathrm{d}, \mathrm{atm}}$.

Each EC resolves SMB according to Equation 4.5, resulting in a vertically resolved SMB that is subsequently downscaled by the CESM2 coupler to the high-resolution ice sheet grid by applying bilinear and linear interpolation in the horizontal and vertical directions, respectively. Along with the down- 
scaled ice surface temperature, this downscaled SMB serves as a boundary condition to CISM. Note that the downscaled fields sometimes contain artefacts due to grid-imprinting, examples of which we briefly discuss in the supporting information (Text S1, Supplement of van Kampenhout et al. [2020]). In case of two-way coupling, a global SMB normalization is applied to ensure mass conservation (for details, see https://escomp.github.io/cism-docs/cism-in-cesm/versions/release-cesm2. $0 / \mathrm{html} /$ index.html). Energy conservation is not an issue as there is no energy exchange between CLM and CISM. The EC infrastructure is not specific to CISM; any ice sheet model could potentially receive surface forcing through the CESM2 coupler infrastructure.

Alongside this online downscaling, EC-indexed variables in CLM can be analyzed directly, e.g. for evaluation purposes. In this study, EC-indexed SEB and SMB components are downscaled offline to an $11 \mathrm{~km}$ RCM grid for comparison compared to RCM output (Section 4.2.6). Our offline downscaling follows a two-step procedure, similar to the online downscaling. First, EC topography and variables of interest are bilinearly interpolated to the target grid. Then, the variable of interest is vertically downscaled towards the target elevation by using the 3D fields from the previous steps. No corrections are made to preserve area-integrated mass or energy, so these offline fluxes may differ from fluxes that were downscaled online.

\subsubsection{Description of the experiments}

The main dataset used in this paper originates from historical (1850-2014) coupled atmosphere-ocean experiments that were carried out using the finite-volume dynamical core at $\sim 1^{\circ}$ horizontal resolution $\left(0.9^{\circ} \times 1.25^{\circ}\right)$ for CMIP6. To limit the effect of decadal variability in the freely evolving CESM2 data - beyond the standard practice of taking 30-year climatologies - we calculate climatologies using a composite of six historical members named HIST-01 to HIST-06. Thus, over the reference period 19611990, a composite climatology is computed using a total of 180 model years. Climatologies are computed using grid cell mean output variables in both CAM and CLM. Whereas standard output is used for CAM variables, we only consider CLM variables that are specific to the glaciated part of the grid cell (i.e. variables that are suffixed_ICE). The 3-dimensional, EC-indexed CLM variables are not available in these six historical experiments since they are non-standard output. Hence, offline-downscaled data presented below (Sect. 4.2.4) are generated from another experiment: a dedicated CESM2 historical simulation (HIST-EC) that was branched off HIST-03 in the year 1950. The climatology from this experiment resembles the composite climatology, but follows a unique climate trajectory.

\subsubsection{Reference data}

Since the CESM2 climate evolves freely, it does not correspond to actual historical weather and climate, nor does it necessarily reproduce the correct phasing in modes of inter-annual and decadal climate variability [Hanna et al., 2018]. Polar RCMs forced by reanalyses, on the other hand, do reproduce historical meteorological observations and SMB measurements across the GrIS with increasingly good agreement [van den Broeke et al., 2016; Fettweis et al., 2017; Langen et al., 2017; Noël et al., 2018; Niwano et al., 2018]. In this study we choose to evaluate mean CESM2 climate and SMB by comparison to polar RCM output from the Royal Netherlands Meteorological Institute (KNMI) regional atmospheric climate model version 2.3p2 (RACMO2 hereafter), which has been extensively validated 
over the GrIS using in-situ measurements [Noël et al., 2018]. Mean climatological data are compared over 1961-1990, a period during which Greenland climate was relatively stable with no obvious trends in individual SMB components [Fettweis et al., 2013a; van den Broeke et al., 2016; Mouginot et al., 2019]. Along with the native $11 \mathrm{~km} \mathrm{RACMO} 2$ data, we use statistically downscaled data at $1 \mathrm{~km}$, which are more accurate in the GrIS ablation zones [Noël et al., 2016]. When compared to 182 SMB measurements from the GrIS accumulation zone, RACMO2 at $11 \mathrm{~km}$ yields an $\mathrm{r}^{2}$ of 0.85 , bias of -21.8 $\mathrm{mm} \mathrm{yr}^{-1}$, and RMSE of $71.7 \mathrm{~mm} \mathrm{yr}^{-1}$ (Noël et al. [2018], their Figure 11a), whereas a comparison at $1 \mathrm{~km}$ against 1073 ablation zone SMB measurements yields an $\mathrm{r}^{2}$ of 0.72 , bias of $120 \mathrm{~mm} \mathrm{yr}^{-1}$, and RMSE of $870 \mathrm{~mm} \mathrm{yr}^{-1}$ (Noël et al. [2018], their Figure 11c).

The large-scale climate in CESM2 is evaluated using ERA-Interim reanalysis data [Dee et al., 2011], which are the same data used to force RACMO2. ERA-Interim data are available only after 1979, so the period of evaluation is changed to 1979-1999 with no impact on the conclusions (not shown).

CESM2 cloud liquid water path (LWP) and ice water path (IWP) are evaluated using remotely-sensed Cloudsat-CALIPSO 2B-FLXHR-LIDAR algorithm products [Van Tricht et al., 2016b], available on a $2^{\circ}$ by $2^{\circ}$ grid [Van Tricht et al., 2016b]. The period for which data are available is 2007-2010, which does not overlap with the historical period (1961-1990) considered in CESM2.

Finally, CESM2 surface albedo is compared to two independent satellite-derived albedo products. The first product is the CM SAF Cloud, Albedo and Surface Radiation dataset from AVHRR (Advanced Very High Resolution Radiometer) data second edition (CLARA-A2, Karlsson et al. [2017]), which originates from the AVHRR sensor aboard polar-orbiting, operational meteorological satellites. The second product is the Moderate Resolution Imaging Spectroradiometer (MODIS) 16-day albedo version 6 product (MCD43A3v6), which was calculated by inverting surface reflectance measurements in MODIS instruments aboard NASA's Terra and Aqua satellites [Stroeve et al., 2013]. In contrast to Alexander et al. [2014] we use the integrated diffuse "white-sky" MODIS albedo rather than the direct beam "black-sky" albedo, since white-sky albedo is not dependent on the solar zenith angle and therefore is more fit for comparisons to models. Monthly climatologies are calculated for each product by averaging monthly 50th percentile (median) albedo over the period 2000-2017 (MODIS) and 2000-2015 (CLARA-A2).

\subsection{Results}

\subsubsection{Large-scale circulation: comparison to ERA-Interim}

Figure 4.1 compares CESM2 surface pressure, geopotential height at $500 \mathrm{hPa}$, and sea ice cover to dataassimilated equivalents in ERA-Interim. The dominant feature in both seasons is the polar vortex-a permanent low-pressure system located around the North Pole-which is stronger in winter than in summer (Figure 4.1a,d). The prevalent atmospheric flow over Greenland is southwesterly and is slightly more zonal in summer than in winter. Most moisture is delivered to the ice sheet by storms that originate in the North Atlantic [Sodemann et al., 2008], as evidenced by the climatological Icelandic Low, centered southwest of Iceland. Sea ice extent is typically greatest in March, extending into Baffin Bay and the Labrador Sea, and least in September, when sea ice is mainly confined to the Arctic basin. CESM2 

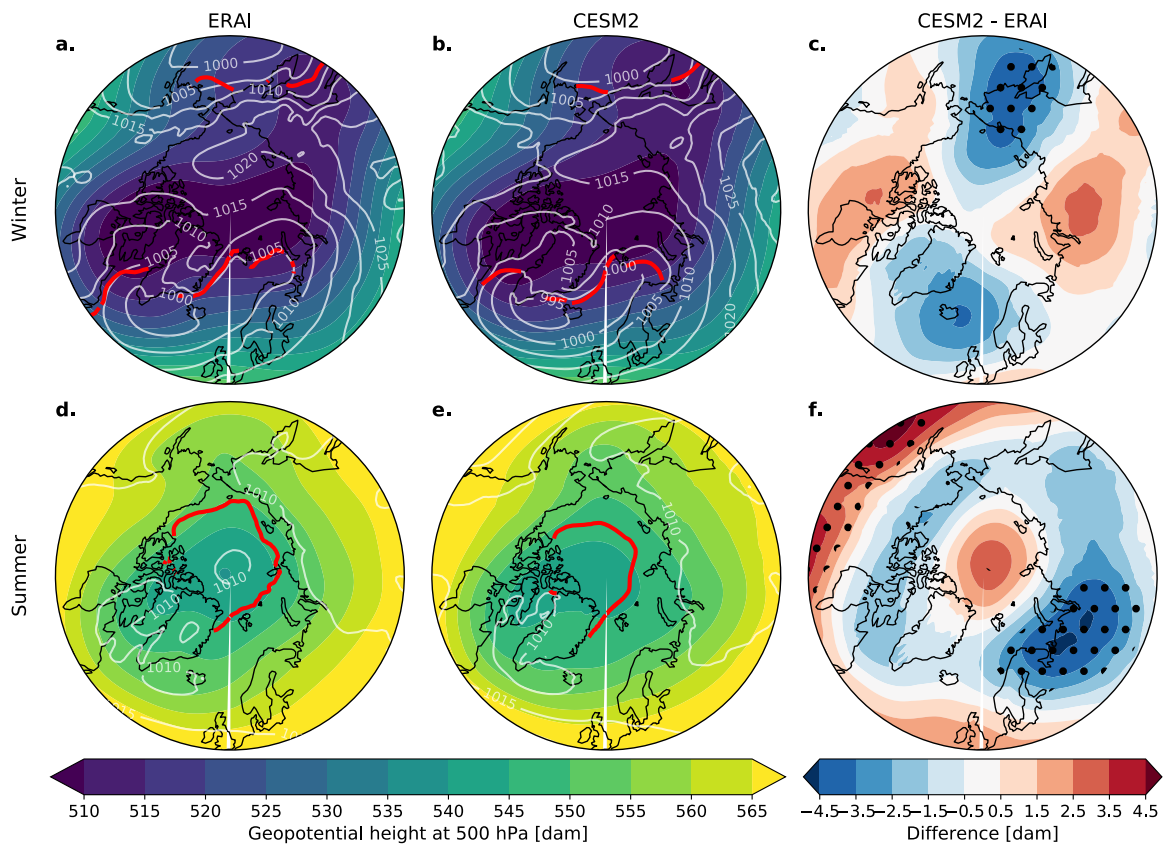

Figure 4.1: Mean geopotential height at $500 \mathrm{hPa}$ (shading, in dam), sea level pressure (white contours, in $\mathrm{hPa}$ ) and $50 \%$ sea ice cover (red contour) over the period 1979-1999 in a. ERA-Interim during December-January-February $(D J F), \boldsymbol{b}$. CESM2 during DJF, $\boldsymbol{c}$. difference, d. ERA-Interim during June-July-August (JJA), e. CESM2 during JJA, $\boldsymbol{f}$ difference. Sea ice cover (red contour) indicates the value for March (September) in boreal winter (summer), when Arctic sea ice extent is typically largest (smallest). For CESM2, a composite has been used of 6 historical members, i.e. the average was computed over 126 years of model data. Stippling indicates statistical significance $(p<0.05$ in $t$-test).

captures these general features of the regional climate in both winter and summer (Figure 4.1b,e). During winter, surface pressure (white contours) is lower in CESM2 (by $\sim 5 \mathrm{hPa}$ ) across the entire Arctic domain. In concert, the polar vortex extends further south around Iceland, leading to a negative geopotential height anomaly up to -4 decameter (dam, Figure 4.1c), which is not significant. In summer, the polar vortex is slightly weaker in CESM2, with its central geopotential height overestimated by 2 dam (Figure 4.1f), although the southward expansion of the polar vortex appears exaggerated. September sea ice extent is slightly underestimated in CESM2 (Figure 4.1e), but there is good agreement near Greenland, suggesting that substantial GrIS SMB biases due to sea ice biases are unlikely [Noël et al., 2014; Stroeve et al., 2017].

The $500 \mathrm{hPa}$ zonal wind speed (Figure S1 in Supplement to van Kampenhout et al. [2020]) generally decreases from mid-latitudes, where it is driven by the polar jet stream, towards the central Arctic, where meridional pressure differences are smaller (Figure S1a,d). CESM2 captures these general features of the zonal wind pattern (Figure S1b,e). During summer, there are significant anomalies in CESM2, with weaker winds across the High Arctic and stronger winds outside the Arctic, likely linked to the more widespread polar vortex in that season (Figure 4.1e). Zonal wind speeds are lower than observed over 

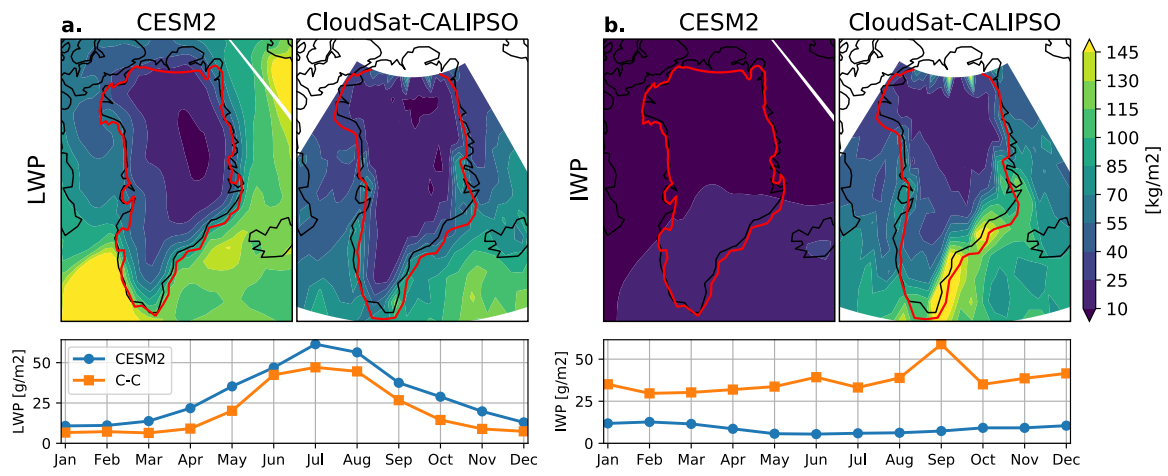

Figure 4.2: Annual mean liquid water path (LWP, $\boldsymbol{a})$ and ice water path $(I W P, \boldsymbol{b})$ in CESM2 and Cloudsat-CALIPSO [Van Tricht et al., 2016b]. CESM2 data represent a 6-member composite over the period 1980-1999 (120 model years), whereas Cloudsat-CALIPSO represents the period 2007-2010. The red line indicates the GrIS ice mask over which the climatology has been calculated (bottom plots), where the CESM2 mask is adjusted to match the limited Cloudsat-CALIPSO extent to the north.

northern Greenland in both seasons. There are few significant differences in the $500 \mathrm{hPa}$ meridional wind speed (Figure S2 in Supplement to van Kampenhout et al. [2020]), and none over Greenland.

Figure S3 (Supplement of van Kampenhout et al. [2020]) shows $700 \mathrm{hPa}$ temperature, a variable that is strongly tied to Greenland melt and runoff [Fettweis et al., 2013a,b]. Again, CESM2 succeeds in reproducing the spatial patterns and magnitude of the seasonal cycle in ERA-Interim (Figure S3a,b,d,e). In wintertime, however, CESM2 has a widespread warm bias $\left(1-2^{\circ} \mathrm{C}\right)$ across the Arctic and over Greenland (Figure S3c). During summertime, this warm bias is confined to the central Arctic Ocean, with cold anomalies of $\sim 1^{\circ} \mathrm{C}$ over Eurasia and the Canadian Arctic. We hypothesise that these cold anomalies are a thermal response to excessive summer snow cover (not shown), and we note that the negative bias does not extend over most of Greenland.

\subsubsection{Cloud water path: comparison to Cloudsat-CALIPSO}

Figure 4.2 compares modeled cloud LWP and IWP to Cloudsat-CALIPSO, and indicates that CESM2 simulates a substantial amount of liquid cloud throughout the year (Figure 4.2a). Integrated over the GrIS, the mean annual LWP is $29.9 \mathrm{~g} \mathrm{~m}^{-2}$, compared to $20.2 \mathrm{~g} \mathrm{~m}^{-2}$ in CloudSat-CALIPSO, an overestimation which is most pronounced in April-May and July-November. The overestimation is most pronounced over the southern part of the ice sheet, due in part to the crude representation of topography [van Kampenhout et al., 2019], and in part to a general overestimation of liquid cloud in the North Atlantic (Figure 4.2a). IWP, on the other hand, is underestimated in CESM2 compared to the observations (Figure 4.2b). CESM2 has few ice clouds over the GrIS throughout the year, with an annual mean IWP of $8.7 \mathrm{~g} \mathrm{~m}^{-2}$ compared to $37.2 \mathrm{~g} \mathrm{~m}^{-2}$ in CloudSat-CALIPSO. For the SEB and SMB, this persistent underestimation in IWP is deemed of secondary importance, given the limited sensitivity of longwave radiation to ice clouds compared to liquid clouds [Morrison et al., 2012]. 

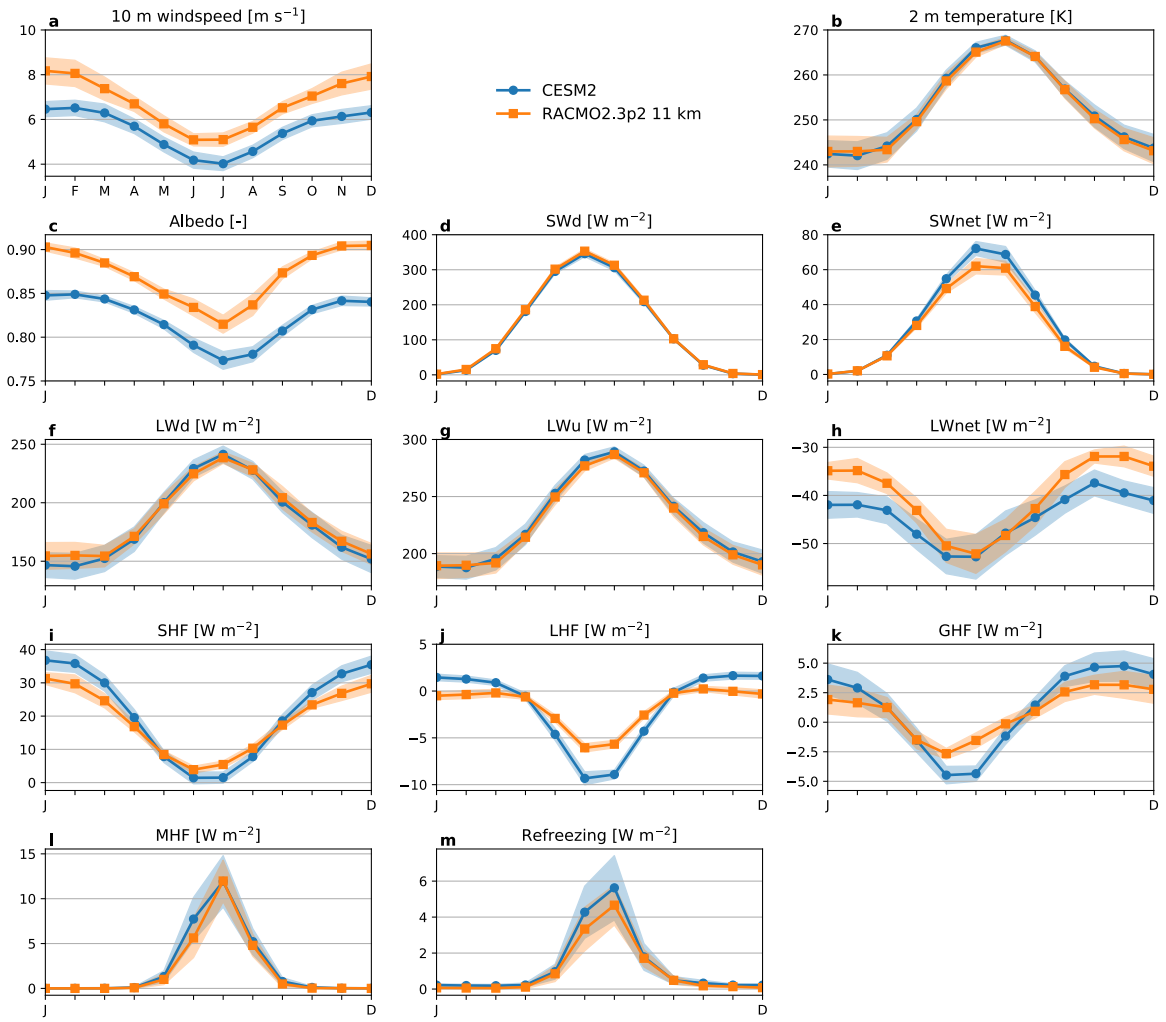

Figure 4.3: Seasonal cycle of GrIS-mean near-surface climate indicators and SEB components over the period 1961-1990. Shading indicates standard deviation in time. Panel a. $10 \mathrm{~m}$ wind speed, $\boldsymbol{b} .2 \mathrm{~m}$ temperature, $\boldsymbol{c}$. albedo, $\boldsymbol{b}$. downwelling shortwave radiation, $\boldsymbol{c}$. net shortwave radiation, $\boldsymbol{d}$. downwelling longwave radiation, $\boldsymbol{e}$. outgoing longwave radiation, $\boldsymbol{f}$. net longwave radiation, $\boldsymbol{g}$. sensible heat flux, $\boldsymbol{h}$. latent heat flux, $\boldsymbol{i}$. ground heat flux, $\boldsymbol{j}$. melt heat flux, and $\boldsymbol{k}$. refreezing heat flux. CESM2 data are specific to the glacier landunit within a grid cell, and represents a 6-member composite ( 180 model years). The averaging domain is the contiguous GrIS which has an area of $1,699,077 \mathrm{~km}^{2}$ (CESM2) and 1,693,317 $\mathrm{km}^{2}$ (RACMO2), respectively.

\subsubsection{Near-surface climate: comparison to RACMO2}

Figure 4.3a shows near-surface wind speed $\mathrm{U}_{10 \mathrm{~m}}$ averaged over the GrIS, in CESM2 and RACMO2. CESM2 reproduces the seasonal cycle of $\mathrm{U}_{10 \mathrm{~m}}$, although wind speed is underestimated throughout the year $\left(-1.2 \mathrm{~m} \mathrm{~s}^{-1}\right)$. The wind speed bias is attributed to the coarse spatial resolution in CESM2 - rather than its physics - as CAM has been found to better resolve strong katabatic flow over the steep ice sheet slopes at higher spatial resolution [van Kampenhout et al., 2019]. CESM2 captures the general spatial pattern of $U_{10 \mathrm{~m}}$, with wind speeds increasing between the GrIS interior and the margins (Figure 4.4a). Over the marginal tundra, where topographic gradients are smaller and the katabatic winds break down (Figure 4.4a, CESM2 simulates low wind speeds, a result that agrees with RACMO2. 


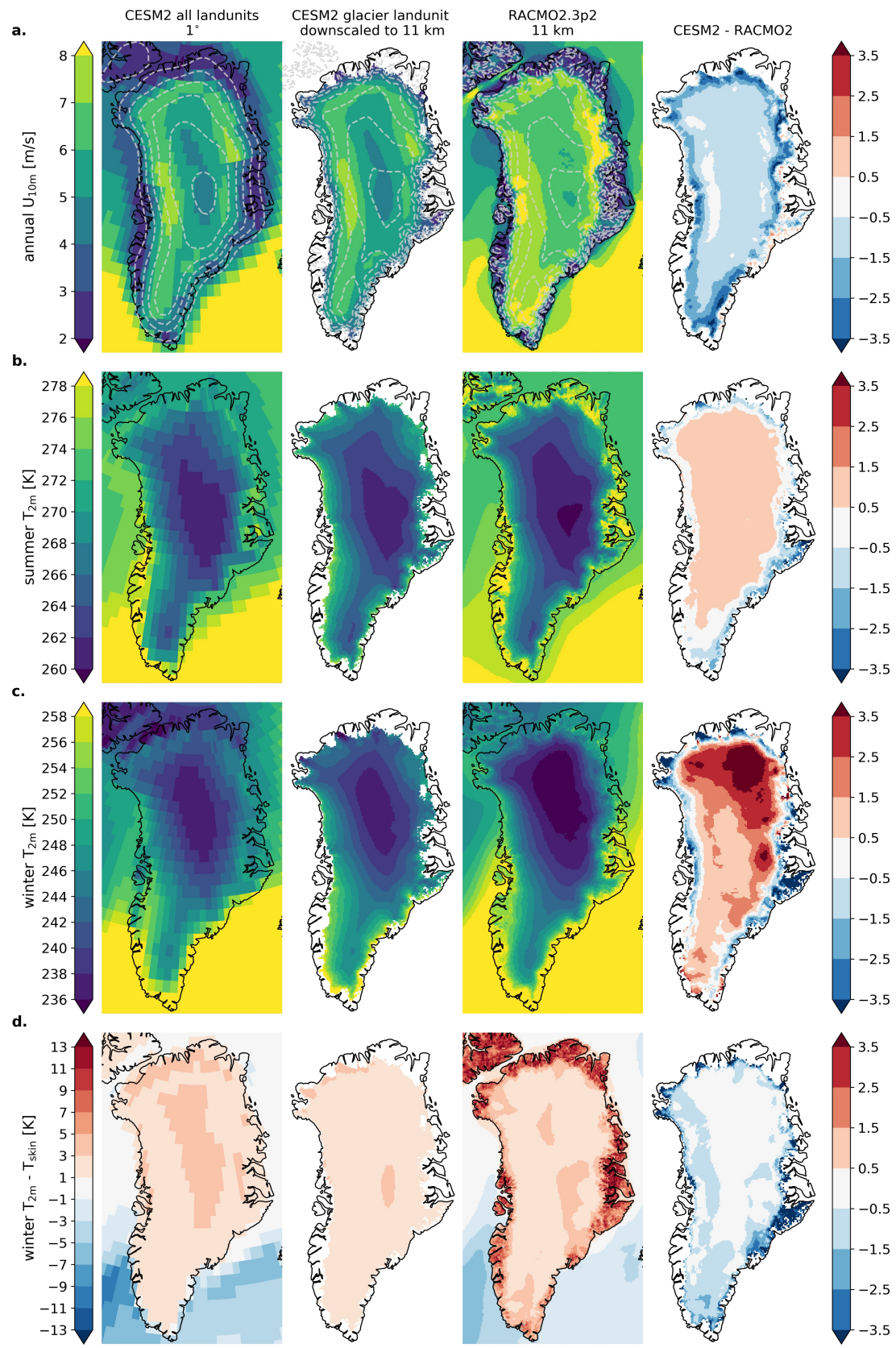

Figure 4.4: Comparison of CESM2 and RACMO2 near-surface climate, a. annual mean $U_{10 m}(m$ $\left.s^{-1}\right)$, b. JJA $T_{2 m}\left({ }^{\circ} \mathrm{K}\right), \boldsymbol{c}$. DJF $T_{2 m}\left({ }^{\circ} \mathrm{K}\right), \boldsymbol{d}$. DJF near-surface temperature gradient $\left({ }^{\circ} \mathrm{K}\right), T_{2 m}$ minus radiative skin temperature $T_{\text {skin. }}$. As $T_{\text {skin }}$ is not an output variable of CLM, it could not be downscaled. CESM2 data stem from a single historical member (HIST-EC) over the period 1961-1990, the same period over which the RACMO2 data are averaged. CESM2 data in the second column have been bilinearly downscaled to the $11 \mathrm{~km}$ RACMO2 grid using EC output over the glacier land cover type (Section 4.2.4). Model topography is shown at $500 \mathrm{~m}$ intervals (first row, dashed grey lines). 
Figure 4.3b shows GrIS-mean 2-m temperature $\mathrm{T}_{2 \mathrm{~m}}$ in CESM2 and RACMO2, and indicates good agreement between the two models. The simulated December-February (DJF) $\mathrm{T}_{2 \mathrm{~m}}$ in CESM2 is -30.4 ${ }^{\circ} \mathrm{C}$, which is $0.3^{\circ} \mathrm{C}$ lower than RACMO2, whereas the mean June-August (JJA) average is $-7.2^{\circ} \mathrm{C}$, which is $0.4^{\circ} \mathrm{C}$ higher (Table 4.1). However, no correction has been applied for topographic height, which may be relevant since $T_{2 m}$ depends strongly on elevation. Mean GrIS topography in CESM2 is $2156 \mathrm{~m}$ (CLM variable TOPO_COL), which exceeds that of RACMO2 $(2119 \mathrm{~m})$ by $37 \mathrm{~m}$, because of the subgrid tiling with ECs in CESM2 (see Section 4.2.4). This suggests that a positive correction of +0.22 ${ }^{\circ} \mathrm{C}$ should be applied to the CESM2 $\mathrm{T}_{2 \mathrm{~m}}$ means to account for this difference in elevation, assuming a lapse rate of $6^{\circ} \mathrm{C} \mathrm{km}^{-1}$.

A map of downscaled $\mathrm{T}_{2 \mathrm{~m}}$ during JJA is shown in Figure $4.4 \mathrm{~b}$ and compared to RACMO2. The spatial correlation between the two models is high over the GrIS $\left(r^{2}=0.97\right.$, Table 4.1). CESM2 is slightly warmer than RACMO2 in the interior, and colder near the margins, with the largest absolute differences along the northern and eastern margins (Figure 4.4b). Our current understanding is that CESM2 fails to simulate the tundra micro-climate well and allows perennial snow to build up, leading to a permanent summer cold bias (Figure S4 in Supplement of van Kampenhout et al. [2020]) which may feed back to the ice sheet. Although RACMO2 predicts a snow-free tundra in summer, this may be for the wrong reasons. RACMO2 uses the simplified surface scheme of ERA-Interim [Dutra et al., 2010] over bare land grid cells, with a single snow layer that does not allow for meltwater percolation or refreezing, and a simplified albedo formulation [Ettema et al., 2010]. In CESM2, a multi-layer snow model is used over both tundra and ice sheet, an approach which is more physically realistic but also prone to biases.

Figure $4.4 \mathrm{c}$ shows $\mathrm{T}_{2 \mathrm{~m}}$ during DJF. There are strong positive anomalies relative to RACMO2 in the interior, especially towards the north where anomalies exceed $3{ }^{\circ} \mathrm{C}$, whereas the margins have negative anomalies $\left(<-3^{\circ} \mathrm{C}\right.$ locally). The overall root mean squared error (RMSE) is $2.3^{\circ} \mathrm{C}$ (Table 4.1). The positive anomalies could be induced by large-scale circulation, as CESM2 is slightly warmer at 700 $\mathrm{hPa}$ than ERA-Interim (Figure S3a,b), or could relate to clouds. The negative $\mathrm{T}_{2 \mathrm{~m}}$ anomalies near the margins are probably caused by the coarse $1^{\circ}$ resolution in CESM2, which mixes in cold air prevailing over the tundra (leftmost panel in Figure 4.4c). Indeed, DJF $\mathrm{T}_{\text {skin }}$ has much less widespread negative anomalies (Figure S5). The cold tundra air at reference height may in turn be explained by the poor representation of strong inversions in stable boundary layers in CESM2, which are ubiquitous during the polar night over flat surfaces [e.g., Vignon et al., 2018]. As a proxy for the near-surface inversion strength, Figure $4.4 \mathrm{~d}$ shows $\mathrm{T}_{2 \mathrm{~m}}-\mathrm{T}_{\text {skin }}$. Over the principally flat tundra surface, RACMO2 simulates strong inversions $\left(>10^{\circ} \mathrm{C}\right)$ which CESM2 does not capture, presumably due to its limited vertical resolution. The midpoint of the lowest atmospheric layer in CAM6 lies at $993 \mathrm{hPa}$ with a reference pressure of $1000 \mathrm{hPa}$, i.e. about $60 \mathrm{~m}$ above the surface.

\subsubsection{Albedo and surface energy balance components}

Next, we evaluate GrIS surface albedo and SEB components (Equation 4.2) with a focus on summer, when the majority of meltwater is produced. Figure 4.5 shows July surface albedo in CESM2, MODIS, CLARA-A2, and RACMO2. We expect higher albedo in the models since the satellite products do not account for variations in zenith angles and cloudy conditions. This is true for RACMO2, which shows higher surface albedo over the majority of the GrIS, with an average anomaly of 0.06 relative to MODIS (Figure 4.5a). CESM2, on the other hand, simulates surface albedo which is not substantially higher 


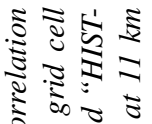

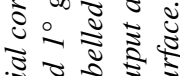
ป ะ

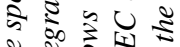

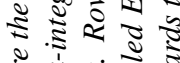

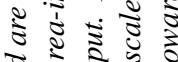
ป ะ ह .) ค่ ภำ $\frac{1}{6}=\mathbb{2}$ ำ ․․ำ का

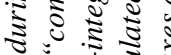

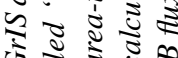
ปิ)

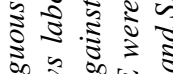

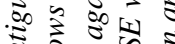

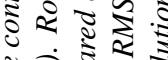

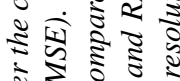
วิ

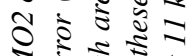

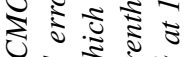
इ

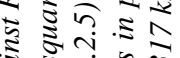
छ $-5 \leqslant 52$ $\Xi \Xi x^{\circ}-$

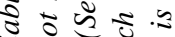

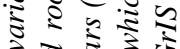
ป⿱一𫝀)

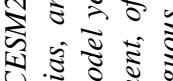
$0: 5 \cong$

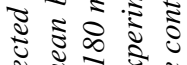
ป इ

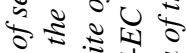

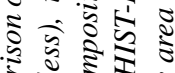

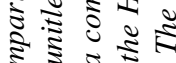

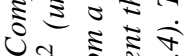

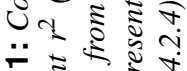

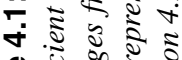

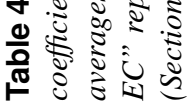

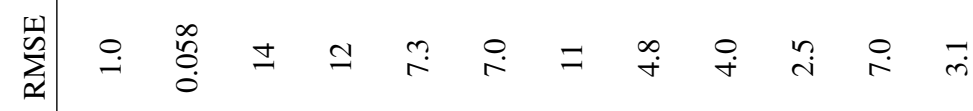

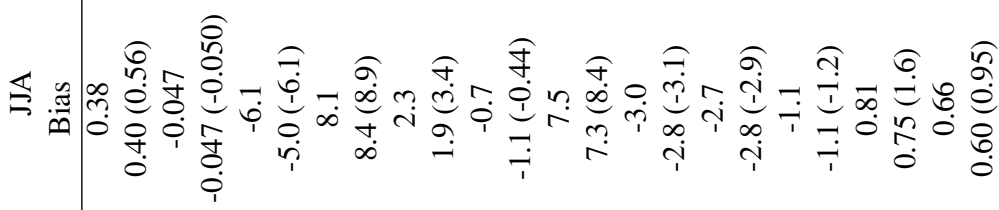

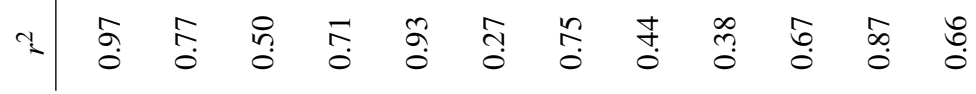

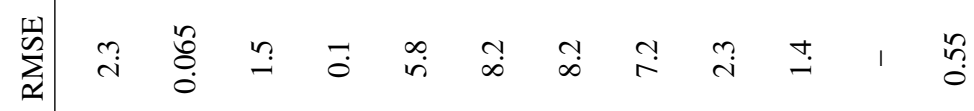

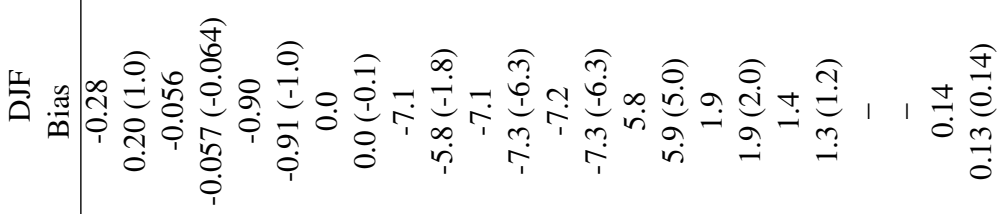
丩 参

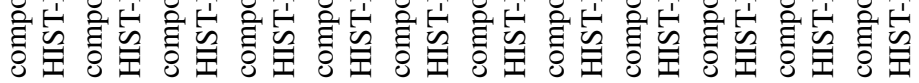

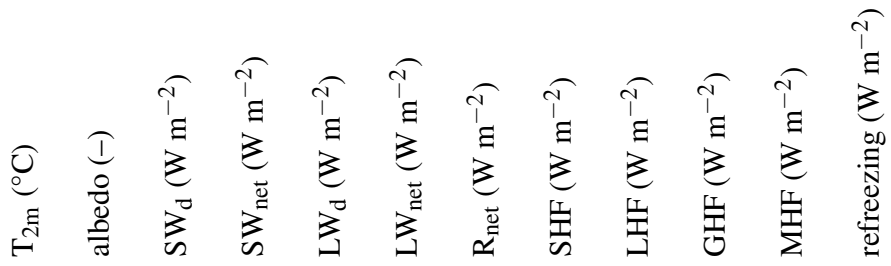




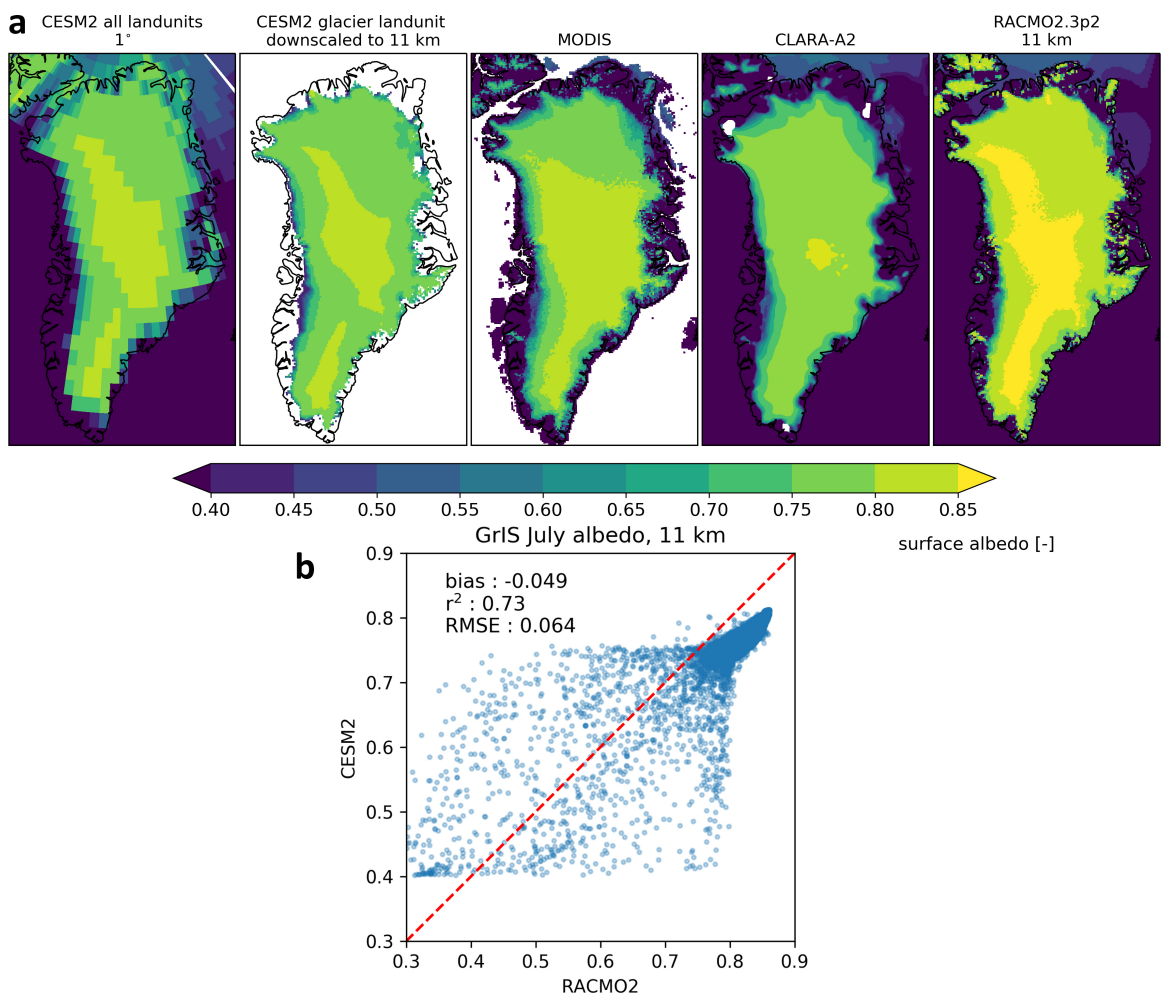

Figure 4.5: a. July surface albedo from models and satellite products. CESM2: all-sky albedo from member HIST-EC, 1961-1990 average; MODIS: white-sky albedo from MCD43A3 product, 20002017 median [Stroeve et al., 2013]; CLARA-A2: black-sky albedo, 2000-2015 median [Karlsson et al., 2017]; RACMO2: all-sky albedo, 1961-1990 average. As described in the main text, model albedo should exceed remotely sensed albedo due to missing corrections in the latter. Uncertainty is added by the use of different averaging periods due to recent trends in GrIS albedo [Alexander et al., 2014]. b. Scatter of downscaled CESM2 albedo against RACMO2 at $11 \mathrm{~km}$, restricted to ice sheet pixels.

than the remote sensing products, and simulates a lower albedo than RACMO2 year-round (Figure 4.3c). The correlation in the high-albedo accumulation zone is fairly good, as illustrated by Figure 4.5b, but in the lower-albedo ablation zone there is a wide spread, suggesting that RACMO2 and CESM2 locate ablation zones differently. The overall spatial correlation is $r^{2}=0.77$ in JJA (Table 4.1). The high albedo values over the northern tundra regions are due to the excessive tundra snow cover in CESM2, as discussed in Section 4.3.3.

The discrepancy in albedo explains why GrIS-wide $\mathrm{SW}_{\text {net }}$ is higher in CESM2 than RACMO2, even though summer insolation is slightly lower in CESM2 (Figure 4.3d-e). Averaged over JJA, the ice sheet surface in CESM2 receives $6 \mathrm{~W} \mathrm{~m}^{-2}$ less shortwave radiation, yet absorbs $8 \mathrm{~W} \mathrm{~m}^{-2}$ more (Table 4.1). Figure 4.6a shows that CESM2 simulates less insolation around the ice sheet margins, where ablation zones are located, and across the southern dome, with local differences exceeding $-25 \mathrm{~W} \mathrm{~m}^{-2}$. On the other hand, CESM2 simulates more insolation across the northern interior $\left(2-10 \mathrm{~W} \mathrm{~m}^{-2}\right)$, and 


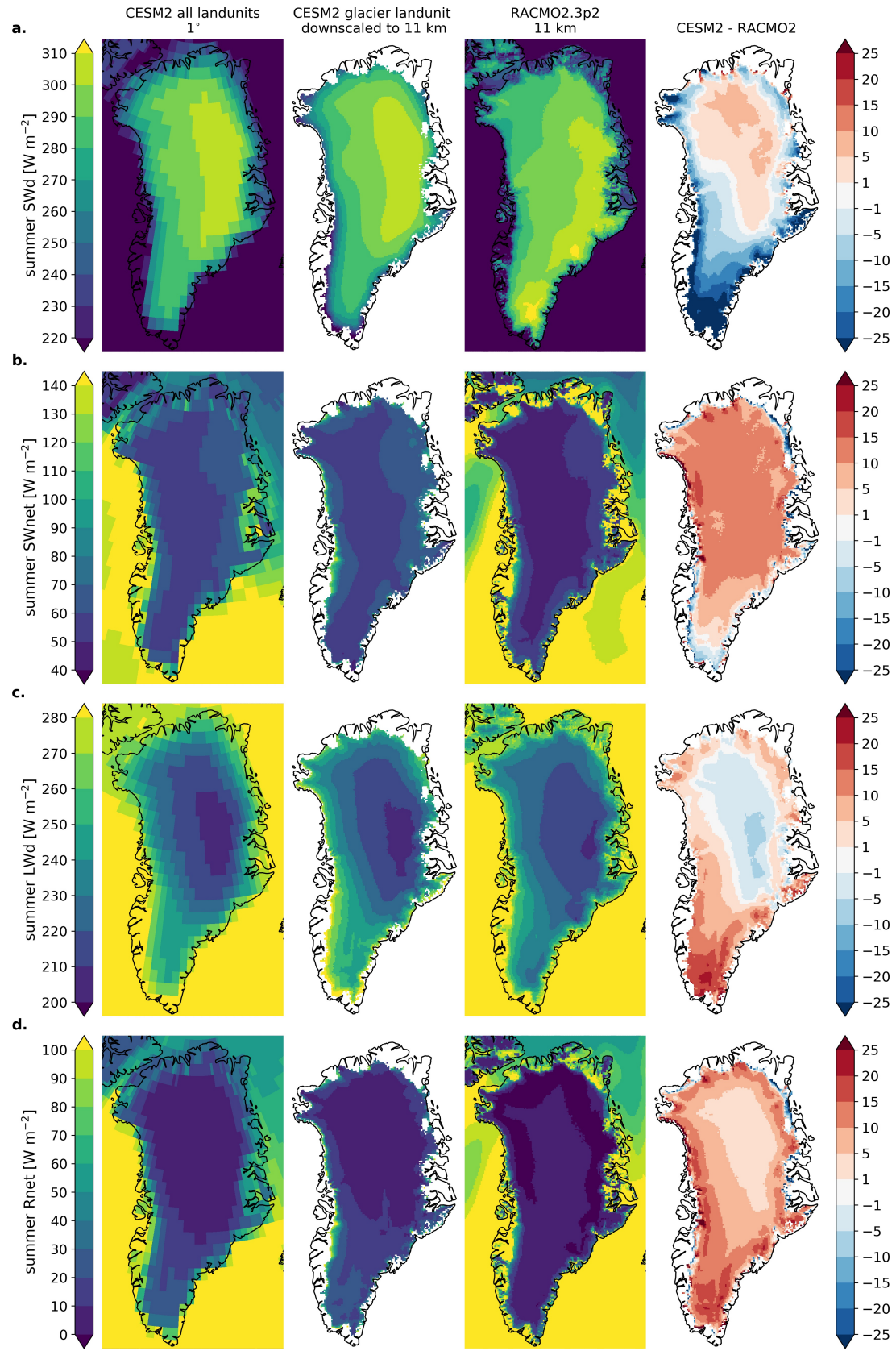

Figure 4.6: Comparison of CESM2 and RACMO2 radiative surface energy fluxes in JJA, a. downwelling shortwave radiation, $\boldsymbol{b}$. downwelling longwave radiation, $\boldsymbol{c}$. net shortwave radiation, $\boldsymbol{d}$. net longwave radiation. Data as in Figure 4.4. 
these anomalies are explained by cloud frequency and cloud optical thickness. CESM2 has different cloud microphysics than RACMO2, and runs at a coarser spatial resolution which spatially smooths orographic uplift, condensation, and therefore cloud formation. Indeed, CAM cloud cover over the southern dome is substantially decreased at higher spatial resolutions [van Kampenhout et al., 2019]. At the same time, it should be noted that the physics of polar cloud formation is notoriously difficult to model. Even regional models struggle to accurately simulate $\mathrm{SW}_{\mathrm{d}}$, as indicated by a recent comparison of RACMO2.3p2 data to 42,456 daily in-situ measurements which resulted in an RMSE of $27 \mathrm{~W} \mathrm{~m}^{-2}$ and a bias of $3.8 \mathrm{~W} \mathrm{~m}^{-2}$ [Noël et al., 2018].

Due to its lower albedo, CESM2 simulates greater $\mathrm{SW}_{\text {net }}$ across most of the island (Figure 4.6b). Notable exceptions include the far south, where insolation is substantially lower (Figure 4.6a), and some ablation areas such as the north-eastern GrIS, where CESM2 does not expose enough bare ice. The opposite can also be observed. For instance, large $\mathrm{SW}_{\text {net }}$ anomalies exceeding $20 \mathrm{~W} \mathrm{~m}^{-2}$ along the northwestern margin indicate ablation zones in CESM2 which are not present in RACMO2.

Figure 4.3f-h shows the GrIS-average seasonal cycle in $\mathrm{LW}_{\mathrm{d}}, \mathrm{LW}_{\mathrm{u}}$, and $\mathrm{LW}_{\text {net }}$ in the CESM2 composite and RACMO2, generally indicating good agreement. One striking difference is the lower $\mathrm{LW}_{\text {net }}$ in CESM2 during winter $\left(-7 \mathrm{~W} \mathrm{~m}^{-2}\right)$, which is matched by a similar anomaly in $\mathrm{LW}_{\mathrm{d}}\left(-7 \mathrm{~W} \mathrm{~m} \mathrm{~m}^{-2}\right.$, Table 4.1). Figure 4.6c shows the spatial distribution of $\mathrm{LW}_{\mathrm{d}}$ in HIST-EC. As a result of longwave radiation EC corrections (Section 4.2.4), strong gradients can be observed near the margins in the downscaled CESM2 product. Overall, the JJA spatial correlation to RACMO2 is much higher $\left(r^{2}=0.93\right)$ than that in $\mathrm{SW}_{\mathrm{d}}\left(r^{2}=0.50\right.$, Table 4.1), which may be partly attributed to the longwave downscaling. Further, the $\mathrm{LW}_{\mathrm{d}}$ anomaly pattern is similar to $\mathrm{SW}_{\mathrm{d}}$ in reverse (Figure 4.6c) which suggests that these differences are driven by the same mechanism. Indeed, whereas clouds reflect and scatter solar radiation back to space, and thus have a cooling effect in the shortwave part of the spectrum, they absorb thermal radiation and have a warming effect in the longwave part. An obvious example is the southern GrIS, where an excess cloud cover leads to both a negative anomaly in $\mathrm{SW}_{\mathrm{d}}$ (Figure 4.6a) and a positive anomaly in $\mathrm{LW}_{\mathrm{d}}$ (Figure 4.6c).

Adding the shortwave and longwave radiation, we find that CESM2 simulates a larger net radiative flux in summer (+7.5 $\mathrm{W} \mathrm{m}^{-2}$, Table 4.1) almost everywhere across the GrIS (Figure 4.6d). In most locations, $\mathrm{R}_{\text {net }}$ anomalies are dominated by positive $\mathrm{SW}_{\text {net }}$, except in the south, where the longwave anomalies are more pronounced (Figure 4.6b,c). Negative $R_{\text {net }}$ anomalies are found in some ablation areas, notably the northeastern GrIS (Figure 4.6d). The spatial correlations of $\mathrm{SW}_{\text {net }}, \mathrm{LW}_{\text {net }}$, and $\mathrm{R}_{\text {net }}$ are $r^{2}=0.71, r^{2}=0.27$, and $r^{2}=0.75$, respectively (Table 4.1 ). The low spatial correlation of $\mathrm{LW}_{\text {net }}$ is attributed to its weaker dependency on elevation and latitude.

The seasonal cycles in the non-radiative SEB terms (SHF, LHF, GHF, and MHF) are averaged over the GrIS and shown in Figures 4.3i-l. The seasonal cycles of these fluxes are generally similar between the two models, but some differences remain. For instance, SHF is higher in CESM2 during DJF (+6 W $\mathrm{m}^{-2}$ ) which we interpret as a compensating effect for the lower $\mathrm{R}_{\text {net }}$ in these months $\left(-7 \mathrm{~W} \mathrm{~m}^{-2}\right.$, Table 4.1). The radiative deficit may also explain the slightly elevated GHF in winter $\left(+1 \mathrm{~W} \mathrm{~m}^{-2}\right)$, indicating more heat conduction towards the surface in CESM2. In contrast, a radiative surplus in CESM2 during

Figure 4.7 (following page): Comparison of CESM2 and RACMO2 non-radiative surface energy fluxes in JJA, a. sensible heat flux, $\boldsymbol{b}$. latent heat flux, $\boldsymbol{c}$. ground heat flux, $\boldsymbol{d}$. melt heat flux, $\boldsymbol{e}$. refreezing flux. Data as in Figure 4.4 and note the different colour scales in $\boldsymbol{d}$ (non-linear) and $\boldsymbol{e}$. 

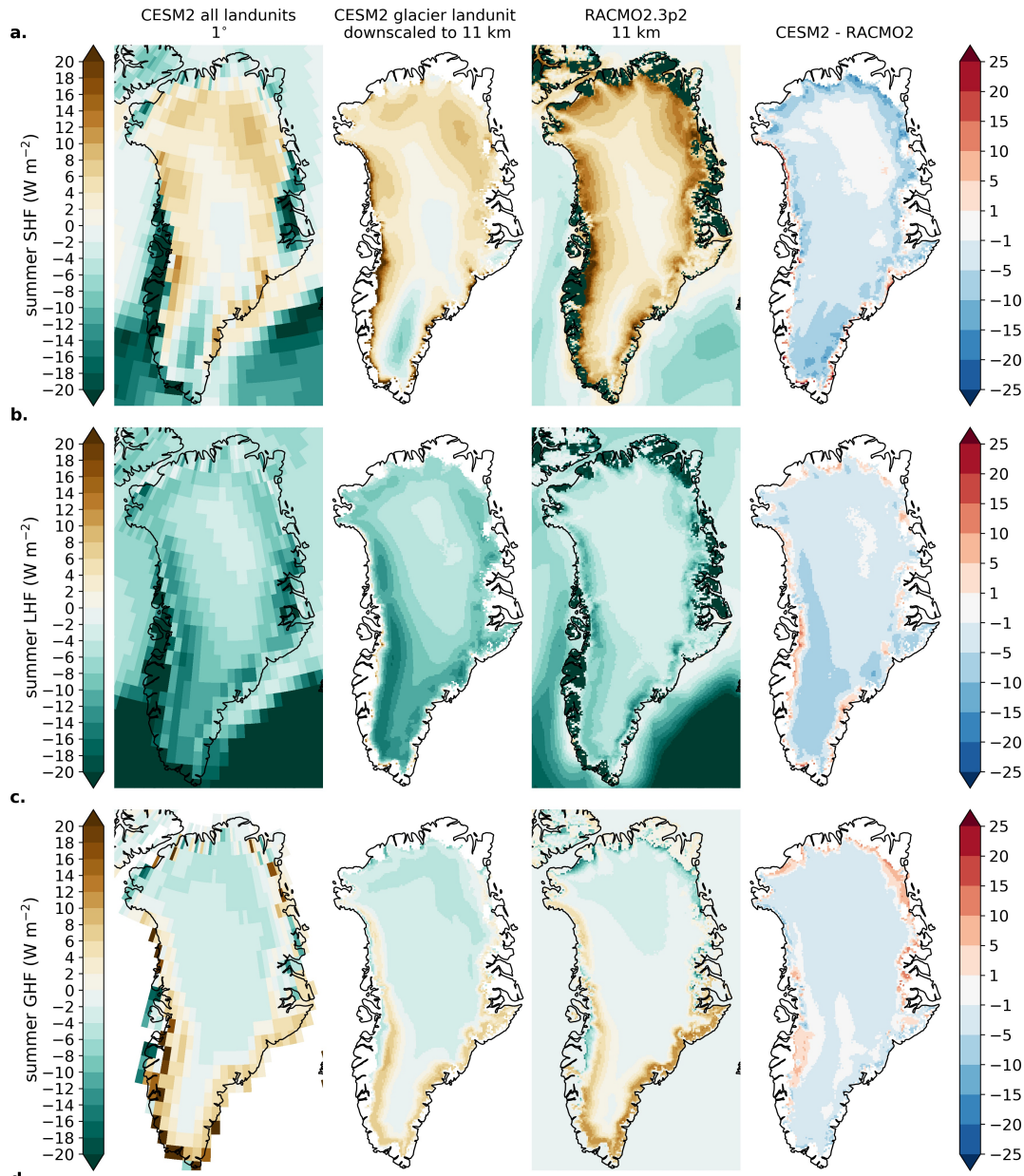

d.
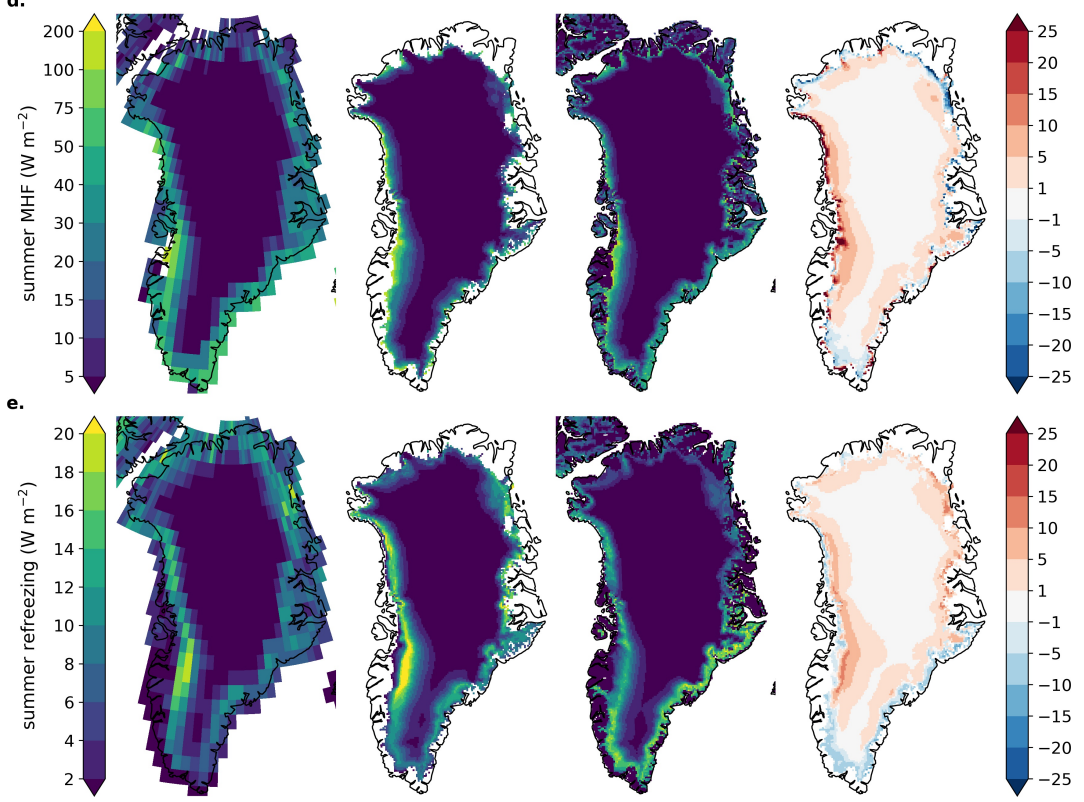
JJA $\left(+8 \mathrm{~W} \mathrm{~m}^{-2}\right)$ likely underpins a lower SHF $\left(-3 \mathrm{~W} \mathrm{~m}^{-2}\right)$, LHF $\left(-3 \mathrm{~W} \mathrm{~m}^{-2}\right)$, and GHF $\left(-1 \mathrm{~W} \mathrm{~m}^{-2}\right.$, Table 4.1). Spatially, this can be seen when comparing the positive $R_{\text {net }}$ anomalies (Figure 4.6d) to the negative anomalies in SHF, LHF, and GHF (Figure 4.7a-c), and observing a large overlap in their areas. This serves as a reminder that all non-radiative heat fluxes are linked to radiation through the SEB and that we should be cautious in drawing bold conclusions from non-radiative SEB components, since cloud-induced radiation biases likely play a role.

There are several more remarks to make about Figure 4.7a. For instance, the most pronounced anomalies in SHF are near the margins, where the negative wind speed bias is largest (Figure 4.4a), weakening turbulent heat exchange. Still, EC downscaling is enhancing SHF along the ice sheet margins because of the increased temperature gradients between atmosphere and surface in low-lying regions (Section 4.2.3). This is most apparent in the south and west, where $>10 \mathrm{~W} \mathrm{~m}^{-2}$ are found (Figure 4.7a), and less so in the north and east, where wind speeds are lowest (Figure S6a in Supplement of van Kampenhout et al. [2020]). Also, bare ice exposure is less frequent in the north and east, thus limiting the inversion strength as suggested by Figure S6d. Finally, the SHF is negative in southern Greenland (Figure 4.7a, first two panels), indicating that heat is extracted from the surface by SHF; probably as a result of the radiative surplus $\left(\mathrm{LW}_{\mathrm{d}}\right.$ mainly). The overall spatial correlation of JJA SHF to RACMO2 is $r^{2}=0.44$ (Table 4.1).

Figure 4.7b shows that CESM2 simulates more negative LHF (i.e. more sublimation) than RACMO2 across most of the GrIS, which we link to the radiative surplus in our model. Very near the ice sheet margin, narrow bands are found where the absolute LHF flux becomes positive that are not present in RACMO2. These positive LHF anomalies are explained by the EC downscaling procedure in which the relative humidity is kept constant with height. At low elevations, specific humidity is enhanced which leads to a weaker humidity gradient to the ice surface, and therefore reduced sublimation. Positive LHF (i.e. condensation) in the GrIS ablation zone is a common feature for the lowest parts of the ablation zone in West Greenland during summer [van den Broeke et al., 2009], so we consider this plausible, even though not simulated by RACMO2. The spatial correlation of JJA LHF is $r^{2}=0.38$ (Table 4.1).

Another interesting finding from Figure $4.7 \mathrm{a}$ and $4.7 \mathrm{~b}$ is that SHF and LHF in RACMO2 are both strongly negative over the marginal tundras, indicating convection and evaporation over the dark tundra surface during summer. This is to some extent simulated by CESM2, except in the north where its turbulent fluxes are weak (Figure 4.7a-b). We hypothesise that this relates to tundra snow cover not melting away early enough in the season, if at all. Also, we recall that RACMO2 adopts a simplified snow model over its tundra grid cells, and may therefore not be entirely representative either.

Negative GHF in Figure 4.7c indicates heat is conducted from the surface downward, which occurs when the surface is warmer than layers below. Positive GHF indicates heat conduction towards the surface, which can occur at night or after refreezing events. Indeed, locations with positive GHF typically have high refreezing rates (Figure 4.7e). Overall, the sign of summer GHF is well captured by CESM2, although the flux is weaker than in RACMO2, especially in the refreezing zones in the south and along the northern margins, suggesting that subsurface temperature gradients are smaller in CESM2. Negative GHF anomalies found in the GrIS interior can be explained by the radiation surplus in CESM2. The spatial correlation of JJA GHF is $r^{2}=0.67$ (Table 4.1).

The seasonal cycle of MHF in Figure 4.31 shows good agreement of CESM2 and RACMO2 in GrISaverage melt, with a mean JJA bias of $1 \mathrm{~W} \mathrm{~m}^{-2}$ (Table 4.1). Figure $4.7 \mathrm{~d}$ shows that most of the positive MHF anomalies occur along the western margin. In some places, such as in the northwest, these 
anomalies can be explained by the coarse atmospheric resolution and the lack of orographically forced snowfall in CESM2, resulting in spurious ablation zones [van Kampenhout et al., 2019]. On the other hand, RACMO2 at $11 \mathrm{~km}$ can underestimate melt with respect to observations [Hermann et al., 2018], with studies suggesting that statistical downscaling is needed to resolve narrow ablation zones [Noël et al., 2018]. Thus, the fact that CESM2 resolves some narrow ablation zones which are missing in RACMO2 at $11 \mathrm{~km}$ is not necessarily unrealistic. Positive MHF anomalies away from the margin, and thus less impacted by EC downscaling, may be explained by the radiation surplus in CESM2. However, most of this additional meltwater refreezes (Figure 4.7e).

Negative MHF anomalies are found along the northern and eastern margins of the GrIS (Figure 4.7d), consistent with the underestimation of $R_{\text {net }}$ in these areas (Figure 4.6d). These differences, however, may not be purely radiation-driven. Instead, overestimated snowfall or the lack of explicit erosion/sublimation by drifting snow in CESM2 could result in an albedo that is too high. Overall, the spatial correlation in MHF between the two models is high $\left(r^{2}=0.88\right)$.

One caveat in these results is that offline downscaling to $11 \mathrm{~km}$ appears to increase the GrIS-integrated MHF. To be precise, the mean JJA bias in HIST-EC increases from 0.8 to $1.6 \mathrm{~W} \mathrm{~m}^{-2}$ when going from online EC downscaling to offline EC downscaling (Table 4.1). One likely explanation is that the two methods use different topography.

\subsubsection{Surface mass balance components: comparison to RACMO2 at $11 \mathrm{~km}$}

The spatial distribution of GrIS snowfall (the main mode of mass gain, cf. Equation 4.4) is captured reasonably well by CESM2 (Figure 4.8a), notably the positive north-south gradient and the high accumulation area in the south-east. Small-scale orographically driven features, however, are missing due to the coarser resolution. Overall, CESM2 simulates more snowfall than RACMO2 across large parts of the GrIS interior (Figure 4.8a). Positive biases exceeding $500 \mathrm{~mm} \mathrm{yr}^{-1}$ are found over the southern dome and the high accumulation areas in the south-east, as a result of the coarse resolution and weak topographic gradients [van Kampenhout et al., 2019]. At a higher spatial resolution, snow would fall closer to the coast, which explains why CESM2 has a negative snowfall bias along the south-eastern margin. Integrated over the GrIS, CESM2 simulates $705 \pm 67 \mathrm{Gt} \mathrm{yr}^{-1}$ of snowfall during the late $20^{\text {th }}$ century, about $9 \%$ more than RACMO2 (Table 4.2).

Rainfall is shown in Figure 4.8b. Comparing the first panel (CESM2 at $1^{\circ}$ ) and the second (CESM2 at $11 \mathrm{~km}$ ), it is clear that the phase repartitioning scheme (Section 4.2.1) removes most of the rain that CAM simulates over the GrIS interior. Still, rainfall at the surface is overestimated in CESM2 (59 $\pm 14 \mathrm{Gt} \mathrm{yr}^{-1}$ ) compared to RACMO2 (19-33 Gt, Table 4.2). The largest rainfall anomalies (> 300

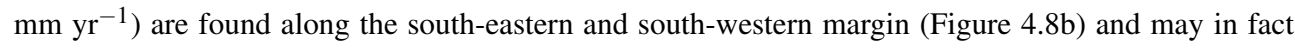

Figure 4.8 (following page): Comparison of CESM2 and RACMO2 annual mean mass fluxes, a. snowfall, $\boldsymbol{b}$. rain, $\boldsymbol{c}$. melt, $\boldsymbol{d}$. runoff, $\boldsymbol{e}$. evaporation/sublimation. Data as in Figure 4.4. Note that all colour scales are non-linear and that those in $\boldsymbol{e}$. differ from the rest. Listed statistics were calculated from HIST-EC output downscaled to $11 \mathrm{~km}$. 

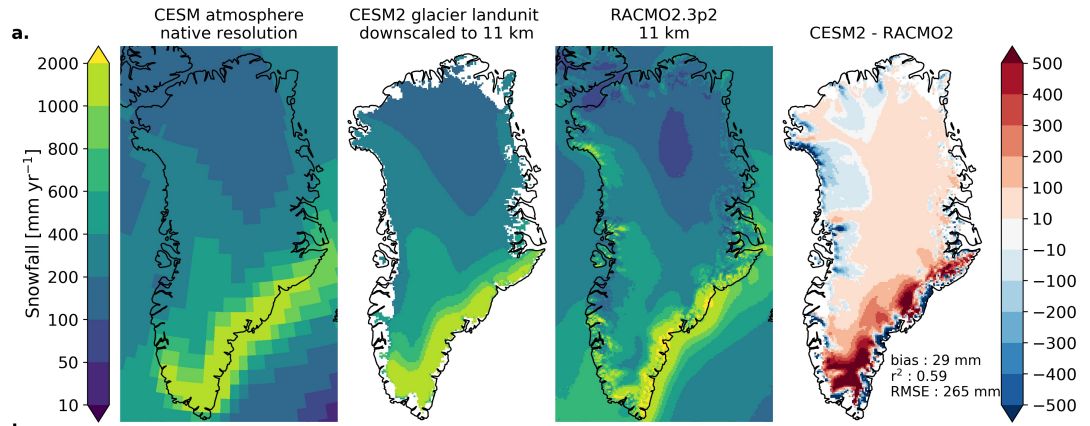

b.
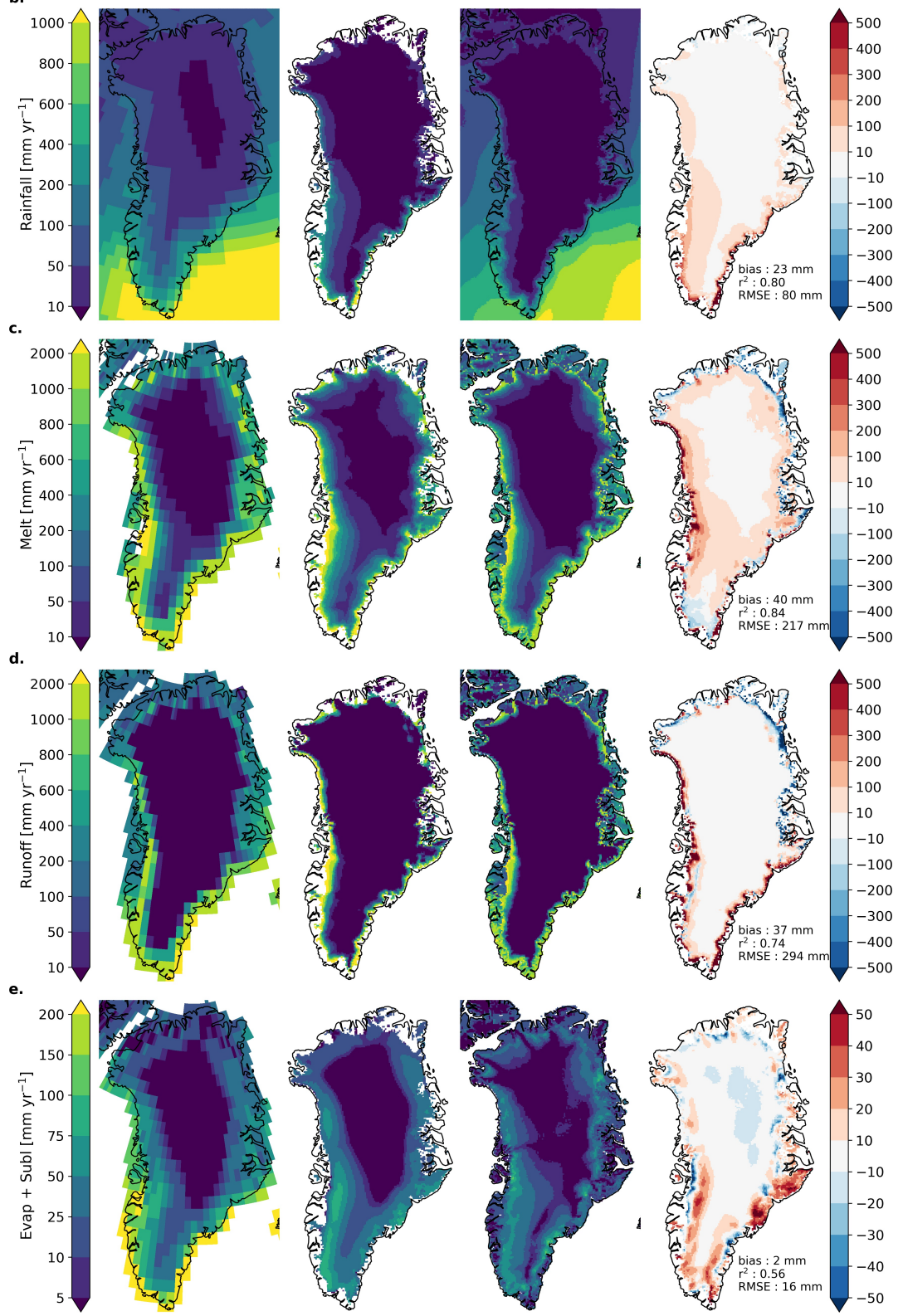
Table 4.2: Overview of CESM2 and RACMO2 integrated mass fluxes (mean \pm standard deviation) over the contiguous GrIS. CESM2 figures represent a composite of 6 historical members, and the total number of model years is shown in parentheses. A similar table for the GrIS + GICs can be found in the supporting information.

\begin{tabular}{llll}
\hline Mean mass flux in $\mathrm{Gt} \mathrm{yr}^{-1}$ & RACMO2.3p2 & RACMO2.3p2 & CESM2 \\
& $11 \mathrm{~km}$ native & $1 \mathrm{~km}$ downscaled & $1^{\circ}$ with 10 ECs \\
& $1961-1990$ & $1961-1990$ & $1961-1990(180)$ \\
\hline area (GrIS) & $1,693,317 \mathrm{~km}^{2}$ & $1,693,952 \mathrm{~km}^{2}$ & $1,699,077 \mathrm{~km}^{2}$ \\
\hline Snowfall & $642 \pm 70$ & $652 \pm 72$ & $705 \pm 67$ \\
Rain & $19 \pm 5$ & $33 \pm 6$ & $59 \pm 14$ \\
Sublimation & $30 \pm 2$ & $31 \pm 2$ & $32 \pm 3$ \\
Melt & $324 \pm 54$ & $462 \pm 56$ & $367 \pm 74$ \\
Refreezing & $157 \pm 21$ & $249 \pm 23$ & $198 \pm 41$ \\
Runoff & $184 \pm 41$ & $260 \pm 49$ & $224 \pm 45$ \\
SMB & $447 \pm 99$ & $393 \pm 109$ & $508 \pm 73$ \\
Ablation area $(\%)$ & 8.0 & 8.4 & 7.5 \\
\hline
\end{tabular}

be exaggerated by the repartitioning scheme. That is, snow may be converted to rain here, based on downscaled temperature.

Figure $4.8 \mathrm{c}$ shows annual mean melt (in $\mathrm{mm} \mathrm{yr}^{-1}$ ). Since most melt takes place during summer, the results in Figure 4.8c resemble the JJA MHF (in $\mathrm{W} \mathrm{m}^{-2}$, Figure 4.8e) and are therefore not discussed in detail. The total GrIS-integrated melt is $367 \pm 74 \mathrm{Gt} \mathrm{yr}^{-1}$ during the late $20^{\text {th }}$ century (Table 4.2) and is partitioned between $\sim \frac{1}{3}$ ice melt $(128 \mathrm{Gt})$ and $\sim \frac{2}{3}$ snow melt $(239 \mathrm{Gt})$. CESM2 melt is bracketed by the RACMO 2 values at $11 \mathrm{~km}(324 \mathrm{Gt})$ and $1 \mathrm{~km}(462 \mathrm{Gt})$, indicating good agreement. Part of the liquid water from melt and rain is refrozen by CESM2, totalling $198 \pm 41 \mathrm{Gt} \mathrm{yr}^{-1}$ over the GrIS (Table 4.2). This estimate is realistic, given the RACMO2 values of $157 \mathrm{Gt}$ and $249 \mathrm{Gt}$. However, refreezing in CESM2 has different spatial features than RACMO2 $\left(r^{2}=0.66\right)$. For example, there is a pronounced maximum along the western margin that is absent in RACMO2 (Figure 4.7e). Also, CESM2 misses the strong refreezing zone in the southern and southeastern GrIS, likely as a result of lower snowfall (Figure 4.8a).

Figure $4.8 \mathrm{~d}$ shows runoff in CESM2 and RACMO2 $\left(r^{2}=0.74\right)$. Naturally, the runoff patterns are similar to patterns of melt (Figure 4.8c), but there are differences. For instance, strong positive runoff anomalies are found along the southeast margin, where CESM2 simulates less refreezing than RACMO2. Integrated over the GrIS, CESM2 simulates $224 \pm 45 \mathrm{Gt} \mathrm{yr}^{-1}$ of runoff, a value that again is bracketed by RACMO2 at $11 \mathrm{~km}(184 \mathrm{Gt})$ and $1 \mathrm{~km}(260 \mathrm{Gt}$, Table 4.2).

Figure 4.8e shows the mean annual evaporation/sublimation flux. The downscaled sublimation field has the same general pattern as RACMO2 $\left(r^{2}=0.56\right)$. (Sublimation is not a separate output variable of CLM, so it is assumed that over glaciers, $100 \%$ of the evaporation/sublimation flux represents sublimation. This is a fair assumption, given that surface water ponding, forming supra-glacial lakes, is not modelled over the glacier landcover type.) Due to coarser resolution, however, the CESM2 pattern is smoother than that of RACMO2, which has an irregular, incised pattern near the margins as a result of drifting snow sublimation (a process not included in CESM2). The difference map in Figure 4.8e shows that CESM2 simulates less sublimation in low-lying regions, which is plausible as discussed previously 

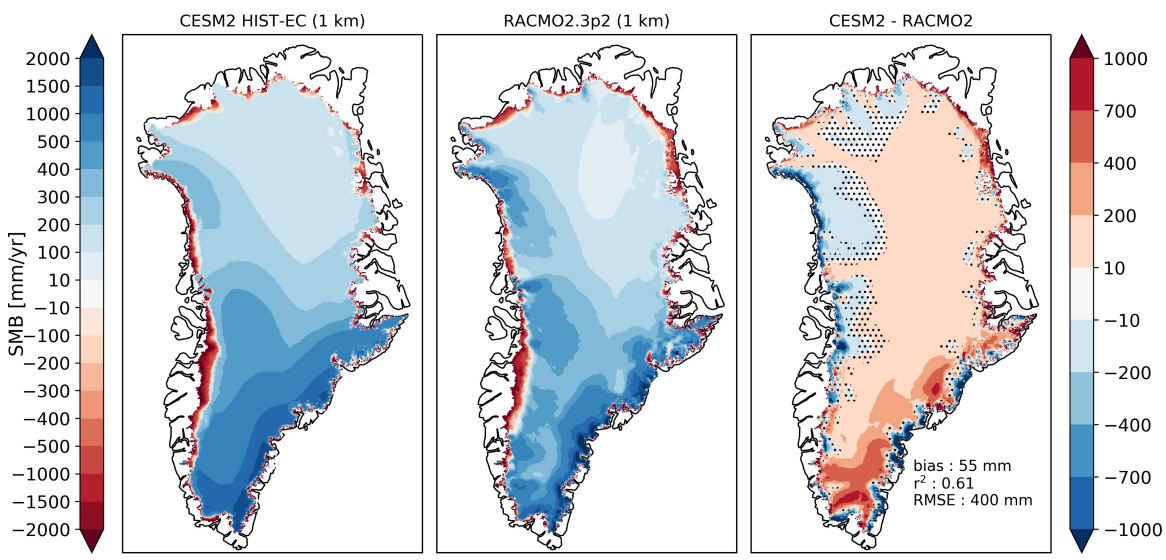

Figure 4.9: Mean contiguous GrIS SMB over the period 1961-1990 at $1 \mathrm{~km}$ resolution. a. CESM2, simulation HIST-EC offline downscaled using ECs, b. RACMO2, statistically downscaled [Noël et al., 2018], $\boldsymbol{c}$. difference. Note the non-linear colour scale. The area under consideration is the grounded contiguous GrIS (1,693,952 $\left.\mathrm{km}^{2}\right)$. Stippling denotes differences that are not significant (t test, $p<0.05$ ). Figure S8 (in Supplement of van Kampenhout et al. [2020]) is the same figure but including GICs and floating glacier tongues.

in Section 4.3.4. Integrated over the GrIS, the CESM2 sublimation rate is $32 \pm 3 \mathrm{Gt} \mathrm{yr}^{-1}$, which compares well with the RACMO2 estimate of $31 \mathrm{Gt} \mathrm{yr}^{-1}$ (Table 4.2). However, there is evidence of compensating errors, with too-strong sublimation during summer and net riming during winter (Figure $4.3 \mathrm{j})$.

\subsubsection{Surface mass balance: comparison to RACMO2 at $1 \mathrm{~km}$}

So far, spatial comparisons to RACMO2 have been made at the native RACMO2 resolution of $11 \mathrm{~km}$, the resolution at which all SEB and SMB fluxes are available. Noël et al. [2016] introduced statistical downscaling of mass fluxes to $1 \mathrm{~km}$, demonstrating improved skill against observations. Figure 4.9 compares CESM2 SMB with RACMO2 at $1 \mathrm{~km}$, using offline EC downscaling (Section 4.2.4). Overall, CESM2 captures the main spatial features of GrIS SMB $\left(r^{2}=0.61\right)$, with narrow ablation zones near the margins, an even narrower equilibrium zone where $\mathrm{SMB} \approx 0$, and the accumulation zone in the interior. Many of the SMB anomalies in the southern GrIS are explained by resolution-related differences in snowfall (cf. Figure 4.8a). The ablation zones in the west are generally well positioned, but are too wide towards the north because of a lack of orographic snowfall. In contrast, ablation zones in the northern and eastern parts of the GrIS are less extensive in CESM2. Factors that likely play a role here are (1) overestimation of snowfall (Figure 4.8a), (2) weaker SHF in CESM2 (Figure 4.7a, caused in part by the inability to resolve summer tundra temperatures (Figure 4.4b), and (3) the missing process of drifting snow erosion and sublimation in CESM2. As a result, the overall ablation extent in CESM2 $(7.5 \%)$ is less than that of RACMO2 (8.4\% at $1 \mathrm{~km}$, Table 4.2). Integrated SMB in CESM2 is $508 \pm 73$

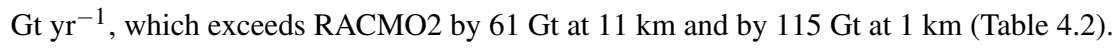




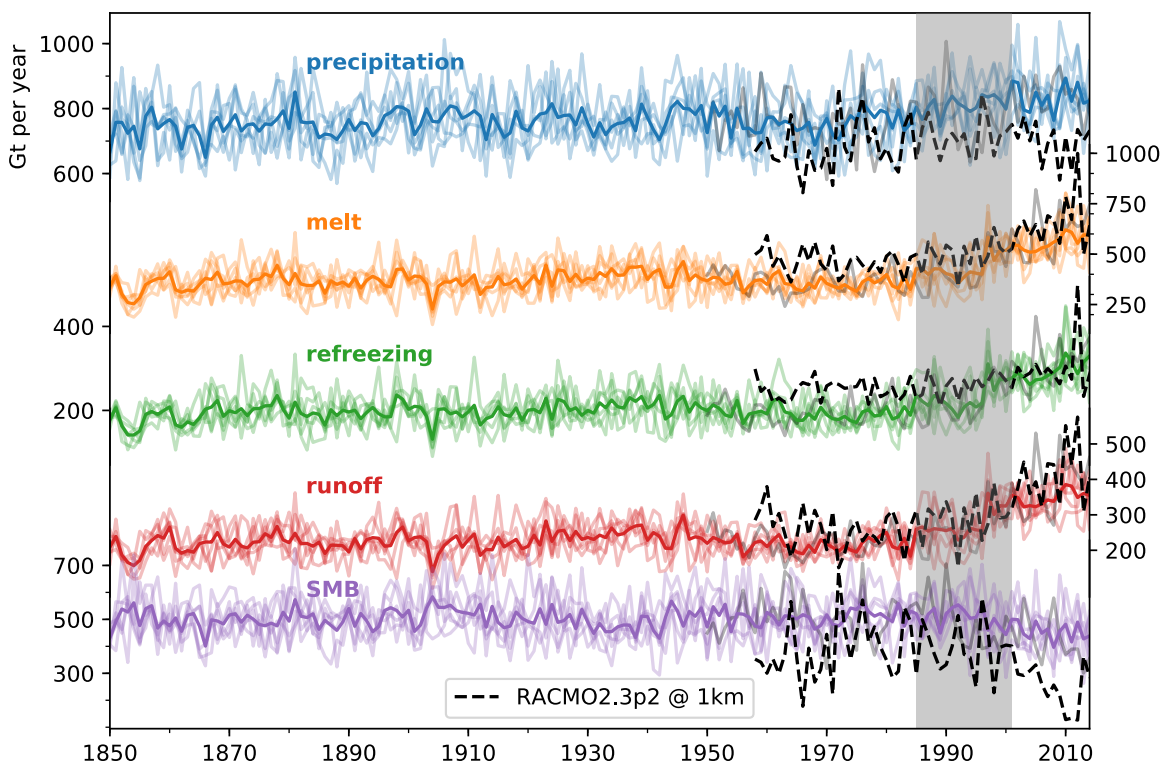

Figure 4.10: Time series of SMB components over the period 1850-2014. Shown are the 6 members HIST-01 to HIST-06 (colored lines), member HIST-EC (grey solid line, starting in 1950), ensemble mean (thick colored lines), and RACMO2 downscaled to $1 \mathrm{~km}$ (dashed black lines). The band with grey shading indicates the $95 \%$ confidence interval of a break point in the SMB ensemble mean time series.

\subsubsection{Time series of surface mass balance components, 1850 2014}

Figure 4.10 shows time series of precipitation, melt, refreezing, runoff, and SMB for all historical CESM2 members analysed in this paper. Before 1990, there are no discernible trends in any component. Mean SMB during 1850-1990 is $503 \pm 78 \mathrm{Gt} \mathrm{yr}^{-1}$ close to the value of $508 \mathrm{Gt} \mathrm{yr}^{-1}$ in Table 4.2. Good matches are also found for the individual SMB components in Table 4.2, suggesting that our period of analysis (1960-1990) is representative of the entire historical period up to $\sim 1990$. Around 1990, however, there is a break point — an abrupt transition from zero trend to a strong trend—in melt, refreezing, runoff, and SMB, driven by increased melt (Figure 4.10). For SMB, this break point occurs in 1993, with a 95\% confidence interval ranging from 1985 to 2001, using the method of Muggeo [2003, 2017]. The timing of the break point is consistent with reanalysis-based methods, which estimate that SMB started to decrease in the early to mid-1990s [Fettweis et al., 2013a; van den Broeke et al., 2016], as illustrated by the superimposed RACMO2 $1 \mathrm{~km}$ data in Figure 4.10. Trends in individual SMB components, however, are not always consistent with RACMO2. For example, the trend in CESM2 precipitation after 1993 is $+1.1 \mathrm{Gt} \mathrm{yr}^{-2}$ whereas RACMO2 simulates a decrease: $-1.7 \mathrm{Gt} \mathrm{yr}^{-2}$. The melt trend is comparable in the two models $\left(+8.8 \mathrm{vs}+9.9 \mathrm{Gt} \mathrm{yr}^{-2}\right)$, but CESM simulates a higher increase in refreezing $\left(+4.7 \mathrm{vs}+2.5 \mathrm{Gt} \mathrm{yr}^{-2}\right)$. As a result, the runoff trend is lower in CESM2 (+5.0 vs $+7.4 \mathrm{Gt} \mathrm{yr}^{-2}$ ), and the decrease in SMB is less than half of that in RACMO2 (-3.9 vs $\left.-9.1 \mathrm{Gt} \mathrm{yr}^{-2}\right)$. These trends can be different across individual ensemble members due to internal variability, and may not always be significant. 
A recent study by Noël et al. [2019b] forced RACMO2 using 6-hourly output from CESM2 and found a stronger runoff increase at $1 \mathrm{~km}$ in the CESM2-forced run (+138 Gt yr${ }^{-1}$ during 1991-2012 relative to 1960-1990) than in the standard ERA-Interim-forced run $\left(+100 \mathrm{Gt} \mathrm{yr}^{-1}\right)$. In contrast, the runoff trend diagnosed directly from CESM2 is smaller than that of the ERA-Interim forced RACMO2. This discrepancy suggests that the sensitivity of GrIS SMB to climate change is underestimated in CESM2 compared to the statistically-downscaled RACMO2.

\subsection{Discussion}

Coupled ice-sheet-climate simulations with the GrIS are a major contribution of the CESM2 community to ISMIP6, and GrIS SMB was therefore considered carefully during the development of CESM2. In this section we reflect on some of the development decisions and suggest directions for future improvements. One key change between CESM1 and CESM2 is that CISM is now enabled by default as a diagnostic component in all coupled experiments. Previously, CISM and therefore CLM elevation classes over the GrIS were active only in dedicated runs, and GrIS SMB could not be diagnosed from most simulations. Now, GrIS SMB is monitored routinely during development, and potential problems are easily flagged.

\subsubsection{Model development to improve ice sheet surface mass bal- ance towards CESM2}

Numerous studies have shown the importance of clouds on GrIS SEB and SMB [e.g., Bennartz et al., 2013; Van Tricht et al., 2016b; Cullather and Nowicki, 2018]. The previous version of CESM used in GrIS SMB studies was CESM1(CAM4) [Vizcaíno et al., 2013, 2014; Fyke et al., 2014b,a], which suffers from an excessive occurrence of liquid-containing clouds over Greenland, as shown in an upcoming study led by J.T.M. Lenaerts. In retrospect, this may explain some of the CESM1(CAM4) surface biases, such as a general warm bias over the GrIS interior, increased $\mathrm{LW}_{\mathrm{d}}$ at the expense of $\mathrm{SW}_{\mathrm{d}}$, and unrealistic rainfall in the interior [Vizcaíno et al., 2013]. In CESM1(CAM5), by contrast, cloud LWP was greatly underestimated, giving major surface radiative biases over Greenland [Mcllhattan et al., 2017; Lacour et al., 2018] and the Arctic region as a whole [Kay et al., 2016]. This model version, used by the CESM Large Ensemble [Kay et al., 2015], was therefore not suitable for GrIS SMB studies. CAM6 largely resolved this problem with several improvements in the cloud microphysics scheme. to a lesser degree, IWP) motivated us to include Figure 4.2 in the current paper, in which we compare CESM2 cloud water to observations.

We deem albedo to be the most important surface property to simulate accurately when modelling Greenland melt. ESMs generally have many parameters controlling ice and snow albedo. In CESM, ice albedo is given by a simple fixed value which has been lowered in CESM2 (based on observational evidence) to obtain larger melt rates for bare ice. Snow albedo is a function of many parameters and factors (e.g., initial snow grain size, snow grain growth, refreezing grain size, and impurities) and is sensitive to external forcing, such as the magnitude and timing of snowfall and rain. Following the decision to correct for the bias of interior GrIS rainfall (detailed in Section 4.2.1), snow albedo was unrealistically high at some point in the development cycle, leading to steep SMB gradients near the 
margins. Multiple trials eventually led to initial snow grain size becoming a temperature-dependent parameter (Section 4.2.2), which lowered the GrIS snow albedo without deteriorating model performance elsewhere.

In CESM2, near-surface wind speed is not only relevant for the turbulent fluxes, but also partly controls snow density through the wind-dependent fresh snow density and drifting snow compaction, both of which were introduced to avoid low snow densities in cold and windy environments [van Kampenhout et al., 2017]. In CAM5, however, near-surface wind speeds were biased low due to the use of the Turbulent Mountain Stress surface drag parametrization [Lindvall et al., 2012]. A new surface drag parametrization was introduced in CAM6 [Beljaars et al., 2004] that raised low-level wind speed to reasonable values (see Figure 4.3a and 4.4) and improved GrIS SEB.

\subsubsection{Directions for future model development to improve ice sheet surface mass balance}

Based on the previous discussion and the results presented in this paper, we make suggestions for improving GrIS SMB in future versions of CESM.

1. A major outstanding model bias is the high CAM6 rainfall over the interior GrIS (Figure 4.8b), which is currently alleviated by phase repartitioning in CLM. This solution is sub-optimal, as there is reason to believe that phase repartitioning degrades SMB gradients. Moreover, supercooled rain could be key to setting off melt-albedo feedbacks in northern Greenland. To resolve this bias, cloud microphysics in polar regions need to be improved. While the precipitation phase is still being repartitioned, the current temperature-only formulation could perhaps be improved upon by adding humidity as a predictor as suggested by Jennings et al. [2018].

2. In order to better resolve stable boundary layers and temperature inversions, CAM vertical resolution could be increased near the surface. Currently, the lowest atmospheric layer in CAM6 has a thickness of $\sim 120 \mathrm{~m}$, whereas $\sim 10 \mathrm{~m}$ may be desirable over ice sheets [Vignon et al., 2018].

3. Adding drifting snow erosion and sublimation to CLM could improve the SMB simulation, for example by widening ablation zones in northern Greenland.

4. It is desirable to re-assess snow grain size, an important control on snow albedo. CESM2 albedo appears to be biased low across most of the interior (Figure 4.5).

5. Artefacts caused by EC downscaling (supporting information in van Kampenhout et al. [2020], Text S1) could be prevented by introducing spatial information to the vertical downscaling. For example, one approach could be to calculate SMB gradients per GrIS drainage basin, as done in Goelzer et al. [2019]. This would also make the method less dependent on the CAM resolution. Another approach is to use variable resolution grids, as done in van Kampenhout et al. [2019]. If done right, this will remove the need to use ECs altogether.

\subsection{Conclusions}

In this study we evaluated GrIS climate, clouds, surface energy balance, and surface mass balance in CESM2, which is the first version of CESM capable of ice-sheet-climate simulations with dynamic land 
cover changes. We used output from six fully coupled CMIP6 historical experiments at $1^{\circ}$ horizontal resolution with fixed ice sheet topography. In addition, we used EC-indexed output from a single historical experiment (HIST-EC) that was downscaled offline to $11 \mathrm{~km}$ and $1 \mathrm{~km}$ grids, allowing for high-resolution comparisons of individual SEB/SMB components against a state-of-the-art regional climate model, RACMO2.3p2.

CESM2 at $1^{\circ}$ simulates reasonably well the Greenland large-scale climate, cloud liquid water path, surface climate, SEB, and SMB. A few biases remain, some of which can be linked to the coarse grid resolution, in both the horizontal direction (wind speed, precipitation, tundra micro-climate) and the vertical (stable boundary layers during winter). Compared to RACMO2 and satellite data (MODIS, CLARA-A2), snow albedo is biased low in CESM2. As a result, we find a JJA radiation surplus with respect to RACMO2 across most of the ice sheet that is compensating for weaker turbulent fluxes in CESM2, which in turn are linked to weaker near-surface winds.

Mean GrIS-integrated SMB during 1961-1990 is $508 \pm 58$ Gt, with precipitation being the leading SMB component that is overestimated compared to RACMO2. Mean GrIS-integrated values of melt, refreezing, and runoff are bracketed by RACMO2 values simulated at $11 \mathrm{~km}$ and $1 \mathrm{~km}$ (Table 4.2). The extent of the northern and eastern GrIS ablation areas, however, is underestimated in CESM2, and the total ablation area is $11 \%$ smaller than in RACMO2. Time series analysis shows that SMB was stable over the historical period up to $\sim 1990$, after which it declines due to increased melt and runoff. Compared to reanalysis-forced RACMO2, CESM2 simulates a comparable trend in melt after 1993, but the trend in refreezing is larger. As a result, simulated trends in runoff and SMB are smaller than that in RACMO2. The timing of the break point in SMB is similar to that in reanalysis-forced RACMO2.

To conclude, CESM2 simulates a GrIS SMB field for the present-day geometry which is physically realistic given the known model limitations, and which adds confidence to coupled ice sheet-climate experiments that assess the GrIS contribution to sea level rise on decadal to millennial time scales in past and future climates. 


\section{A 21st century warming threshold for Greenland ice sheet mass loss}

\section{Summary}

Under anticipated future warming, the Greenland ice sheet (GrIS) may pass a threshold when meltwater runoff exceeds the accumulation of snow, resulting in a negative surface mass balance $(\mathrm{SMB}<0)$ and irreversible mass loss. In spite of several recent warm summers with high melt rates, SMB $<0$ has so far never been reached. Here we dynamically and statistically downscale output from an Earth System Model to $1 \mathrm{~km}$ resolution to infer that a Greenland near surface atmospheric warming of $4.5 \pm 0.3{ }^{\circ} \mathrm{C}$, relative to pre-industrial, is required for GrIS SMB to become persistently negative. Climate models from the Coupled Model Intercomparison Project Phase 5 (CMIP5) and Phase 6 (CMIP6) translate this regional threshold into a global warming threshold of $2.7 \pm 0.2{ }^{\circ} \mathrm{C}$. In future scenarios without mitigation of greenhouse gas emissions, these warming thresholds may be reached around 2055, while for a strong mitigation scenario the threshold will likely not be reached.

\subsection{Introduction}

Complete melting of the Greenland ice sheet (GrIS) would raise global mean sea level by $7.4 \mathrm{~m}$ [Morlighem et al., 2017]. The rate of GrIS mass change, or mass balance (MB; Gigatonnes per year or

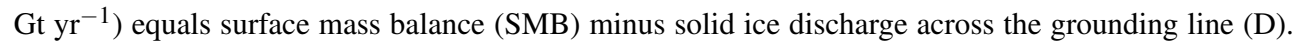

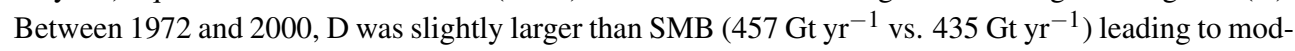
erate mass loss [Mouginot et al., 2019] that may have persisted throughout the 20th century [Kjeldsen et al., 2015]. After 2000, D increased owing to the acceleration of marine-terminating outlet glaciers and SMB decreased following atmospheric warming that increased meltwater runoff. The resulting cumulative mass loss between 1992 and 2018 contributed $1.1 \pm 0.1 \mathrm{~cm}(13 \pm 1 \%)$ to global mean sea

This chapter is based on: Noël, B., van Kampenhout, L., Lenaerts, J. T. M., Van de Berg, W. J., and Van den Broeke, M. A 21st century warming threshold for irreversible Greenland ice sheet mass loss. Communications Earth \& Environment, in review. The first and second authors contributed equally to this work. 
level rise [The IMBIE team, 2020]. In the most recent decade (2007-2016), GrIS mass loss further increased to $\sim 280 \mathrm{Gt} \mathrm{yr}^{-1}$ [Bamber et al., 2018b], mainly due to enhanced meltwater runoff. This mass loss amounts to $\sim 40 \%$ of the annual snow accumulation on the ice sheet $\left(\sim 710 \mathrm{Gt} \mathrm{yr}^{-1}\right)$, indicating that the GrIS is currently significantly out of balance, and making it the largest single contributor to contemporary global mean sea level rise.

The rate and reversibility of future GrIS mass loss remain highly uncertain, owing mainly to complex ocean-ice interactions in marine-terminating parts of the ice sheet, which to a large extent determine D [Straneo et al., 2016; Pattyn, 2018]. These processes are only schematically represented in current dynamical ice sheet models that are used to predict future GrIS mass loss [Goelzer et al., 2020]. Since geometrical changes and the associated (elevation-temperature) feedback are expected to remain small during the 21st century [Oppenheimer et al., 2019], first-order inferences about the reversibility of future GrIS mass loss can be made based on surface processes (SMB) alone. An important threshold is passed when SMB becomes negative-since D is positive by definition, this would make MB strictly negative, implying irreversible GrIS mass loss given the warming is sustained [Huybrechts et al., 1991].

For SMB to become negative, meltwater runoff must exceed accumulation, a situation that has not occurred since at least 1958, the first year with reliable reanalysis-based estimates of GrIS SMB [van den Broeke et al., 2016]. Even for years in which meltwater mass significantly exceeded total snow accumulation (e.g. years 2012 and 2019), SMB remained positive [?] because a large fraction ( 45\%) of the meltwater is retained in the firn, i.e. the up to $100 \mathrm{~m}$ thick layer of compressed, perennial snow covering most of the ice sheet. In the firn layer, meltwater either refreezes as ice lenses/slabs [Machguth et al., 2016a; MacFerrin et al., 2019] or is retained as liquid water in perennial firn aquifers [Forster et al., 2013].

Simply extrapolating the recent negative trend into the future predicts the zero SMB threshold to occur within $\sim 20$ years [van den Broeke et al., 2016]. However, such predictions are uncertain given the relative brevity of the time series [Hanna et al., 2020] and the large interannual SMB variability [Wouters et al., 2013]. Here we use an Earth System Model, a regional climate model, and statistical downscaling techniques to infer a regional Greenland warming threshold of $4.5 \pm 0.3{ }^{\circ} \mathrm{C}$ which translates to a global warming of $2.7 \pm 0.2^{\circ} \mathrm{C}$ using climate models from the Coupled Model Intercomparison Project Phase 5 (CMIP5) and Phase 6 (CMIP6) model archives. The warming threshold will likely be passed in $\sim 2060$ for a scenario without mitigation of greenhouse gas emissions (RCP8.5/SSP5-8.5), while this warming threshold will likely not be reached during this century in a strong mitigation scenario (RCP2.6/SSP1-2.6).

\subsection{Summary of methodology}

Our main GrIS SMB product was obtained by dynamically downscaling the Community Earth System Model version 2.1 (CESM2 henceforth, Danabasoglu et al. [2020]) over the period 1950-2100 using the regional climate model RACMO2.3p2 (RACMO2 henceforth). The most extreme warming scenario SSP5-8.5 was selected to obtain maximum leverage for correlations between SMB and regional temperature $\mathrm{T}_{\mathrm{GrIS}}$ (see Methods). To better resolve low-lying, narrow outlet glaciers that are primary contributors to meltwater runoff, RACMO2 SMB components were further statistically downscaled 


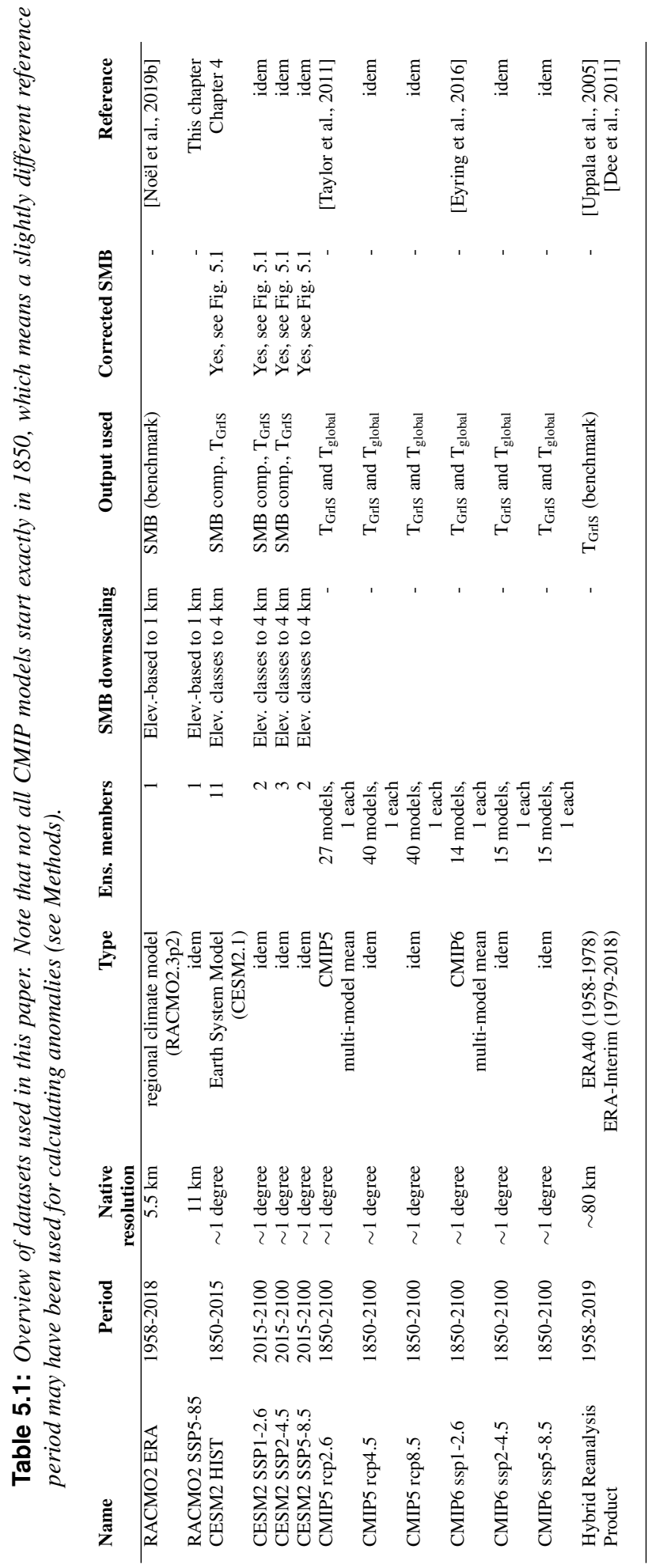



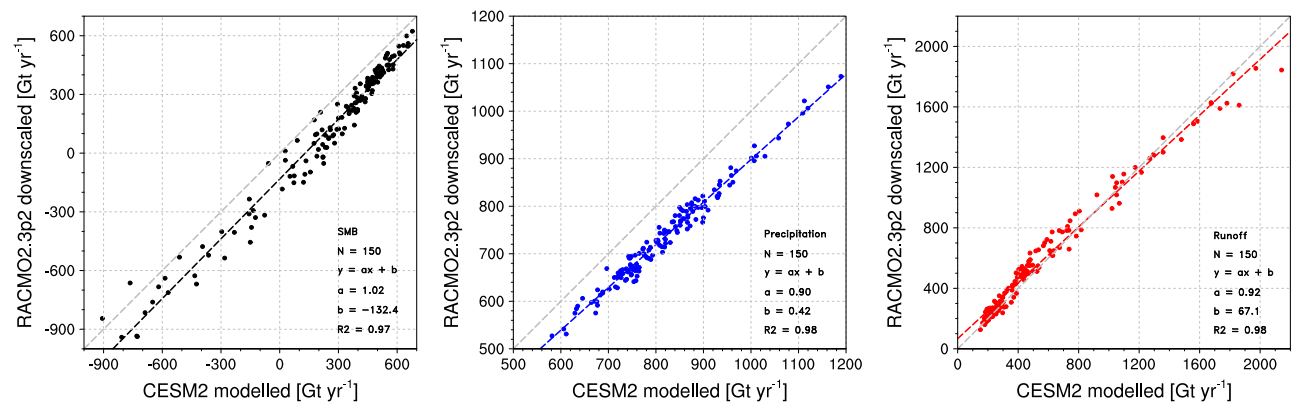

Figure 5.1: Cross-model correlation for individual SMB components. Linear correlations between CESM2 SSP5-8.5 and RACMO2 SSP5-8.5 annual total GrIS precipitation (a), runoff (b) and SMB (c), for the period 1950-2100.
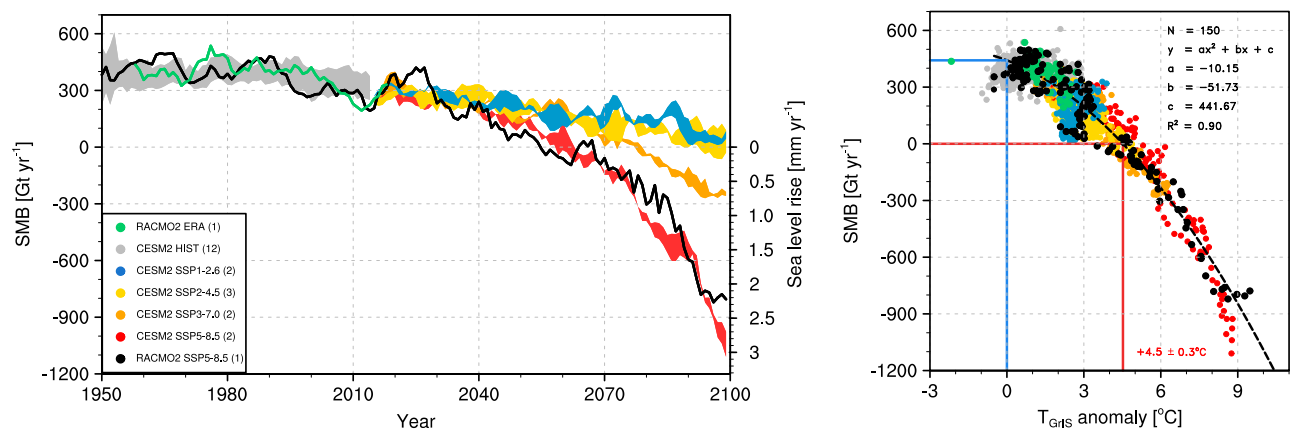

Figure 5.2: A regional warming threshold for negative Greenland surface mass balance. (a) Fiveyear moving average of GrIS SMB for RACMO2 ERA ('observations', green), CESM2 historical (HIST, grey), RACMO2 SSP5-8.5 (black), and CESM2 scenario runs (colours, see legend). Numbers in parentheses indicate number of ensemble members, coloured bands span maximum and minimum ensemble value. (b) Five-year average SMB values (1950-2100) plotted as a function of the anomaly (relative to 1850-1899) of annual mean near surface temperature averaged over Greenland ( $T_{G r I S}$, see Methods), including quadratic fit statistics. Colours are the same as in (a). See Table 1 for experiment names.

from 11 to $1 \mathrm{~km}$ resolution and the resulting product is referred to as "RACMO2 SSP5-8.5"-see Table 5.1 for an overview of the various data products. SMB time series for other warming scenarios and ensemble members are reconstructed using SMB components from CESM2. Both RACMO2 and CESM2 have been extensively evaluated over the GrIS and compare well to in-situ measurements (see Methods).

Figure 5.1 compares annual GrIS SMB, precipitation, and runoff as calculated by CESM2 and RACMO2 SSP5-8.5. We find very strong linear correlations $\left(\mathrm{r}^{2}=0.96\right)$ between the two products, with remaining differences primarily related to the low horizontal resolution of the CESM2 atmospheric model. For instance, too gentle coastal ice sheet slopes in the low-resolution model topography allow moist air masses to propagate too far inland, which results in overestimated precipitation in the GrIS interior and cannot be corrected for with elevation classes (Chapter 3). The inferred regression statistics (Figure 

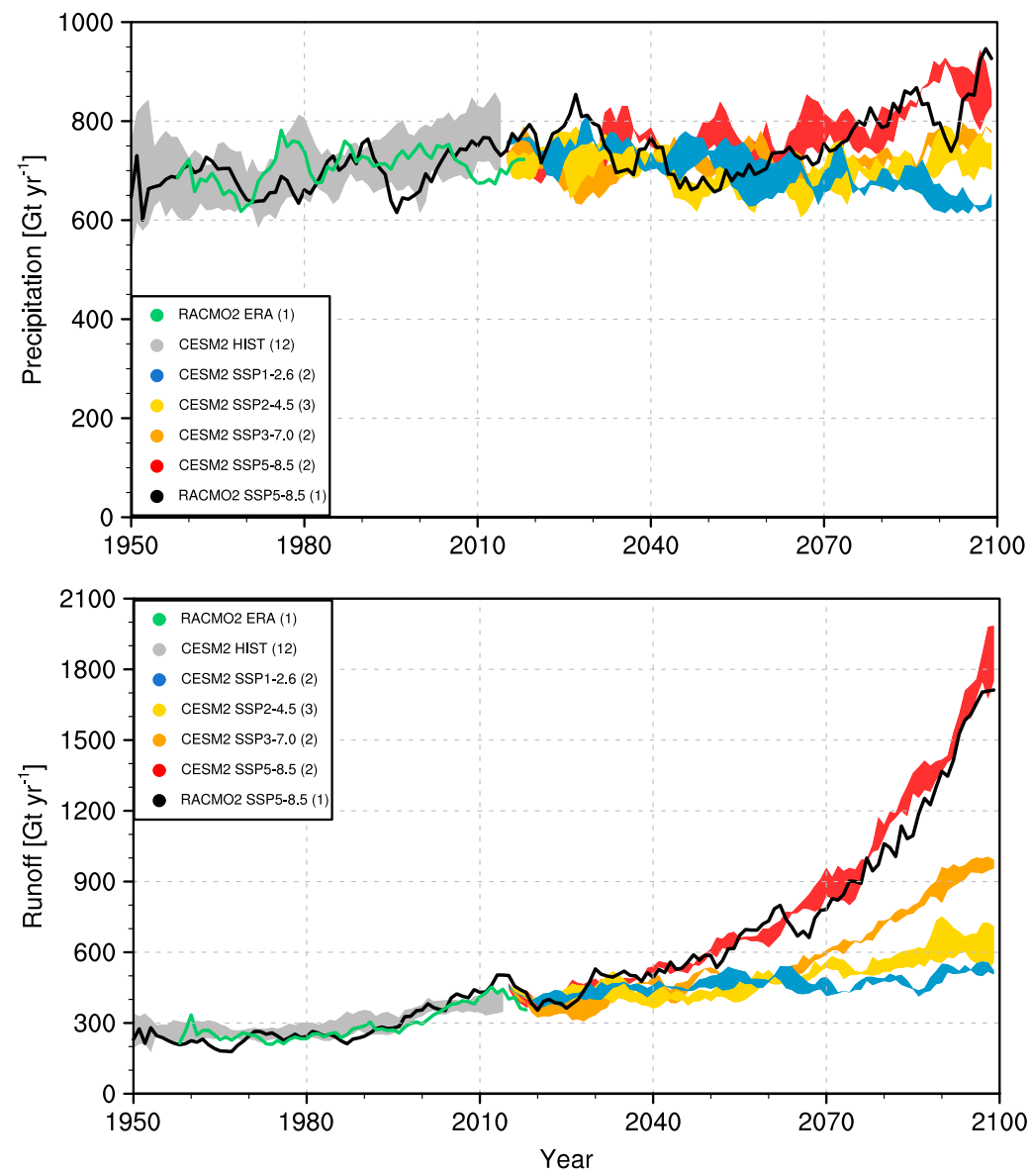

Figure 5.3: 21st century Greenland SMB components under various warming scenarios. Five-year simple moving average of GrIS precipitation (a) and runoff (b) for RACMO2 ERA ('observations', green), CESM2 historical (HIST, grey) and scenario runs (colours, see legend). Numbers in parentheses indicate number of ensemble members, coloured bands span maximum and minimum ensemble value. Black line represents RACMO2 SSP5-8.5. See Table 5.1 for experiment names.

5.1) are then used to correct SMB, precipitation, and runoff fields for all available CESM2 ensemble members (see Table 5.1, column 'Corrected SMB').

\subsection{Results}

The resulting time series are presented in Figure 5.2a for SMB and in Figure 5.3 for precipitation and runoff. Note that CESM2 is only forced with greenhouse gas and aerosol concentrations and does not assimilate observations, so that period averages, average interannual variability and trends can be compared to observations but not individual high/low SMB years. In spite of this, the historical ensemble 
members (grey; 1950-2014) agree well with the observationally-based benchmark SMB product (green line, see Table 5.1), including the relatively stable precipitation (Figure 5.3a), the recent increase in runoff (Figure 5.3b), and the resulting decrease in SMB (Figure 5.2a), and a seamless transition into the subsequent scenario runs.

Only for the SSP5-8.5 scenario does precipitation increase significantly (1.1 to $2.3 \mathrm{Gt} \mathrm{yr}^{-2}, \mathrm{p}<0.05$ ) after 2015 (Figure 5.3a), confirming the expectation that higher atmospheric temperatures will enhance snowfall in cold regions. However, the overall signal is dominated by greater runoff (Figure 5.3c) leading to an SMB decrease and surface-driven GrIS mass loss (Figure 5.2a). Most runoff ( $\sim 85 \%$ of the total) originates from the narrow and widening marginal ablation zone [Noël et al., 2019a]. In combination with the hypsometry of the ice sheet, which flattens inland, this leads to a stronger-thanlinear increase in runoff with increasing temperature (Figure 5.3b) and, in the absence of increased or only linearly increasing precipitation (Figure 5.3a), also a nonlinear decrease in SMB (Figure 5.2a). Similar but less outspoken changes are seen in the other warming scenarios (Figure 5.2a, Figure 5.3).

We consider the SMB $=0$ threshold to be exceeded when the 5 year moving average SMB becomes negative. Figure 5.2b displays five-year-averaged SMB as a function of the near-surface Greenland temperature anomaly $\left(\mathrm{T}_{\mathrm{GrIS}}\right.$ ) with respect to pre-industrial conditions (see Methods). The black points representing RACMO2 SSP5-8.5 roughly fall onto a single quadratic curve $\left(r^{2}=0.90\right)$ described by

$$
\mathrm{SMB}=-10.2 \cdot \mathrm{T}_{\mathrm{GrIS}}^{2}-51.7 \cdot \mathrm{T}_{\mathrm{GrIS}}+441.7
$$

allowing us to determine a robust regional warming threshold for which GrIS SMB becomes negative: $4.5 \pm 0.3{ }^{\circ} \mathrm{C}$ (vertical red line in 5.2b). The uncertainty in this threshold is based on the model SMB uncertainty of $48 \mathrm{Gt} \mathrm{yr}^{-1}$ (see Methods). These results are robust under inclusion of the reconstructed CESM2 scenarios (coloured dots in 5.2b), which suggests that the nonlinear dependence of SMB on $\mathrm{T}_{\mathrm{GrIS}}$ is independent of the actual scenario or ensemble member used (see Methods).

Figure 5.4 shows a map of five-year average specific (local) surface mass balance (units $\mathrm{kg} \mathrm{m}^{-2} \mathrm{yr}^{-1}$ or $\mathrm{mm}$ w.e. (water equivalent) $\mathrm{yr}^{-1}$ ) that represents the situation at the $4.5{ }^{\circ} \mathrm{C}$ warming threshold, i.e. when $\mathrm{SMB} \approx 0$. Ablation rates at the low-lying GrIS margins are enhanced by high atmospheric temperatures and the low albedo of bare ice that is exposed in the ablation zone during summer [Box et al., 2012], and in magnitude exceed the interior accumulation rates (Figure 5.4). As a result, only a relatively modest expansion of the ablation zone is required to reach $\mathrm{SMB}=0$, increasing from an average of $8 \%$ of the contiguous GrIS area in the period $1961-1990$ to $21 \%$ in $2051-2055(+163 \%)$. The strongest expansion occurs in the relatively dry southwest, from 13 to $32 \%,(+146 \%$ and in the northwest GrIS, from 7 to $19 \%$ (+171\% in line with recent observations [Noël et al., 2019a].

\subsection{Discussion}

Previous work by Gregory and Huybrechts [2006] used contemporary climate model output and a degree-day model for ablation and found a regional warming threshold of $4.5 \pm 0.9^{\circ} \mathrm{C}$, similar to our results, and a global warming threshold of $3.1 \pm 0.8^{\circ} \mathrm{C}$. Here we refine these estimates by combining recently developed state-of-the-art modeling tools. However, the temperature threshold presented in this paper should be considered conservative for two reasons. First, SMB $=0$ does not take into 


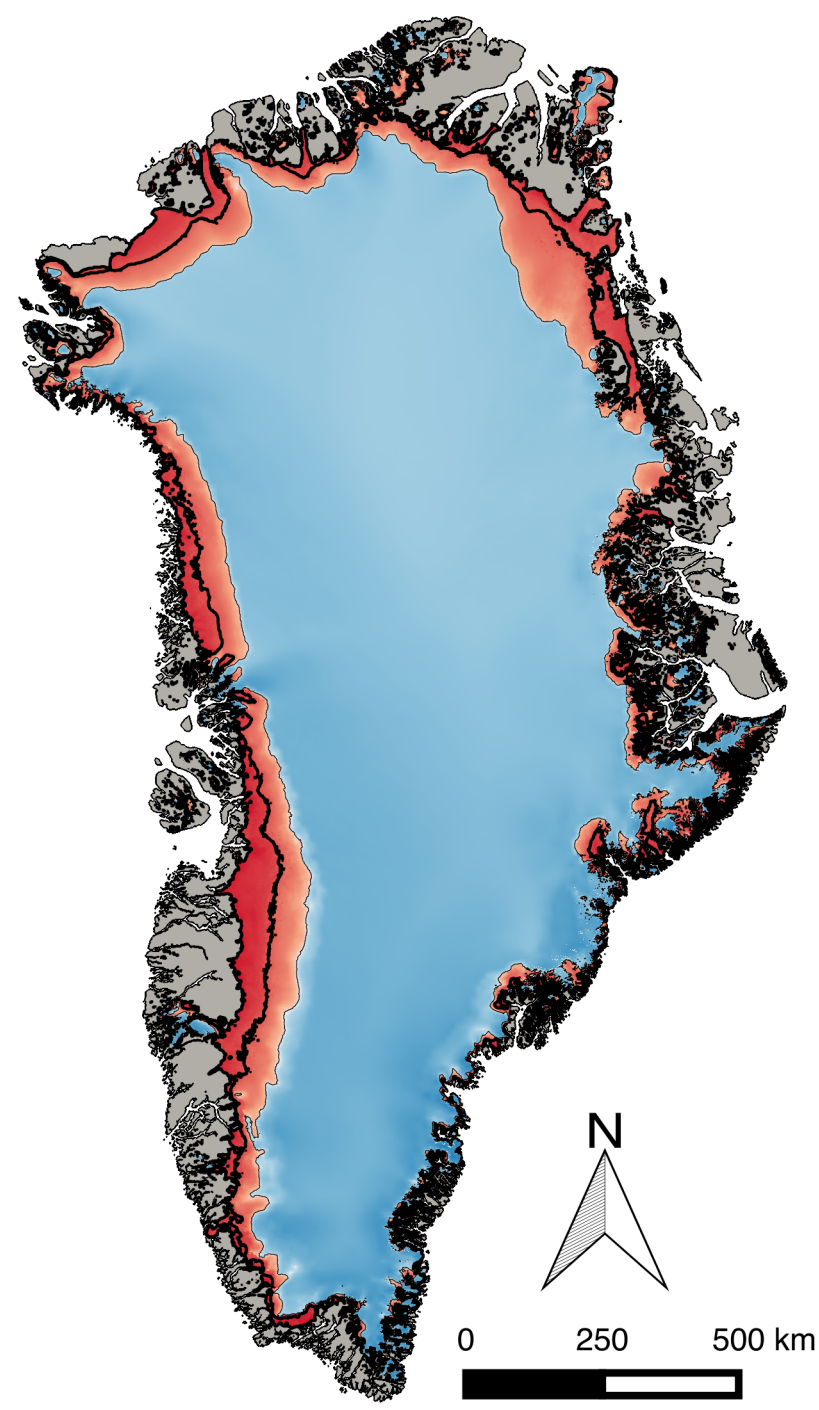

SMB

$\mathrm{mm}$ w.e. $\mathrm{yr}-1$

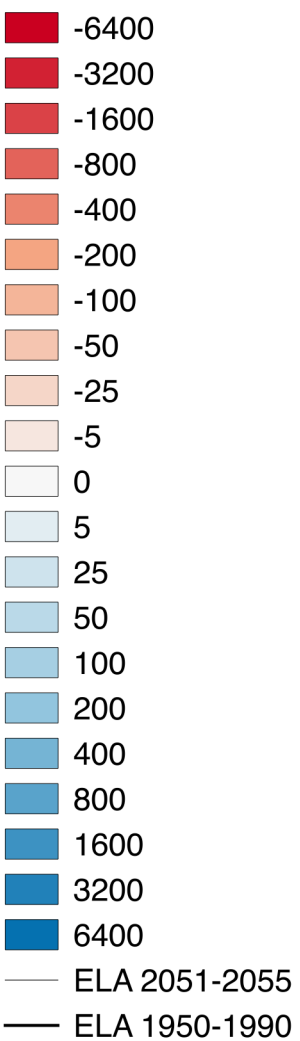

Figure 5.4: State of the Greenland ice sheet for $S M B=0$. Five-year averaged specific surface mass balance (units $\mathrm{mm}$ w.e. $y \mathrm{r}^{-1}$ ) from RACMO2 at $1 \mathrm{~km}$ resolution with the accumulation zone (where annual snow accumulation exceeds runoff) in blue and ablation zone (where runoff exceeds snow accumulation) in red. Shown are the years 2051-2055 during which the warming threshold for $S M B=0$ is first reached. Thick black line represents the equilibrium line altitude (ELA), which separates accumulation and ablation zone, for the contemporary climate (1950-1990). 

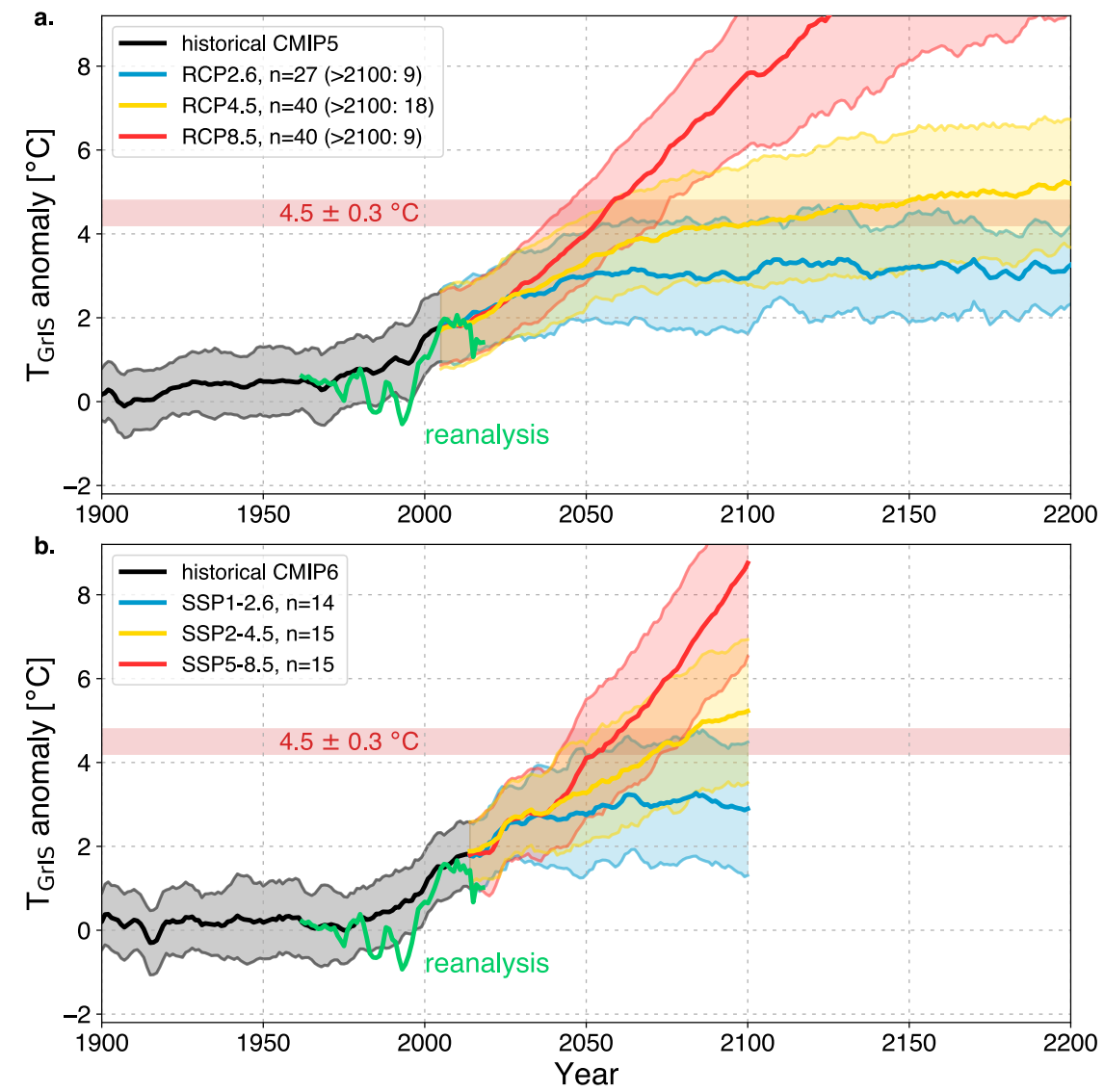

Figure 5.5: Multi-model estimate of regional Greenland warming under multiple scenario projections. Five-year simple moving average of the anomaly (relative to 1850-1899) of near-surface temperature averaged over Greenland $\left(T_{G r I S}\right)$. Presented are the model ensemble means (solid lines) and model ensemble standard deviation (shading) for all available CMIP5 (a) and CMIP6 (b) models, and three emission scenarios. Number of models included is listed in the legend as $n$. The green solid line represents a hybrid reanalysis temperature product for comparison (see Methods) and the inferred GrIS warming threshold is shown as a horizontal red bar.

account dynamical retreat of the ice sheet, a response that operates at time scales greater than the $\sim 100$ years considered here. By coupling an intermediate complexity climate model with a dynamical ice sheet model, Robinson et al. [2012] found that the GrIS may already tip towards deglaciation at SMB

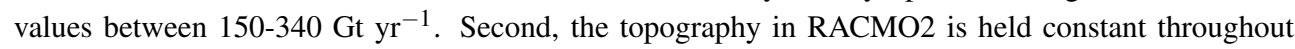
the simulation, thereby ignoring the positive melt-elevation feedback. Fettweis et al. [2013a] estimated that this feedback could cause an additional surface mass loss of $8 \pm 5 \%$ towards the end of the $21 \mathrm{st}$ century, implying a lower temperature threshold for $\mathrm{SMB}=0$. 
Table 5.2: Estimated year of crossing of the $S M B=0$ warming threshold. The $66 \%$ likely range is calculated from the uncertainties in the temperature threshold $\left( \pm 0.3{ }^{\circ} \mathrm{C}\right)$ and in the CMIP model spread $( \pm 1 \sigma)$. For CMIP5, the period 1850-2200 is considered, and for CMIP6 the period 1850-2100 due to the current unavailability of data.

\begin{tabular}{lllll} 
ensemble & period & scenario & ensemble mean & $66 \%$ likely range \\
\hline CMIP5 & $1850-2200$ & RCP2.6 & not reached & - \\
& & RCP4.5 & 2125 & {$[2037-\mathrm{N} / \mathrm{A}]$} \\
& & RCP8.5 & 2056 & {$[2034-2073]$} \\
CMIP6 & \multirow{2}{*}{$1850-2100$} & SSP1-RCP2.6 & not reached & - \\
& & SSP2-RCP4.5 & 2084 & {$[2040-\mathrm{N} / \mathrm{A}]$} \\
& & SSP3-RCP7.0 & 2073 & {$[2041-2087]$} \\
& & SSP5-RCP8.5 & 2060 & {$[2039-2079]$} \\
\hline
\end{tabular}

It is unclear by how much $\mathrm{T}_{\text {GrIS }}$ has already increased since the pre-industrial period. Observations from (mainly coastal) meteorological stations indicate a significant warming since the mid-1990s of $\sim 5^{\circ} \mathrm{C}$ in winter and $\sim 2{ }^{\circ} \mathrm{C}$ in summer [Hanna et al., 2012]. Here we consider ensemble-averaged $\mathrm{T}_{\mathrm{GrIS}}$ anomalies from the CMIP5 (Figure 5.5a) and CMIP6 (Figure 5.5b) climate model archives, with the uncertainty band representing the inter-model standard deviation. $\mathrm{T}_{\mathrm{GrIS}}$ from a hybrid ECMWF reanalysis product (Table 5.1) is scaled to the same baseline period (see Methods) and is used as a proxy for observations, with the remark that re-analyses temperature products are not well constrained over the GrIS because of poorly represented snow/ice processes in the used land model and the scarcity of near-surface observations to assimilate.

In agreement with state-of-the-art GrIS SMB estimates, the SMB $=0$ warming threshold (indicated by the horizontal red bar, Figure 5.5) has been reached in neither the reanalysis nor CMIP models up until today. Looking towards the future, the CMIP5 RCP8.5 ensemble-mean crosses the warming threshold in 2056, with a 66\% likely range of [2034 - 2073] with similar estimates for CMIP6 (Table 5.2). However, for the medium warming scenario (RCP4.5) the CMIP5 and CMIP6 archives disagree on the year of crossing. Whereas the CMIP5 ensemble mean crosses the threshold in 2125, the CMIP6 mean crosses four decades earlier (Table 5.2), which could be attributed to the higher climate sensitivities of some CMIP6 models (Zelinka and others, 2020). For both ensembles, a likely range could not be calculated due to the flatness of the curves (Figure 5.5). Finally, in the high mitigation scenario RCP2.6 the ensemble-mean remains below the warming threshold for the entire time period considered (Figure $5.5)$.

Using the CMIP ensembles, we can translate the regional threshold of $4.5 \pm 0.2{ }^{\circ} \mathrm{C}$ into a global temperature warming threshold. Figure 5.6 indicates near perfect correlation $\left(r^{2}>0.99\right)$ between $\mathrm{T}_{\mathrm{GrIS}}$ and global average surface temperature, $\mathrm{T}_{\text {global }}$, in the ensemble mean. The slope of the correlation yields a Greenland warming amplification of $~ 1.6$ in both CMIP5 and CMIP6. Results by Frieler and others (2011) suggest that these results are robust when individual models are used, rather than the ensemble mean. From the linear relationship in Figure 5.6 we derive a $\mathrm{T}_{\text {global }}$ warming threshold of $2.7 \pm 0.2^{\circ} \mathrm{C}$ for irreversible GrIS mass loss under sustained warming.

We apply the quadratic SMB- $\mathrm{T}_{\text {GrIS }}$ anomaly relation (Equation 5.1) to the CMIP5 and CMIP6 model ensembles to reconstruct 21st century SMB (Figure 5.7a) and global mean sea level rise (Figure 5.7b). 

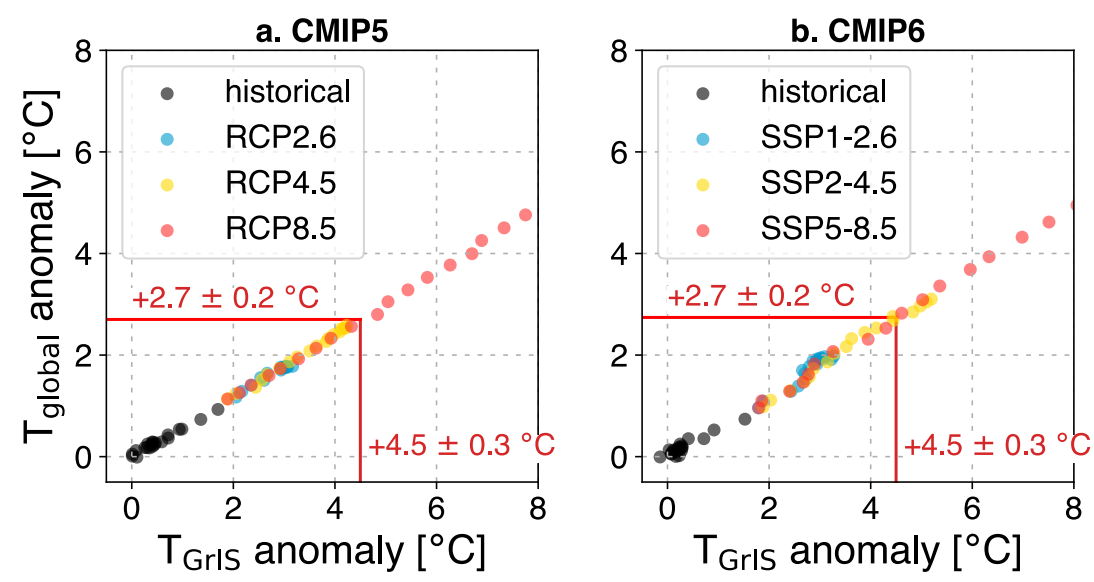

Figure 5.6: A global warming threshold for Greenland $S M B=0$. Correlation of anomalies in mean near-surface Greenland $\left(T_{G r I S}\right)$ and global $\left(T_{\text {global }}\right)$ temperature for CMIP5 $(a)$ and CMIP6 $(b)$ models. Shown are five-year block averages over the period 1900-2100 relative to the period 1850-1899. Vertical red line indicates the Greenland $S M B=0$ warming threshold, horizontal red line the associated global warming threshold.

Table 5.3: Sea level rise contribution from Greenland SMB. Values are in $\mathrm{cm}$ and represent the increase in 2081-2100 relative to 1986-2005 for the various RCP greenhouse gas scenarios. Listed is the ensemble median and likely range. The likely range represents the 5-95 percentile range, which is obtained by scaling the standard deviation by a factor of 1.645, a valid approximation under the assumption that the ensemble spread is normally distributed. SROCC stands for the IPCC Special Report on the Ocean and Cryosphere in a Changing Climate [Oppenheimer et al., 2019].

\begin{tabular}{llll} 
Scenario & $\begin{array}{l}\text { SROCC } \\
\text { Table 4.4 }\end{array}$ & $\begin{array}{l}\text { This study } \\
\text { using CMIP5 }\end{array}$ & $\begin{array}{l}\text { This study } \\
\text { using CMIP6 }\end{array}$ \\
\hline RCP 2.6 & $3[1-7]$ & $5.2[2.5-8.9]$ & $4.7[2.0-8.6]$ \\
RCP 4.5 & $4[1-9]$ & $6.6[3.4-11]$ & $6.5[3.1-11]$ \\
RCP 7.0 & n/a & n/a & $7.6[3.5-13]$ \\
RCP 8.5 & $7[3-16]$ & $10.1[5.8-16]$ & $9.6[4.5-17]$ \\
\hline
\end{tabular}

Obviously, the largest sea level rise contributions are predicted for the strongest warming scenarios $(\sim 13$ $\mathrm{cm}$ in 2100 for RCP8.5, Figure 5.7b). Substantial contributions from GrIS SMB is still expected for the strong mitigation scenarios ( $\sim 6 \mathrm{~cm}$ in 2100 for RCP2.6) since persistent GrIS mass imbalance remains even when the warming threshold is not reached. Table 5.3 summarizes 2081-2100 our global mean sea level estimates for the different scenarios and comparing them against existing IPCC values. Our median estimates are consistently higher than those of IPCC, but the likely ranges have a large overlap. It is important to note that our method is only valid for a fixed ice sheet geometry, an assumption that becomes questionable beyond 2100 [Fettweis et al., 2013a]. On these longer time scales, projections require a coupled atmosphere-ocean-ice sheet model system [Le clec'h et al., 2019]. 

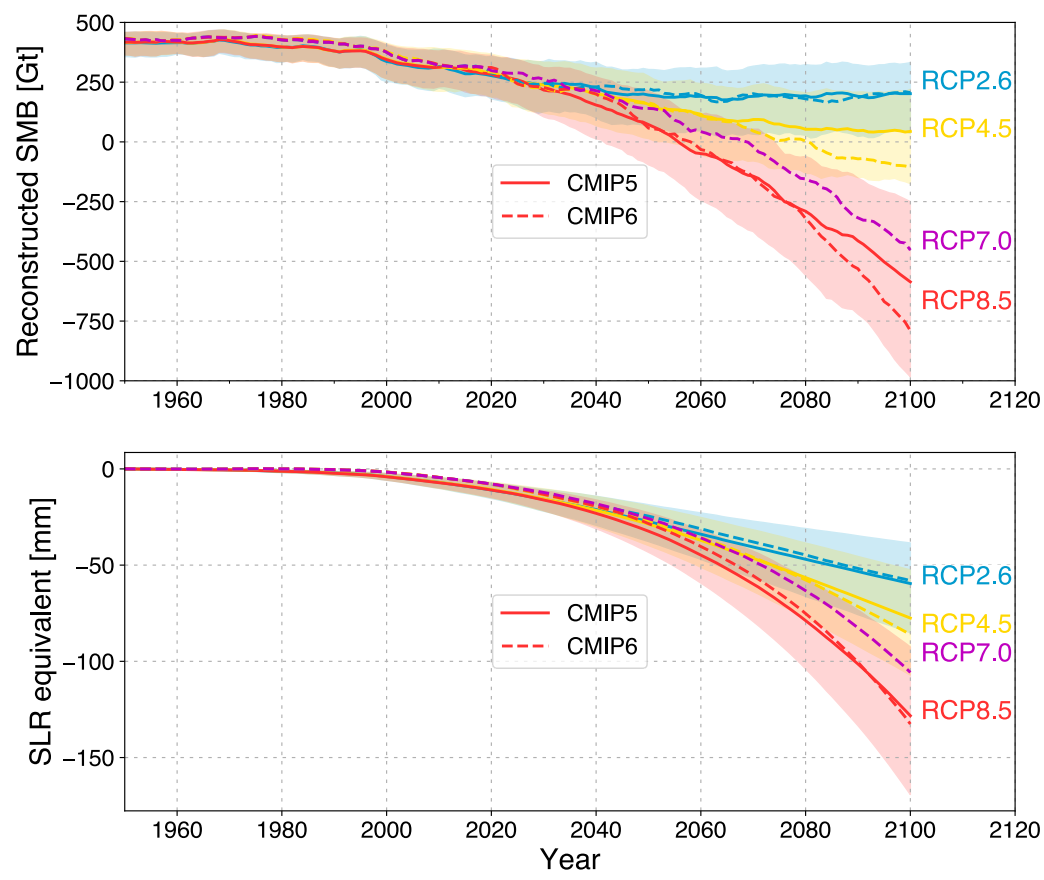

Figure 5.7: 21st century Greenland-driven sea level rise under multiple warming scenarios. (a) Time series of reconstructed GrIS SMB from the $S M B-T_{G r I S}$ relation in Fig. $1 b$, applied to ensemble mean $T_{G r I S}$ from CMIP5 and CMIP6 models and selected RCP and SSP scenarios. Lines are smoothed with 5-year running mean. Shading indicates \pm one standard deviation of the inter-model spread. (b) As (a), but showing cumulative SMB loss expressed in equivalent sea level rise with respect to the mean SMB during the period 1900-1950. No smoothing is applied here.

\subsection{Methods}

CESM2 elevation classes and SMB. Over ice sheets, CESM2 employs multiple elevation classes to downscale GrIS SMB from the $1^{\circ}(\sim 111 \mathrm{~km})$ atmosphere grid to a $4 \mathrm{~km}$ ice sheet grid as described in Chapter 4. Within each grid cell, up to 10 elevation classes are defined with weighting based on a high-resolution topographic map. Each elevation class maintains its own snow pack and downscales 2$\mathrm{m}$ temperature, humidity, downwelling longwave radiation and precipitation phase based on fixed lapse rates. Elevation class variables are aggregated on the $1^{\circ}$ grid using the topographic weights, and SMB is interpolated towards the high-resolution ice sheet grid. CESM2 implements a relatively sophisticated treatment of snow albedo [Dang et al., 2019] and firn processes (Chapter 2) and has been shown to realistically simulate GrIS climate and SMB (Chapter 4).

Dynamical and statistical downscaling. We use the regional atmospheric climate model RACMO2.3p2 at $11 \mathrm{~km}$ spatial resolution to dynamically downscale CESM2 over the greater Greenland area. Using elevation dependence, daily RACMO2 output is further statistically downscaled to a $1 \mathrm{~km}$ resolution grid, using the GIMP digital elevation model and ice mask [Howat et al., 2014]. We use a $500 \mathrm{~m}$ Moderate Resolution Imaging Spectroradiometer (MODIS) albedo product (retrieved from 
http://dx.doi.org/10.5067/MODIS/MCD43A3.006) to correct melt and runoff for underestimated bare ice albedo at the GrIS margins on the $11 \mathrm{~km}$ grid. Details about the RACMO2 settings and the statistical downscaling procedure are provided in [Noël et al., 2018] and results for present-day are presented in [Noël et al., 2019b]. Ice-sheet wide SMB is calculated by integrating specific SMB over the contiguous ice sheet. An SMB uncertainty of $48 \mathrm{Gt} \mathrm{yr}^{-1}$ is estimated for the final downscaled product by summing the mean accumulation $(20.5 \mathrm{~mm}$ w.e.) and ablation biases ( $180 \mathrm{~mm}$ w.e.) over the long-term (1950-2014) accumulation (1,521,400 km²) and ablation $\left(179,400 \mathrm{~km}^{2}\right)$ zone of the GrIS:

$$
\sigma=\sqrt{\left(\text { bias }^{\text {abl. }} \times \text { area }^{\text {abl. }}\right)^{2}+\left(\text { bias }^{\text {acc. }} \times \text { area }^{\text {acc. }}\right)^{2}}
$$

$\mathbf{T}_{\text {GrIS }}$ anomaly and uncertainty. Greenland temperature $\left(\mathrm{T}_{\mathrm{GrIS}}\right)$ is defined as the average 2-m air temperature over grid points with at least $50 \%$ land cover between $72{ }^{\circ} \mathrm{W}$ and $12{ }^{\circ} \mathrm{W}$ longitude, $59{ }^{\circ} \mathrm{N}$ and $85^{\circ} \mathrm{N}$ latitude. It is calculated per model using each model's native land sea ice mask. Hence, CMIP climate models that do not provide this mask had to be excluded. For CESM2, the $\mathrm{T}_{\mathrm{GrIS}}$ anomaly is calculated with respect to the ensemble mean of the twelve historical CESM2 members for the period 1850-1899. A $\mathrm{T}_{\mathrm{GrIS}}$ uncertainty of $0.3{ }^{\circ} \mathrm{C}$ is estimated using the quadratic regression shown in Figure

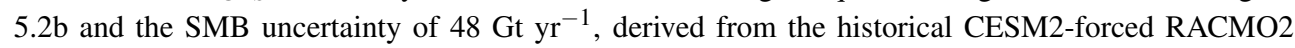
simulation at $1 \mathrm{~km}$ [Noël et al., 2019b]. For the CMIP models, the $\mathrm{T}_{\mathrm{GrIS}}$ anomaly is calculated with respect to the same reference period (1850-1899) in their historical run. Some CMIP models start later than 1850 and therefore have a shorter reference period, but never shorter than 39 years.

$\mathbf{T}_{\text {GrIS }}$ from reanalysis. Figure 3 compares $\mathrm{T}_{\text {GrIS }}$ anomalies derived from the hybrid reanalysis product (Table 5.1) to those from the CMIP5 and CMIP6 ensemble. The reanalysis anomalies are calculated with respect to the baseline period 1958-1977, and offset by the accumulated warming in that same period with respect to $1850-1899$, using the ensemble mean of the ensemble it is plotted against.

Robustness of the regression method. The regression in 5.2b was performed on the RACMO2 SSP58.5 data (black points). When including also all reconstructed CESM2 scenarios (blue, yellow and red points in Figure 5.2b, see Table 5.1) then the quadratic relation of Equation 5.1 becomes

$$
\mathrm{SMB}=-14.2 \cdot \mathrm{T}_{\mathrm{GrIS}}^{2}-12.7 \cdot \mathrm{T}_{\mathrm{GrIS}}+353
$$

with an $\mathrm{r}^{2}$ of 0.83 and an inferred SMB $=0$ threshold of $4.6 \pm 0.3{ }^{\circ} \mathrm{C}$, deviating only $0.1{ }^{\circ} \mathrm{C}$ from the result in Figure 5.2b.

Ensemble mean and spread. CMIP5 and CMIP6 ensemble means and standard deviations are calculated arithmetically from the entire ensemble without model weighting. A full list of model names will be published as a supplement to the journal article version of this Chapter [Noël et al., in review].

Reconstructed SMB and sea level rise estimates from CMIP climate models. The quadratic relationship in Equation 5.1 is applied to the ensemble mean, and the mean \pm one standard deviation. This yields the SMB time series in Figure 5.7a, and which are integrated in Figure 5.7b. Table 5.3 uses the ensemble median for consistency with the IPCC. 


\section{6}

\section{Conclusions \& Outlook}

\subsection{General conclusions from this thesis}

One important aim of this thesis is to assess and improve the representation of the surface mass balance (SMB) of the Greenland ice sheet (GrIS) in the Community Earth System Model (CESM). Modelling a realistic SMB field directly within Earth system models (ESMs) - that is, without dynamical downscaling by regional models - is an important prerequisite for tight coupling of ESMs to dynamical ice-sheet models. Such two-way coupled setups are valuable tools to hindcast and forecast sea level rise on long time scales, since they capture interactions and feedbacks between the ice sheet and the rest of the climate system (Chapter 1).

In this thesis we have shown that CESM is able to realistically simulate GrIS SMB in a physically-based way, given a few remaining model limitations, and that important progress has been made since the first application of the model over the GrIS [Vizcaíno et al., 2013]. In Chapter 2, we discussed several deficiencies in the modelling of polar snow in the land component, and implemented new parametrizations to alleviate these. In Chapter 3, the resolution-dependence of CESM SMB was tested using a novel, variable grid. In Chapter 4, we described model progress towards CESM2, and presented a detailed assessment of GrIS surface energy and mass balance (SEB and SMB) using six historical ensemble members. A complementary study by Lenaerts et al. [2020a] demonstrated that the Community Atmosphere Model version 6 (CAM6, the atmosphere component in CESM2) is so far the best CAM version for modelling clouds over Greenland, which further adds confidence to our results. On balance, we conclude that CESM2 is a capable tool in modelling GrIS SMB in a physically-based way, and is likely one of the few ESMs that can currently do this.

In Chapter 5, we used CESM2 output to determine a regional warming threshold $(\mathrm{SMB}<0)$ for the GrIS of $4.5 \pm 0.3^{\circ} \mathrm{C}$. This was translated into a global warming threshold of $2.7 \pm 0.2{ }^{\circ} \mathrm{C}$ using output from the Coupled Model Intercomparison Project (CMIP) phase 5 and 6 . These results suggests that were the Paris Agreement to succeed, meaning that the global average temperature increase is kept "well below $2{ }^{\circ} \mathrm{C}$ ", the GrIS would not retreat into irreversible mass loss. However, we recognize that our methodology is conservative and that the real threshold for irreversible mass loss is likely to be lower than our estimate. Follow-up work must determine to what extent these results would change when ice dynamical feedbacks are included, and whether the SMB-temperature relationship is robust in simulations where temperature is stabilized. 


\subsection{Modelling challenges: discussion \& recommen- dations}

In Chapter 1, we highlighted three important challenges relating to modelling ice sheet SMB directly within ESMs. Here, we revisit these challenges and discuss how the work presented in this thesis relates to them. Where applicable, we suggest recommendations for future work.

\section{Challenge 1: Grid resolution}

The first challenge concerned the model grid resolution. State-of-the-art polar regional climate models operate on grids having a grid spacing on the order of $5-20 \mathrm{~km}$, where $20 \mathrm{~km}$ is deemed an upper limit for resolving the narrow GrIS ablation zones and orographic precipitation [Rae et al., 2012]. By contrast, ESMs are limited to (global) grids in the order of $1^{\circ}(\sim 110 \mathrm{~km})$ due to computational constraints, which historically has been insufficient for a realistic simulation of GrIS SMB [Meehl et al., 2007; Cullather et al., 2014].

In this thesis, we have extensively used and evaluated the elevation classes (EC) method, a semistatistical technique introduced in CESM1 to better resolve SMB gradients [Lipscomb et al., 2013]. Chapter 4 describes how the EC downscaling method has been refined in CESM2, with a new downscaling formulation for downwelling longwave radiation and repartitioning of precipitation phase. ECindexed fluxes were downscaled offline towards the $11 \mathrm{~km}$ regional grid, allowing for a detailed spatial comparison to the state-of-the-art RACMO2 regional climate model. The effectiveness of elevation classes (ECs) was demonstrated by comparing $2 \mathrm{~m}$ temperature, downwelling longwave radiation, and turbulent heat fluxes, amongst others. Integrated over the GrIS, melt, runoff and refreezing were bracketed by RACMO2 estimates at $11 \mathrm{~km}$ (native) and $1 \mathrm{~km}$ (statistically downscaled). Without ECs, GrIS ablation zones would not nearly be resolved as realistically, as illustrated by Figure 3.3 in Chapter 3 . We believe that EC downscaling is an essential component of SMB modelling within ESMs, as long as the horizontal resolution in the atmosphere model is coarser than $\sim 25 \mathrm{~km}$ or when the topographic variability within a single grid cell exceeds $\sim 100 \mathrm{~m}$.

In Chapter 3, we have applied a regional grid refinement technique (variable resolution CESM, or VR-CESM) to the Greenland region, in an attempt to cost-effectively increase horizontal resolution. Ultimately, this may eliminate the need for semi-statistical downscaling using ECs, as well as any dynamical downscaling using regional climate models (RCMs), and enable two-way coupling to an ice sheet model (ISM) using the CESM framework. A positive result was that VR-CESM at $55 \mathrm{~km}$ and $28 \mathrm{~km}$ improve patterns of orographic precipitation and that comparisons to observational data in the accumulation zone are on-par with RCMs at the same resolution. However, with increasing resolution also biases emerged (or deepened) in ablation zones near the margins. These regressions were attributed to two independent factors, (1) cloud redistribution, causing a delay in melt; and (2) a reduced effectiveness of the EC method, exposing a previously hidden regional climate bias. These two factors could not readily be separated from one another. Still, we conclude that VR-CESM is a promising technique for GrIS SMB studies since it enables the combination of high resolution modelling while retaining feedbacks with the rest of the globe. Before scientific questions can be addressed, however, effort must be put into reducing outstanding regional climate biases that inhibited meltwater runoff in our high-resolution simulations. 


\section{Challenge 2: Atmospheric forcing}

A realistic representation of atmospheric macroproperties, such as clouds, is a prerequisite for a realistic GrIS surface radiative budget and SMB. This is challenging to ESMs, which have global scope and must employ uniform cloud parameterizations across tropics and polar regions alike. Still, rapid progress is being made on this subject, also within CESM. A recent study by Lenaerts et al. [2020a] compares atmosphere-only simulations performed with different Community Atmosphere Model (CAM) physics (CAM versions 4, 5, 6, and some intermediate versions) to ground and satellite observations, and finds that CAM6 compares best to observations in terms of cloud liquid water and longwave cloud forcing. This aligns with our results in Chapter 5, where we favorably compare cloud output from coupled CESM2 simulations to Cloudsat-CALIPSO. However, both our study and [Lenaerts et al., 2020a] indicate that the representation of clouds in CAM6 is not perfect, as for instance illustrated by biases in ice water path and longwave cloud forcing.

Atmospheric forcing was also touched upon in Chapter 3, where we looked at the performance of VRCESM in simulating GrIS SMB. Changes in cloud distribution occurred at higher resolutions due to the better refined topography. We did not test whether these new cloud distributions / surface radiative budgets are more realistic, which would require observations of cloud statistics and surface radiation at a spatial scale that currently do not exist. In the context of VR, an important modelling concept is a so-called resolution-aware parameterization, which means that cloud parameterizations should not be sensitive to changes in horizontal resolution, at least in emergent properties such as cloud forcing. Gettelman et al. [2018] demonstrates that the cloud microphysics in CAM5 and CAM6 perform much better in this respect than those in their predecessor, CAM4.

Atmospheric forcing also includes precipitation. Chapter 4 describes the rain-to-snow repartitioning scheme that was implemented into CLM, as a means to prevent unrealistic rainfall being modelled over the interior GrIS. It can be argued that this repartitioning is a physically-based bias-correction, with the underlying bias being the CAM6 precipitation phase. As suggested in Section 4.4.2, this rainfall bias should be included in a list of priorities for future model development, as it has important implications for GrIS SMB. Overall, we conclude that atmospheric forcing over ice sheets should remain a focus point for future development in CESM, but substantial progress has certainly been made over the last years.

\section{Challenge 3: Snow and radiation physics}

The third and last challenge to modelling ice-sheet SMB within ESMs relates to the physical representation of surface processes, in particular albedo and snow. In Chapter 2 we took a closer look at how CESM simulates polar snow and firn. Snow density was identified as a likely source of SMB bias through the control that snow density has on heat conduction and, indirectly, melt. This did not only impact the GrIS, but also affected seasonal snowcover and permafrost distribution [Lawrence et al., 2019], and was linked to excessive surface melt in East Antarctica [Lenaerts et al., 2016].

New parameterizations were implemented for fresh snow density and wind-driven snow compaction, and the snow overburden compaction parameters were updated, all tested to agree better with observations. The increase of the maximum snow depth to $10 \mathrm{~m}$ water equivalent (w.e.), reflecting the existence of deep firn packs, was shown to raise ice temperature through enhanced (and deeper) refreezing of 
meltwater. This is potentially an important finding in two-way coupling studies, since temperature at the firn-ice interface serves as a boundary forcing for the dynamical ice-sheet model. Most of these changes were evaluated in land-only simulations with prescribed atmospheric forcing. However, we are aware that changes in land surface properties can drive large responses in the atmospheric forcing, drawing on our own experience and on the study by Laguë et al. [2019]. Therefore, evaluation of surface parameters should also directly take place in coupled atmosphere-land simulations, which is one recommendation for future research. The computational expense, associated with long coupled simulations needed to establish a robust climatology, may be circumvented when atmospheric dynamics are prescribed/nudged [Wehrli et al., 2018].

In Chapter 4, other relevant CLM updates in CESM2 were described and evaluated. For instance, CESM2 features updated parameters for bare ice albedo and fresh grain size, which are both highly relevant parameters in simulating melt and runoff. Our results suggest that surface albedo in CESM2 is biased low, but that this may be desirable to compensate for weaker turbulent sensible heat exchange towards the surface, a problem connected to the coarse spatial resolution. Surface albedo will remain an essential quantity to assess and improve in future model versions.

Finally, below follows a non-exhaustive list of other (sub)surface processes that are deemed relevant for modelling ice-sheet SMB in ESMs, but which are either not implemented in CESM, or only very schematically, or the effect of which has not been properly quantified. Given adequate spatial resolution (Challenge 1) and improved atmospheric forcing (Challenge 2), these are subjects that may lead to further improvement of the GrIS SMB in ESMs, partly guided by similar developments taking place in RCMs.

These processes are: blowing snow sublimation and erosion [Lenaerts and van den Broeke, 2012]; soot content in snow [Tuzet et al., 2017]; physics of liquid water retention and refreezing [Verjans et al., 2019; van Angelen et al., 2012]; vertical resolution and Lagrangian snow layering [Ligtenberg et al., 2018]; bio-albedo [Stibal et al., 2017]; prognostic snow grain shape [Räisänen et al., 2017]; narrowband or spectral albedo [van Dalum et al., 2019]; ice slabs [MacFerrin et al., 2019]; water vapour fluxes in snow [Domine et al., 2019]; snow saturation and aquifers [Steger et al., 2017b,a]; heterogeneous water percolation [van As et al., 2016]; and supraglacial lakes or ice shelf hydrofracturing [Bell et al., 2018].

\subsection{Science outlook}

Constraining the rate of ice-sheet mass loss on centennial time scales is an active and societally relevant science problem (Chapter 1). ESMs with dynamically active ice-sheet models are emerging as versatile tools to map out different climate scenarios and quantify feedbacks that ice sheets have with the rest of the climate system. CESM2, as one example, is capable of modelling the interactions of the GrIS with the atmosphere and has dynamic land units that allow for glacial retreat or expansion [Danabasoglu et al., 2020]. Efforts are currently underway with CESM2 to quantify the interaction effects that the GrIS has with the rest of the climate system [e.g., Muntjewerf et al., 2020]. Here, we take a wider perspective and review some unsettled science questions that may potentially be addressed using twoway coupled ESMs.

The first question relates to the reversibility of GrIS mass loss. It is not entirely impossible that within a century, greenhouse gas concentrations would start to decrease due to a combination of direct and indi- 
rect carbon capture methods. Climate scenarios exist that reflect this possibility, the so-called overshoot scenarios [O'Neill et al., 2016]. This poses the question to what extent GrIS mass loss can be slowed down or even completely halted, if such a scenario were to play out. Of course, ice-sheet-climate feedbacks like those discussed in Chapter 1 will play a major role in determining the outcome. Previous work by [Robinson et al., 2012] indicated that there is at least one intermediate stable state of the GrIS possible in a warmer climate, and that reversibility depends on the initial rate of warming. We recognize a major potential for ESMs with active ice sheets to contribute to this science question.

The second science question concerns the role of atmospheric circulation change in future GrIS mass loss. The Greenland Blocking Index (GBI) is a simple climate variability indicator associated with greater surface melt and has been repeatedly high in summers since the 2000s [Hanna et al., 2016]. Furthermore, the high-melt year 2019 was characterized by spatial weather patterns that were very unusual. The occurrence of such patterns fell five standard deviations above the 1981-2010 mean occurrence [Tedesco and Fettweis, 2020]. It is an open question as to which extent such circulation anomalies are persistent features of a warmer world. Studies suggesting that they are express their concern that ESMs are not capturing this correctly, and imply that current GrIS mass loss estimates are too low [Hanna et al., 2018; Delhasse et al., 2018]. Others believe that the recent circulation changes are not persistent but are rather driven by multidecadal variability [Ding et al., 2014]. But even then, there is a strong need to understand the ESM shortcomings in their representation of large-scale circulation variability in the Arctic region, which obviously has a large impact on GrIS SMB.

A third science question and an active frontier is ice-ocean coupling. So far, CESM2 uses highly parameterized interactions between glacial ice and the ocean, such as the assumption that floating ice breaks off immediately when it forms. These assumptions may work to some extent for present-day Greenland where floating tongues are sparse and play a minor role, but are certainly not adequate in other regimes. For instance when modelling colder climates such as the Last Glacial Maximum, or when modelling the large marine-based ice sheet on the other side of the planet-Antarctica. Here, floating ice shelves and their interaction with the ocean (calving, sub-shelf melting) are essential processes for correctly simulating the extent and velocity of the ice. Progress is dependent on both observational understanding of processes taking place between ocean and ice, as well as increases in computational power and progress with numerical modelling [Pattyn, 2018; Hanna et al., 2020].

\subsection{The need for transformative change}

An ever-expanding array of scientific instruments including satellites, ocean-drifting robots, in-situ measurement devices (such as weather stations), and computer models (such as ESMs), are starting to form what we could call a planetary monitoring system. For the first time, this monitoring system enables humanity to diagnose the state of its home planet, interpret ongoing changes, and make informed projections for the future. In the decades to come, it is paramount that the scientific community keeps up this monitoring role which forms the basis of any global environmental management [Schellnhuber, 1999].

Nevertheless, a call for the continuation and strengthening of climate research should not delay immediate and decisive climate action. The general conclusions on climate change as put forward by the geoscientific community - and summarized in the various Intergovernmental Panel on Climate Change 


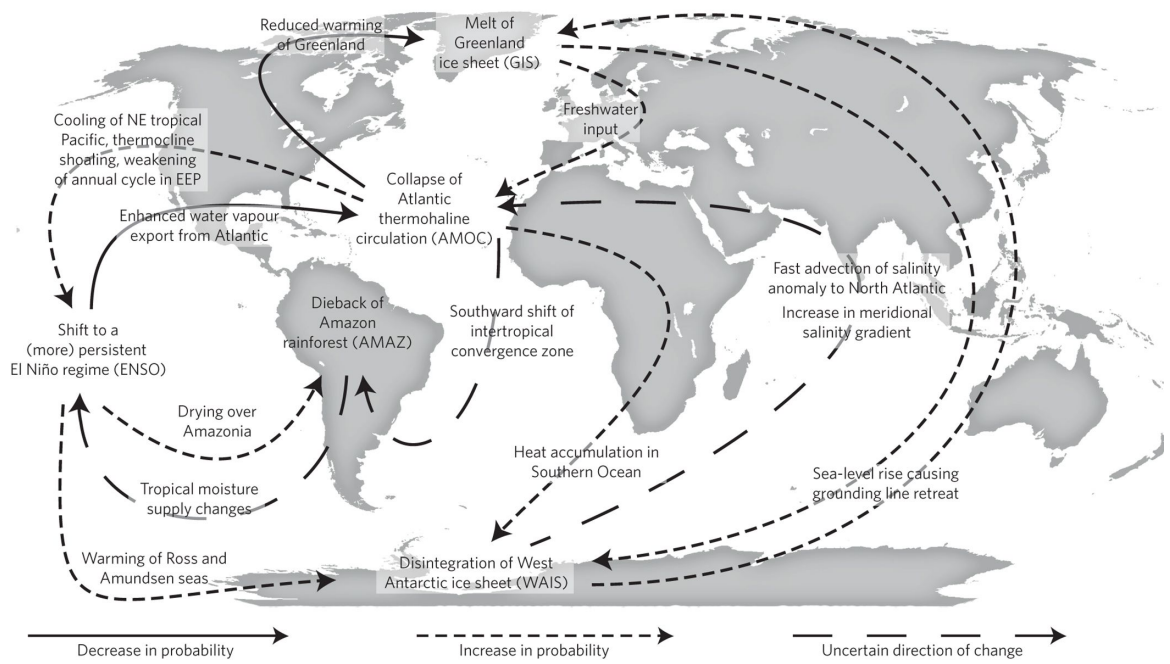

Figure 6.1: Five tipping elements in the Earth system. A tipping element is defined as a component of the Earth system that may pass a tipping point at some point. Arrows indicate possible interactions between elements. Reprinted with permission from Lenton et al. [2008].

(IPCC) reports-are well-founded and robust. The most important conclusion: the Earth's atmosphere and oceans are heating up, humans are causing it, and the impacts are visible across the globe. Humanity now knows that it is capable of qualitatively changing the state of the planetary ecosystem and by forcing these changes, it is accidentally creating a massive risk for itself (for examples of these threats, see Chapter 1). This realization is relatively fresh and is only slowly integrating into humanity's social and economic systems. The urgency of the climate problem, however, makes it paramount that the integration is sped up and that transformative changes are implemented [Díaz et al., 2019]. The challenge of transforming our economical systems, financial systems, and our behavioural patterns-all within a few decades-is enormous. Yet we recognize that it can be done. Unlike the global climate system, social and economic systems are not subject to any physical laws, and therefore flexible.

The cost of failing the climate challenge is impossible to quantify exactly. However, what we do know from geological evidence is that the response of the Earth system to external forcing is non-linear [Alley et al., 2003; Rial et al., 2004] meaning that even with a gradual increase in greenhouse gas concentrations, climate impacts may increase unexpectedly rapidly. An expanding body of literature on tipping elements in the climate system (Figure 1) adds further urgency to the situation. Would some of these elements be tipped, runaway effects start to reinforce themselves, basically putting humanity out of control at that point [Lenton et al., 2008; Drijfhout et al., 2015; Cai et al., 2016; Steffen et al., 2018]. Would such a situation occur, runaway warming beyond $5{ }^{\circ} \mathrm{C}$ is possible, which acts as an existential threat to human civilization and even the very survival of our species [Xu and Ramanathan, 2017; Spratt et al., 2018]. Obviously, it would be very unwise for humanity to take this risk [Lenton et al., 2019].

Large-scale net negative emissions have been proposed as a means to buy more time [Tollefson, 2018]. In such a scenario, transformative change could be delayed as excess carbon emissions, i.e. those above perceived 'safe' levels, would be drawn down from the atmosphere using carbon capture and 
sequestration methods. Although this sounds good on paper, we see three problems with this proposal. First, technology to draw down greenhouse gases in large amounts either does not exist or has not been tested at the scale required. Secondly, existing technologies often compete for already scarce resources such as energy or land surface. As an example, the existing technology of bio-energy with carbon capture and storage would require vast amounts of cropland which then cannot be used to feed the growing world population or secure nature's biodiversity. Thirdly, such overshoot scenarios still have the inherent risk of crossing tipping points, after which runaway climate change may occur. Eminent climate experts have therefore referred to such a scenario as "the world's biggest gamble" [Rockström et al., 2016].

In conclusion, to ensure the future prosperity of humanity on planet Earth, greenhouse gas emissions must be brought down to zero globally without further delay. After that, negative emission technology should still be applied at scale, in order to reduce adverse climate impacts already manifest [MassonDelmotte et al., 2018] and reduce the risk of crossing tipping points [Lenton et al., 2019].

"Climate change is now reaching the end-game, where very soon humanity must choose between taking unprecedented action, or accepting that it has been left too late and bear the consequences."

—Hans Joachim Schnellnhuber, climate scientist, 2018.

"What's the use of having developed a science well enough to make predictions if, in the end, all we're willing to do is stand around and wait for them to come true?"

—Sherwood Rowland, atmospheric chemist and Nobel laureate, 1986.

"Studying climate change is so much more fun than experiencing it."

—Kate Marvel, climate scientist, 2019. 


\section{Bibliography}

Alexander, P. M., Tedesco, M., Fettweis, X., van de Wal, R. S. W., Smeets, C. J. P. P., and van den Broeke, M. R. Assessing spatio-temporal variability and trends in modelled and measured Greenland Ice Sheet albedo (2000-2013). The Cryosphere, 8(6):2293-2312, Dec. 2014. ISSN 1994-0424. doi: 10.5194/tc-8-2293-2014.

Alexander, P. M., LeGrande, A. N., Fischer, E., Tedesco, M., Fettweis, X., Kelley, M., Nowicki, S. M. J., and Schmidt, G. A. Simulated Greenland Surface Mass Balance in the GISS ModelE2 GCM: Role of the Ice Sheet Surface. Journal of Geophysical Research: Earth Surface, 124(3):750-765, 2019. ISSN 2169-9011. doi: 10.1029/2018JF004772.

Alley, R. B., Marotzke, J., Nordhaus, W. D., Overpeck, J. T., Peteet, D. M., Pielke, R. A., Pierrehumbert, R. T., Rhines, P. B., Stocker, T. F., Talley, L. D., and Wallace, J. M. Abrupt Climate Change. Science, 299(5615):2005-2010, Mar. 2003. ISSN 0036-8075, 1095-9203. doi: 10.1126/science.1081056.

Anderson, E. A. A Point Energy and Mass Balance Model of a Snow Cover. NOAA Technical Report NWS 19, NOAA National Weather Service, 1976.

Arthern, R. J., Winebrenner, D. P., and Vaughan, D. G. Antarctic snow accumulation mapped using polarization of 4.3-cm wavelength microwave emission. J. Geophys. Res., 111(D6), Mar. 2006. ISSN 2156-2202. doi: 10.1029/ 2004JD005667.

Arthern, R. J., Vaughan, D. G., Rankin, A. M., Mulvaney, R., and Thomas, E. R. In situ measurements of Antarctic snow compaction compared with predictions of models. Journal of Geophysical Research: Earth Surface, 115(F3), July 2010. ISSN 0148-0227. doi: 10.1029/2009JF001306.

Aschwanden, A., Fahnestock, M. A., Truffer, M., Brinkerhoff, D. J., Hock, R., Khroulev, C., Mottram, R., and Khan, S. A. Contribution of the Greenland Ice Sheet to sea level over the next millennium. Science Advances, 5(6):eaav9396, June 2019. ISSN 2375-2548. doi: 10.1126/sciadv.aav9396.

Bacmeister, J. T., Wehner, M. F., Neale, R. B., Gettelman, A., Hannay, C., Lauritzen, P. H., Caron, J. M., and Truesdale, J. E. Exploratory High-Resolution Climate Simulations using the Community Atmosphere Model (CAM). J. Climate, 27(9):3073-3099, May 2014. ISSN 0894-8755. doi: 10.1175/JCLI-D-13-00387.1.

Bales, R. C., Guo, Q., Shen, D., McConnell, J. R., Du, G., Burkhart, J. F., Spikes, V. B., Hanna, E., and Cappelen, J. Annual accumulation for Greenland updated using ice core data developed during 2000-2006 and analysis of daily coastal meteorological data. Journal of Geophysical Research: Atmospheres, 114(D6):D06116, 2009. ISSN 2156-2202. doi: 10.1029/2008JD011208.

Bamber, J. L., Tedstone, A. J., King, M. D., Howat, I. M., Enderlin, E. M., van den Broeke, M. R., and Noel, B. Land Ice Freshwater Budget of the Arctic and North Atlantic Oceans: 1. Data, Methods, and Results. Journal of Geophysical Research: Oceans, 123(3):1827-1837, 2018a. ISSN 2169-9291. doi: 10.1002/2017JC013605.

Bamber, J. L., Westaway, R. M., Marzeion, B., and Wouters, B. The land ice contribution to sea level during the satellite era. Environ. Res. Lett., 13(6):063008, 2018b. ISSN 1748-9326. doi: 10.1088/1748-9326/aac2f0.

Beljaars, A. C. M., Brown, A. R., and Wood, N. A new parametrization of turbulent orographic form drag. Q.J.R. Meteorol. Soc., 130(599):1327-1347, Apr. 2004. ISSN 1477-870X. doi: 10.1256/qj.03.73.

Bell, R. E., Banwell, A. F., Trusel, L. D., and Kingslake, J. Antarctic surface hydrology and impacts on ice-sheet mass balance. Nature Climate Change, 8(12):1044, Dec. 2018. ISSN 1758-6798. doi: 10.1038/s41558-018-0326-3.

Bennartz, R., Shupe, M. D., Turner, D. D., Walden, V. P., Steffen, K., Cox, C. J., Kulie, M. S., Miller, N. B., and Pettersen, C. July 2012 Greenland melt extent enhanced by low-level liquid clouds. Nature, 496(7443):83-86, Apr. 2013. ISSN 0028-0836. doi: 10.1038/nature12002.

Benson, C. S. Stratigraphic Studies in the Snow and Firn of the Greenland Ice Sheet. Tech. Rep. RR70, US Cold Regions Research and Engineering Laboratory, 1962.

Bhatia, M. P., Kujawinski, E. B., Das, S. B., Breier, C. F., Henderson, P. B., and Charette, M. A. Greenland meltwater as a significant and potentially bioavailable source of iron to the ocean. Nature Geoscience, 6(4):274-278, Apr. 2013. ISSN 1752-0908. doi: 10.1038/ngeo1746.

Bogenschutz, P. A., Gettelman, A., Morrison, H., Larson, V. E., Craig, C., and Schanen, D. P. Higher-Order Turbulence Closure and Its Impact on Climate Simulations in the Community Atmosphere Model. Journal of Climate, 26(23): 9655-9676, Dec. 2013. ISSN 0894-8755, 1520-0442. doi: 10.1175/JCLI-D-13-00075.1. 
Böning, C. W., Behrens, E., Biastoch, A., Getzlaff, K., and Bamber, J. L. Emerging impact of Greenland meltwater on deepwater formation in the North Atlantic Ocean. Nature Geoscience, 9(7):523-527, July 2016. ISSN 1752-0908. doi: $10.1038 /$ ngeo 2740 .

Bougamont, M., Bamber, J. L., Ridley, J. K., Gladstone, R. M., Greuell, W., Hanna, E., Payne, A. J., and Rutt, I. Impact of model physics on estimating the surface mass balance of the Greenland ice sheet. Geophys. Res. Lett., 34(17), Sept. 2007. ISSN 1944-8007. doi: 10.1029/2007GL030700.

Box, J. E., Fettweis, X., Stroeve, J. C., Tedesco, M., Hall, D. K., and Steffen, K. Greenland ice sheet albedo feedback: Thermodynamics and atmospheric drivers. The Cryosphere, 6(4):821-839, Aug. 2012. ISSN 1994-0424. doi: 10. 5194/tc-6-821-2012.

Bromwich, D. H., Nicolas, J. P., and Monaghan, A. J. An Assessment of Precipitation Changes over Antarctica and the Southern Ocean since 1989 in Contemporary Global Reanalyses. Journal of Climate, 24(16):4189-4209, Aug. 2011. ISSN 0894-8755, 1520-0442. doi: 10.1175/2011JCLI4074.1.

Brun, E., Martin, E., and Spiridonov, V. Coupling a multi-layered snow model with a GCM. Annals of Glaciology, 25: 66-72, Jan. 1997. ISSN 0260-3055, 1727-5644. doi: 10.1017/S0260305500013811.

Brun, E., Six, D., Picard, G., Vionnet, V., Arnaud, L., Bazile, E., Boone, A., Bouchard, A., Genthon, C., Guidard, V., et al. Snow/atmosphere coupled simulation at Dome C, Antarctica. Journal of Glaciology, 57(204):721-736, 2011.

Cai, Y., Lenton, T. M., and Lontzek, T. S. Risk of multiple interacting tipping points should encourage rapid CO 2 emission reduction. Nature Clim Change, 6(5):520-525, May 2016. ISSN 1758-6798. doi: 10.1038/nclimate2964.

Church, J. A., Clark, P. U., Cazenave, A., Gregory, J. M., Jevrejeva, S., Levermann, A., Merrifield, M. A., Milne, G. A., Nerem, R. S., and Nunn, P. D. Climate change 2013: The physical science basis. Contribution of Working Group I to the Fifth Assessment Report of the Intergovernmental Panel on Climate Change. Sea level change, pages 1137-1216, 2013.

Citterio, M. and Ahlstrøm, A. P. Brief communication "The aerophotogrammetric map of Greenland ice masses". The Cryosphere, 7(2):445-449, Mar. 2013. ISSN 1994-0424. doi: 10.5194/tc-7-445-2013.

Cogley, J., Hock, R., Rasmussen, L., Arendt, A., Bauder, A., Jansson, P., Braithwaite, R., Kaser, G., Möller, M., Nicholson, L., and Zemp, M. Glossary of glacier mass balance and related terms, 2011.

Cogley, J. G. Greenland accumulation: An error model. Journal of Geophysical Research: Atmospheres, 109(D18): D18101, 2004. ISSN 2156-2202. doi: 10.1029/2003JD004449.

Cuffey, K. M. and Paterson, W. S. B. The Physics of Glaciers. Elsevier [u.a.], Amsterdam, 4. [rev.] ed edition, 2010. ISBN 978-0-12-369461-4.

Cullather, R. I. and Nowicki, S. M. J. Greenland Ice Sheet Surface Melt and Its Relation to Daily Atmospheric Conditions. Journal of Climate, 31(5):1897-1919, Mar. 2018. ISSN 0894-8755, 1520-0442. doi: 10.1175/JCLI-D-17-0447.1.

Cullather, R. I., Nowicki, S. M. J., Zhao, B., and Suarez, M. J. Evaluation of the Surface Representation of the Greenland Ice Sheet in a General Circulation Model. Journal of Climate, 27(13):4835-4856, July 2014. ISSN 0894-8755, 1520-0442. doi: 10.1175/JCLI-D-13-00635.1.

Danabasoglu, G., Lamarque, J.-F., Bacmeister, J., Bailey, D. A., DuVivier, A. K., Edwards, J., Emmons, L. K., Fasullo, J., Garcia, R., Gettelman, A., Hannay, C., Holland, M. M., Large, W. G., Lauritzen, P. H., Lawrence, D. M., Lenaerts, J. T. M., Lindsay, K., Lipscomb, W. H., Mills, M. J., Neale, R., Oleson, K. W., Otto-Bliesner, B., Phillips, A. S., Sacks, W., Tilmes, S., van Kampenhout, L., Vertenstein, M., Bertini, A., Dennis, J., Deser, C., Fischer, C., Fox-Kemper, B., Kay, J. E., Kinnison, D., Kushner, P. J., Larson, V. E., Long, M. C., Mickelson, S., Moore, J. K., Nienhouse, E., Polvani, L., Rasch, P. J., and Strand, W. G. The Community Earth System Model Version 2 (CESM2). Journal of Advances in Modeling Earth Systems, 12(2):e2019MS001916, 2020. ISSN 1942-2466. doi: 10.1029/2019MS001916.

Dang, C., Zender, C. S., and Flanner, M. G. Intercomparison and improvement of two-stream shortwave radiative transfer schemes in Earth system models for a unified treatment of cryospheric surfaces. The Cryosphere, 13(9):2325-2343, Sept. 2019. ISSN 1994-0416. doi: 10.5194/tc-13-2325-2019.

DeConto, R. M. and Pollard, D. Contribution of Antarctica to past and future sea-level rise. Nature, 531(7596):591-597, Mar. 2016. ISSN 0028-0836, 1476-4687. doi: 10.1038/nature17145.

Dee, D. P., Uppala, S. M., Simmons, A. J., Berrisford, P., Poli, P., Kobayashi, S., Andrae, U., Balmaseda, M. A., Balsamo, G., Bauer, P., Bechtold, P., Beljaars, A. C. M., van de Berg, L., Bidlot, J., Bormann, N., Delsol, C., Dragani, R., Fuentes, M., Geer, A. J., Haimberger, L., Healy, S. B., Hersbach, H., Hólm, E. V., Isaksen, L., Kållberg, P., Köhler, M., Matricardi, M., McNally, A. P., Monge-Sanz, B. M., Morcrette, J.-J., Park, B.-K., Peubey, C., de Rosnay, P., Tavolato, C., Thépaut, J.-N., and Vitart, F. The ERA-Interim reanalysis: Configuration and performance of the data assimilation system. Q.J.R. Meteorol. Soc., 137(656):553-597, Apr. 2011. ISSN 1477-870X. doi: 10.1002/qj.828.

Delhasse, A., Fettweis, X., Kittel, C., Amory, C., and Agosta, C. Brief communication: Impact of the recent atmospheric circulation change in summer on the future surface mass balance of the Greenland ice sheet. The Cryosphere Discussions, pages 1-13, Apr. 2018. ISSN 1994-0440. doi: 10.5194/tc-2018-65.

Delworth, T. L., Rosati, A., Anderson, W., Adcroft, A. J., Balaji, V., Benson, R., Dixon, K., Griffies, S. M., Lee, H.-C., Pacanowski, R. C., Vecchi, G. A., Wittenberg, A. T., Zeng, F., and Zhang, R. Simulated Climate and Climate Change 
in the GFDL CM2.5 High-Resolution Coupled Climate Model. J. Climate, 25(8):2755-2781, Nov. 2011. ISSN 0894-8755. doi: 10.1175/JCLI-D-11-00316.1.

Dennis, J. M., Edwards, J., Evans, K. J., Guba, O., Lauritzen, P. H., Mirin, A. A., St-Cyr, A., Taylor, M. A., and Worley, P. H. CAM-SE: A scalable spectral element dynamical core for the Community Atmosphere Model. The International Journal of High Performance Computing Applications, 26(1):74-89, Feb. 2012. ISSN 1094-3420. doi: $10.1177 / 1094342011428142$.

Díaz, S., Settele, J., Brondízio, E. S., Ngo, H. T., Agard, J., Arneth, A., Balvanera, P., Brauman, K. A., Butchart, S. H. M., Chan, K. M. A., Garibaldi, L. A., Ichii, K., Liu, J., Subramanian, S. M., Midgley, G. F., Miloslavich, P., Molnár, Z., Obura, D., Pfaff, A., Polasky, S., Purvis, A., Razzaque, J., Reyers, B., Chowdhury, R. R., Shin, Y.-J., VisserenHamakers, I., Willis, K. J., and Zayas, C. N. Pervasive human-driven decline of life on Earth points to the need for transformative change. Science, 366(6471), Dec. 2019. ISSN 0036-8075, 1095-9203. doi: 10.1126/science.aax3100.

Ding, Q., Wallace, J. M., Battisti, D. S., Steig, E. J., Gallant, A. J. E., Kim, H.-J., and Geng, L. Tropical forcing of the recent rapid Arctic warming in northeastern Canada and Greenland. Nature, 509(7499):209-212, May 2014. ISSN 0028-0836, 1476-4687. doi: 10.1038/nature13260.

Domine, F., Picard, G., Morin, S., Barrere, M., Madore, J.-B., and Langlois, A. Major Issues in Simulating Some Arctic Snowpack Properties Using Current Detailed Snow Physics Models: Consequences for the Thermal Regime and Water Budget of Permafrost. Journal of Advances in Modeling Earth Systems, 11(1):34-44, Jan. 2019. ISSN 1942-2466. doi: 10.1029/2018MS001445.

Drijfhout, S., Bathiany, S., Beaulieu, C., Brovkin, V., Claussen, M., Huntingford, C., Scheffer, M., Sgubin, G., and Swingedouw, D. Catalogue of abrupt shifts in Intergovernmental Panel on Climate Change climate models. PNAS, 112(43):E5777-E5786, Oct. 2015. ISSN 0027-8424, 1091-6490. doi: 10.1073/pnas.1511451112.

Dutra, E., Balsamo, G., Viterbo, P., Miranda, P. M. A., Beljaars, A., Schär, C., and Elder, K. An Improved Snow Scheme for the ECMWF Land Surface Model: Description and Offline Validation. J. Hydrometeor, 11(4):899-916, Apr. 2010. ISSN 1525-755X. doi: 10.1175/2010JHM1249.1.

Erokhina, O., Rogozhina, I., Prange, M., Bakker, P., Bernales, J., Paul, A., and Schulz, M. Dependence of slope lapse rate over the Greenland ice sheet on background climate. Journal of Glaciology, pages 1-5, Apr. 2017. ISSN 0022-1430, 1727-5652. doi: 10.1017/jog.2017.10.

Ettema, J., van den Broeke, M. R., van Meijgaard, E., van de Berg, W. J., Box, J. E., and Steffen, K. Climate of the Greenland ice sheet using a high-resolution climate model - Part 1: Evaluation. The Cryosphere, 4(4):511-527, Dec. 2010. ISSN 1994-0424. doi: 10.5194/tc-4-511-2010.

Evans, K. J., Lauritzen, P. H., Mishra, S. K., Neale, R. B., Taylor, M. A., and Tribbia, J. J. AMIP Simulation with the CAM4 Spectral Element Dynamical Core. J. Climate, 26(3):689-709, July 2012. ISSN 0894-8755. doi: 10.1175/ JCLI-D-11-00448.1.

Evans, K. J., Kennedy, J. H., Lu, D., Forrester, M. M., Price, S., Fyke, J., Bennett, A. R., Hoffman, M. J., Tezaur, I., Zender, C. S., and Vizcaíno, M. LIVVkit 2.1: Automated and extensible ice sheet model validation. Geoscientific Model Development Discussions, pages 1-31, Mar. 2018. ISSN 1991-962X. doi: 10.5194/gmd-2018-70.

Eyring, V., Bony, S., Meehl, G. A., Senior, C. A., Stevens, B., Stouffer, R. J., and Taylor, K. E. Overview of the Coupled Model Intercomparison Project Phase 6 (CMIP6) experimental design and organization. Geoscientific Model Development, 9(5):1937-1958, May 2016. ISSN 1991-9603. doi: 10.5194/gmd-9-1937-2016.

Fausto, R. S., Ahlstrøm, A. P., Van As, D., Bøggild, C. E., and Johnsen, S. J. A new present-day temperature parameterization for Greenland. Journal of Glaciology, 55(189):95-105, 2009.

Fernandoy, F., Meyer, H., Oerter, H., Wilhelms, F., Graf, W., and Schwander, J. Temporal and spatial variation of stableisotope ratios and accumulation rates in the hinterland of Neumayer station, East Antarctica. Journal of Glaciology, 56(198):673-687, Jan. 2010. ISSN 0022-1430, 1727-5652. doi: 10.3189/002214310793146296.

Fettweis, X., Franco, B., Tedesco, M., van Angelen, J. H., Lenaerts, J. T. M., van den Broeke, M. R., and Gallée, H. Estimating the Greenland ice sheet surface mass balance contribution to future sea level rise using the regional atmospheric climate model MAR. The Cryosphere, 7(2):469-489, Mar. 2013a. ISSN 1994-0424. doi: 10.5194/ tc-7-469-2013.

Fettweis, X., Hanna, E., Lang, C., Belleflamme, A., Erpicum, M., and Gallée, H. Brief communication: Important role of the mid-tropospheric atmospheric circulation in the recent surface melt increase over the Greenland ice sheet. The Cryosphere, 7(1):241-248, Feb. 2013b. ISSN 1994-0424. doi: 10.5194/tc-7-241-2013.

Fettweis, X., Box, J. E., Agosta, C., Amory, C., Kittel, C., Lang, C., van As, D., Machguth, H., and Gallée, H. Reconstructions of the 1900-2015 Greenland ice sheet surface mass balance using the regional climate MAR model. The Cryosphere, 11(2):1015-1033, Apr. 2017. ISSN 1994-0416. doi: 10.5194/tc-11-1015-2017.

Fettweis, X., Hofer, S., Krebs-Kanzow, U., Amory, C., Aoki, T., Berends, C. J., Born, A., Box, J. E., Delhasse, A., Fujita, K., Gierz, P., Goelzer, H., Hanna, E., Hashimoto, A., Huybrechts, P., Kapsch, M.-L., King, M. D., Kittel, C., Lang, C., Langen, P. L., Lenaerts, J. T. M., Liston, G. E., Lohmann, G., Mernild, S. H., Mikolajewicz, U., Modali, K., Mottram, R. H., Niwano, M., Noël, B., Ryan, J. C., Smith, A., Streffing, J., Tedesco, M., van de Berg, W. J., 
van den Broeke, M., van de Wal, R. S. W., van Kampenhout, L., Wilton, D., Wouters, B., Ziemen, F., and Zolles, T. GrSMBMIP: Intercomparison of the modelled 1980\&ndash;2012 surface mass balance over the Greenland Ice sheet. The Cryosphere Discussions, pages 1-35, Jan. 2020. ISSN 1994-0416. doi: 10.5194/tc-2019-321.

Fichefet, T., Poncin, C., Goosse, H., Huybrechts, P., Janssens, I., and Treut, H. L. Implications of changes in freshwater flux from the Greenland ice sheet for the climate of the 21st century. Geophysical Research Letters, 30(17), 2003. ISSN 1944-8007. doi: 10.1029/2003GL017826.

Fischer, R., Nowicki, S., Kelley, M., and Schmidt, G. A System of Conservative Regridding for Ice-Atmosphere Coupling in a General Circulation Model (GCM). Geoscientific Model Development, 7:p. 883-907, Dec. 2014. doi: 10.5194/ gmd-7-883-2014.

Flanner, M. G. and Zender, C. S. Snowpack radiative heating: Influence on Tibetan Plateau climate. Geophysical Research Letters, 32(6):L06501, 2005. ISSN 0094-8276. doi: 10.1029/2004GL022076.

Flanner, M. G. and Zender, C. S. Linking snowpack microphysics and albedo evolution. Journal of Geophysical Research, 111(D12), 2006. ISSN 0148-0227. doi: 10.1029/2005JD006834.

Flanner, M. G., Zender, C. S., Randerson, J. T., and Rasch, P. J. Present-day climate forcing and response from black carbon in snow. Journal of Geophysical Research: Atmospheres, 112(D11), 2007. ISSN 2156-2202. doi: 10.1029/ 2006JD008003.

Forster, R. R., Box, J. E., van den Broeke, M. R., Miège, C., Burgess, E. W., van Angelen, J. H., Lenaerts, J. T. M., Koenig, L. S., Paden, J., Lewis, C., Gogineni, S. P., Leuschen, C., and McConnell, J. R. Extensive liquid meltwater storage in firn within the Greenland ice sheet. Nature Geoscience, 7(2):95-98, Dec. 2013. ISSN 1752-0894, 17520908. doi: 10.1038/ngeo2043.

Fyke, J., Sergienko, O., Löfverström, M., Price, S., and Lenaerts, J. T. M. An Overview of Interactions and Feedbacks Between Ice Sheets and the Earth System. Reviews of Geophysics, 56(2):361-408, 2018. ISSN 1944-9208. doi: 10.1029/2018RG000600.

Fyke, J. G., Vizcaíno, M., Lipscomb, W., and Price, S. Future climate warming increases Greenland ice sheet surface mass balance variability. Geophysical Research Letters, 41(2):470-475, Jan. 2014a. ISSN 00948276. doi: 10.1002/ 2013 GL058172.

Fyke, J. G., Vizcaíno, M., and Lipscomb, W. H. The pattern of anthropogenic signal emergence in Greenland Ice Sheet surface mass balance. Geophysical Research Letters, 41(16):6002-6008, Aug. 2014b. ISSN 00948276. doi: 10.1002/2014GL060735.

Gates, W. L., Boyle, J. S., Covey, C., Dease, C. G., Doutriaux, C. M., Drach, R. S., Fiorino, M., Gleckler, P. J., Hnilo, J. J., Marlais, S. M., Phillips, T. J., Potter, G. L., Santer, B. D., Sperber, K. R., Taylor, K. E., and Williams, D. N. An Overview of the Results of the Atmospheric Model Intercomparison Project (AMIP I). Bull. Amer. Meteor. Soc., 80 (1):29-56, Jan. 1999. ISSN 0003-0007. doi: 10.1175/1520-0477(1999)080<0029:AOOTRO>2.0.CO;2.

Gerdes, R., Hurlin, W., and Griffies, S. M. Sensitivity of a global ocean model to increased run-off from Greenland. Ocean Modelling, 12(3):416-435, Jan. 2006. ISSN 1463-5003. doi: 10.1016/j.ocemod.2005.08.003.

Gettelman, A. and Morrison, H. Advanced Two-Moment Bulk Microphysics for Global Models. Part I: Off-Line Tests and Comparison with Other Schemes. J. Climate, 28(3):1268-1287, Sept. 2014. ISSN 0894-8755. doi: 10.1175/ JCLI-D-14-00102.1.

Gettelman, A., Morrison, H., Santos, S., Bogenschutz, P., and Caldwell, P. M. Advanced Two-Moment Bulk Microphysics for Global Models. Part II: Global Model Solutions and Aerosol-Cloud Interactions. J. Climate, 28(3): 1288-1307, Sept. 2014. ISSN 0894-8755. doi: 10.1175/JCLI-D-14-00103.1.

Gettelman, A., Callaghan, P., Larson, V. E., Zarzycki, C. M., Bacmeister, J., Lauritzen, P. H., Bogenschutz, P. A., and Neale, R. Regional Climate Simulations With the Community Earth System Model. Journal of Advances in Modeling Earth Systems, 10:1245-1265, Mar. 2018. ISSN 19422466. doi: 10.1002/2017MS001227.

Gettelman, A., Truesdale, J. E., Bacmeister, J. T., Caldwell, P. M., Neale, R. B., Bogenschutz, P. A., and Simpson, I. R. The Single Column Atmosphere Model Version 6 (SCAM6): Not a Scam but a Tool for Model Evaluation and Development. Journal of Advances in Modeling Earth Systems, 11(5):1381-1401, 2019. ISSN 1942-2466. doi: 10.1029/2018MS001578.

Gillard, L. C., Hu, X., Myers, P. G., and Bamber, J. L. Meltwater pathways from marine terminating glaciers of the Greenland ice sheet. Geophysical Research Letters, 43(20):10,873-10,882, Oct. 2016. ISSN 0094-8276. doi: 10. 1002/2016GL070969.

Goelzer, H., Huybrechts, P., Fürst, J. J., Nick, F. M., Andersen, M. L., Edwards, T. L., Fettweis, X., Payne, A. J., and Shannon, S. Sensitivity of Greenland Ice Sheet Projections to Model Formulations. Journal of Glaciology, 59(216): 733-749, Jan. 2013. ISSN 0022-1430, 1727-5652. doi: 10.3189/2013JoG12J182.

Goelzer, H., Robinson, A., Seroussi, H., and Wal, R. Recent Progress in Greenland Ice Sheet Modelling. Current Climate Change Reports, Nov. 2017. doi: 10.1007/s40641-017-0073-y.

Goelzer, H., Nowicki, S., Edwards, T., Beckley, M., Abe-Ouchi, A., Aschwanden, A., Calov, R., Gagliardini, O., GilletChaulet, F., Golledge, N. R., Gregory, J., Greve, R., Humbert, A., Huybrechts, P., Kennedy, J. H., Larour, E., Lip- 
scomb, W. H., Le clec'h, S., Lee, V., Morlighem, M., Pattyn, F., Payne, A. J., Rodehacke, C., Rückamp, M., Saito, F., Schlegel, N., Seroussi, H., Shepherd, A., Sun, S., van de Wal, R., and Ziemen, F. A. Design and results of the ice sheet model initialisation experiments initMIP-Greenland: An ISMIP6 intercomparison. The Cryosphere, 12(4): 1433-1460, Apr. 2018. ISSN 1994-0424. doi: 10.5194/tc-12-1433-2018.

Goelzer, H., Noel, B. P. Y., Edwards, T. L., Fettweis, X., Gregory, J. M., Lipscomb, W. H., van de Wal, R. S. W., and van den Broeke, M. R. Remapping of Greenland ice sheet surface mass balance anomalies for large ensemble sealevel change projections. The Cryosphere Discussions, pages 1-20, Sept. 2019. ISSN 1994-0416. doi: 10.5194/ tc-2019-188.

Goelzer, H., Nowicki, S., Payne, A., Larour, E., Seroussi, H., Lipscomb, W. H., Gregory, J., Abe-Ouchi, A., Shepherd, A., Simon, E., Agosta, C., Alexander, P., Aschwanden, A., Barthel, A., Calov, R., Chambers, C., Choi, Y., Cuzzone, J., Dumas, C., Edwards, T., Felikson, D., Fettweis, X., Golledge, N. R., Greve, R., Humbert, A., Huybrechts, P., Clec'h, S. L., Lee, V., Leguy, G., Little, C., Lowry, D. P., Morlighem, M., Nias, I., Quiquet, A., Rückamp, M., Schlegel, N.-J., Slater, D., Smith, R., Straneo, F., Tarasov, L., van de Wal, R., and van den Broeke, M. The future sea-level contribution of the Greenland ice sheet: A multi-model ensemble study of ISMIP6. The Cryosphere Discussions, pages 1-43, Jan. 2020. ISSN 1994-0416. doi: 10.5194/tc-2019-319.

Graf, W. and Oerter, H. High resolution density, conductivity, deuterium, and d180 of ice core FRI09C90_13, Nov. 2006.

Gregory, J. and Huybrechts, P. Ice-sheet contributions to future sea-level change. Philosophical Transactions of the Royal Society A: Mathematical, Physical and Engineering Sciences, 364(1844):1709-1732, July 2006. doi: 10.1098/ rsta.2006.1796.

Greuell, W. and Konzelmann, T. Numerical modelling of the energy balance and the englacial temperature of the Greenland Ice Sheet. Calculations for the ETH-Camp location (West Greenland, $1155 \mathrm{~m}$ asl). Global and Planetary change, 9(1-2):91-114, 1994.

Groot Zwaaftink, C. D., Cagnati, A., Crepaz, A., Fierz, C., Macelloni, G., Valt, M., and Lehning, M. Event-driven deposition of snow on the Antarctic Plateau: Analyzing field measurements with SNOWPACK. The Cryosphere, 7 (1):333-347, Feb. 2013. ISSN 1994-0424. doi: 10.5194/tc-7-333-2013.

Guba, O., Taylor, M. A., Ullrich, P. A., Overfelt, J. R., and Levy, M. N. The spectral element method (SEM) on variableresolution grids: Evaluating grid sensitivity and resolution-aware numerical viscosity. Geosci. Model Dev., 7(6): 2803-2816, Nov. 2014. ISSN 1991-9603. doi: 10.5194/gmd-7-2803-2014.

Guyomarc'h, G. and Mérindol, L. Validation of an application for forecasting blowing snow. Annals of Glaciology, 26 (1):138-143, Jan. 1998. doi: 10.3198/1998AoG26-1-138-143.

Haarsma, R. J., Roberts, M. J., Vidale, P. L., Senior, C. A., Bellucci, A., Bao, Q., Chang, P., Corti, S., Fučkar, N. S., Guemas, V., von Hardenberg, J., Hazeleger, W., Kodama, C., Koenigk, T., Leung, L. R., Lu, J., Luo, J.-J., Mao, J., Mizielinski, M. S., Mizuta, R., Nobre, P., Satoh, M., Scoccimarro, E., Semmler, T., Small, J., and von Storch, J.-S. High Resolution Model Intercomparison Project (HighResMIP v1.0) for CMIP6. Geoscientific Model Development, 9(11):4185-4208, Nov. 2016. ISSN 1991-9603. doi: 10.5194/gmd-9-4185-2016.

Hanna, E., Huybrechts, P., Janssens, I., Cappelen, J., Steffen, K., and Stephens, A. Runoff and mass balance of the Greenland ice sheet: 1958-2003. Journal of Geophysical Research: Atmospheres, 110(D13), 2005. ISSN 21562202. doi: 10.1029/2004JD005641.

Hanna, E., Mernild, S. H., Cappelen, J., and Steffen, K. Recent warming in Greenland in a long-term instrumental (1881-2012) climatic context: I. Evaluation of surface air temperature records. Environ. Res. Lett., 7(4):045404, Oct. 2012. ISSN 1748-9326. doi: 10.1088/1748-9326/7/4/045404.

Hanna, E., Cropper, T. E., Hall, R. J., and Cappelen, J. Greenland Blocking Index 1851-2015: A regional climate change signal. Int. J. Climatol., 36(15):4847-4861, Dec. 2016. ISSN 1097-0088. doi: 10.1002/joc.4673.

Hanna, E., Fettweis, X., and Hall, R. J. Brief communication: Recent changes in summer Greenland blocking captured by none of the CMIP5 models. The Cryosphere, 12(10):3287-3292, Oct. 2018. ISSN 1994-0416. doi: 10.5194/ tc-12-3287-2018.

Hanna, E., Pattyn, F., Navarro, F., Favier, V., Goelzer, H., van den Broeke, M. R., Vizcaino, M., Whitehouse, P. L., Ritz, C., Bulthuis, K., and Smith, B. Mass balance of the ice sheets and glaciers - Progress since AR5 and challenges. Earth-Science Reviews, 201:102976, Feb. 2020. ISSN 0012-8252. doi: 10.1016/j.earscirev.2019.102976.

Helsen, M. M., Van Den Broeke, M. R., Van De Wal, R. S., Van De Berg, W. J., Van Meijgaard, E., Davis, C. H., Li, Y., and Goodwin, I. Elevation changes in Antarctica mainly determined by accumulation variability. Science, 320(5883): $1626-1629,2008$.

Helsen, M. M., van de Berg, W. J., van de Wal, R. S. W., van den Broeke, M. R., and Oerlemans, J. Coupled regional climate-ice-sheet simulation shows limited Greenland ice loss during the Eemian. Clim. Past, 9(4):1773-1788, Aug. 2013. ISSN 1814-9332. doi: 10.5194/cp-9-1773-2013. 
Helsen, M. M., van de Wal, R. S. W., Reerink, T. J., Bintanja, R., Madsen, M. S., Yang, S., Li, Q., and Zhang, Q. On the importance of the albedo parameterization for the mass balance of the Greenland ice sheet in EC-Earth. The Cryosphere, 11(4):1949-1965, Aug. 2017. ISSN 1994-0424. doi: 10.5194/tc-11-1949-2017.

Hermann, M., Box, J. E., Fausto, R. S., Colgan, W. T., Langen, P. L., Mottram, R., Wuite, J., Noël, B., van den Broeke, M. R., and van As, D. Application of PROMICE Q-Transect in Situ Accumulation and Ablation Measurements (2000-2017) to Constrain Mass Balance at the Southern Tip of the Greenland Ice Sheet. Journal of Geophysical Research: Earth Surface, 2018. ISSN 2169-9011. doi: 10.1029/2017JF004408.

Herrington, A. and Reed, K. An Idealized Test of the Response of the Community Atmosphere Model to Near-GridScale Forcing Across Hydrostatic Resolutions. Journal of Advances in Modeling Earth Systems, 10(2):560-575, Mar. 2018. ISSN 1942-2466. doi: 10.1002/2017MS001078.

Herron, M. M. and Langway, C. C. Firn Densification: An Empirical Model. Journal of Glaciology, 25(93):373-385, 1980. doi: 10.3189/S0022143000015239.

Howat, I. M., Negrete, A., and Smith, B. E. The Greenland Ice Mapping Project (GIMP) land classification and surface elevation data sets. The Cryosphere, 8(4):1509-1518, Aug. 2014. ISSN 1994-0424. doi: 10.5194/tc-8-1509-2014.

Hu, A., Meehl, G. A., Han, W., and Yin, J. Transient response of the MOC and climate to potential melting of the Greenland Ice Sheet in the 21st century. Geophys. Res. Lett., 36(10), May 2009. ISSN 1944-8007. doi: 10.1029/ 2009GL037998.

Hu, A., Meehl, G. A., Han, W., Yin, J., Wu, B., and Kimoto, M. Influence of Continental Ice Retreat on Future Global Climate. J. Climate, 26(10):3087-3111, Nov. 2012. ISSN 0894-8755. doi: 10.1175/JCLI-D-12-00102.1.

Huang, X., Rhoades, A. M., Ullrich, P. A., and Zarzycki, C. M. An evaluation of the variable-resolution CESM for modeling California's climate. J. Adv. Model. Earth Syst., 8(1):345-369, Mar. 2016. ISSN 1942-2466. doi: 10.1002/ 2015 MS000559.

Hunke, E. C., Lipscomb, W. H., Turner, A. K., Jeffery, N., and Elliott, S. CICE: The Los Alamos Sea Ice Model Documentation and Software User's Manual Version 4.1 LA-CC-06-012. T-3 Fluid Dynamics Group, Los Alamos National Laboratory, 675, 2010.

Hunke, E. C., Lipscomb, W. H., Turner, A. K., Jeffery, N., and Elliott, S. CICE: The Los Alamos Sea Ice Model Documentation and Software User's Manual Version 5. page 116, 2015.

Hurrell, J. W., Hack, J. J., Shea, D., Caron, J. M., and Rosinski, J. A New Sea Surface Temperature and Sea Ice Boundary Dataset for the Community Atmosphere Model. J. Climate, 21(19):5145-5153, Oct. 2008. ISSN 0894-8755. doi: 10.1175/2008JCLI2292.1.

Hurrell, J. W., Holland, M. M., Gent, P. R., Ghan, S., Kay, J. E., Kushner, P. J., Lamarque, J.-F., Large, W. G., Lawrence, D., Lindsay, K., Lipscomb, W. H., Long, M. C., Mahowald, N., Marsh, D. R., Neale, R. B., Rasch, P., Vavrus, S., Vertenstein, M., Bader, D., Collins, W. D., Hack, J. J., Kiehl, J., and Marshall, S. The Community Earth System Model: A Framework for Collaborative Research. Bull. Amer. Meteor. Soc., 94(9):1339-1360, Feb. 2013. ISSN 0003-0007. doi: 10.1175/BAMS-D-12-00121.1.

Huybrechts, P., Letreguilly, A., and Reeh, N. The Greenland ice sheet and greenhouse warming. Global and Planetary Change, 3(4):399-412, Mar. 1991. ISSN 0921-8181. doi: 10.1016/0921-8181(91)90119-H.

Jennings, K. S., Winchell, T. S., Livneh, B., and Molotch, N. P. Spatial variation of the rain-snow temperature threshold across the Northern Hemisphere. Nature Communications, 9(1):1148, Mar. 2018. ISSN 2041-1723. doi: 10.1038/ s41467-018-03629-7.

Jordan, R. A one-dimensional temperature model for a snow cover: Technical documentation for SNTHERM. 89. Technical report, Cold Regions Research and Engineering Lab, Hanover, NH, 1991.

Karlsson, K.-G., Anttila, K., Trentmann, J., Stengel, M., Fokke Meirink, J., Devasthale, A., Hanschmann, T., Kothe, S., Jääskeläinen, E., Sedlar, J., Benas, N., van Zadelhoff, G.-J., Schlundt, C., Stein, D., Finkensieper, S., Håkansson, N., and Hollmann, R. CLARA-A2: The second edition of the CM SAF cloud and radiation data record from 34 years of global AVHRR data. Atmospheric Chemistry and Physics, 17(9):5809-5828, May 2017. ISSN 1680-7316. doi: 10.5194/acp-17-5809-2017.

Kay, J. E., Deser, C., Phillips, A., Mai, A., Hannay, C., Strand, G., Arblaster, J. M., Bates, S. C., Danabasoglu, G., Edwards, J., Holland, M., Kushner, P., Lamarque, J.-F., Lawrence, D., Lindsay, K., Middleton, A., Munoz, E., Neale, R., Oleson, K., Polvani, L., and Vertenstein, M. The Community Earth System Model (CESM) Large Ensemble Project: A Community Resource for Studying Climate Change in the Presence of Internal Climate Variability. Bulletin of the American Meteorological Society, 96(8):1333-1349, Aug. 2015. ISSN 0003-0007, 1520-0477. doi: 10.1175/ BAMS-D-13-00255.1.

Kay, J. E., Bourdages, L., Miller, N. B., Morrison, A., Yettella, V., Chepfer, H., and Eaton, B. Evaluating and improving cloud phase in the Community Atmosphere Model version 5 using spaceborne lidar observations. J. Geophys. Res. Atmos., 121(8):2015JD024699, Apr. 2016. ISSN 2169-8996. doi: 10.1002/2015JD024699.

Kennedy, J. H., Bennett, A. R., Evans, K. J., Price, S., Hoffman, M., Lipscomb, W. H., Fyke, J., Vargo, L., Boghozian, A., Norman, M., and Worley, P. H. LIVVkit: An extensible, python-based, land ice verification and validation toolkit 
for ice sheet models. Journal of Advances in Modeling Earth Systems, 9(2):854-869, 2017. ISSN 1942-2466. doi: 10.1002/2017MS000916.

Khan, S. A., Aschwanden, A., Bjørk, A. A., Wahr, J., Kjeldsen, K. K., and Kjær, K. H. Greenland ice sheet mass balance: A review. Reports on Progress in Physics, 78(4):046801, Apr. 2015. ISSN 0034-4885, 1361-6633. doi: 10.1088/0034-4885/78/4/046801.

Kjeldsen, K. K., Korsgaard, N. J., Bjørk, A. A., Khan, S. A., Box, J. E., Funder, S., Larsen, N. K., Bamber, J. L., Colgan, W., van den Broeke, M., Siggaard-Andersen, M.-L., Nuth, C., Schomacker, A., Andresen, C. S., Willerslev, E., and Kjær, K. H. Spatial and temporal distribution of mass loss from the Greenland Ice Sheet since AD 1900. Nature, 528 (7582):396-400, Dec. 2015. ISSN 0028-0836, 1476-4687. doi: 10.1038/nature16183.

Kuipers Munneke, P., Ligtenberg, S. R. M., Noël, B. P. Y., Howat, I. M., Box, J. E., Mosley-Thompson, E., McConnell, J. R., Steffen, K., Harper, J. T., Das, S. B., and van den Broeke, M. R. Elevation change of the Greenland Ice Sheet due to surface mass balance and firn processes, 1960-2014. The Cryosphere, 9(6):2009-2025, Nov. 2015. ISSN 1994-0424. doi: 10.5194/tc-9-2009-2015.

Kuo, C., Feldman, D. R., Huang, X., Flanner, M., Yang, P., and Chen, X. Time-Dependent Cryospheric Longwave Surface Emissivity Feedback in the Community Earth System Model. Journal of Geophysical Research: Atmospheres, Jan. 2018. ISSN 2169897X. doi: 10.1002/2017JD027595.

Lacour, A., Chepfer, H., Miller, N. B., Shupe, M. D., Noel, V., Fettweis, X., Gallee, H., Kay, J. E., Guzman, R., and Cole, J. How Well Are Clouds Simulated over Greenland in Climate Models? Consequences for the Surface Cloud Radiative Effect over the Ice Sheet. J. Climate, 31(22):9293-9312, Sept. 2018. ISSN 0894-8755. doi: 10.1175/ JCLI-D-18-0023.1.

Laguë, M. M., Bonan, G. B., and Swann, A. L. S. Separating the Impact of Individual Land Surface Properties on the Terrestrial Surface Energy Budget in both the Coupled and Uncoupled Land-Atmosphere System. J. Climate, 32(18): 5725-5744, June 2019. ISSN 0894-8755. doi: 10.1175/JCLI-D-18-0812.1.

Lamorey, G. W. Siple Shallow Core Density Data. National Snow and Ice Data Center, 2003. doi: 10.7265/N52F7KCD.

Langen, P. L., Fausto, R. S., Vandecrux, B., Mottram, R. H., and Box, J. E. Liquid Water Flow and Retention on the Greenland Ice Sheet in the Regional Climate Model HIRHAM5: Local and Large-Scale Impacts. Frontiers in Earth Science, 4, Jan. 2017. ISSN 2296-6463. doi: 10.3389/feart.2016.00110.

Lauritzen, P. H., Nair, R. D., Herrington, A. R., Callaghan, P., Goldhaber, S., Dennis, J. M., Bacmeister, J. T., Eaton, B. E., Zarzycki, C. M., Taylor, M. A., Ullrich, P. A., Dubos, T., Gettelman, A., Neale, R. B., Dobbins, B., Reed, K. A., Hannay, C., Medeiros, B., Benedict, J. J., and Tribbia, J. J. NCAR Release of CAM-SE in CESM2.0: A Reformulation of the Spectral Element Dynamical Core in Dry-Mass Vertical Coordinates With Comprehensive Treatment of Condensates and Energy. Journal of Advances in Modeling Earth Systems, 10(7):1537-1570, July 2018. ISSN 1942-2466. doi: 10.1029/2017MS001257.

Lawrence, D. M., Oleson, K. W., Flanner, M. G., Thornton, P. E., Swenson, S. C., Lawrence, P. J., Zeng, X., Yang, Z.-L., Levis, S., Sakaguchi, K., Bonan, G. B., and Slater, A. G. Parameterization improvements and functional and structural advances in Version 4 of the Community Land Model. Journal of Advances in Modeling Earth Systems, 3 (3), Mar. 2011. ISSN 1942-2466. doi: 10.1029/2011MS000045.

Lawrence, D. M., Fisher, R. A., Koven, C. D., Oleson, K. W., Swenson, S. C., Bonan, G., Collier, N., Ghimire, B., van Kampenhout, L., Kennedy, D., Kluzek, E., Lawrence, P. J., Li, F., Li, H., Lombardozzi, D., Riley, W. J., Sacks, W. J., Shi, M., Vertenstein, M., Wieder, W. R., Xu, C., Ali, A. A., Badger, A. M., Bisht, G., Broeke, M., Brunke, M. A., Burns, S. P., Buzan, J., Clark, M., Craig, A., Dahlin, K., Drewniak, B., Fisher, J. B., Flanner, M., Fox, A. M., Gentine, P., Hoffman, F., Keppel-Aleks, G., Knox, R., Kumar, S., Lenaerts, J., Leung, L. R., Lipscomb, W. H., Lu, Y., Pandey, A., Pelletier, J. D., Perket, J., Randerson, J. T., Ricciuto, D. M., Sanderson, B. M., Slater, A., Subin, Z. M., Tang, J., Thomas, R. Q., Val Martin, M., and Zeng, X. The Community Land Model Version 5: Description of New Features, Benchmarking, and Impact of Forcing Uncertainty. J. Adv. Model. Earth Syst., page 2018MS001583, Dec. 2019. ISSN 1942-2466, 1942-2466. doi: 10.1029/2018MS001583.

Le clec'h, S., Charbit, S., Quiquet, A., Fettweis, X., Dumas, C., Kageyama, M., Wyard, C., and Ritz, C. Assessment of the Greenland ice sheet-atmosphere feedbacks for the next century with a regional atmospheric model coupled to an ice sheet model. The Cryosphere, 13(1):373-395, 2019. doi: 10.5194/tc-13-373-2019.

Lefebre, F., Fettweis, X., Gallée, H., Ypersele, J.-P. V., Marbaix, P., Greuell, W., and Calanca, P. Evaluation of a high-resolution regional climate simulation over Greenland. Climate Dynamics, 25(1):99-116, July 2005 . ISSN 0930-7575, 1432-0894. doi: 10.1007/s00382-005-0005-8.

Leguy, G., Lipscomb, W. H., and Sacks, W. J. CESM Land Ice Documentation and User Guide. https://escomp.github.io/cism-docs/cism-in-cesm/versions/release-cesm2.0/html/index.html, 2018

Lehning, M., Bartelt, P., Brown, B., Fierz, C., and Satyawali, P. A physical SNOWPACK model for the Swiss avalanche warning: Part II. Snow microstructure. Cold regions science and technology, 35(3):147-167, 2002. 
Lenaerts, J. T., Vizcaino, M., Fyke, J., van Kampenhout, L., and van den Broeke, M. R. Present-day and future Antarctic ice sheet climate and surface mass balance in the Community Earth System Model. Climate Dynamics, 47(5-6): 1367-1381, 2016. doi: 10.1007/s00382-015-2907-4.

Lenaerts, J. T. M. and van den Broeke, M. R. Modeling drifting snow in Antarctica with a regional climate model: 2. Results. Journal of Geophysical Research: Atmospheres, 117(D5), Mar. 2012. ISSN 01480227. doi: 10.1029/ 2010JD015419.

Lenaerts, J. T. M., van den Broeke, M. R., Déry, S. J., van Meijgaard, E., van de Berg, W. J., Palm, S. P., and Sanz Rodrigo, J. Modeling drifting snow in Antarctica with a regional climate model: 1. Methods and model evaluation. Journal of Geophysical Research: Atmospheres, 117(D5), Mar. 2012. ISSN 01480227. doi: 10.1029/2011JD016145.

Lenaerts, J. T. M., Le Bars, D., van Kampenhout, L., Vizcaino, M., Enderlin, E. M., and van den Broeke, M. R. Representing Greenland ice sheet freshwater fluxes in climate models. Geophysical Research Letters, 42(15):6373-6381, Aug. 2015. ISSN 00948276. doi: 10.1002/2015GL064738.

Lenaerts, J. T. M., Medley, B., van den Broeke, M. R., and Wouters, B. Observing and Modeling Ice Sheet Surface Mass Balance. Reviews of Geophysics, 0(0), May 2019. ISSN 8755-1209. doi: 10.1029/2018RG000622.

Lenaerts, J. T. M., Camron, M. D., Wyburn-Powell, C. R., and Kay., J. E. Present-day and future Greenland Ice Sheet precipitation frequency from satellite observations and an Earth System Model. The Cryosphere Discussions, pages 1-18, Feb. 2020a. ISSN 1994-0416. doi: 10.5194/tc-2020-31.

Lenaerts, J. T. M., Gettelman, A., Tricht, K. V., van Kampenhout, L., and Miller, N. B. Impact of Cloud Physics on the Greenland Ice Sheet Near-Surface Climate: A Study With the Community Atmosphere Model. Journal of Geophysical Research: Atmospheres, 125(7):e2019JD031470, 2020b. ISSN 2169-8996. doi: 10.1029/2019JD031470.

Lenton, T. M., Held, H., Kriegler, E., Hall, J. W., Lucht, W., Rahmstorf, S., and Schellnhuber, H. J. Tipping elements in the Earth's climate system. Proceedings of the National Academy of Sciences, 105(6):1786-1793, Feb. 2008. ISSN 0027-8424, 1091-6490. doi: 10.1073/pnas.0705414105.

Lenton, T. M., Rockström, J., Gaffney, O., Rahmstorf, S., Richardson, K., Steffen, W., and Schellnhuber, H. J. Climate tipping points — too risky to bet against. Nature, 575(7784):592-595, Nov. 2019. doi: 10.1038/d41586-019-03595-0.

Levermann, A. and Winkelmann, R. A simple equation for the melt elevation feedback of ice sheets. The Cryosphere, 10(4):1799-1807, Aug. 2016. ISSN 1994-0424. doi: 10.5194/tc-10-1799-2016.

Lewis, G., Osterberg, E., Hawley, R., Whitmore, B., and Marshall, H. P. Regional Greenland Accumulation Variability from Operation IceBridge Airborne Accumulation Radar. The Cryosphere Discussions, pages 1-29, Nov. 2016. ISSN 1994-0440. doi: 10.5194/tc-2016-248.

Li, J. and Zwally, H. J. Modeling the density variation in the shallow firn layer. Annals of Glaciology, 38:309-313, Jan. 2004. ISSN 0260-3055, 1727-5644. doi: 10.3189/172756404781814988.

Ligtenberg, S. R. M., Helsen, M. M., and van den Broeke, M. R. An improved semi-empirical model for the densification of Antarctic firn. The Cryosphere, 5(4):809-819, Oct. 2011. ISSN 1994-0424. doi: 10.5194/tc-5-809-2011.

Ligtenberg, S. R. M., Kuipers Munneke, P., Noël, B. P. Y., and van den Broeke, M. R. Brief communication: Improved simulation of the present-day Greenland firn layer (1960-2016). The Cryosphere, 12(5):1643-1649, May 2018. ISSN 1994-0424. doi: 10.5194/tc-12-1643-2018.

Lindvall, J., Svensson, G., and Hannay, C. Evaluation of Near-Surface Parameters in the Two Versions of the Atmospheric Model in CESM1 using Flux Station Observations. J. Climate, 26(1):26-44, June 2012. ISSN 0894-8755. doi: 10.1175/JCLI-D-12-00020.1.

Lipscomb, W. H., Fyke, J. G., Vizcaíno, M., Sacks, W. J., Wolfe, J., Vertenstein, M., Craig, A., Kluzek, E., and Lawrence, D. M. Implementation and Initial Evaluation of the Glimmer Community Ice Sheet Model in the Community Earth System Model. Journal of Climate, 26(19):7352-7371, Oct. 2013. ISSN 0894-8755, 1520-0442. doi: 10.1175/ JCLI-D-12-00557.1.

Lipscomb, W. H., Price, S. F., Hoffman, M. J., Leguy, G. R., Bennett, A. R., Bradley, S. L., Evans, K. J., Fyke, J. G., Kennedy, J. H., Perego, M., Ranken, D. M., Sacks, W. J., Salinger, A. G., Vargo, L. J., and Worley, P. H. Description and evaluation of the Community Ice Sheet Model (CISM) v2.1. Geoscientific Model Development, 12(1):387-424, Jan. 2019. ISSN 1991-959X. doi: 10.5194/gmd-12-387-2019.

Liston, G. E., Haehnel, R. B., Sturm, M., Hiemstra, C. A., Berezovskaya, S., and Tabler, R. D. Simulating complex snow distributions in windy environments using SnowTran-3D. Journal of Glaciology, 53(181):241-256, 2007.

Little, C. M., Piecuch, C. G., and Chaudhuri, A. H. Quantifying Greenland freshwater flux underestimates in climate models. Geophysical Research Letters, 43(10):5370-5377, May 2016. ISSN 00948276. doi: 10.1002/ 2016GL068878.

MacFerrin, M., Machguth, H., van As, D., Charalampidis, C., Stevens, C. M., Heilig, A., Vandecrux, B., Langen, P. L., Mottram, R., Fettweis, X., van den Broeke, M. R., Pfeffer, W. T., Moussavi, M. S., and Abdalati, W. Rapid expansion of Greenland's low-permeability ice slabs. Nature, 573(7774):403-407, Sept. 2019. ISSN 1476-4687. doi: 10.1038/s41586-019-1550-3. 
Machguth, H., MacFerrin, M., van As, D., Box, J. E., Charalampidis, C., Colgan, W., Fausto, R. S., Meijer, H. A. J., Mosley-Thompson, E., and van de Wal, R. S. W. Greenland meltwater storage in firn limited by near-surface ice formation. Nature Clim. Change, 6(4):390-393, Apr. 2016a. ISSN 1758-678X. doi: 10.1038/nclimate2899.

Machguth, H., Thomsen, H. H., Weidick, A., Ahlstrøm, A. P., Abermann, J., Andersen, M. L., Andersen, S. B., Bjørk, A. A., Box, J. E., Braithwaite, R. J., Bøggild, C. E., Citterio, M., Clement, P., Colgan, W., Fausto, R. S., Gleie, K., Gubler, S., Hasholt, B., Hynek, B., Knudsen, N. T., Larsen, S. H., Mernild, S. H., Oerlemans, J., Oerter, H., Olesen, O. B., Smeets, C. J. P. P., Steffen, K., Stober, M., Sugiyama, S., As, D. V., Broeke, M. R. V. D., and Wal, R. S. W. V. D. Greenland surface mass-balance observations from the ice-sheet ablation area and local glaciers. Journal of Glaciology, 62(235):861-887, Oct. 2016b. ISSN 0022-1430, 1727-5652. doi: 10.1017/jog.2016.75.

Manabe, S. and Broccoli, A. J. The influence of continental ice sheets on the climate of an ice age. Journal of Geophysical Research: Atmospheres, 90(D1):2167-2190, 1985. ISSN 2156-2202. doi: 10.1029/JD090iD01p02167.

Masson-Delmotte, V., Kageyama, M., Braconnot, P., Charbit, S., Krinner, G., Ritz, C., Guilyardi, E., Jouzel, J., AbeOuchi, A., Crucifix, M., Gladstone, R. M., Hewitt, C. D., Kitoh, A., LeGrande, A. N., Marti, O., Merkel, U., Motoi, T., Ohgaito, R., Otto-Bliesner, B., Peltier, W. R., Ross, I., Valdes, P. J., Vettoretti, G., Weber, S. L., Wolk, F., and Yu, Y. Past and future polar amplification of climate change: Climate model intercomparisons and ice-core constraints. Climate Dynamics, 26(5):513-529, Apr. 2006. ISSN 0930-7575, 1432-0894. doi: 10.1007/s00382-005-0081-9.

Masson-Delmotte, V., Zhai, P., Pörtner, H.-O., and others. IPCC Special Report on the impacts of global warming of $1.5^{\circ}$ above pre-industrial levels and related global greenhouse gas emission pathyways, in the context of strengthening the global response to the threat of climate change, sustainable development, and efforts to eradicate poverty. Summary for Policymakers. Technical report, 2018.

Matte, D., Laprise, R., Thériault, J. M., and Lucas-Picher, P. Spatial spin-up of fine scales in a regional climate model simulation driven by low-resolution boundary conditions. Clim Dyn, 49(1-2):563-574, July 2017. ISSN 0930-7575, 1432-0894. doi: 10.1007/s00382-016-3358-2.

McIlhattan, E. A., L'Ecuyer, T. S., and Miller, N. B. Observational Evidence Linking Arctic Supercooled Liquid Cloud Biases in CESM to Snowfall Processes. J. Climate, 30(12):4477-4495, Feb. 2017. ISSN 0894-8755. doi: 10.1175/ JCLI-D-16-0666.1.

Meehl, G. A., Stocker, T. F., Collins, W. D., Friedlingstein, P., Gaye, A. T., Gregory, J. M., Kitoh, A., Knutti, R., Murphy, J. M., Noda, A., Raper, S. C. B., Watterson, I. G., Weaver, A. J., Zhao, Z.-C., Alley, R. B., Annan, J., Arblaster, J., Bitz, C., Brockmann, P., Brovkin, V., Buja, L., Cadule, P., Clarke, G., Collier, M., Collins, M., Driesschaert, E., Dianksy, N. A., Dix, M., Dixon, K., Dufresne, J.-L., Dyurgerov, M., Eby, M., Edwards, N. R., Emori, S., Forster, P., Furrer, R., Gleckler, P., Hansen, J., Harris, G., Hegerl, G. C., Holland, M., Hu, A., Huybrechts, P., Jones, C., Joos, F., Jungclaus, J. H., Kettleborough, J., Kimoto, M., Knutson, T., Krynytzky, M., Lawrence, D., Le Brocq, A., Loutre, M.-F., Lowe, J., Matthews, H. D., Meinshausen, M., Müller, S. A., Nawrath, S., Oerlemans, J., Oppenheimer, M., Orr, J., Overpeck, J., Palmer, T., Payne, A., Plattner, G.-K., Räisänen, J., Rinke, A., Roeckner, E., Russell, G. L., Salas y Melia, D., Santer, B., Schmidt, G., Schmittner, A., Schneider, B., Shepherd, A., Sokolov, A., Stainforth, D., Stott, P. A., Stouffer, R. J., Taylor, K. E., Tebaldi, C., Teng, H., Terray, L., van de Wal, R., Vaughan, D., Volodin, E. M., Wang, B., Wigley, T. M. L., Wild, M., Yoshimura, J., Yu, R., and Yukimoto, S. Global climate projections. In Climate Change 2007: The Physical Science Basis, pages 747-846. Cambridge University Press, 2007. ISBN 978-0-521-88009-1.

Meierbachtol, T. W., Harper, J. T., Johnson, J. V., Humphrey, N. F., and Brinkerhoff, D. J. Thermal boundary conditions on western Greenland: Observational constraints and impacts on the modeled thermomechanical state. Journal of Geophysical Research: Earth Surface, 120(3):623-636, Mar. 2015. ISSN 21699003. doi: 10.1002/2014JF003375.

Mikolajewicz, U., Gröger, M., Maier-Reimer, E., Schurgers, G., Vizcaíno, M., and Winguth, A. M. E. Long-term effects of anthropogenic CO2 emissions simulated with a complex earth system model. Climate Dynamics, 28(6):599-633, Mar. 2007. ISSN 0930-7575, 1432-0894. doi: 10.1007/s00382-006-0204-y.

Molod, A., Takacs, L., Suarez, M., and Bacmeister, J. Development of the GEOS-5 atmospheric general circulation model: Evolution from MERRA to MERRA2. Geosci. Model Dev., 8(5):1339-1356, May 2015. ISSN $1991-9603$. doi: 10.5194/gmd-8-1339-2015.

Morice, C. P., Kennedy, J. J., Rayner, N. A., and Jones, P. D. Quantifying uncertainties in global and regional temperature change using an ensemble of observational estimates: The HadCRUT4 data set. Journal of Geophysical Research: Atmospheres, 117(D8), 2012. ISSN 2156-2202. doi: 10.1029/2011JD017187.

Morlighem, M., Rignot, E., Mouginot, J., Seroussi, H., and Larour, E. Deeply incised submarine glacial valleys beneath the Greenland ice sheet. Nature Geoscience, 7(6):418-422, May 2014. ISSN 1752-0894, 1752-0908. doi: 10.1038/ ngeo2167.

Morlighem, M., Williams, C. N., Rignot, E., An, L., Arndt, J. E., Bamber, J. L., Catania, G., Chauché, N., Dowdeswell, J. A., Dorschel, B., Fenty, I., Hogan, K., Howat, I., Hubbard, A., Jakobsson, M., Jordan, T. M., Kjeldsen, K. K., Millan, R., Mayer, L., Mouginot, J., Noël, B. P. Y., O’Cofaigh, C., Palmer, S., Rysgaard, S., Seroussi, H., Siegert, M. J., Slabon, P., Straneo, F., van den Broeke, M. R., Weinrebe, W., Wood, M., and Zinglersen, K. B. BedMachine v3: 
Complete Bed Topography and Ocean Bathymetry Mapping of Greenland From Multibeam Echo Sounding Combined With Mass Conservation. Geophysical Research Letters, 44(21):11,051-11,061, Nov. 2017. ISSN 00948276. doi: 10.1002/2017GL074954.

Morris, E. M. and Wingham, D. J. The effect of fluctuations in surface density, accumulation and compaction on elevation change rates along the EGIG line, central Greenland. Journal of Glaciology, 57(203):416-430, Jan. 2011. ISSN 0022-1430, 1727-5652. doi: 10.3189/002214311796905613.

Morrison, H., de Boer, G., Feingold, G., Harrington, J., Shupe, M. D., and Sulia, K. Resilience of persistent Arctic mixed-phase clouds. Nature Geoscience, 5(1):11-17, Jan. 2012. ISSN 1752-0908. doi: 10.1038/ngeo1332.

Mosley-Thompson, E., McConnell, J. R., Bales, R. C., Li, Z., Lin, P.-N., Steffen, K., Thompson, L. G., Edwards, R., and Bathke, D. Local to regional-scale variability of annual net accumulation on the Greenland ice sheet from PARCA cores. J. Geophys. Res., 106(D24):33839-33851, Dec. 2001. ISSN 2156-2202. doi: 10.1029/2001JD900067.

Mottram, R., Boberg, F., Langen, P., Yang, S., Rodehacke, C., Christensen, J. H., and Madsen, M. S. Surface mass balance of the Greenland ice sheet in the regional climate model HIRHAM5: Present state and future prospects. Low Temperature Science, 75:105-115, 2017. doi: 10.14943/lowtemsci.75.105.

Mouginot, J., Rignot, E., Bjørk, A. A., van den Broeke, M., Millan, R., Morlighem, M., Noël, B., Scheuchl, B., and Wood, M. Forty-six years of Greenland Ice Sheet mass balance from 1972 to 2018. PNAS, 116(19):9239-9244, May 2019. ISSN 0027-8424, 1091-6490. doi: 10.1073/pnas.1904242116.

Muggeo, V. M. R. Estimating regression models with unknown break-points. Statistics in Medicine, 22(19):3055-3071, 2003. ISSN 1097-0258. doi: 10.1002/sim.1545.

Muggeo, V. M. R. Interval estimation for the breakpoint in segmented regression: A smoothed score-based approach. Australian \& New Zealand Journal of Statistics, 59(3):311-322, 2017. ISSN 1467-842X. doi: 10.1111/anzs.12200.

Müller, W. A., Jungclaus, J. H., Mauritsen, T., Baehr, J., Bittner, M., Budich, R., Bunzel, F., Esch, M., Ghosh, R., Haak, H., Ilyina, T., Kleine, T., Kornblueh, L., Li, H., Modali, K., Notz, D., Pohlmann, H., Roeckner, E., Stemmler, I., Tian, F., and Marotzke, J. A Higher-resolution Version of the Max Planck Institute Earth System Model (MPIESM1.2-HR). Journal of Advances in Modeling Earth Systems, 10(7):1383-1413, July 2018. ISSN 1942-2466. doi: 10.1029/2017MS001217.

Muntjewerf, L., Petrini, M., Vizcaino, M., da Silva, C. E., Sellevold, R., Scherrenberg, M. D. W., Thayer-Calder, K., Bradley, S. L., Lenaerts, J. T. M., Lipscomb, W. H., and Lofverstrom, M. Greenland Ice Sheet Contribution to 21st Century Sea Level Rise as Simulated by the Coupled CESM2.1-CISM2.1. Geophysical Research Letters, 47(9): e2019GL086836, 2020. ISSN 1944-8007. doi: 10.1029/2019GL086836.

Neale, R. B., Chen, C.-C., Gettelman, A., Lauritzen, P. H., Park, S., Williamson, D. L., Conley, A. J., Garcia, R., Kinnison, D., and Lamarque, J.-F. Description of the NCAR community atmosphere model (CAM 5.0). NCAR Tech. Note NCAR/TN-486+STR, 2012.

Niwano, M., Aoki, T., Hashimoto, A., Matoba, S., Yamaguchi, S., Tanikawa, T., Fujita, K., Tsushima, A., Iizuka, Y., Shimada, R., and Hori, M. NHM-SMAP: Spatially and temporally high-resolution nonhydrostatic atmospheric model coupled with detailed snow process model for Greenland Ice Sheet. The Cryosphere, 12(2):635-655, Feb. 2018. ISSN 1994-0424. doi: 10.5194/tc-12-635-2018.

Noël, B., Fettweis, X., van de Berg, W. J., van den Broeke, M. R., and Erpicum, M. Sensitivity of Greenland Ice Sheet surface mass balance to perturbations in sea surface temperature and sea ice cover: A study with the regional climate model MAR. The Cryosphere, 8, Oct. 2014. ISSN 1994-0416. doi: 10.5194/tc-8-1871-2014.

Noël, B., van de Berg, W. J., van Meijgaard, E., Kuipers Munneke, P., van de Wal, R. S. W., and van den Broeke, M. R. Evaluation of the updated regional climate model RACMO2.3: Summer snowfall impact on the Greenland Ice Sheet. The Cryosphere, 9(5):1831-1844, Sept. 2015. ISSN 1994-0424. doi: 10.5194/tc-9-1831-2015.

Noël, B., van de Berg, W. J., Machguth, H., Lhermitte, S., Howat, I., Fettweis, X., and van den Broeke, M. R. A daily, $1 \mathrm{~km}$ resolution data set of downscaled Greenland ice sheet surface mass balance (1958-2015). The Cryosphere, 10 (5):2361-2377, Oct. 2016. ISSN 1994-0424. doi: 10.5194/tc-10-2361-2016.

Noël, B., van de Berg, W. J., Lhermitte, S., Wouters, B., Machguth, H., Howat, I., Citterio, M., Moholdt, G., Lenaerts, J. T. M., and van den Broeke, M. R. A tipping point in refreezing accelerates mass loss of Greenland's glaciers and ice caps. Nature Communications, 8:14730, Mar. 2017. ISSN 2041-1723. doi: 10.1038/ncomms14730.

Noël, B., van de Berg, W. J., van Wessem, J. M., van Meijgaard, E., van As, D., Lenaerts, J. T. M., Lhermitte, S., Kuipers Munneke, P., Smeets, C. J. P. P., van Ulft, L. H., van de Wal, R. S. W., and van den Broeke, M. R. Modelling the climate and surface mass balance of polar ice sheets using RACMO2 - Part 1: Greenland (1958-2016). The Cryosphere, 12(3):811-831, Mar. 2018. ISSN 1994-0424. doi: 10.5194/tc-12-811-2018.

Noël, B., van de Berg, W. J., Lhermitte, S., and van den Broeke, M. R. Rapid ablation zone expansion amplifies north Greenland mass loss. Science Advances, 5(9):eaaw0123, Sept. 2019a. ISSN 2375-2548. doi: 10.1126/sciadv. aaw0123. 
Noël, B., van Kampenhout, L., van de Berg, W. J., Lenaerts, J. T. M., Wouters, B., and van den Broeke, M. R. Brief communication: CESM2 climate forcing (1950-2014) yields realistic Greenland ice sheet surface mass balance. The Cryosphere Discussions, pages 1-17, Sept. 2019b. ISSN 1994-0416. doi: 10.5194/tc-2019-209.

Noël, B., van Kampenhout, L., Lenaerts, J. T. M., Van de Berg, W. J., and Van den Broeke, M. A 21st century warming threshold for irreversible Greenland ice sheet mass loss. Communications Earth \& Environment, in review.

Nowicki, S., Bindschadler, R. A., Abe-Ouchi, A., Aschwanden, A., Bueler, E., Choi, H., Fastook, J., Granzow, G., Greve, R., Gutowski, G., Herzfeld, U., Jackson, C., Johnson, J., Khroulev, C., Larour, E., Levermann, A., Lipscomb, W. H., Martin, M. A., Morlighem, M., Parizek, B. R., Pollard, D., Price, S. F., Ren, D., Rignot, E., Saito, F., Sato, T., Seddik, H., Seroussi, H., Takahashi, K., Walker, R., and Wang, W. L. Insights into spatial sensitivities of ice mass response to environmental change from the SeaRISE ice sheet modeling project II: Greenland. J. Geophys. Res. Earth Surf., 118 (2):1025-1044, June 2013. ISSN 2169-9011. doi: 10.1002/jgrf.20076.

Nowicki, S. M. J., Payne, A., Larour, E., Seroussi, H., Goelzer, H., Lipscomb, W., Gregory, J., Abe-Ouchi, A., and Shepherd, A. Ice Sheet Model Intercomparison Project (ISMIP6) contribution to CMIP6. Geosci. Model Dev., 9(12): 4521-4545, Dec. 2016. ISSN 1991-9603. doi: 10.5194/gmd-9-4521-2016.

Oerter, H., Wilhelms, F., Jung-Rothenhäusler, F., Göktas, F., Miller, H., Graf, W., and Sommer, S. Accumulation rates in Dronning Maud Land, Antarctica, as revealed by dielectric-profiling measurements of shallow firn cores. Annals of Glaciology, 30:27-34, Jan. 2000. doi: 10.3189/172756400781820705.

Oleson, K. W. Technical description of version 4.5 of the Community Land Model (CLM). NCAR Technical Note NCAR/TN-503+ STR, National Center for Atmospheric Research, Boulder, CO, 2013.

Oleson, K. W., Niu, G.-Y., Yang, Z.-L., Lawrence, D. M., Thornton, P. E., Lawrence, P. J., Stöckli, R., Dickinson, R. E., Bonan, G. B., Levis, S., Dai, A., and Qian, T. Improvements to the Community Land Model and their impact on the hydrological cycle. J. Geophys. Res., 113(G01), Mar. 2008. ISSN 2156-2202. doi: 10.1029/2007JG000563.

Oleson, K. W., Lawrence, D. M., Bonan, G. B., Flanner, M. G., Kluzek, E., Lawrence, P. J., Levis, S., Swenson, S. C., and Thornton, P. E. Technical Description of version 4.0 of the Community Land Model (CLM). NCAR Technical Note NCAR/TN-478+STR, National Center for Atmospheric Research, 2010.

O’Neill, B. C., Tebaldi, C., van Vuuren, D. P., Eyring, V., Friedlingstein, P., Hurtt, G., Knutti, R., Kriegler, E., Lamarque, J.-F., Lowe, J., Meehl, G. A., Moss, R., Riahi, K., and Sanderson, B. M. The Scenario Model Intercomparison Project (ScenarioMIP) for CMIP6. Geoscientific Model Development, 9(9):3461-3482, Sept. 2016. ISSN 1991-959X. doi: 10.5194/gmd-9-3461-2016.

Oppenheimer, M., Glavovic, B. C., Hinkel, J., van de Wal, R., Magnan, A. K., Abd-Elgawad, A., Cai, R., Cifuentes-Jara, M., Rica, C., DeConto, R. M., Ghosh, T., Hay, J., Islands, C., Isla, F., Marzeion, B., Meyssignac, B., Sebesvari, Z., Biesbroek, R., Buchanan, M. K., de Campos, R. S., Cozannet, G. L., Domingues, C., Dangendorf, S., Döll, P., Duvat, V. K. E., Edwards, T., Ekaykin, A., Frederikse, T., Gattuso, J.-P., Kopp, R., Lambert, E., Lawrence, J., Narayan, S., Nicholls, R. J., Renaud, F., Simm, J., Smit, A., Woodruff, J., Wong, P. P., Xian, S., Abe-Ouchi, A., Gupta, K., and Pereira, J. Sea Level Rise and Implications for Low-Lying Islands, Coasts and Communities. In: IPCC Special Report on 'The Oceans and Cryosphere in a Changing Climate' (SROCC), page 126, 2019.

PAGES2k Consortium. Consistent multidecadal variability in global temperature reconstructions and simulations over the Common Era. Nat. Geosci., 12(8):643-649, Aug. 2019. ISSN 1752-0894, 1752-0908. doi: 10.1038/ s41561-019-0400-0.

Pattyn, F. The paradigm shift in Antarctic ice sheet modelling. Nature Communications, 9(1):2728, July 2018. ISSN 2041-1723. doi: 10.1038/s41467-018-05003-z.

Pattyn, F., Ritz, C., Hanna, E., Asay-Davis, X., DeConto, R., Durand, G., Favier, L., Fettweis, X., Goelzer, H., Golledge, N. R., Munneke, P. K., Lenaerts, J. T. M., Nowicki, S., Payne, A. J., Robinson, A., Seroussi, H., Trusel, L. D., and van den Broeke, M. The Greenland and Antarctic ice sheets under $1.5^{\circ} \mathrm{C}$ global warming. Nature Climate Change, 8(12):1053, Dec. 2018. ISSN 1758-6798. doi: 10.1038/s41558-018-0305-8.

Pelt, V., J, W. J., Pohjola, V. A., and Reijmer, C. H. The Changing Impact of Snow Conditions and Refreezing on the Mass Balance of an Idealized Svalbard Glacier. Front. Earth Sci., 4, 2016. ISSN 2296-6463. doi: 10.3389/feart.2016.00102.

Picard, G., Domine, F., Krinner, G., Arnaud, L., and Lefebvre, E. Inhibition of the positive snow-albedo feedback by precipitation in interior Antarctica. Nature Climate Change, 2(11):795-798, Nov. 2012. ISSN 1758-6798. doi: 10.1038/nclimate1590.

Pollard, D. A retrospective look at coupled ice sheet-climate modeling. Climatic Change, 100(1):173-194, May 2010. ISSN 0165-0009, 1573-1480. doi: 10.1007/s10584-010-9830-9.

Pritchard, M. S., Bush, A. B. G., and Marshall, S. J. Neglecting ice-atmosphere interactions underestimates ice sheet melt in millennial-scale deglaciation simulations. Geophysical Research Letters, 35(1), Jan. 2008. ISSN 0094-8276. doi: 10.1029/2007GL031738.

Punge, H. J., Gallée, H., Kageyama, M., and Krinner, G. Modelling snow accumulation on Greenland in Eemian, glacial inception, and modern climates in a GCM. Climate of the Past, 8:1801-1819, Nov. 2012. doi: 10.5194/ cp-8-1801-2012. 
Rae, J. G. L., Aðalgeirsdóttir, G., Edwards, T. L., Fettweis, X., Gregory, J. M., Hewitt, H. T., Lowe, J. A., Lucas-Picher, b., Mottram, R. H., Payne, A. J., Ridley, J. K., Shannon, S. R., van de Berg, W. J., van de Wal, R. S. W., and van den Broeke, M. R. Greenland ice sheet surface mass balance: Evaluating simulations and making projections with regional climate models. The Cryosphere, 6(6):1275-1294, Nov. 2012. ISSN 1994-0424. doi: 10.5194/tc-6-1275-2012.

Räisänen, P., Makkonen, R., Kirkevåg, A., and Boldingh Debernard, J. Effects of snow grain shape on climate simulations: Sensitivity tests with the Norwegian Earth System Model. The Cryosphere Discuss., 2017:1-41, Aug. 2017. ISSN 1994-0440. doi: 10.5194/tc-2017-118.

Rhoades, A. M., Huang, X., Ullrich, P. A., and Zarzycki, C. M. Characterizing Sierra Nevada Snowpack Using Variable-Resolution CESM. J. Appl. Meteor. Climatol., 55(1):173-196, Oct. 2015. ISSN 1558-8424. doi: 10.1175/JAMC-D-15-0156.1.

Rhoades, A. M., Ullrich, P. A., and Zarzycki, C. M. Projecting 21st century snowpack trends in western USA mountains using variable-resolution CESM. Clim Dyn, 50(1-2):261-288, Mar. 2017. ISSN 0930-7575, 1432-0894. doi: 10. 1007/s00382-017-3606-0.

Rhoades, A. M., Ullrich, P. A., Zarzycki, C. M., Johansen, H., Margulis, S. A., Morrison, H., Xu, Z., and Collins, W. Sensitivity of Mountain Hydroclimate Simulations in Variable-Resolution CESM to Microphysics and Horizontal Resolution. Journal of Advances in Modeling Earth Systems, May 2018. ISSN 19422466. doi: 10.1029/2018MS001326.

Rial, J. A., Pielke, R. A., Beniston, M., Claussen, M., Canadell, J., Cox, P., Held, H., de Noblet-Ducoudré, N., Prinn, R., Reynolds, J. F., and Salas, J. D. Nonlinearities, Feedbacks and Critical Thresholds within the Earth's Climate System. Climatic Change, 65(1):11-38, July 2004. ISSN 1573-1480. doi: 10.1023/B:CLIM.0000037493.89489.3f.

Ridley, J. K., Huybrechts, P., Gregory, J. M., and Lowe, J. A. Elimination of the Greenland Ice Sheet in a High CO2 Climate. J. Climate, 18(17):3409-3427, Sept. 2005. ISSN 0894-8755. doi: 10.1175/JCLI3482.1.

Rignot, E. and Mouginot, J. Ice flow in Greenland for the International Polar Year 2008-2009. Geophysical Research Letters, 39(11):L11501, June 2012. ISSN 1944-8007. doi: 10.1029/2012GL051634.

Robinson, A., Calov, R., and Ganopolski, A. Multistability and critical thresholds of the Greenland ice sheet. Nature Clim Change, 2(6):429-432, June 2012. ISSN 1758-6798. doi: 10.1038/nclimate1449.

Rockström, J., Schellnhuber, H. J., Hoskins, B., Ramanathan, V., Schlosser, P., Brasseur, G. P., Gaffney, O., Nobre, C., Meinshausen, M., Rogelj, J., and Lucht, W. The world's biggest gamble. Earth's Future, 4(10):465-470, 2016. ISSN 2328-4277. doi: 10.1002/2016EF000392.

Sandells, M., Essery, R., Rutter, N., Wake, L., Leppänen, L., and Lemmetyinen, J. Microstructure representation of snow in coupled snowpack and microwave emission models. The Cryosphere, 11(1):229-246, Jan. 2017. ISSN $1994-0424$. doi: 10.5194/tc-11-229-2017.

Sato, T., Kosugi, K., Mochizuki, S., and Nemoto, M. Wind speed dependences of fracture and accumulation of snowflakes on snow surface. Cold Regions Science and Technology, 51(2-3):229-239, Feb. 2008. ISSN 0165232X. doi: 10.1016/ j.coldregions.2007.05.004.

Schellnhuber, H. J. 'Earth system' analysis and the second Copernican revolution. Nature, 402(6761):C19-C23, Dec. 1999. ISSN 1476-4687. doi: 10.1038/35011515.

Sellevold, R., van Kampenhout, L., Lenaerts, J. T. M., Noël, B., Lipscomb, W. H., and Vizcaino, M. Surface mass balance downscaling through elevation classes in an Earth system model: Application to the Greenland ice sheet. The Cryosphere, 13(12):3193-3208, Dec. 2019. ISSN 1994-0416. doi: 10.5194/tc-13-3193-2019.

Shannon, S., Smith, R., Wiltshire, A., Payne, T., Huss, M., Betts, R., Caesar, J., Koutroulis, A., Jones, D., and Harrison, S. Global glacier volume projections under high-end climate change scenarios. The Cryosphere, 13(1):325-350, Feb. 2019. ISSN 1994-0416. doi: 10.5194/tc-13-325-2019.

Small, R. J., Bacmeister, J., Bailey, D., Baker, A., Bishop, S., Bryan, F., Caron, J., Dennis, J., Gent, P., Hsu, H.-m., Jochum, M., Lawrence, D., Muñoz, E., diNezio, P., Scheitlin, T., Tomas, R., Tribbia, J., Tseng, Y.-h., and Vertenstein, M. A new synoptic scale resolving global climate simulation using the Community Earth System Model. Journal of Advances in Modeling Earth Systems, 6(4):1065-1094, Dec. 2014. ISSN 19422466. doi: 10.1002/2014MS000363.

Smith, R., Jones, P., Briegleb, B., Bryan, F., Danabasoglu, G., Dennis, J., Dukowicz, J., Eden, C., Fox-Kemper, B., and Gent, P. The parallel ocean program (POP) reference manual ocean component of the community climate system model (CCSM) and community earth system model (CESM). Rep. LAUR-01853, 141:1-140, 2010.

Sodemann, H., Schwierz, C., and Wernli, H. Interannual variability of Greenland winter precipitation sources: Lagrangian moisture diagnostic and North Atlantic Oscillation influence. Journal of Geophysical Research: Atmospheres, 113(D3):D03107, 2008. ISSN 2156-2202. doi: 10.1029/2007JD008503.

Spratt, D., Dunlop, I., and Schellnhuber, F. H. J. The understatement of existential climate risk. page 44, 2018.

Steffen, W., Rockström, J., Richardson, K., Lenton, T. M., Folke, C., Liverman, D., Summerhayes, C. P., Barnosky, A. D., Cornell, S. E., Crucifix, M., Donges, J. F., Fetzer, I., Lade, S. J., Scheffer, M., Winkelmann, R., and Schellnhuber, H. J. Trajectories of the Earth System in the Anthropocene. PNAS, 115(33):8252-8259, Aug. 2018. ISSN 0027-8424, 1091-6490. doi: 10.1073/pnas.1810141115. 
Steger, C. R., Reijmer, C. H., and van den Broeke, M. R. The modelled liquid water balance of the Greenland Ice Sheet. The Cryosphere, 11(6):2507-2526, Nov. 2017a. ISSN 1994-0424. doi: 10.5194/tc-11-2507-2017.

Steger, C. R., Reijmer, C. H., van den Broeke, M. R., Wever, N., Forster, R. R., Koenig, L. S., Kuipers Munneke, P., Lehning, M., Lhermitte, S., Ligtenberg, S. R. M., Miège, C., and Noël, B. P. Y. Firn Meltwater Retention on the Greenland Ice Sheet: A Model Comparison. Frontiers in Earth Science, 5, Jan. 2017b. ISSN 2296-6463. doi: 10.3389/feart.2017.00003.

Stibal, M., Box, J. E., Cameron, K. A., Langen, P. L., Yallop, M. L., Mottram, R. H., Khan, A. L., Molotch, N. P., Chrismas, N. A. M., Calì Quaglia, F., Remias, D., Smeets, C. J. P. P., van den Broeke, M. R., Ryan, J. C., Hubbard, A., Tranter, M., van As, D., and Ahlstrøm, A. P. Algae Drive Enhanced Darkening of Bare Ice on the Greenland Ice Sheet: Algae Drive Greenland Bare Ice Darkening. Geophysical Research Letters, 44(22):11,463-11,471, Nov. 2017. ISSN 00948276. doi: 10.1002/2017GL075958.

Stocker, T. Introduction to Climate Modelling. Advances in Geophysical and Environmental Mechanics and Mathematics. Springer Berlin Heidelberg, Berlin, Heidelberg, 2011. ISBN 978-3-642-00772-9 978-3-642-00773-6. doi: 10.1007/978-3-642-00773-6.

Straneo, F., Hamilton, G., Stearns, L., and Sutherland, D. Connecting the Greenland Ice Sheet and the Ocean: A Case Study of Helheim Glacier and Sermilik Fjord. Oceanog., 29(4):34-45, Dec. 2016. doi: 10.5670/oceanog.2016.97.

Stroeve, J., Box, J. E., Wang, Z., Schaaf, C., and Barrett, A. Re-evaluation of MODIS MCD43 Greenland albedo accuracy and trends. Remote Sensing of Environment, 138:199-214, Nov. 2013. ISSN 00344257. doi: 10.1016/j.rse.2013.07. 023.

Stroeve, J. C., Mioduszewski, J. R., Rennermalm, A., Boisvert, L. N., Tedesco, M., and Robinson, D. Investigating the local-scale influence of sea ice on Greenland surface melt. The Cryosphere, 11(5):2363-2381, Oct. 2017. ISSN 1994-0424. doi: 10.5194/tc-11-2363-2017.

Swenson, S. C. and Lawrence, D. M. A new fractional snow-covered area parameterization for the Community Land Model and its effect on the surface energy balance. Journal of Geophysical Research: Atmospheres, 117(D21): D21107, Nov. 2012. ISSN 01480227. doi: 10.1029/2012JD018178.

Taylor, K. E., Stouffer, R. J., and Meehl, G. A. An Overview of CMIP5 and the Experiment Design. Bull. Amer. Meteor. Soc., 93(4):485-498, Oct. 2011. ISSN 0003-0007. doi: 10.1175/BAMS-D-11-00094.1.

Tedesco, M. and Fettweis, X. Unprecedented atmospheric conditions (1948-2019) drive the 2019 exceptional melting season over the Greenland ice sheet. The Cryosphere, 14(4):1209-1223, Apr. 2020. ISSN 1994-0416. doi: 10.5194/ tc-14-1209-2020.

The IMBIE team. Mass balance of the Greenland Ice Sheet from 1992 to 2018. Nature, 579(7798):233-239, Mar. 2020. ISSN 1476-4687. doi: 10.1038/s41586-019-1855-2.

Tilmes, S., MacMartin, D. E., Lenaerts, J. T. M., van Kampenhout, L., Muntjewerf, L., Xia, L., Harrison, C. S., Krumhardt, K. M., Mills, M. J., Kravitz, B., and Robock, A. Reaching $1.5^{\circ} \mathrm{C}$ and $2.0^{\circ} \mathrm{C}$ global surface temperature targets using stratospheric aerosol geoengineering. Earth System Dynamics Discussions, pages 1-37, Dec. 2019. ISSN 2190-4979. doi: 10.5194/esd-2019-76.

Tollefson, J. IPCC says limiting global warming to $1.5^{\circ} \mathrm{C}$ will require drastic action. Nature, 562(7726):172-173, Oct. 2018. doi: 10.1038/d41586-018-06876-2.

Tuzet, F., Dumont, M., Lafaysse, M., Picard, G., Arnaud, L., Voisin, D., Lejeune, Y., Charrois, L., Nabat, P., and Morin, S. A multilayer physically based snowpack model simulating direct and indirect radiative impacts of light-absorbing impurities in snow. The Cryosphere, 11(6):2633-2653, Nov. 2017. ISSN 1994-0424. doi: 10.5194/tc-11-2633-2017.

Ullrich, P. A. SQuadGen: Spherical Quadrilateral Grid Generator. https://climate.ucdavis.edu/squadgen.php, 2014.

Uppala, S. M., KÅllberg, P. W., Simmons, A. J., Andrae, U., Bechtold, V. D. C., Fiorino, M., Gibson, J. K., Haseler, J., Hernandez, A., Kelly, G. A., Li, X., Onogi, K., Saarinen, S., Sokka, N., Allan, R. P., Andersson, E., Arpe, K., Balmaseda, M. A., Beljaars, A. C. M., Berg, L. V. D., Bidlot, J., Bormann, N., Caires, S., Chevallier, F., Dethof, A., Dragosavac, M., Fisher, M., Fuentes, M., Hagemann, S., Hólm, E., Hoskins, B. J., Isaksen, L., Janssen, P. A. E. M., Jenne, R., Mcnally, A. P., Mahfouf, J.-F., Morcrette, J.-J., Rayner, N. A., Saunders, R. W., Simon, P., Sterl, A., Trenberth, K. E., Untch, A., Vasiljevic, D., Viterbo, P., and Woollen, J. The ERA-40 re-analysis. Quarterly Journal of the Royal Meteorological Society, 131(612):2961-3012, Oct. 2005. ISSN 00359009, 1477870X. doi: 10.1256/qj.04.176.

van Angelen, J. H., Lenaerts, J. T. M., Lhermitte, S., Fettweis, X., Kuipers Munneke, P., van den Broeke, M. R., van Meijgaard, E., and Smeets, C. J. P. P. Sensitivity of Greenland Ice Sheet surface mass balance to surface albedo parameterization: A study with a regional climate model. The Cryosphere, 6(5):1175-1186, Oct. 2012. ISSN 19940424. doi: 10.5194/tc-6-1175-2012.

van Angelen, J. H., M. Lenaerts, J. T., van den Broeke, M. R., Fettweis, X., and van Meijgaard, E. Rapid loss of firn pore space accelerates 21st century Greenland mass loss. Geophys. Res. Lett., 40(10):2109-2113, May 2013. ISSN 1944-8007. doi: 10.1002/grl.50490. 
van As, D., Box, J. E., and Fausto, R. S. Challenges of Quantifying Meltwater Retention in Snow and Firn: An Expert Elicitation. Front. Earth Sci., 4, 2016. ISSN 2296-6463. doi: 10.3389/feart.2016.00101.

van Dalum, C. T., van de Berg, W. J., Libois, Q., Picard, G., and van den Broeke, M. R. A module to convert spectral to narrowband snow albedo for use in climate models: SNOWBAL v1.2. Geoscientific Model Development, 12(12): 5157-5175, Dec. 2019. ISSN 1991-959X. doi: 10.5194/gmd-12-5157-2019.

van de Berg, W. J., van Meijgaard, E., and van Ulft, L. H. The added value of high resolution in estimating the surface mass balance in southern Greenland. The Cryosphere Discussions, pages 1-28, Dec. 2019. ISSN 1994-0416. doi: 10.5194/tc-2019-256.

van den Broeke, M. Depth and Density of the Antarctic Firn Layer. Arctic, Antarctic, and Alpine Research, 40(2): 432-438, May 2008. ISSN 1523-0430, 1938-4246. doi: 10.1657/1523-0430(07-021)[BROEKE]2.0.CO;2.

van den Broeke, M., Smeets, P., and Ettema, J. Surface layer climate and turbulent exchange in the ablation zone of the west Greenland ice sheet. Int. J. Climatol., 29(15):2309-2323, Dec. 2009. ISSN 08998418, 10970088. doi: 10.1002/joc. 1815 .

van den Broeke, M., Box, J., Fettweis, X., Hanna, E., Noël, B., Tedesco, M., van As, D., van de Berg, W. J., and van Kampenhout, L. Greenland Ice Sheet Surface Mass Loss: Recent Developments in Observation and Modeling. Curr Clim Change Rep, pages 1-12, Nov. 2017. ISSN 2198-6061. doi: 10.1007/s40641-017-0084-8.

van den Broeke, M. R. On the role of Antarctica as heat sink for the global atmosphere. J. Phys. IV France, 121:115-124, Dec. 2004. ISSN 1155-4339. doi: 10.1051/jp4:2004121006.

van den Broeke, M. R., Enderlin, E. M., Howat, I. M., Kuipers Munneke, P., Noël, B. P. Y., van de Berg, W. J., van Meijgaard, E., and Wouters, B. On the recent contribution of the Greenland ice sheet to sea level change. The Cryosphere, 10(5):1933-1946, Sept. 2016. ISSN 1994-0424. doi: 10.5194/tc-10-1933-2016.

van Kampenhout, L., Lenaerts, J. T. M., Lipscomb, W. H., Sacks, W. J., Lawrence, D. M., Slater, A. G., and van den Broeke, M. R. Improving the Representation of Polar Snow and Firn in the Community Earth System Model. J. Adv. Model. Earth Syst., 9(7):2583-2600, Nov. 2017. ISSN 1942-2466. doi: 10.1002/2017MS000988.

van Kampenhout, L., Rhoades, A. M., Herrington, A. R., Zarzycki, C. M., Lenaerts, J. T. M., Sacks, W. J., and van den Broeke, M. R. Regional grid refinement in an Earth system model: Impacts on the simulated Greenland surface mass balance. The Cryosphere, 13(6):1547-1564, June 2019. ISSN 1994-0416. doi: 10.5194/tc-13-1547-2019.

van Kampenhout, L., Lenaerts, J. T. M., Lipscomb, W. H., Lhermitte, S., Noël, B., Vizcaíno, M., Sacks, W. J., and van den Broeke, M. R. Present-Day Greenland Ice Sheet Climate and Surface Mass Balance in CESM2. Journal of Geophysical Research: Earth Surface, 125(2):e2019JF005318, 2020. ISSN 2169-9011. doi: 10.1029/2019JF005318.

Van Tricht, K., Lhermitte, S., Gorodetskaya, I. V., and van Lipzig, N. P. M. Improving satellite-retrieved surface radiative fluxes in polar regions using a smart sampling approach. The Cryosphere, 10(5):2379-2397, Oct. 2016a. ISSN 19940424. doi: 10.5194/tc-10-2379-2016.

Van Tricht, K., Lhermitte, S., Lenaerts, J. T. M., Gorodetskaya, I. V., L’Ecuyer, T. S., Noël, B., van den Broeke, M. R., Turner, D. D., and van Lipzig, N. P. M. Clouds enhance Greenland ice sheet meltwater runoff. Nature Communications, 7:10266, Jan. 2016b. ISSN 2041-1723. doi: 10.1038/ncomms10266.

Van Wessem, J., Reijmer, C., Morlighem, M., Mouginot, J., Rignot, E., Medley, B., Joughin, I., Wouters, B., Depoorter, M., Bamber, J., Lenaerts, J., De Van Berg, W., Van Den Broeke, M., and Van Meijgaard, E. Improved representation of East Antarctic surface mass balance in a regional atmospheric climate model. Journal of Glaciology, 60(222): 761-770, Oct. 2014. ISSN 00221430, 17275652. doi: 10.3189/2014JoG14J051.

Verjans, V., Leeson, A. A., Stevens, C. M., MacFerrin, M., Noël, B., and van den Broeke, M. R. Development of physically based liquid water schemes for Greenland firn-densification models. The Cryosphere, 13(7):1819-1842, July 2019. ISSN 1994-0416. doi: 10.5194/tc-13-1819-2019.

Vignon, E., Hourdin, F., Genthon, C., Van de Wiel, B. J. H., Gallée, H., Madeleine, J.-B., and Beaumet, J. Modeling the Dynamics of the Atmospheric Boundary Layer Over the Antarctic Plateau With a General Circulation Model. Journal of Advances in Modeling Earth Systems, 10(1):98-125, Jan. 2018. ISSN 19422466. doi: 10.1002/2017MS001184.

Vionnet, V., Brun, E., Morin, S., Boone, A., Faroux, S., Le Moigne, P., Martin, E., and Willemet, J.-M. The detailed snowpack scheme Crocus and its implementation in SURFEX v7.2. Geoscientific Model Development, 5(3):773-791, May 2012. ISSN 1991-9603. doi: 10.5194/gmd-5-773-2012.

Vizcaino, M. Ice sheets as interactive components of Earth System Models: Progress and challenges: Ice sheets as interactive components of Earth System Models. Wiley Interdisciplinary Reviews: Climate Change, 5(4):557-568, July 2014. ISSN 17577780. doi: 10.1002/wcc.285.

Vizcaíno, M., Mikolajewicz, U., Jungclaus, J., and Schurgers, G. Climate modification by future ice sheet changes and consequences for ice sheet mass balance. Clim Dyn, 34(2-3):301-324, Feb. 2010. ISSN 0930-7575, 1432-0894. doi: 10.1007/s00382-009-0591-y.

Vizcaíno, M., Lipscomb, W. H., Sacks, W. J., van Angelen, J. H., Wouters, B., and van den Broeke, M. R. Greenland Surface Mass Balance as Simulated by the Community Earth System Model. Part I: Model Evaluation and 
1850-2005 Results. Journal of Climate, 26(20):7793-7812, Oct. 2013. ISSN 0894-8755, 1520-0442. doi: 10.1175/JCLI-D-12-00615.1.

Vizcaíno, M., Lipscomb, W. H., Sacks, W. J., and van den Broeke, M. Greenland Surface Mass Balance as Simulated by the Community Earth System Model. Part II: Twenty-First-Century Changes. Journal of Climate, 27(1):215-226, Jan. 2014. ISSN 0894-8755, 1520-0442. doi: 10.1175/JCLI-D-12-00588.1.

Wagenbach, D., Graf, W., Minikin, A., Trefzer, U., Kipfstuhl, S., Oerter, H., and Blindow, N. Annual means of density, d180, deuterium, tritium, and accumulation rates of firn core BER01C90_01, Nov. 1994.

Wehner, M. F., Reed, K. A., Li, F., Prabhat, Bacmeister, J., Chen, C.-T., Paciorek, C., Gleckler, P. J., Sperber, K. R., Collins, W. D., Gettelman, A., and Jablonowski, C. The effect of horizontal resolution on simulation quality in the Community Atmospheric Model, CAM5.1. J. Adv. Model. Earth Syst., 6(4):980-997, Dec. 2014. ISSN 1942-2466. doi: 10.1002/2013MS000276.

Wehrli, K., Guillod, B. P., Hauser, M., Leclair, M., and Seneviratne, S. I. Improved dynamics due to introducing a nudging approach in the Community Earth System Model (CESM) and thermodynamic origin of the remaining errors. EGU General Assembly, 20:12237, Apr. 2018.

WMO. State of Global Climate 2019. Report 1248, 2020.

Wouters, B., Bamber, J. L., van den Broeke, M. R., Lenaerts, J. T. M., and Sasgen, I. Limits in detecting acceleration of ice sheet mass loss due to climate variability. Nature Geoscience, 6(8):613, Aug. 2013. ISSN 1752-0908. doi: 10.1038/ngeo1874.

$\mathrm{Xu}, \mathrm{Y}$. and Ramanathan, V. Well below $2{ }^{\circ} \mathrm{C}$ : Mitigation strategies for avoiding dangerous to catastrophic climate changes. PNAS, 114(39):10315-10323, Sept. 2017. ISSN 0027-8424, 1091-6490. doi: 10.1073/pnas.1618481114.

Yang, Y., Marshak, A., Han, M., Palm, S. P., and Harding, D. J. Snow grain size retrieval over the polar ice sheets with the Ice, Cloud, and land Elevation Satellite (ICESat) observations. Journal of Quantitative Spectroscopy and Radiative Transfer, 188:159-164, Feb. 2017. ISSN 0022-4073. doi: 10.1016/j.jqsrt.2016.03.033.

Yen, Y.-C. Review of Thermal Properties of Snow, Ice, and Sea Ice. CRREL Report 81-10, Cold Regions Research and Engineering Lab, Hanover, NH, 1981.

Zarzycki, C. M. and Jablonowski, C. A multidecadal simulation of Atlantic tropical cyclones using a variable-resolution global atmospheric general circulation model. J. Adv. Model. Earth Syst., 6(3):805-828, Sept. 2014. ISSN 1942-2466. doi: 10.1002/2014MS000352.

Zarzycki, C. M., Levy, M. N., Jablonowski, C., Overfelt, J. R., Taylor, M. A., and Ullrich, P. A. Aquaplanet Experiments Using CAM's Variable-Resolution Dynamical Core. Journal of Climate, 27(14):5481-5503, July 2014. ISSN 08948755, 1520-0442. doi: 10.1175/JCLI-D-14-00004.1.

Zarzycki, C. M., Jablonowski, C., Thatcher, D. R., and Taylor, M. A. Effects of Localized Grid Refinement on the General Circulation and Climatology in the Community Atmosphere Model. J. Climate, 28(7):2777-2803, Jan. 2015. ISSN 0894-8755. doi: 10.1175/JCLI-D-14-00599.1.

Zhu, J., Liu, Z., Zhang, X., Eisenman, I., and Liu, W. Linear weakening of the AMOC in response to receding glacial ice sheets in CCSM3. Geophys. Res. Lett., 41(17):6252-6258, Sept. 2014. ISSN 1944-8007. doi: 10.1002/2014GL060891.

Ziemen, F., Rodehacke, C., and Mikolajewicz, U. Coupled ice sheet-climate modeling under glacial and preindustrial boundary conditions. Climate of the Past, 10:1817-1836, Oct. 2014. ISSN 1814-9324. doi: 10.5194/ cp-10-1817-2014. 



\section{Acknowledgements}

You can be lucky or unlucky when it comes to your PhD advisor, they say, and I was lucky. Michiel, I greatly appreciate your ideas around what science entails in the 21 st century, in particular on the role and form of (international) co-operation, and I am sure these ideas explain part of the success of your research group. Furthermore, through your editorial work and co-authorship on uncountable articles you carry with you an extremely wide view on glaciology, as well as an excellent instinct for what subjects are scientifically interesting but still understudied. Others said in this context that you possess some kind of "golden touch", which says it all. On the interpersonal level you are friendly and accessible, but also know how to use a critical voice when needed. For my intermittent feelings of climate anxiety you've expressed understanding, something that still means a lot to me. Michiel, I am incredibly grateful for the opportunities you gave me and I look forward to working with you in the years to come!

Much gratitude also goes to my co-promotor. Jan, we were office mates for my first 3 years at IMAU and you quickly got me going into the project. You have a critical mind and your work ethics are an inspiration (or should I say aspiration?) to me. I enjoyed our work trips together to Colorado and the skiing, with the hottub and game night at Cheryls place as a definite highlight. You moved from Utrecht to Boulder when the opportunity came, which was great for you but also a pity for us. Nonetheless, I was happy we could keep up some sort of long-distance work connection through Skype and Slack, and I will surely stay in your basement next time I'm around in Boulder (since I now try to abstain from flying, this may take a while). Jan, it's always a pleasure working with you!

Furthermore, I would like to thank my US-based collaborators that have contributed in so many different ways to the content of this thesis. In the CESM terrestrial group: Dave Lawrence, Keith Oleson and Bill Sacks. Bill, next to a great appreciation of your software developing skills, I always enjoyed hanging out with you in Boulder. In the CESM land ice group: Bill Lipscomb, Marcus, Jeremy, Kate, Sarah, Shawn, Bette, Raymond, Laura, Gunter and Erik. A special thanks to Miren Vizcaino for the many interesting chats about work and academic life, and for being part of my committee. Adam Herrington and Colin Zarzycki, thanks for the collaboration and your important work on VR-CESM. Alan Rhoades, thanks for getting me going with VR-CESM and hanging out in Berkeley and on Google Meet. Finally, thanks to all the people at the LBL EESA lab for their hospitality during my stay in 2018.

Many thanks go to all the wonderful people at my institute IMAU, who make working there a privilege. The administrative staff Yvonne, Floor, Clara and Sandra: you run the place and make people feel at home. Michael, cheers for introducing me to CESM and the Olympos gym. Can't say I'm as fit as you are. Heiko, I'm sorry you're leaving IMAU but we'll surely stay in touch. Marcel, thanks for your technical support ranging from low-tech albedo-meters to high-tech MacPort upgrades. Erwin and Sharon, thanks for the moral support and the fun we had preparing our 'Klimaatpraat' video project. A special thanks to Hans Oerlemans for organizing the Karthaus summer school in glaciology for 
many years. Fellow (ex-)Hoemba-folks Brice, Christiaan, Christian, Kat, Larissa, Lennert, Marta, Maurice, Max, Meike, Melchior, Sharon, Stan, Tijn: thanks for the fun and intimate chats about PhD life. Lunch-colleagues André, Antonija, Bert, Carina, Carleen, Daniele, David, Elena, Erik, Getch, Hans de L, Hossein, Lisa, Marco, Michiel B, Michiel H, Paul, PKM, Qingyi, Renske, Rianne, Roderik, Sarah, Sitar, Stefan, Werner, Willem Jan, and all the others I undoubtly forget: thanks for the nice chats and for making IMAU such a pleasant place to work at.

Thanks to the folks involved with Scientists4Future NL for your vision and your dedication: Ana, Arthur, David, Joseline, Karlijn, Kevin, Martina, Peter, Sanli, Tanya, and all the others. Working with you keeps the despair at bay.

I'm also grateful to the numerous international climate activists and scientivists for actively trying to change the course of history. You inspire me.

Thanks to the open source software community for developing and maintaining some extremely powerful tools. The work in this thesis builds on programs like Linux, screen, LaTeX, VIM, NCL, Python, SciPy, and Jupyter.

$\mathrm{Nu}$ even verder in het Nederlands voor een grote groet aan alle lieve vrienden voor de broodnodige gezelligheid en relativering.

Beiler mooiboys Elting, CJP, Maarten, Mulder, Jaap, Menno, Meijering, Harmen: man man man, wat een niveautje altijd weer.

Maarten, Bia, Phuong en KS: snel weer een spellenweekendje plannen!

Maria en Koos: bedankt voor alle burenhulp en gezelligheid samen.

Brullers Beejee, Kampf Sr., Mart’n, Zomer, Smit, Broek: Slück auf!

Meester Gerrits, altijd leuk om efkes te fietsen. Hopelijk kom je tot inkeer en verruil je Californië weer voor Drenthe!

Leonie en Bram: bedankt voor de good times in Rotterdam en daarbuiten.

Nienke en Niels: zonder jullie zat ik nog steeds vast in een escaperoom ergens in Zuid-Limburg.

Frank en Stefanie: na onze verhuizing naar Beilen gaan we elkaar hopelijk weer vaker zien dan eens per eeuw.

Johan en Willemijn: tot in de Koningshof!

En dan zijn er nog zoveel andere vrienden en kennissen te bedanken: Auke, Lin, Saskia, Prakalp, Nynke, Sanne, Carel, Eveline, Frederique, Dunc, Resa, Bodil, de buurmannen, alle Anderwijzers, de mensen van EMEC, de mensen van Earthlings in Eindhoven, AV in Maastricht en United for Life in Roermond, de mensen van Extinction Rebellion NL: stuk voor stuk heeft ieder van jullie mijn leven 
interessanter, makkelijker of leuker gemaakt! Dank je wel ook Maya voor het prachtig vormgeven van de omslag van dit boekje.

Tot slot wil ik graag mijn familie en schoonfamilie bedanken. Lieve papa en mama, van jullie mocht ik zelf kiezen wat ik "later wilde worden". Dit, samen met jullie onvoorwaardelijke liefde, is heel belangrijk voor mij geweest. Reinier: donders bedankt voor de morele ondersteuning en het verslepen van mijn boedel naar alle verre uithoeken van het land. Cornelie: op jou kan ik altijd rekenen voor wijze raad, ongeacht het onderwerp. Cám ơn tình cảm yêu thương của ba má và những món ăn ngon gửi cho gia đình con. An, Ngọc, Phuong, Kam Sing, Mai, Martijn, Sjors, Lotte, Ruben, Benjamin: dank voor alle hulp en huiselijke gezelligheid. Lieve Lieu: wij hebben het best redelijk leuk samen (het is te doen) en indirect heb je veel bijgedragen aan dit proefschrift, waarvoor dank! 



\section{List of publications}

\section{First author}

(1) van Kampenhout, L., Lenaerts, J. T. M., Lipscomb, W. H., Sacks, W. J., Lawrence, D. M., Slater, A. G., and van den Broeke, M. R. Improving the Representation of Polar Snow and Firn in the Community Earth System Model. J. Adv. Model. Earth Syst., 9(7):2583-2600, Nov. 2017. ISSN 1942-2466. doi: 10.1002/2017MS000988

(2) van Kampenhout, L., Rhoades, A. M., Herrington, A. R., Zarzycki, C. M., Lenaerts, J. T. M., Sacks, W. J., and van den Broeke, M. R. Regional grid refinement in an Earth system model: Impacts on the simulated Greenland surface mass balance. The Cryosphere, 13(6):1547-1564, June 2019. ISSN 19940416. doi: 10.5194/tc-13-1547-2019

(3) van Kampenhout, L., Lenaerts, J. T. M., Lipscomb, W. H., Lhermitte, S., Noël, B., Vizcaíno, M., Sacks, W. J., and van den Broeke, M. R. Present-Day Greenland Ice Sheet Climate and Surface Mass Balance in CESM2. Journal of Geophysical Research: Earth Surface, 125(2):e2019JF005318, 2020. ISSN 2169-9011. doi: 10.1029/2019JF005318

(4) Noël, B., van Kampenhout, L., Lenaerts, J. T. M., Van de Berg, W. J., and Van den Broeke, M. A 21 st century warming threshold for irreversible Greenland ice sheet mass loss. Communications Earth \& Environment, in review

\section{Co-author}

(1) Lenaerts, J. T. M., Le Bars, D., van Kampenhout, L., Vizcaino, M., Enderlin, E. M., and van den Broeke, M. R. Representing Greenland ice sheet freshwater fluxes in climate models. Geophysical Research Letters, 42(15):6373-6381, Aug. 2015. ISSN 00948276. doi: 10.1002/2015GL064738

(2) Lenaerts, J. T., Vizcaino, M., Fyke, J., van Kampenhout, L., and van den Broeke, M. R. Present-day and future Antarctic ice sheet climate and surface mass balance in the Community Earth System Model. Climate Dynamics, 47(5-6):1367-1381, 2016. doi: 10.1007/s00382-015-2907-4

(3) van den Broeke, M., Box, J., Fettweis, X., Hanna, E., Noël, B., Tedesco, M., van As, D., van de Berg, W. J., and van Kampenhout, L. Greenland Ice Sheet Surface Mass Loss: Recent Developments 
in Observation and Modeling. Curr Clim Change Rep, pages 1-12, Nov. 2017. ISSN 2198-6061. doi: 10.1007/s40641-017-0084-8

(4) Noël, B., van Kampenhout, L., van de Berg, W. J., Lenaerts, J. T. M., Wouters, B., and van den Broeke, M. R. Brief communication: CESM2 climate forcing (1950-2014) yields realistic Greenland ice sheet surface mass balance. The Cryosphere Discussions, pages 1-17, Sept. 2019b. ISSN 19940416. doi: 10.5194/tc-2019-209

(5) Sellevold, R., van Kampenhout, L., Lenaerts, J. T. M., Noël, B., Lipscomb, W. H., and Vizcaino, M. Surface mass balance downscaling through elevation classes in an Earth system model: Application to the Greenland ice sheet. The Cryosphere, 13(12):3193-3208, Dec. 2019. ISSN 1994-0416. doi: 10.5194/tc-13-3193-2019

(6) Lawrence, D. M., Fisher, R. A., Koven, C. D., Oleson, K. W., Swenson, S. C., Bonan, G., Collier, N., Ghimire, B., van Kampenhout, L., Kennedy, D., Kluzek, E., Lawrence, P. J., Li, F., Li, H., Lombardozzi, D., Riley, W. J., Sacks, W. J., Shi, M., Vertenstein, M., Wieder, W. R., Xu, C., Ali, A. A., Badger, A. M., Bisht, G., Broeke, M., Brunke, M. A., Burns, S. P., Buzan, J., Clark, M., Craig, A., Dahlin, K., Drewniak, B., Fisher, J. B., Flanner, M., Fox, A. M., Gentine, P., Hoffman, F., Keppel-Aleks, G., Knox, R., Kumar, S., Lenaerts, J., Leung, L. R., Lipscomb, W. H., Lu, Y., Pandey, A., Pelletier, J. D., Perket, J., Randerson, J. T., Ricciuto, D. M., Sanderson, B. M., Slater, A., Subin, Z. M., Tang, J., Thomas, R. Q., Val Martin, M., and Zeng, X. The Community Land Model Version 5: Description of New Features, Benchmarking, and Impact of Forcing Uncertainty. J. Adv. Model. Earth Syst., page 2018MS001583, Dec. 2019. ISSN 1942-2466, 1942-2466. doi: 10.1029/2018MS001583

(7) Danabasoglu, G., Lamarque, J.-F., Bacmeister, J., Bailey, D. A., DuVivier, A. K., Edwards, J., Emmons, L. K., Fasullo, J., Garcia, R., Gettelman, A., Hannay, C., Holland, M. M., Large, W. G., Lauritzen, P. H., Lawrence, D. M., Lenaerts, J. T. M., Lindsay, K., Lipscomb, W. H., Mills, M. J., Neale, R., Oleson, K. W., Otto-Bliesner, B., Phillips, A. S., Sacks, W., Tilmes, S., van Kampenhout, L., Vertenstein, M., Bertini, A., Dennis, J., Deser, C., Fischer, C., Fox-Kemper, B., Kay, J. E., Kinnison, D., Kushner, P. J., Larson, V. E., Long, M. C., Mickelson, S., Moore, J. K., Nienhouse, E., Polvani, L., Rasch, P. J., and Strand, W. G. The Community Earth System Model Version 2 (CESM2). Journal of Advances in Modeling Earth Systems, 12(2):e2019MS001916, 2020. ISSN 1942-2466. doi: 10.1029/2019MS001916

(8) Lenaerts, J. T. M., Gettelman, A., Tricht, K. V., van Kampenhout, L., and Miller, N. B. Impact of Cloud Physics on the Greenland Ice Sheet Near-Surface Climate: A Study With the Community Atmosphere Model. Journal of Geophysical Research: Atmospheres, 125(7):e2019JD031470, 2020b. ISSN 2169-8996. doi: 10.1029/2019JD031470

(9) Fettweis, X., Hofer, S., Krebs-Kanzow, U., Amory, C., Aoki, T., Berends, C. J., Born, A., Box, J. E., Delhasse, A., Fujita, K., Gierz, P., Goelzer, H., Hanna, E., Hashimoto, A., Huybrechts, P., Kapsch, M.-L., King, M. D., Kittel, C., Lang, C., Langen, P. L., Lenaerts, J. T. M., Liston, G. E., Lohmann, G., Mernild, S. H., Mikolajewicz, U., Modali, K., Mottram, R. H., Niwano, M., Noël, B., Ryan, J. C., 
Smith, A., Streffing, J., Tedesco, M., van de Berg, W. J., van den Broeke, M., van de Wal, R. S. W., van Kampenhout, L., Wilton, D., Wouters, B., Ziemen, F., and Zolles, T. GrSMBMIP: Intercomparison of the modelled 1980\&ndash;2012 surface mass balance over the Greenland Ice sheet. The Cryosphere Discussions, pages 1-35, Jan. 2020. ISSN 1994-0416. doi: 10.5194/tc-2019-321

(10) Tilmes, S., MacMartin, D. E., Lenaerts, J. T. M., van Kampenhout, L., Muntjewerf, L., Xia, L., Harrison, C. S., Krumhardt, K. M., Mills, M. J., Kravitz, B., and Robock, A. Reaching $1.5^{\circ} \mathrm{C}$ and $2.0^{\circ} \mathrm{C}$ global surface temperature targets using stratospheric aerosol geoengineering. Earth System Dynamics Discussions, pages 1-37, Dec. 2019. ISSN 2190-4979. doi: 10.5194/esd-2019-76 



\section{Curriculum vitae}

Leonardus (Leo) van Kampenhout

1986 born in Beilen, Drenthe, The Netherlands

1998 - 2004 VWO Atheneum, CS Vincent van Gogh, Assen

2004 - 2008 BSc Applied Mathematics, Rijksuniversiteit Groningen

Thesis title: Deflation-based preconditioning in the THCM model

2008 - 2011 MSc Applied Mathematics, Rijksuniversiteit Groningen

Major in Computational Science and Numerical Mathematics

Thesis title: Simulation of wall bounded turbulent channel flow in the PETSc toolkit

2011 - 2013 Scientific software engineer at Alten PTS, Capelle aan den IJssel

Contractor to Royal Dutch Shell, geophysics group, Rijswijk

2014 - 2016 Model support engineer at Universiteit Utrecht

$2015-2020 \quad \mathrm{PhD}$ candidate at Universiteit Utrecht (this thesis) 